\title{
The stepwise development of a comprehensive family caregiver support programme
}

Citation for published version (APA):

Krieger, R. T. (2019). The stepwise development of a comprehensive family caregiver support programme. [Doctoral Thesis, Maastricht University]. Maastricht University. https://doi.org/10.26481/dis.20190614rk

Document status and date:

Published: 01/01/2019

DOI:

10.26481/dis.20190614rk

Document Version:

Publisher's PDF, also known as Version of record

\section{Please check the document version of this publication:}

- A submitted manuscript is the version of the article upon submission and before peer-review. There can be important differences between the submitted version and the official published version of record.

People interested in the research are advised to contact the author for the final version of the publication, or visit the DOI to the publisher's website.

- The final author version and the galley proof are versions of the publication after peer review.

- The final published version features the final layout of the paper including the volume, issue and page numbers.

Link to publication

\footnotetext{
General rights rights.

- You may freely distribute the URL identifying the publication in the public portal. please follow below link for the End User Agreement:

www.umlib.nl/taverne-license

Take down policy

If you believe that this document breaches copyright please contact us at:

repository@maastrichtuniversity.nl

providing details and we will investigate your claim.
}

Copyright and moral rights for the publications made accessible in the public portal are retained by the authors and/or other copyright owners and it is a condition of accessing publications that users recognise and abide by the legal requirements associated with these

- Users may download and print one copy of any publication from the public portal for the purpose of private study or research.

- You may not further distribute the material or use it for any profit-making activity or commercial gain

If the publication is distributed under the terms of Article $25 \mathrm{fa}$ of the Dutch Copyright Act, indicated by the "Taverne" license above, 


\section{The stepwise development of a comprehensive family caregiver support programme}

Regina Theresia Krieger 
The research presented in this thesis was conducted at the Department of Social Medicine at Maastricht University. The German Ministry for Research and Education (BMBF, Nr. 03FH008SX2) funded the Caregivers' Guide programme.

Cover design: Johanna Sandau, Christiane Hupe, Regina Theresia Krieger

Layout and design: Christiane Hupe

Print: University Print

ISBN 978-90-829801-5-8

Copyright (c) Regina Theresia Krieger, Aachen 2019

All rights are reserved. No part of this thesis may be reproduced, distributed or transmitted in any form or by any means without written permission of the author. 


\title{
The stepwise development of a comprehensive family caregiver support programme
}

\author{
Dissertation \\ to obtain the degree of Doctor at Maastricht University, \\ on the authority of the Rector Magnificus, Prof.dr. Rianne M. Letschert \\ in accordance with the decision of the Board of Deans, \\ to be defended in public \\ on Friday, 14th June 2019, at 10:00 hours \\ by \\ Regina Theresia Krieger
}


Promotor:

Prof. dr. F.J.M. Feron

Co-promotor:

Dr. E. Dorant

Assessment Committee:

Prof. dr. G.D.E.M. van der Weijden (Chair)

Prof. dr. habil. H. S. Görres, Bremen University

Prof. dr. W. Schnepp, University of Witten-Herdecke

Prof. dr. J.M.G.A. Schols 


\section{CONTENTS}

CHAPTER $1 \quad$ General introduction...............................................................

CHAPTER 2 Developing a complex intervention programme for informal ................ 19 caregivers of stroke survivors: The Caregivers' Guide

CHAPTER 3 The development of implementation management instruments ............ 39 for a new complex stroke caregiver intervention based on systematic stakeholder and risk analyses

CHAPTER 4 Optimising a complex caregiver support programme in practice: 65 a participatory action research study

CHAPTER 5 Evaluating a complex intervention for stroke caregivers 91 on individual and system level: the Caregivers' Guide example

CHAPTER 6 Contextual exploration of a new family caregiver support 127 concept for geriatric settings using a Participatory Health Research strategy

CHAPTER 7 General discussion

CHAPTER 8

Summary .183

CHAPTER 9 Valorisation, References, List of figures, List of tables. 189

CHAPTER 10 Acknowledgements, About the author, List of publications 219 



\section{CHAPTER 1 \\ General introduction}




\section{Introduction to family caregiver support}

Chapter 1 gives a short overview on family caregiving with focus on stroke caregivers. Background information regarding stroke, its rehabilitation and support system, family caregiver burdens and needs is given. Finally, detailed contextual information, on which the new stroke caregiver support programme was developed, is provided.

Family caregivers are relatives, partners, friends or neighbours, who support and/or provide voluntary physical, practical and emotional care to a person with a chronic or acute disability in the home environment (adapted from National Alliance for Caregiving, 2018). Family caregivers are considered as the backbone of the long-term support system in the community (Nowossadeck et al., 2016). They are the major contributor of individual support and assistance in navigating health care services in the home care phase (Smith \& Smith, 2000).

The impacts of family caregiving are complex. On individual level it has consequences on caregiver's health status, relationship, perceived quality of life across the lifespan and work-life balance, e.g. role conflict, spill over from work to home and vice versa of the primary family caregiver (Talley \& Crews, 2007; Dorant \& Boumans, 2016). Caregiving may provoke objective burden related to the task of providing physical assistance as well as subjective burden occasioning of the emotional, social and psychological impact of caregiving (Rigby et al., 2009; Montgomery et al., 1985, Adelman et al., 2014). Additionally, family caregiving impacts on family systems, care supports systems, communities, and states (National Alliance for Caregiving, 2018). Family caregiving is a public health concern, which needs be addressed.

The principal aim of this dissertation is to provide a practical example on the step-wise development of a new and comprehensive family caregiver support programme by illuminating all phases of the project management cycle (initiation, development, implementation and evaluation). Furthermore, as family caregiver support programmes are not implemented in a vacuum, the second aim is to improve scientific knowledge and augment the perception of comprehensive family caregiver support. New knowledge will be generated from two caregiver support projects: (1) the Caregivers' Guide, a stroke-specific, and (2) Vade Mecum, a disease-unspecific support in a geriatric setting, both conducted in Germany. 


\section{Stroke}

Worldwide, stroke is highly prevalent (Thrift et al., 2017, World Stroke Organisation 2018). In most industrialized countries, stroke incidence is decreasing due to medical advancements; however, the absolute numbers are increasing due to the overageing of societies (World Health Organisation, 2015).

Stroke is a complex medical emergency, demanding multidisciplinary knowledge and collaboration between the different disciplines and organizations who participate in the treatment and rehabilitation process (Clarke \& Forster, 2015). The rehabilitation requires the involvement of different health care levels, e.g. acute care, rehabilitation and home care, and the collaboration with the community-based support system (Clarke \& Forster, 2015; Cameron et al. 2014).

Stroke is a leading cause of serious, long-term disability in adults (Benjamin et al., 2017), and therefore poses a burden on the societal, system and individual levels (Clarke \& Forster, 2015). After rehabilitation, many survivors are left with one or more deficiencies, e.g. motor impairments or cognitive decline (Brewer et al., 2013); as well as language and speech disorders (Mashur et al. 2013). Approximately $15 \%$ of the patients experience mild cognitive dysfunctions (Liman et al., 2011), and one third of the survivors develop depressive symptoms (Hackett et al., 2014). When being restricted in accomplishing the daily living activities, family caregivers play a key role in the day-to-day care of stroke survivors (Bakas et al., 2014).

\section{The German stroke rehabilitatiown and support system}

In Germany, 240.000 individuals suffer an ischemic stroke annually (German Federal Statistical Office, 2013). The medical treatment and care of stroke has significantly changed recently. In 2005 only $15 \%$ of stroke patients were treated in stroke units (Nimptsch \& Mansky, 2012), whereas in 2012 around 58\% of the stroke patients were admitted to a hospital with a specialized stroke unit (Hillmann et al., 2017). The stroke units' multidisciplinary working approach and the prompt start of early rehabilitation resulted in achieving a more favourable outcome for the patients (Stroke Unit Trialist's Collaboration, 2013). Nowadays, stroke survivors stay in the acute care hospital only approximately 11 days (Nimptsch \& Mansky, 2012). 
The German rehabilitation system includes 6 phases (figure 1).

As depicted in figure 1, after the acute phase the German rehabilitation and care trajectory appears fragmented. The stroke survivor's rehabilitation process is characterised by multiple transition points and diverse bureaucratic, informational and logistical bottlenecks (Schuler \& 0ster, 2004), which pose challenges for the support system, the patient, and the family caregiver. Often, this process is characterised by deficits in coordination, communication and navigation through the different phases (Schuler \& 0ster, 2004). The rehabilitation is patient-centred rather than system-centred. Current guidelines neither highlight family caregiver's role in the rehabilitation process nor put professional's attention to the caregiver's needs, e.g. informational or emotional needs.

\section{Stroke family caregiving}

Stroke hits a family unexpectedly and is often experienced as a traumatic event (Letho et al., 2013). Directly after stroke, family caregivers describe themselves as 'living in a focused state of chaos', meanwhile trying to stabilize themselves emotionally and to organize the future (Bulley et al., 2009; Letho et al., 2013). After the patient's discharge and during the first months of providing support at home, caregivers frequently struggle to achieve normality and control (Bäckström \& Sundin, 2010).

The abrupt onset of complex demands immediately after stroke differentiates stroke caregivers from other caregiver groups, e.g. dementia caregivers (Bulley et al., 2009). When the patient is still treated in the hospital, stroke caregivers

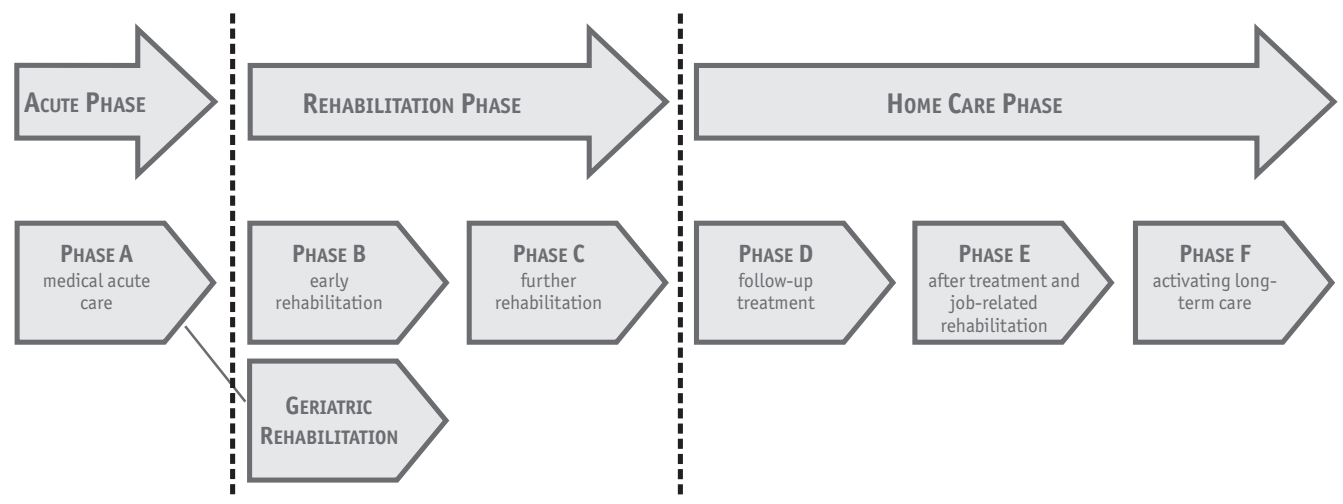

Figure 1: The German stroke rehabilitation support system (adapted from BAR, 2018) 
are required to manage numerous individual, interpersonal and organisational issues, f.i. financial support (Grant al., 2014; Cameron et al., 2008). After transferal to the home, caregivers are responsible for the provision of one or more tasks, such as care, safety and emotional support to the patient, medication management and the availability of suitable support services or equipment (Plank et al., 2012).

Due to the short length of stay in the acute or rehabilitation care, stroke caregivers have little time to prepare themselves for their new role, e.g. gain caregiving knowledge or skills (Greenwood et al., 2009), and, it is difficult to adjust their house for the caregiving needs, e.g. provide a disabled access to the house (Creasy et al., 2013).

For being able to take over the new role as a stroke caregiver it is necessary to possess a sound understanding of stroke and its consequences, support system, and available support offers (Grant et al., 2010). Besides, caregivers may need help in adapting to their new role, which includes rebuilding life, taking care of complex needs and developing coping strategies that help balance their emotional well-being (Letho et al., 2013). However, many caregivers feel thrown in their new role without receiving adequate information, training and emotional support and/or lack the time to learn the necessary skills (Forster et al., 2013; Smith et al., 2004). Consequently, they may feel disconnected, excluded, uncertain or inadequately prepared to manage complex demands of stroke care (Lutz \& Young, 2010; Creasy et al, 2013).

Stroke caregiver's needs are dynamic and change throughout the patient's trajectory (Forster et al., 2013; Cameron \& Gignac 2008). Health care professionals are the first source of information for family caregivers, and therefore should allocate time to listen to them from the beginning of the patient's trajectory (Cameron et al. 2012). Over time, caregivers may require informational, emotional, psycho-social and peer support, as well as accompaniment during the transitional phases (Wilz \& Böhm, 2007; Egan et al., 2010). Additionally, caregivers need time to acquire skills for managing and coping with the physical, cognitive and emotional challenges related to stroke (Plank et al., 2012). Caregivers seem to benefit most from long-term support which is provided across the care continuum (Lutz et al., 2016). It is recommended to early and systematically assess caregiver's needs (Lutz \& Young, 2010; MacIsaac et al., 2010), and the "Timing it Right" framework has been proposed to assist service providers in systemati- 
cally supporting caregivers needs (Cameron \& Gignac, 2008).

Caregiver support programmes differ in terms of their content, approach and timing, and therefore comparison between programmes is difficult (Bakas et al., 2014). Visser-Meily (2005) described four types of caregiver support programmes: (1) specialist services, e.g. case management (2) (psycho-)education, (3) counselling, and (4) social support by peers. A recent review on interventions for stroke patient-caregiver dyads showed that most interventions offer multiple components, like 'skills-building' which involves strategies that focus on processes, e.g. stress management or hands-on training; and 'psycho-educational support' which entails the provision of information (Bakas et al., 2014).

Personalized face-to-face or telephone support instead of group support is most frequently used in caregiver support (Bakas et al., 2014). According to 0stwald et al. (2014) seem to profit family caregivers most from personalized support, f.i. case management approach.

Bakas and colleagues' review specified that the outcomes of a caregiver support programme were predominantly assessed on individual caregiver or caregiver-dyad level, showing a significant improvements on caregivers' preparedness, quality of life and social functioning, and a decline on the perceived burden, stress, anxiety and strain. Only few studies assessed outcome on the system 's level, and those who did only evaluated caregivers system knowledge and service use, f.i. use of communal services (Gräsel et al., 2005; Franzen-Dahlin et al., 2008). No study reported on assessing outcomes on system level attributed to the support programme.

\section{Stroke family caregiver support in Germany}

Today, 3-5 Million German citizens provide informal care to 4-5 Million persons in need (Nowossadeck et al., 2016). Most family caregivers are females aged between 40-85 years, and two out of three caregivers below the age of 65 are employed (Wetzstein et al., 2015).

Stroke-specific caregiver data are not available and detailed knowledge on stroke caregiver needs are scarce. Publications mainly describe in general caregivers diverse challenges, needs, and legislative or financial support options (Wetzstein et al. 2015; Nowossadeck et al. 2016), but fail to explain in detail how comprehensive caregiver support programmes could be developed, implemen- 
ted and financed. Likewise, stroke-caregiver specific considerations are also missing.

Publications on two German stroke caregiver support programmes were found, both were not conducted in Northrhine-Westphalia but in two other German federal states: Saxony and Baden Wuerttemberg. A psychosocial support programme was offered to spouses in the home-care phase in Saxony (Wilz \& Barskova, 2007), and a problem solving programme was offered to caregivers directly after rehabilitation discharge in Baden-Wuerttemberg (Pfeiffer et al. 2014).

German family caregiver support offers are not formalized and no comprehensive programme with a primary caregiver-strengthening approach is implemented on national level up to now. Current support services differs not only from federal state to federal state, but also from supports portfolio and between different communes. In the federal state North Rhine-Westphalia some caregiver support and counselling services are available and free-of-charge. Some communal services offer individual care and living support (Pflege- und Wohnberatung); one health insurance (DAK) offers a caregiving online course, another health insurance (AOK) provides group caregiving courses, and some church based organisations offer group programmes for caregivers of dementia patients. However, professionals perceived the current support as fragmented, inadequate and isolated (Pieniak et al., 2017; Specht 2014).

'Familiale Pflege' is with its 10 years the oldest disease-unspecific caregiver project in Germany, offering training and support in individual and group sessions to caregivers (Gröning et al. 2018). 'Familiale Pflege' is not accessible in all German federal states. In North Rhine-Westphalia some regions organizations are offering this support. However, our stakeholders mentioned that the content, approach and duration of this support varies between the involved organizations and also between the trained nurses in different departments within one setting.

The Besides, service providers stated that their services are insufficiently or too late utilized or visited by caregivers for different reasons, f.i. caregiver-unfriendly office hours (Wetzstein et al., 2015). Finally, especially new caregivers simply do not know the existing services (Pieniak et al., 2017).

In the Aachen region (North Rhine-Westphalia), some general, free-of-charge family caregiver support offers are provided by different providers: some rehabilitation care providers offer practical bed-side training, f.i. an ambulant rehabilitation center; one health insurance offers a hands-on training for family 
caregivers; and the communal service of the Aachen region offers individual caregiver counselling. 'Familiale Pflege' is offered in some hospital in the Aachen region, however not specifically at stroke units or neurological departments. A comprehensive stroke-caregiver programme, offering proactively support to caregivers from as early as possible and across the stroke patient's trajectory, is missing.

\section{Developing a new caregiver support programme}

To fill the gap of the missing family caregiver support, the Caregivers`'Guide, a new stroke family caregiver support programme, was developed, implemented and evaluated in the Aachen region by the Institute for Health Research and Social Psychiatry (igsp), which belongs to the Catholic University of Applied Sciences North Rhine-Westphalia. It was completely financed for 36 months by the German Ministry of Education and Research (BMBF). The project's proposal was written by Prof. Dr. Johannes Jungbauer and was based on the existing scientific insights and comprehensions up to 2010, mainly international literature, and some previous experiences $(2003,2008)$.

The new programme should aim to maintain the quality of life of stroke caregivers and reduce their burden by offering professional support parallel to the current patient-centred stroke rehabilitation trajectory (figure 1) in the Aachen region. In the proposal, three unique selling points were outlined: (1) professional diachronic support through all phases of rehabilitation, (2) individual support with an outreach counselling option, and (3) information and psychosocial support. After funding approval, the multidisciplinary research team was formed. Under the leadership of Prof. Jungbauer a clinical social worker and nurse \& public health expert (PhD applicant) were contracted as research fellows. Both were not previously involved in caregiver support, stroke specific research or experienced in the stroke rehabilitation support in the Aachen region.

Between the years 2012-2015 the stroke specific Caregivers' Guide programme was developed, tested and evaluated in the Aachen region. The Caregivers' Guide closure was followed by a new project: Vade Mecum, a new support programme for family caregivers of elderly patients. The idea of this new programme emerged during the Caregivers' Guide research completion. Vade Mecum evolved from new insights gained by studying complexity issues in public health research, and early acknowledgement of the role of stakeholders in the development of a new support programme. In 2017 the preliminary step (initiation phase) of Vade Mecum was conducted in the geriatric department of the Rhein-Maas 
Clinic in Würselen, which is the largest geriatric setting in the Aachen region (North Rhine-Westphalia). The actual caregiver support provided by the multidisciplinary team in the geriatric department was explored, and professionals' needs for providing comprehensive support to family caregivers were assessed.

The research part in the Caregivers`'Guide and Vade Mecum as described in the following chapters was mainly designed, supported and accomplished by the Department of Social Medicine in Maastricht University. The Caregivers' Guide research process was guided by exploring in detail: (1) how the stroke specific caregiver support programme was developed and implemented, and (2) what was perceived as the programme's outcomes on the individual and system levels. Vade Mecum 's preliminary step focussed on gaining a multiperspective understanding of the actual situation and needs for caregiver support within the geriatric department.

\section{Outline of the dissertation}

In order to achieve the dissertation's principal aim, five consecutive project management guided studies were performed through two projects: Caregivers' Guide and Vade Mecum. Mixed methods research designs, qualitative and quantitative methods, top-down and bottom-up working approaches, project management techniques and Participatory Action Research (PAR) strategies were applied. In each project both programmes ' end-users and service providers were involved in the entire development process. The step-wise development process of the new programme is depicted in figure 2.

In generally, projects pass through different time-bounded phases, interlinked to each other in a project life cycle (Project Management Institute - PMI, 2013, pp. 38). The following chapters refer to the development, implementation, evaluation and initiation phase.

Chapter 2 and 3 report on the development phase of the Caregivers' Guide which required a comprehensive context-specific understanding of the: 1) actual needs for stroke caregiver support, and 2) multistakeholder settings with the possible implementation risks. Chapter 2 describes in detail the development of the new programme's preliminary concept with its Conceptual Building Blocks. Prospective programme's end-users and service providers affiliated to the current support system participated in this study. Chapter 3 reports on the process 
of systematically exploring the complex context-specific stroke support system in order to prepare the implementation of the new caregiver support programme. Project management techniques were used to analyse stakeholders and possible implementation risks, and based on this, implementation management instruments were designed.

In chapter 4 the stepwise optimisation of the preliminary concept in practice is described. In this part of the study new knowledge was generated by engaging with the programme's end-users, service providers and the Caregivers' Guide counsellor.

Chapter 5 presents the results of the Caregivers' Guide programme evaluation on both individual and system levels. A multi-methodological design and quantitative as well qualitative data collection methods were applied. Programme's end-users and service providers participated in this study.

Chapter 6 reflects on the very first step of Vade Mecum. This part of the dissertation focusses on its initiation phase, which prepared the exploration of the

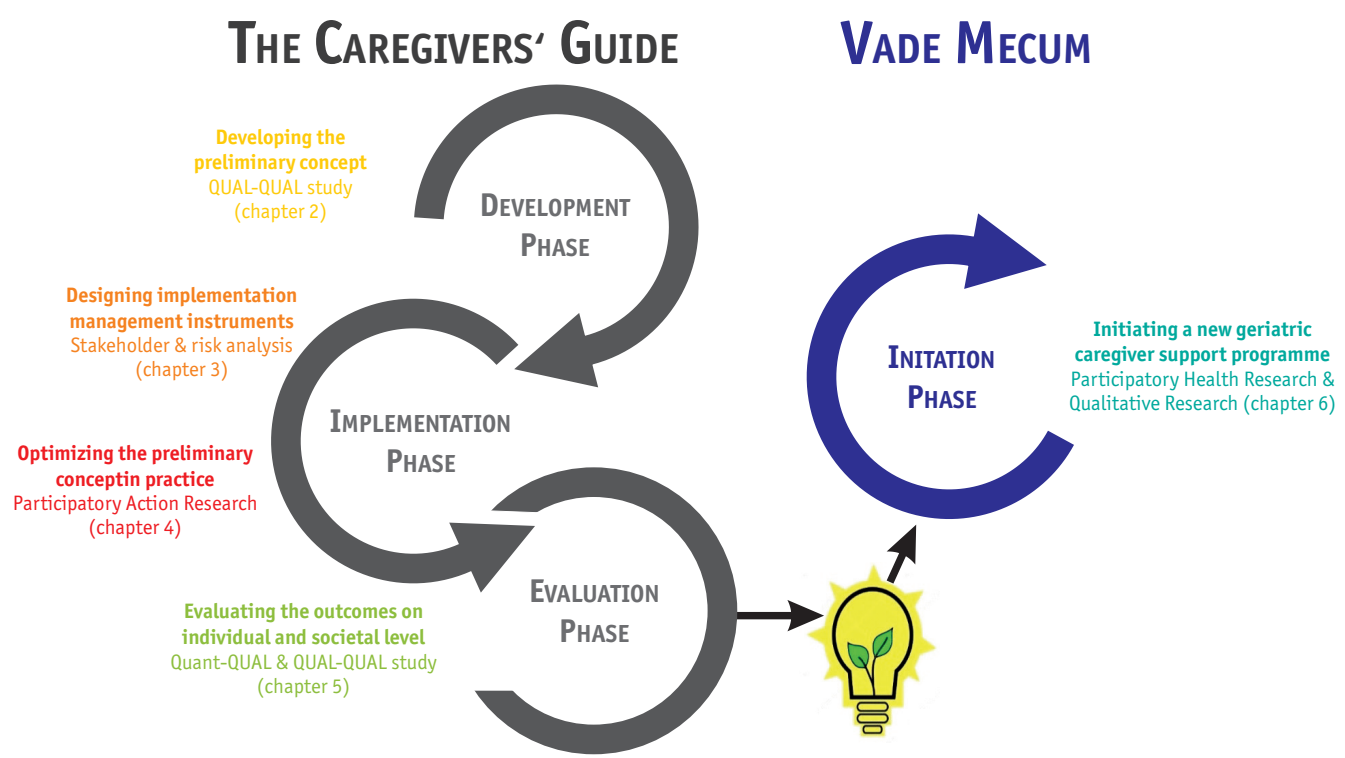

Figure 2: Outline of the dissertation showing all steps taken in the development of a new caregiver support programme illustrated on the project life cycles of the Caregivers' Guide and Vade Mecum 
actual state, and the assessment of needs for comprehensive caregiver support in the geriatric setting. Members of the multidisciplinary geriatric support were engaged as co-researchers and were enabled to actively participate in the entire research process within their own setting. We report in detail on the first phases of the project's life cycle: orientation, setting-up and planning.

Finally, chapter 7 provides a summary of the main findings, methodological considerations and further implications for research and policy makers. 
The stepwise development of a comprehensive family caregiver support programme. 
CHAPTER 2 Developing a complex intervention programme for informal caregivers of stroke survivors: The Caregivers' Guide

Krieger T, Feron F, Dorant E (2016) Developing a complex intervention programme for informal caregivers of stroke survivors: The Caregivers' Guide. Scandinavian Journal of Caring Sciences; 31(1):146-156. doi: $10.1111 /$ scs.12344 


\section{Abstract}

Background: Stroke affects the entire family system. Failure to meet the needs of caregivers leads to physical and mental overburdening. Stroke caregivers may benefit from professional support. Literature reviews have shown that there is still no clarity concerning the most appropriate set up of a support programme. In Germany there is no stroke caregiver support programme that operates throughout the course of rehabilitation.

Aim: The aim is to develop a complex intervention programme for stroke caregivers in North-Rhine Westphalia, Germany.

Methods: A naturalistic inquiry approach, using a mixed method design, was applied. Within one overarching qualitative study three separate, explorative, inductive, qualitative sub-studies were conducted: (1) seven explorative interviews with experienced stroke caregivers, (2) six semi-structured interviews with professionals working within stroke rehabilitation, and (3) seventeen participant observations with focus on professional - caregiver interactions. Regional stroke units, rehabilitation centres, outpatient services and the home environment of caregivers were included. By means of a four-step qualitative content analysis all three datasets were coded, categorized and subsequently condensed into subthemes, clustered into main themes, and finally translated into 'Conceptual Building Blocks' of the programme.

Results: The need for a personalized, holistic and multicomponent caregiver support programme emerged from all three sub-studies. Fourteen themes were condensed from the subthemes. Caregivers should be approached directly after stroke using outreach counselling. Support should be provided by a specially trained focal person across the entire patient's rehabilitation trajectory. The newly developed support programme consists of five flexible 'Conceptual Building Blocks': Content, Human Resources, Personalized Approach, Timing, and Setting.

Conclusion: Through a qualitative mixed-methods design an in-depth contextual understanding of stroke caregiver needs within the rehabilitative support system was reached. This allowed the development of a context tailored comprehensive caregiver support programme consisting of five 'Conceptual Building Blocks`. 


\section{Introduction}

Stroke is highly prevalent worldwide (Thrift et al., 2014). Approximately five million people suffer permanently from stroke related disabilities (World Heart Federation, 2015). Support at home is provided mostly by family caregivers, who are thus an essential source of care (Cameron et al., 2013). A 'family caregiver" is defined as "any relative, partner, friend or neighbour who has a significant personal relationship with, and provides a broad range of assistance for an adult with a chronic or disabling condition" (Family caregiver Alliance, 2016). Throughout this article the term 'caregiver` will be used for the term `family caregiver`.

Since the introduction of stroke units in Germany stroke-related mortality has decreased, but stroke related disability has increased simultaneously (German Stroke Aid Foundation, 2015). In contrast with other industrialized countries, where the caregiver role is widely recognized (Collins et al., 2011; Schure et al, 2006), in Germany caregiver needs have yet to be framed. A universal definition of the term 'caregiver' is absent (Meyer, 2006), and comprehensive support programmes to alleviate burdens on caregivers are scarce and unstructured.

Apart from providing direct personal care to the stroke patient, a sudden onset of multiple burdens on families of stroke survivors, such as emotional, societal, structural, managerial or financial burdens, pose substantial risk of negative health consequences for the stroke caregivers themselves (van Exel et al., 2005; Greenwood et al., 2010). Compared with other caregiving situations, such as dementia, stroke hits families like an earthquake, with an abrupt onset of complex demands (Redfern et al., 2006). The provision of the five components of psychological first aid (Gunderson et al., 2012) is urgently needed, as most stroke caregivers experience this situation as a 'biographical disruption' (Greenwood et al., 2010) to their lives.

Caregivers also face new challenges, such as interactions with different health care providers, taking care of the multifaceted needs of the entire family, or recreating a normal social life (Letho et al., 2013). In few support programmes of which the development was published, some of these challenges were specifically addressed (Robinson et al. 2005). Also burdens and needs change over the process of rehabilitation, as was pointed out in the "Timing It Right" caregiver support framework (Cameron \& Gignac, 2008). Special attention should be given to care transitions and information provision when supporting caregivers (0’Brien et al., 2014). 
Many reviews published since 2000, even Cochrane reviews (e.g. Forster et al., 2012; Smith et al., 2008), focused on interventions for stroke patients and their caregivers. One review analysed interventions for caregivers of stroke survivors exclusively (Legg et al., 2011). Recently a systematic review of systematic reviews demonstrated a limited understanding of the effectiveness of caregiver specific interventions for stroke survivors (Corry et al., 2015). It appears that stroke caregiver interventions can be grouped into four types of content: specialist services, psycho-education, counselling, and peer support (Visser-Meily et al., 2005). A "multicomponent" approach, combining all four options with psychotherapeutic methods, has also been introduced (Wilz \& Böhm, 2007). Four different modes of approaching caregivers have been reported: personal contact with a caregiver group (Smith et al., 2012) or with an individual (Burton, 2005), and internet or telephone communication with a group (Smith et al., 2012) or with an individual (Burton, 2005).

Comparing target group specific intervention programmes, they appeared very heterogeneous regarding their timing over the stroke trajectory. Some support programmes start in the acute phase (Aguirrezabal et al., 2013), while others start much later in the rehabilitation phases (Kalra et al, 2004), or only address home care (Tilling et al., 2005). Two German studies on programmes for stroke caregivers were published internationally; both addressed only the home care phase (Wilz \& Barskova, 2007; Pfeiffer et al., 2014). The length of the interventions also varies greatly, ranging from only 2 hours (Aguirrezabal et al., 2013) to 15 months (Wilz \& Barskova, 2007). One programme indicated the benefit of supporting caregivers through all rehabilitation phases (Cameron \& Gignac, 2008).

None of the before mentioned reviews emphasized the complexity of the caregiving situation. Combining different qualitative methods, embedded in a mixed methods design, may help to create a comprehensive and more holistic picture of the complexity of the caregiving situation within the support system (Morse, 2015). Our research was guided by the United Kingdom Medical Research Council guideline for complex interventions (Craig et al., 2008), with focus on intervention development. The research question was: "How should one conceptualize a complex programme of intervention for caregivers of stroke survivors?" This article reports on the first phase, the intervention development phase, of the complex intervention programme for stroke caregivers in Germany - 'The Caregivers' Guide`, conducted in Aachen, North-Rhine Westphalia (Germany). 


\section{Methods}

\section{Ethical considerations}

Ethical approval was provided by the Ethical committee of the Catholic University North- Rhine Westphalia, following the COREQ guideline (Tong et al., 2008). Informed consent was given by all participants.

\section{Research design}

A naturalistic inquiry approach, using a QUAL-qual mixed method design (Morse $\&$ Cheek, 2014) was applied. Within the framework of an overarching qualitative study design (QUAL) three interconnected, interrelated qualitative sub-studies (qual) were conducted using: (1) explorative and (2) semi-structured interviewing, as well as (3) participant observation methods (Morse, 2015). Grounded in a lifeworld perspective all three sub-studies put the caregiver in the centre of attention.

\section{Participants}

In sub-study 1, seven experienced stroke caregivers were selected by a key stakeholder, working in home care service using convenience sampling. Interviewees were nuclear family members and resident in the Aachen region. The length of caregiving experiences ranged from three months to ten years. Caregivers were between 47-78 years old (median 62 years) and were related to the stroke survivor as partner or adult child. Six participants were female and five were retired.

In sub-study 2, six professionals working in stroke rehabilitation were selected through snowball sampling. Participants were included if they had worked at least one year professionally in the stroke rehabilitation trajectory, working on a daily basis with stroke caregivers. Participants represented all three phases of rehabilitation. The acute phase was represented by a case manager with nursing background, a clinical social worker, a physician and a physiotherapist. The rehabilitation phase was represented by an experienced nurse working as a case manager. An experienced geriatric nurse, managing a home care service, reflected on the home care phase. Four participants were female, ages ranged from 32-59 years. 
In sub-study 3, professional-caregiver interactions were observed in seventeen settings, representing the entire stroke trajectory. Professionals were selected if they were actively involved in the stroke rehabilitation trajectory in the Aachen region and had face-to-face contact with the target group. Five settings were observed in the acute phase: in two stroke units, at social services, case management services and emergency room. Ten observations were made in early rehabilitation, inpatient and outpatient rehabilitation settings. The home care phase was observed with special focus on the role of social services as well as provision of care.

\section{Data collection and analysis}

Interviews were prepared, piloted and conducted by the first author, an experienced nurse in the fields of acute care, family care and public health. Observations were conducted by the first author and a clinical social worker with an understanding of the German social welfare system. The sub-studies were conducted sequentially; data were analysed simultaneous (Onwuegbuzie \& Teddlie, 2003).

In sub-study 1, conversational telephone interviews were conducted, aiming to gain a first understanding of caregiver needs. Each interview followed a set of open-ended questions. The interviews offered maximum flexibility from various perspectives (Patton, 2002) and lasted between 15 and 45 minutes. Data were collected in November 2012.

In sub-study 2, semi-structured face to face interviews were conducted. It was expedient to achieve an increased understanding (Morse, 2015) regarding professionals' perception towards caregiver support needs. The process was guided by a flexible interview plan (Laforest, 2009). Interviews were conducted over a two-month period at the beginning of 2013.

In sub-study 3, non-participative observations were conducted (Dewalt \& Dewalt, 2010), focussing on professional-caregiver interactions and roles within the operating system. Over a period of three months at the beginning of 201325 hours of observations were made.

The three datasets were analysed by means of qualitative content analyses (Mayring, 2010; Graneheim \& Lundman, 2004), using a four-step approach. The entire process was critically and constructively accompanied by team discussions, 
Table 1: Examples of the four-step content analysis

\begin{tabular}{|c|c|c|c|c|}
\hline STEP 1 & \multicolumn{2}{|c|}{ STEP 2} & STEP 3 & STEP 4 \\
\hline $\begin{array}{c}\text { Focus of } \\
\text { interest* / } \\
\text { source of } \\
\text { information }\end{array}$ & $\begin{array}{l}\text { Quote / source of } \\
\text { information / phase of } \\
\text { rehabilitation }\end{array}$ & Sub-theme** & Main theme $* * *$ & $\begin{array}{l}\text { 'Conceptual } \\
\text { Building } \\
\text { Block' }\end{array}$ \\
\hline $\begin{array}{l}\text { Caregiver } \\
\text { experiences } \\
\text { (caregiver, } \\
\text { professional) }\end{array}$ & $\begin{array}{l}\text { "I was paralyzed, unable to } \\
\text { think objectively...." } \\
\text { (caregiver, acute care) } \\
\text { "mentally strongly } \\
\text { strained" (professional, } \\
\text { acute care) }\end{array}$ & $\begin{array}{l}\text { Capability to act } \\
\text { Emotional support }\end{array}$ & 'Psychosocial advice' & Content \\
\hline $\begin{array}{c}\text { Caregiver } \\
\text { involvement } \\
\text { (observation) }\end{array}$ & $\begin{array}{l}\text { Social services are in most } \\
\text { setting understaffed, partly } \\
\text { trained in counselling and } \\
\text { stroke survivor focused. } \\
\text { (observation, rehabilitation } \\
\text { care) }\end{array}$ & $\begin{array}{l}\text { Psychological skills } \\
\text { Family support }\end{array}$ & $\begin{array}{l}\text { Professional support } \\
\text { Participation }\end{array}$ & $\begin{array}{l}\text { Human } \\
\text { resources } \\
\text { Personalized } \\
\text { Approach }\end{array}$ \\
\hline $\begin{array}{l}\text { Caregiver } \\
\text { role in the } \\
\text { trajectory } \\
\text { (professional) }\end{array}$ & $\begin{array}{l}\text { "caregiver are the critical } \\
\text { eye" (professional, acute } \\
\text { care) } \\
\text { "caregiver sometimes seem } \\
\text { insane" (professional, } \\
\text { acute care) }\end{array}$ & $\begin{array}{l}\text { Process orientation } \\
\text { Psychosocial skills }\end{array}$ & $\begin{array}{c}\text { 'Personalized information' } \\
\text { Professional support }\end{array}$ & $\begin{array}{l}\text { Content } \\
\text { Human } \\
\text { resources }\end{array}$ \\
\hline $\begin{array}{l}\text { Caregiver } \\
\text { needs } \\
\text { (caregiver, } \\
\text { professional, } \\
\text { observation) }\end{array}$ & $\begin{array}{l}\text { "I felt many difficulties to } \\
\text { understand what the doctor } \\
\text { said and the social worker } \\
\text { was very impatient with } \\
\text { me." (caregiver) } \\
\text { "Caregiver should receive } \\
\text { long term support from the } \\
\text { beginning to the end" } \\
\text { (professional, } \\
\text { rehabilitation care) }\end{array}$ & $\begin{array}{c}\text { Medical translation } \\
\text { Active involvement } \\
\text { Through all phases } \\
\text { of the stroke }\end{array}$ & $\begin{array}{l}\text { 'Personalized Information' } \\
\text { Participation } \\
\text { Long term support }\end{array}$ & $\begin{array}{c}\text { Content } \\
\text { Personalized } \\
\text { Approach } \\
\\
\text { Timing }\end{array}$ \\
\hline $\begin{array}{c}\text { Program } \\
\text { provision details } \\
\text { (caregiver, } \\
\text { professional) }\end{array}$ & $\begin{array}{l}\text { "face-to-face counselling" } \\
\text { (professional, acute care) } \\
\text { "someone, who knows my } \\
\text { husband from the } \\
\text { beginning." (caregiver) } \\
\text { "The place must be } \\
\text { perceived as neutral by the } \\
\text { caregiver." (professional, } \\
\text { acute care) } \\
\text { "Someone who gives me } \\
\text { the time I need and where I } \\
\text { also can show emotions." } \\
\text { (caregiver) }\end{array}$ & $\begin{array}{c}\text { Convenience } \\
\text { Privacy } \\
\text { Context tailored } \\
\text { support, } \\
\text { Psychosocial skills }\end{array}$ & $\begin{array}{c}\text { Face-to-face } \\
\text { communication } \\
\text { Through all phases } \\
\text { Flexibility } \\
\text { Focal person support } \\
\text { Professionalized support }\end{array}$ & $\begin{array}{c}\text { Personalized } \\
\text { approach } \\
\text { Timing } \\
\text { Setting }\end{array}$ \\
\hline
\end{tabular}

*The focus was set in the structured interview and observation matrix.

** All findings were transformed in a positivistic manner regarding caregiver needs.

*** Elaborated themes / higher level of the theme 
which continued until consensus about how to group the findings was reached. Initially, all narrative materials were read several times and discussed within the team, aiming to gain a profound understanding of the different perceptions of caregiver needs within the system. All data were transcribed, coded and grouped into the five topics of interest: experiences, involvement within the rehabilitation system, role, needs and important programme provision details. The extracted quotes and observations were condensed into subthemes, after converting all findings in a positivistic manner. In a third step, subthemes were merged in one matrix and subsequently categorized in main themes, together forming the overall QUAL study. Finally, the programmes 'Conceptual Building Blocks` were generated from the main themes, translating the theoretical knowledge into suggestions for the practical implementation. Table 1 depicts examples of these four steps.

\section{Results}

All participants agreed that a caregiver support programme, offering help across the whole stroke rehabilitation trajectory, is required. A programme should aim to strengthen stroke caregivers in their new role, prevent overburdening by perceiving the caregiver holistically, providing adequate attention and social support. Active involvement of caregivers in decision making and a conceptualization of caregiver support activities would be helpful.

Yes, I would have needed help, but there was nobody! [sub-study 1, caregiver1]

Caregivers are seen as a vehicle to facilitate decisions regarding the next step of rehabilitation, but are not actively involved in information provision and care. [sub-study 3, observation 7, rehabilitation phase]

Overall, five `Conceptual Building Blocks` were generated based on main themes, by conjoining overlapping sub-themes from the three sub-studies. A detailed overview is provided in table 2. 


\section{Table 2: The development of the conceptual building blocks for the personalized} multicomponent caregiver support programme- 'The Caregivers Guide'.

\begin{tabular}{|c|c|c|}
\hline \multicolumn{3}{|c|}{$\begin{array}{l}\text { The development of the Conceptual Building Blocks for the personalized multicomponent } \\
\text { caregiver support programme } \\
\text { 'The Caregivers Guide'. }\end{array}$} \\
\hline SUB-THEME / SOURCE OF INFORMATION & MAIN THEME & $\begin{array}{c}\text { 'CONCEPTUAL } \\
\text { BUILDING BLOCK' }\end{array}$ \\
\hline $\begin{array}{l}\text { Empowerment (caregiver, professional, observation) } \\
\text { Emotional support (caregiver, professional, } \\
\text { observation) } \\
\text { Capability to act (caregiver, professional) } \\
\text { Self-protection (caregiver, professional) } \\
\text { Anxiety reduction (caregiver, professional) } \\
\text { Future orientation (caregiver, professional) } \\
\text { Hope (caregiver) } \\
\text { Mourning process support (professional) } \\
\text { Caregiver needs assessment (professional) } \\
\text { Conflict management (professional) } \\
\text { Social involvement (professional) }\end{array}$ & $\begin{array}{c}\text { 'Psychosocial advices' } \\
\text { Coping strategies } \\
\text { Resource activation } \\
\text { Problem solving strategies }\end{array}$ & Content \\
\hline $\begin{array}{l}\text { Active caregiver communication (caregiver, } \\
\text { professional, observation) } \\
\text { Structural guidance (caregiver, professional) } \\
\text { Process orientation (caregiver, professional) } \\
\text { Medical translation (caregiver, professional) } \\
\text { Education (e.g. medical, rehabilitation, care process) } \\
\text { (caregiver, professional) } \\
\text { Administrative support (caregiver) } \\
\text { Optimization of the care and support system at home } \\
\text { (caregiver) }\end{array}$ & $\begin{array}{l}\text { 'Personalized information' } \\
\text { Information transmission } \\
\text { Information brokerage }\end{array}$ & \\
\hline $\begin{array}{l}\text { Psychosocial skills (professional, observation) } \\
\text { Family support skills (professional) } \\
\text { Expertise concerning social law and welfare system } \\
\text { (caregiver) } \\
\text { Risk assessment (professional) }\end{array}$ & Professional support & Human Resources \\
\hline $\begin{array}{l}\text { Working experiences (caregiver, professional) } \\
\text { Network building skills (caregiver, professional, obs.) } \\
\text { Perspective adaption skills (caregiver; professional) } \\
\text { Active listening skills (professional) } \\
\text { Communication skills (professional, observation) } \\
\text { Reflection skills (caregiver) } \\
\text { Relationship building skills (professional) } \\
\text { Conflict solving skills (professional) }\end{array}$ & Social skills & \\
\hline $\begin{array}{l}\text { Empathy (caregiver, professional) } \\
\text { Open mindedness (caregiver, professional, observation) } \\
\text { Appreciation (caregiver, observation) } \\
\text { Tolerance (professional) }\end{array}$ & Personality traits & \\
\hline
\end{tabular}

Table continues on the next page. 


\begin{tabular}{|c|c|c|}
\hline \multicolumn{3}{|c|}{$\begin{array}{l}\text { The development of the Conceptual Building Blocks for the personalized multicomponent } \\
\text { caregiver support programme } \\
\text { 'The Caregivers Guide'. }\end{array}$} \\
\hline SUB-THEME / SOURCE OF INFORMATION & MAIN THEME & $\begin{array}{c}\text { 'CONCEPTUAL } \\
\text { BUILDING BLOCK' }\end{array}$ \\
\hline $\begin{array}{l}\text { Active case finding (professional, observation) } \\
\text { Accessibility (caregiver, professional, observation) } \\
\text { Structured personalized information provision } \\
\text { (caregiver, professional) } \\
\text { Guidance trough the SS trajectory system (caregiver, } \\
\text { professional, observation) } \\
\text { Context tailored support (professional, observation) }\end{array}$ & $\begin{array}{l}\text { Outreach counselling } \\
\text { Focal person support }\end{array}$ & $\begin{array}{l}\text { Personalized } \\
\text { Approach }\end{array}$ \\
\hline $\begin{array}{l}\text { Direct communication mode (caregiver, professional) } \\
\text { Relation building (caregiver, observation) }\end{array}$ & Face-to-face communication & \\
\hline $\begin{array}{l}\text { Family support (professional, observation) } \\
\text { Active involvement (professional, observation) }\end{array}$ & Participation & \\
\hline $\begin{array}{l}\text { Through all phases of the SS rehabilitation trajectory } \\
\text { (caregiver, professional, observation) }\end{array}$ & Long term support & Timing \\
\hline Since the beginning (professional, observation) & Through all phases & \\
\hline Flexible end (professional, observation) & $\begin{array}{l}\text { As early as possible } \\
\text { As long as needed }\end{array}$ & \\
\hline $\begin{array}{l}\text { Convenience (professional, observation) } \\
\text { Privacy (professional) } \\
\text { Trustful atmosphere (professional, observation) }\end{array}$ & Flexibility & Setting \\
\hline
\end{tabular}

\section{Description of the newly developed 'Conceptual Building Blocks'}

The first 'Conceptual Building Block` is labelled 'Content', and consists of two main themes, 'psychosocial advice' and 'personalized information'. In our study the term 'psychosocial advice' includes coping and problem solving strategies, as well as resource activation. Since the subthemes 'empowerment' and 'emotional support' emerged in all phases, psychosocial advice is desirable over the entire rehabilitation trajectory.

I don't only need information, but also emotional support, someone who empowers me. [sub-study 1, caregiver 3]

Someone who listens to them and organizes the perceived chaos. [sub-study 2, professional 3, case manager/nurse, acute care]

However, psychosocial advice needs to be adapted over the course of rehabilitation. All experienced caregivers remembered the time immediately after the stroke as very challenging. They described themselves as being in a "state of mental emergency" [caregiver 1] and feeling overwhelmed. The "provision of 
hope` [caregiver 4] was declared as an important element. Additionally, professionals stated a form of mourning process support as well as assessment of the needs of a caregiver to be central in the early post stroke phase.

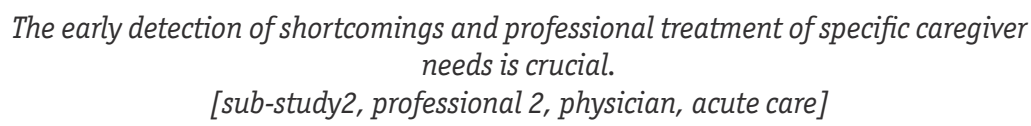

Towards the end of the rehabilitation process and in the home care phase caregivers articulated the need for support in optimizing the existing care and support system, so that they could handle the work load and grow in their new role. Professionals stated that the caregiver's social participation is very important in the late phase, in order to prevent loneliness and isolation. Furthermore, due to the role change within the relationship and the perceived changes in the patient's personality, conflict management should be considered.

Personalized information is preferred in all phases of rehabilitation and should be provided individually. The term 'personalized information' is made up of the elements 'information brokerage' and 'transmission'. As may be seen in Table 2 'personalized information` includes the subthemes structural guidance, process orientation, medical translation, education concerning medical issues as well as rehabilitation and care process, and administrative support.

I was so confused by the amount of information on the internet.

[sub-study 1, caregiver 3]

It took me a lot of energy to understand the complex health process.

[sub-study 1, caregiver 4]

The findings indicate that information brokerage must be provided by actively communicating with the caregiver. Professionals should confirm that the information was understood. Caregivers should feel invited to ask clarifying questions.

Caregivers need someone who explains important issues in a comprehensive way. [sub-study 2, professional 6, clinical social worker, acute care]

In each sub-study there was consensus that caregiver needs change over the process of rehabilitation. Hence, the 'Conceptual Building Blocks' 'Content' and 'Timing' are linked.

The second `Conceptual Building Block` focuses on `Human Resources`, which 
appeared to be central for the upcoming programme in each sub-study. It contains three main themes: professional support, social skills and personal traits. A holistic caregiver support requires multifaceted knowledge, indicating a professional support. In the interviews with the professionals and the observation it was perceived that psychosocial skills seem to be imperative for caregiver support. Moreover, this professional should ideally have expertise in social law and welfare systems, as well as basic knowledge concerning the stroke rehabilitation trajectory, and should be skilled in risk management and family support.

\author{
Caregivers need a road map and someone who can use a compass. \\ [sub-study 2, professional 4, case manager /nurse, rehabilitation care]
}

We need independent, professional counselling for future planning. [sub-study 1, caregiver 5]

"It is important to early detect the most vulnerable cases."

[sub-study 2, professional 2, physician, acute care]

Social skills seem to be crucial for support in this setting. The counsellor should have skills in network building, active listening, communication, reflection, building relationships, and in conflict resolution. Both interview groups also viewed 'perspective adoption skills' as essential, referring to the ability to analyse and structure the complex caregiver situations and to guide the client through the process in an appropriate way. Moreover, the interviews showed that professional and social skills are not alone sufficient to fulfil the requirements of the jobs. Personal traits such as tolerance, appreciation, empathy, and open mindedness were considered crucial for the successful implementation and acceptance of caregiver support.

An administrative style of person would be miscast ...

[sub-study 2, professional 3, nurse, rehabilitation care]

I would need a warm person who is interested in me and my situation. [sub-study 1, caregiver 5]

The third 'Conceptual Building Block' was named 'Personalized Approach`. Four main themes contributed to this building block: outreach counselling, focal person support, face to face communication, and participation.

In all studies the question of 'how to reach the target group?' appeared to be essential. It became apparent in sub-study 2 and sub-study 3 that caregivers should be actively reached out. Professionals stated that, especially at the be- 
ginning, caregivers are so overwhelmed, that they would not themselves search actively for support. Therefore the "outreach counselling" [professional 6, clinical social worker, acute care] approach was chosen as a suitable strategy. Over the trajectory caregivers are in contact with many professionals. They may feel challenged by "constantly changing support teams" [professional 2, physician, acute care]. Communication lines were not clearly outlined, and miscommunication and neglected opportunities to communicate were observed. A focal person support would be a benefit for the target group as the entire process of stroke rehabilitation is characterized by several transition phases.

Somebody who brings all the strings together is missing.

[sub-study 2, professional 1, physiotherapist, acute care]

In Germany a variety of agencies are involved in the stroke rehabilitation process, which was perceived as being highly non-transparent. Experienced caregivers criticized the non-supportive role of the health insurance providers.

\section{I was trying to control the process but sometimes it took me a lot of energy to unders- tand the underlying agenda and the complex health processes. \\ [sub-study 1, caregiver 2] \\ Every time I call the health insurance provider a different person is handling our case. \\ [sub-study 1, caregiver 5]}

Face to face communication would be the most appropriate mode of contacting the caregiver, especially at the beginning when caregivers are in a vulnerable state. Through this approach it will be possible to build a trusting relationship, which is crucial for the counselling process.

I need someone who gives me the time I need and where I can also show emotions. [sub-study 1, caregiver 4]

Later additional modes of contact, such as telephone or Email, might be an option. This supports the need for flexibility regarding the context tailored mode of communication.

In sub-study 2 and 3 it was observed that caregivers were rarely actively involved in the decision making. The findings suggest that active caregiver involvement would strengthen caregivers in their new role. Some professionals perceive caregivers as `trouble makers or critical eye` [professional 3, nurse, rehabilitation care]. In the rehabilitation phase caregivers have only limited contact with the 
medical and therapeutic team and are less involved in the communication. Therefore, professionals already recognized signs of loneliness in this phase. In the home care phase the feeling of isolation grows, because of increasing caregiving obligations.

The fourth 'Conceptual Building Block' (4) centres on 'Timing', being nourished from the themes 'long term support”, 'through all phases`, ' as early as possible` and `as long as needed`. In each sub-study there was consensus that the needs of a caregiver change over the process of rehabilitation. Therefore, the 'Conceptual Building Blocks 'Content' and 'Timing' are linked to each other. Findings from sub-study 2 and 3 indicated that the support should be started as early as possible and be provided flexibly as long as it is needed.

Caregivers should receive long-term support from the beginning to the end.

[sub-study 2, professional 6, clinical social worker, acute care]

The fifth 'Conceptual Building Block', the 'Setting', was generated using only findings from sub-study 2 and 3. It includes the main theme 'flexibility', which was condensed from the subthemes 'trustful atmosphere', 'place of convenience' and 'privacy`. The 'Setting' is connected with 'Personalized Approach', especially with the components `outreach counselling ' and 'face to face communication`.

The counselling place must be perceived by the caregiver as neutral.

[sub-study 2, professional 3, case manager/ nurse, acute care]

The hospital would be an unsuitable place for counselling. [sub-study 2, professional 1, physiotherapist, acute care]

In summary, this new caregiver support programme will be containing of five 'Conceptual Building Blocks' with high flexibility regarding 'Content', 'Personalized Approach ', 'Timing' and 'Setting '. A focal person system with a specially trained professional will be mandatory.

\section{Discussion}

This study provides a methodological example of how to develop a complex intervention programme, using a qualitative mixed methods (QUAL-qual) design (Morse, 2015). This design appeared most appropriate because of its focus on exploring new fields, allowing for creativity and inductivity (Morse, 2015; Mor- 
se \& Cheek, 2014; Borglin, 2015). The nature of the complex and contextual depending phenomena was gathered in a structured, straightforward qualitative content analysis (Laforest, 2009). Every sub-study introduced significant insights or added to the picture of caregiver needs in this context, as recommended when aiming to develop a new programme (Morse, 2015; Graneheim \& Lundman, 2004). In order to gain an in-depth contextual understanding of caregiver needs over all phases of the German stroke care trajectory we included three sources of information and two different data collection methods: interviews with experienced caregivers and with professionals working in different settings representing the entire stroke trajectory and observations of caregiver - professional interactions in different rehabilitation settings. The inclusion of an observation sub-study, allowed us specifically to reflect on issues concerning 'Setting` and 'Personalized Approach`of our prospective programme. Different qualitative researchers explicitly highlight the advantage of including observations in the mixed methods design (Pelto, 2015; Guba, 1981). The triangulation of different information sources, using qualitative content analysis, displayed several overlapping subthemes. Moreover, by adding an extra step, we were able to generate the 'Conceptual Building Blocks`, which we thought important in view of closing the gap between theory and practice.

We aimed to conceptualize a comprehensive intervention programme for stroke caregivers. When conducting our study in Germany for this specific group only very few isolated and unstructured support initiatives were available (Specht, 2014). Our findings indicate the need for an intervention programme, aimed at reducing stress and strengthening the caregivers in their role by offering personalized support.

As stated earlier, many interventions have been tested for their effectiveness in reducing the negative consequences of caregiving (Legg et al., 2011). However Corry et al. (2015) indicated that more investigation regarding the support is needed. An integrated intervention approach might me most promising (Tilling et al., 2005).

Developing complex interventions is particularly challenging in family caregiving situations, where in-depth understanding of the context is crucial (Redfern et al., 2006). Moreover, complex interventions, such as our `Caregivers' Guide`, need to be contextually modified. The transfer of an intervention, successfully tested in one setting, to another setting is still difficult without adaptation, as the example from the United Kingdom 's TRACS programme displays (Clarke et 
al., 2014). For the development of our programme the detailed guidelines for complex interventions published by the Medical Research Council (Craig et al., 2008), specifically focussing on the development phase, proved to be very helpful.

Caregiver support has to cover the entire trajectory of stroke care and rehabilitation. Our findings are in line with 0 'Brien et al. (2014) in accentuating the need for long-term support. The need for a holistic approach became most clear through observing caregiver- professional interactions. Earlier the "Timing-itRight" programme (2008) acknowledged the importance of caregiver support across the trajectory. Our findings indicate that caregiver support should start as early as possible, preferably in the acute stroke care phase; this in line with other qualitative research, advocating early caregiver engagement (Grant et al., 2014). Since the transfer of a stroke survivor from the rehabilitation to the home phase is recognized to be very stressful (Grant et al., 2014) or even highly problematic (Loupis \& Faux, 2013) for the caregiver, an adequate support programme should include the home care phase.

Combining the findings from all sub-studies accentuated the need for flexibility. Our study displayed that caregivers have very different perceptions of how their burdens and specific tasks change over the rehabilitation process, implying that the programme has to be personalized. We agree with 0stwald et al. (Ostwald et al., 2014), underpinning that stroke caregiver interventions with "one size fits all" strategies will be ineffective. Also other authors (Creasy et al., 2013; Adelman et al., 2014) emphasized that the intervention must be adopted to caregivers'specific needs.

In sub-study 1 we explicitly included experienced caregivers in the development of the programme, which is rarely done (Brereton et al., 2007; Funk \& Stajduhar, 2009). However their contribution proved to be very valuable, especially regarding the 'Conceptual Building Blocks ' 'Content' and 'Human Resources'. Parts of our multicomponent support programme consist of the provision of 'psychosocial advice' and 'personalized information', incorporating psychotherapeutic elements, which is in line with earlier recommendations (Visser-Meily et al., 2005; Wilz \& Böhm, 2007). Therefore, professional counselling experience is recommended. In contrast with the Timing It Right framework (Cameron \& Gignac, 2008), who specified that support can be provided by different, not exclusively professionally trained, persons within the trajectory, our findings indicate 
a focus person system. In other research fields benefits have been reported from the introduction of a focal person system (Komatsu \& Yagasaki, 2014).

Furthermore, experienced caregivers and professionals highlighted the importance of personal traits of the counsellor. These outcomes are comparable to the suggestions of the Psychological First Aid (Gunderson et al., 2012). We introduced this issue in the 'Conceptual Building Block' 'Human Resources' .

In sub-study 2 we actively included different professionals, working on different settings in stroke care. Another qualitative study selected only one uniform professional group, in this case nurses (Useros et al., 2012). Only recently greater emphasis has been given on investigating the perceptions of different health care providers in the stroke caregiving field (Cameron et al., 2013; 0`Brien et al., 2014). Through the different professional backgrounds of the participants we were able to recognize the potential to evaluate the needs of caregivers and to identify places for improvement of the current system. All professionals added important aspects to our programme, especially to the 'Conceptual Building Blocks 'Timing', 'Human Resources', and 'Setting'. However, our results also indicate that some of the interviewed professionals did not recognize the importance of the caregiver role during the stroke rehabilitation process. Although it is well recognized that active caregiver involvement has a potentially positive effect on a patient's recovery (0`Brien et al., 2014; Harris et al., 2010), Lutz \& Young (2010) have remarked that stroke caregivers are not sufficiently involved in stroke rehabilitation. Professionals should be encouraged to involve caregivers as an integral part of the entire health care system (Grant et al., 2014).

An innovative insight from our study was that a caregiver support programme should include 'outreach counselling' for early detection of vulnerable cases (van Heutgen et al., 2006). This approach is frequently used in humanitarian crisis intervention as an important psychological intervention tool (Lucchi, 2013; Henley et al., 2011), but also in other fields such as HIV prevention (Chippendale \& French, 2001). In Sweden, 'outreach counselling' was tested in families of children with acquired brain injury (Emanuelson et al., 2003). It was shown that "active, early intervention" reduced caregiver related stress. In Denmark, this approach was also used in the support families with Alzheimer patients (Soersen et al., 2008).

Our findings of sub-study 1 and 2 are in line with Bakas et al. (2014), underpin- 
ning that face to face support would be most suitable approach, especially in the acute stroke care phase, when alleviation of emotional distress is important. Caregivers find it difficult to identify or utilize services that will support them, as was earlier reported in a study in the American setting (Grant et al., 2014). In particular the role of the German social system in the various transitions and especially in the transfer back to the home environment is confusing (Unrath et al., 2013). Caregivers and professionals mentioned that the amount of unstructured information provided by the different players involved in the German stroke rehabilitation system adds considerable stress to the already demanding situation of suddenly becoming a stroke caregiver. Structured and professional guidance by a professional with expert knowledge concerning the social and health support system and legal issues would be very helpful.

Research is missing on the influence of the place of support, which is in our study is referred to 'Setting ' '. In our programme 'Setting' is one of the five 'Conceptual Building Block'. We have indications that the flexible offer of the support's place, for instance in the home environment, may influence the acceptance of the programme.

\section{Methodological considerations}

The sample sizes of the sub-studies were relatively low. However, the aim was to gain comprehensive contextual understanding, to reach saturation in each sub-study was not essential (Morse \& Cheek, 2014). Credibility was achieved through adaptation of the research methods to the research question, triangulation of findings from the sub-studies, frequent debriefing sessions within the research team, and a multifaceted professional background, qualifications and experience of the investigators. By providing an in-depth description of the study design as well as profound data gathering details Dependability was guaranteed. By triangulating the findings the effect of research bias might be diminished supporting the study's confirmability. Since we conducted our study in this particular context transferability is provided only to some extent. Based on this argumentation our study achieved trustworthiness (Guba, 1981; Shenton, 2004).

Before implementing the new caregiver support programme it seems worthwhile to conduct a stakeholder and risk analysis, informing about the acceptance and implementation potential of the new program (Schlarmann et al., 2011; Richards, 2015). 


\section{Conclusion}

In the developmental phase of this complex intervention programme the information gained through the naturalistic research design (QUAL-qual) were providing a profound contextual understanding. It resulted in five 'Conceptual Building Blocks` of the complex intervention programme for stroke caregivers: (1) 'Content' - including a multicomponent approach, combining psychosocial advice with personalized information, (2) 'Human Resources`- professional support with a background in health or social services, as well as psychosocial skills, (3) 'Personalized Approach`- utilizing outreach counselling, a one focal person system, and a preference for face to face counselling, (4) 'Timing ` - providing long term support, starting as early as possible after stroke, and continuing flexibly for as long as it is needed, and (5) 'Setting '- flexible services offered in a place of convenience. 
The stepwise development of a comprehensive family caregiver support programme. 
CHAPTER 3 The development of implementation management instruments for a new complex stroke caregiver intervention based on systematic stakeholder and risk analyses

Krieger T, Boumans N, Feron F, Dorant E (2019) Developing implementation management instruments in a complex intervention for stroke caregivers based on combined stakeholder and risk analyses. Scandinavian Journal of Caring Sciences. (accepted for publication) 


\section{Abstract}

Background. Stakeholders are important contributors in the implementation of a complex public health intervention. During the development phase of an implementation, alongside careful design of its components and investing in the exploration of the intricate and dynamic multi-stakeholder stroke rehabilitation setting, it is essential to assess possible implementation risks. Systematic stakeholder- and risk analyses can guide the exploration process and enable teams involved in complex interventions to develop context-tailored implementation management instruments.

Objective. To develop instruments that facilitate the implementation of the complex stroke caregiver intervention project in the real-life support system. Design. Stakeholder and risk analyses.

Setting. Stroke support system in a middle sized city and it urban surrounding in the western part of Germany

Participants. Twenty-four individual stakeholders which were categorized into twelve stakeholder groups, representing the current stroke support system within the geographic region.

Methods. We first conducted systematic stakeholder and risk analyses using different project management techniques. Project stakeholders were identified, classified, and assessed using a top-down approach, while implementation risks were identified and assessed by applying a bottom-up approach.

Subsequently specific knowledge of the stakeholders and risks was utilized, topdown, to develop context-tailored implementation management instruments.

Results. Two instruments were developed: (1) a comprehensive 'stakeholder-risk atlas' providing individual stakeholder information, such as role, access, contribution, power and interest, expectations, perceived risks, and specific engagement activities, and (2) an overall 'project implementation strategy' concentrating on communication, transparency, network building and professionalism.

Conclusion. Complex interventions will benefit from early and comprehensive stakeholder and risk analyses. The early involvement of stakeholders, with their 
insightful knowledge, enables the research team to develop context-tailored implementation management instruments. Instruments will support the team during implementation and may impact positively on the outcome of the intervention. Knowledge can be obtained by combining top-down and bottom-up working approaches. 


\section{Introduction}

\section{Stroke caregivers}

Family caregivers play an essential role in the day-to-day care of stroke survivors (Elmore, 2014; Family Caregiver Alliance, 2018). These caregivers may be a relative, a partner, a friend or a neighbour, and they provide 'free of charge' assistance to a person with a chronic disability (Family Caregiver Alliance, 2018). In the case of a stroke survivor, first-time caregivers are obliged to deal with multi-various and complex demands associated with their care receivers without the benefit of adequate preparation time (Redfern et al., 2006). Unexpected situations and new interactions with health care providers, exhausting administrative and financial demands, or excessive information load are all known to provoke feelings of stress and overburdening (Redfren et al., 2006; Bienstein, 2006).

\section{Complex interventions}

Stroke caregiver interventions, in common with most interventions in public health, tend to be complex and strongly context dependent (Pandi-Perumal et al., 2015; Rychetnik et al., 2002). The development of a complex intervention warrants a systematic design of its content (Craig et al., 2008). Moreover, it requires a comprehensive understanding of the situation of its end-users, the current support system and the organisations or actors involved, along with their specific socio-political context (Campbell et al., 2007). A sound understanding of barriers and enablers is imperative for the implementation of a new intervention in the real-world (Dogherty \& Estabrooks, 2015). Furthermore, careful and systematic preparation is essential for the management of the different stakeholders (Rychetnik et al., 2002; Caron, 2014). Stakeholders are defined as "individuals or groups who have an interest or some aspects of rights or ownership in a project, and can contribute to, or be impacted by either the work or the outcome of the project" (Walker et al., 2008). In public health care settings, stakeholders are essential in the implementation of a complex intervention, as they possess critical internal knowledge, but simultaneously present a major source of complexity and uncertainty (Rychetnik et al., 2002; Caron, 2014; Ward \& Chapman, 2008).

Implementation management instruments are essential in facilitating the implementation process in a complex setting, and an early stakeholder involve- 
ment is recommended for their development (Pandi-Perumal et al., 2015; Caron, 2014; Project Management Institute - PMI - , 2013). For instance, the instrument 'stakeholder register' should facilitate the day-to-day stakeholder engagement during implementation by outlining individual stakeholder information and activities (Pandi-Perumal et al., 2015; Jeffery, 2009). Other instruments, such as 'project implementation strategies', are methods or techniques which guide the overall project and its adaptation or transferal into the real-world by considering implementation barriers or enablers, and declaring general activities (Curran et al., 2012; Achterberg, 2015). However, no reports are to be found in the literature on the development process of these useful management instruments in public health interventions.

\section{Stakeholder and risk analyses}

Although stakeholder involvement and engagement, as well as the identification of possible implementation barriers are imperative in complex interventions (Craig et al., 2008; Abraham et al., 2015; World Health Organisation, 2009; Moore \& Evans, 2017), clear instructions from the health or public health domain concerning this are scarce. Only a few examples have been published. Bradley et al. (1999) proposed gathering the perceptions of end-users and health professionals in the development of a cardiovascular risk reduction programme; while Silver et al. (2016) recommended stakeholder analyses to improve the quality of kidney health care provision. In addition, Pandi-Perumal et al. (2015) published a stepwise approach of stakeholder management in a clinical research environment, outlining practical suggestions for stakeholder engagement.

Project management is the application of knowledge, skills, tools, and techniques and project activities so as to meet the project requirements (PMI, 2013). Consecutive stakeholder and risk analyses are frequently conducted in this field, especially in the development phase (Pandi-Perumal et al., 2015; PMI, 2013). Stakeholder landscapes are not static but, rather, dynamic (Aaltonen \& Kujala, 2015). Stakeholder analyses help to understand stakeholders from their different perspectives and should include stakeholder identification, classification, and assessment (Caron, 2014; Burgha \& Varasovszky, 2000; Schiller et al., 2013). More specifically, information concerning stakeholders' contribution (Bourne, 2015), engagement (Jepsen \& Eskarod, 2009) or stakeholders' power and interest (Ackermann \& Eden, 2011), which are imperative for developing implementation management instruments, can be obtained through these analyses (Caron, 2014; Jepsen \& Eskarod, 2009). 
Risk analyses contribute in systematically identifying possible project implementation risks within a multi-stakeholder setting (Ward \& Chapman, 2003), and assessing their likelihood is required in order to manage them (Ammar et al., 2007; Zabaleta-del-0lmo et al., 2015). Risk analyses provide a base for generating appropriate strategies to reduce, control, or prevent risks (Pandi-Peruma et al., 2015; Ward \& Chapman, 2008). Thus stakeholders may contribute their expertise and knowledge as an integral part of the risk exploration process (Evans et al, 2013; Greenhalgh et al., 2016).

\section{Developing a new stroke caregiver support programme}

Stroke rehabilitation in Germany operates on different levels, with various professional groups within a complex "multistakeholder setting" (Rühli et al., 2017). As presented in Figure 1, the patient's rehabilitation trajectory is fragmented and characterized by multiple transition points between acute, rehabilitation and home care, resulting in a variety of bureaucratic, informational and logistical bottlenecks (Bundesarbeitsgemeinschaft Rehabilitation - BAR, 2014). This rehabilitation process implies various impediments not only for the medical care and societal support system, but also for the patients and their family caregivers (Schuler \& Oster, 2004).

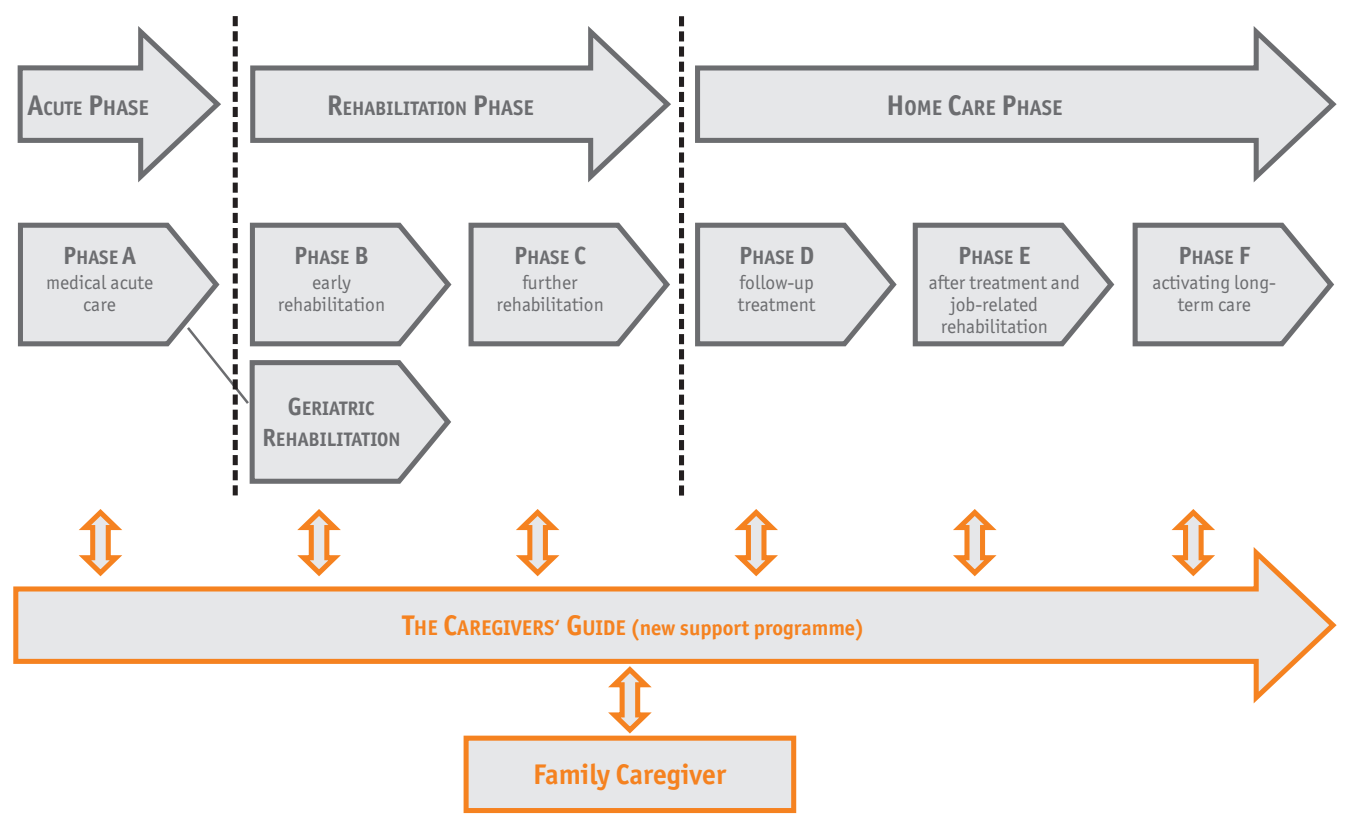

Figure 1: The German stroke rehabilitation support system and the Caregivers' Guide support programme (adapted from BAR, 2014). 
The Caregivers' Guide is a primary prevention programme that was developed in Germany and fits the definition of complex intervention as published by the Medical Research Council UK [7]. The programme aims to: (1) offer personalised support to stroke caregivers parallel to the patients' rehabilitation trajectory, (2) reduce the burden of stroke caregivers, and (3) maintain their quality of life by offering early, flexible and personalized support (Krieger et al., 2017).

The Caregivers' Guide emerged from a project management cycle (PMI, 2013) that comprised of three phases: development, implementation and evaluation (Figure 2). The development phase was split into two parts. Part one focused on the programmes overall design and content (Krieger et al., 2017). Part two concentrated on preparing its implementation in the real world by developing implementation management instruments through systematic stakeholder- and risk analyses (figure 2).

In this paper we report on part two of the Caregivers`'Guide development phase which consists of two steps:

1) the systematic stakeholder and risks analyses, and 2) the development of implementation management instruments. Exploration of the stakeholder setting and implementation risks gathered new knowledge, labelled 'inputs'. These 'inputs' were utilized to develop context-tailored implementation management instruments, labelled `outputs` (figure 2).
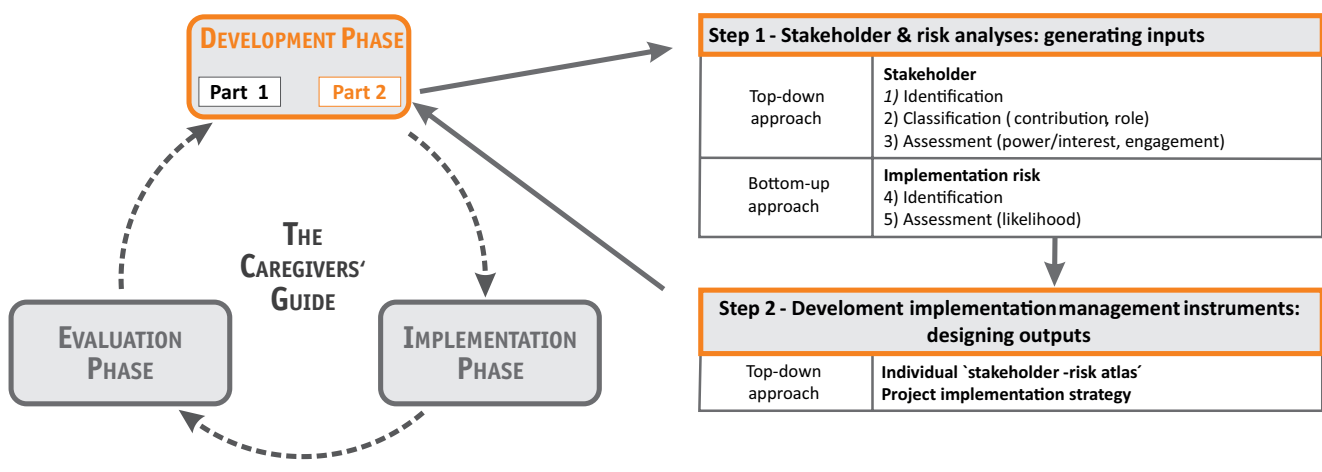

Figure 2: The Caregivers ' Guide project management cycle with an elaboration of part 2 of the development phase (adapted from Pandi-Perumal et al., 2015). 


\section{Methods}

The development phase of the project used a mixed-methods approach for generating the 'inputs' and developing the 'outputs'. Stakeholder analyses and the development of the implementation management instruments were conducted top-down by two members of the research team, namely a clinical social worker and a nurse specialized in public health. The implementation risks were analysed bottom-up by engaging with the projects' stakeholders during a stakeholder meeting.

\section{Step 1 - Stakeholder \& risk analyses: generating ‘inputs}

'Inputs' were generated by conducting qualitative stakeholder and risk analyses, consisting of five consecutive activities (Figure 2).

In activities one, two and three, the stakeholders were identified, classified and assessed. This was done by application of a top-down or expert-led approach (Khadka \& Vacik, 2012) over a span of 3 months. The two research team members conducted 12 field visits in order to explore the current support system and its stakeholders, to initiate working relations, and to understand a stakeholders position, needs, requirements, and concerns,. The following 9 groups of stroke caregiver support were visited: two acute care providers, two rehabilitation care providers, two home care providers, one ambulant service provider, one communal service provider, one content-near peer group, one health cost provider, one technical support group and one research community group (Figure 3). During these visits 30 explorative interviews were held with 13 different professions (service provider): 3 medical doctors, 2 health managers, 3 social workers, 6 nurses, 2 physiotherapists, 2 ergo-therapists, 2 speech therapists, 2 psychologists, 4 case manager, 1 nurse-trainer, 1 technical support manager, 1 health science manager, and 1 public health expert. In addition, 'input' of the stakeholder ' caregiver' (end-users) was generated from interview materials that had been collected in the part 1 of the project's development phase (Krieger et al., 2017; Figure 2). In order to safeguard the information, respective notes of the conversation were written down after each interview.

In activities four and five, we conducted bottom-up implementation risk analyses during the stakeholder meeting (Khadka \& Vacik, 2012) by obtaining the stakeholder's active participation. In this meeting 2 medical doctors, 3 case managers, 2 social workers and 4 nurses provided their considerations about possible implementation risks. Results from this meeting were supplemented by 
implementation risk information gained during the field visits.

Data collection and examination of the findings occurred concurrently, and results were built on each other.

Activity 1 - Stakeholder Identification

In this activity we aimed to gain a systematic overview of the potential individual stakeholders of the new programme by applying different identification methods. On the basis of the contextual understanding we first identified the organisational stakeholders representing the patient-centred, real-world stroke rehabilitation support setting via brainstorming by the research team (Figure 1). Second, the acute, rehabilitation and home care setting was explored by questioning at least two key informants within each setting, e.g. social workers and nurses. Third, snowballing was used to explore the broad community support system. Potential stakeholders were added until the team was convinced that all relevant stakeholders representing the current caregiver support system had been identified. Finally, individual stakeholders within the same contextual affiliation, e.g. participants in acute care, were categorized in a so-called Caregivers'Guide stakeholder map (Figure 3) (Schiller et al. 2013).

Activity 2 - Stakeholder classification

In theory not all stakeholders can or should be involved during implementation with the same intensity. Therefore, we classified the identified stakeholders of activity 1 by: (1) exploring stakeholders' contribution, and (2) assigning them to a role. For this purpose the identified stakeholders were visited personally in their setting, or contacted by telephone, and their context-specific contribution, expectations, and perceived risks were assessed.

During the interviews, inspired by Bourne (2015), the potential contribution of stakeholders during programme implementation was explored using six criteria: 'active participation', 'occasional involvement', 'knowledge', 'ownership', 'funding', and 'campaigning'. 'Active participation' refers to the moral obligation to participate and act in the programme as an end-user or gatekeeper; 'occasional involvement' refers to the need of being professionally involved within a specific setting (e.g. rehabilitation care); ' context-specific knowledge' emphasizes the need to include stakeholders' expertise; 'ownership' clarifies the intellectual property of the programme; 'funding' refers to the need for financial contribution; and 'campaigning' highlights stakeholder-driven 
activities that promote the programme.

Stakeholders were assigned to one of four possible roles on the basis of their contribution: 'player', ' context setter', 'subject' or 'crowd' (Ackermann \& Eden, 2011). The 'Players' are essential to the implementation of the programme, as they are the only group able to directly impact upon or be affected by the intervention through 'active participation'. 'Context setters' can influence the projects' implementation by cooperating with or by working against it, and they may have little interest, being only occasionally involved. 'Subjects' are neither directly nor indirectly involved in, nor affected by the intervention. However, they show high interest in the implementation process and are likely to stimulate the programme with their ideas. 'Crowd' are not actively involved in the implementation process, but may possibly play an advisory role or may be important for transferal activities when finalizing the project.

Activity 3 - stakeholder assessment

Managing the large number of diverse stakeholders during implementation can be a difficult and complex task. It is, therefore, necessary to assess the stakeholders' potential power (influence) and interest in the implementation process in order to develop stakeholder management or engagement strategies. Stakeholders' 'power' is defined as the ability to positively or negatively influence the practical implementation process, and 'interest ' is based on stakeholders' concerns regarding the projects' outcome (PMI, 2013; Ackermann \& Eden, 2011). The research team estimated the 'power' and 'interest' of the identified stakeholders by use of the information gathered during their field visits. The power/interest grid was used to assign an appropriate engagement strategy for each of the four stakeholder roles (Ackermann \& Eden, 2011).

Activity 4 -risk identification

A variety of risks may appear when implementing a new intervention within the real-life support system. Risks are uncertain events that have an effect on the achievement of the objectives of the projects (Walker et al., 2008; Ward \& Chapman, 2008).

Potential project implementation risks were identified in a 'co-creative process' (Greenhalgh et al., 2016) together with the stakeholders during the stakeholder meeting. Ten individuals, presenting six stakeholder groups, namely individual stakeholders from the 'Players' and 'Context setters' (Figure 4), were 
present and participated in focus group discussions. Firstly, we brainstormed 'what may jeopardise the projects' implementation process'. Subsequently, in a mind mapping exercise, all potential risks were designated to a project- or stakeholder-related risk category, and were finally assigned to overarching risk domains (Table 2). The perceptions of the 'subjects' and 'crowd', representing the other six groups (Figure 4), were assembled afterwards via face-to-face or telephone conversations.

Activity 5 - Risk assessment

Not all risks are equally represented in the implementation phase. Therefore, determining the likelihood of each risk is important for its management. In the stakeholder meeting the identified risk domains (activity 4) were examined on the basis of their potential likelihood, which is defined as the possibility that a risk will occur (PMI, 2013). This process resulted in categorizing risk domains in three ranks: high, moderate and low (Table 2).

\section{Step 2 - Developing implementation management instruments: designing the 'outputs'}

After comprehensively exploring the multi-stakeholder setting and the implementation risks, the research team was able to use this knowledge further for facilitating the implementation. Over a one-month time span, the research team designed 'outputs' by summarizing the findings of the systematic stakeholder and risk analysing 'inputs', '. These 'outputs', the so-called implementation management instruments, should facilitate the projects`implementation within the multi-stakeholder stroke rehabilitation support system.

\section{Results}

\section{Step 1 - Stakeholder and risk analyses: generating inputs}

Activity 1- stakeholder identification: Twenty-four individual stakeholders were identified and categorized into twelve stakeholder groups (Figure 3). We explicitly included not only the service providers but also the interventions' endusers, i.e. the stroke family caregivers, in our map. 
Activity 2 - stakeholder classification: The classification included both exploration of the contribution of each stakeholder group and their assignment to a prospective role in the upcoming implementation phase (Table 1).

In accordance to their contribution stakeholders were assigned to one of four possible roles: 'player', 'context setter', 'subject' and 'crowd' (Table 1).

Family caregivers and acute care providers were labelled 'players'. They were the sole contributors through 'active participation'. As the end-users of the programmes, family caregivers will be directly affected by and influence the intervention through interaction with the counsellor. Acute care providers should play an active role in the recruitment process by holding a gatekeeper position and referring suitable clients for the programme.

The 'context setter' role was assigned to four stakeholders: rehabilitation care providers, home care providers, communal social services, and the research community. Their contribution would be considered in three of the following criteria: 'occasional involvement', 'context-specific knowledge', 'campaigning' and 'ownership'. Rehabilitation care providers and home care providers will be involved only when a previously included caregiver-patient dyad is transferred to them from the acute care setting. Communal social services will be involved on demand, e.g. when structural adjustments in the home environment

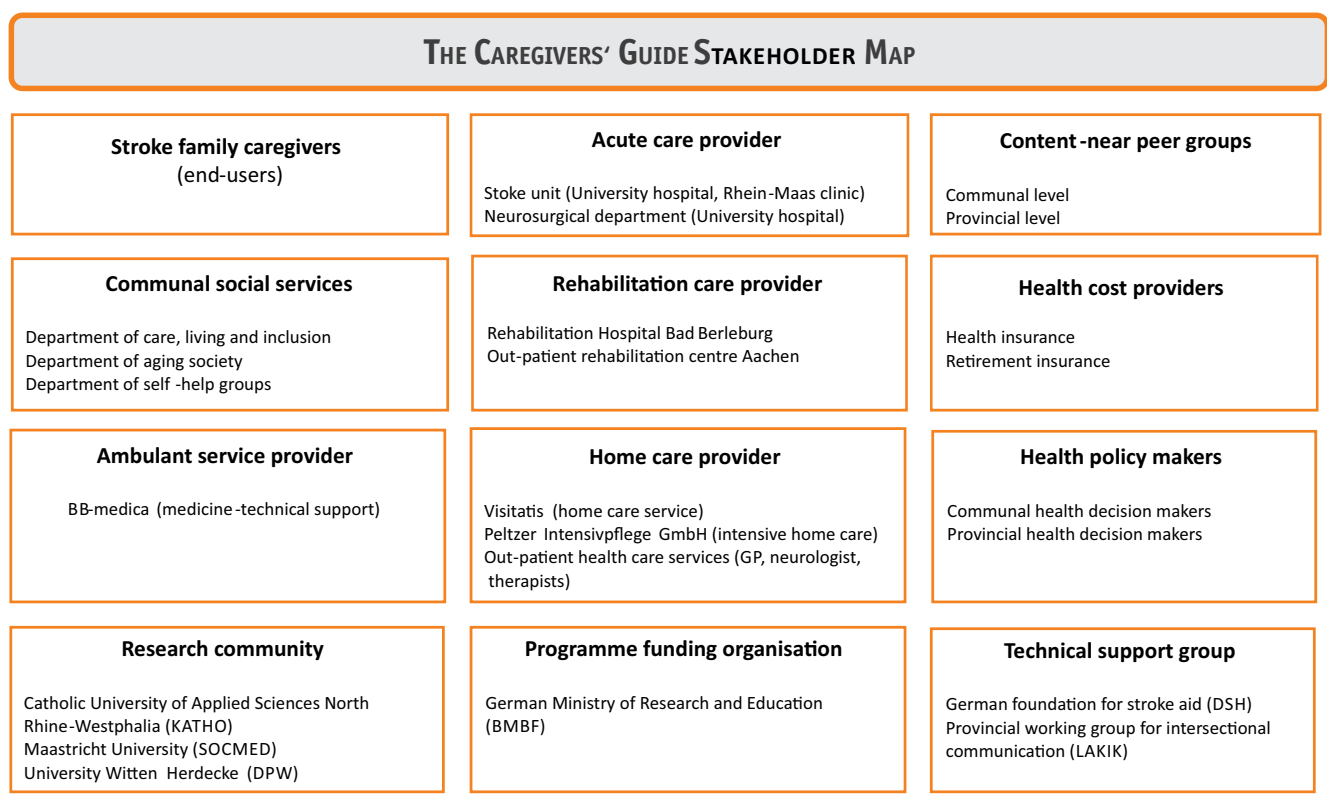

Figure 3: The Caregivers ' Guide stakeholder map (adapted from Schiller et al., 2013) 
are necessary. The research community possesses intellectual ownership and may provide their knowledge in a critical discussion. They will not, however, be involved in the counselling process itself.

Four stakeholders were considered 'subjects': the technical support group, content-near peer groups, ambulant service providers, and the project funding organisation (BMBF). The latter will be the only stakeholder with a financial contribution, whereas the other three will provide their expertise.

Two stakeholders were designated in the 'crowd' role: health policy makers and health cost providers, both possibly supporting the implementation through campaigning.

Activity 3 - stakeholder assessment: Stakeholder's power and interest was assessed using a power (influence) / interest grid (Figure 4).

During implementation 'players' were considered to possess high power and high interest. Therefore, they require close engagement as well as constant involvement in the decision-making or optimization processes through a partici-

\section{Table 1: Results of activity 2: stakeholders ' contribution and role in the Caregivers' Guide} implementation phase.

\begin{tabular}{|c|c|c|c|c|c|c|c|}
\hline \multirow{2}{*}{$\begin{array}{l}\text { PROGRAMME } \\
\text { STAKEHOLDER }\end{array}$} & \multicolumn{6}{|c|}{ STAKEHOLDERS' CONTRIBUTION* } & \multirow[t]{2}{*}{ ROLE } \\
\hline & $\begin{array}{l}\text { Active } \\
\text { partici- } \\
\text { pation }\end{array}$ & $\begin{array}{c}\text { Occasional } \\
\text { involve- } \\
\text { ment }\end{array}$ & $\begin{array}{c}\text { Context- } \\
\text { specific } \\
\text { knowledge }\end{array}$ & $\begin{array}{l}\text { Owner- } \\
\text { ship }\end{array}$ & $\begin{array}{l}\text { Campaig- } \\
\text { ning }\end{array}$ & Funding & \\
\hline Family caregivers (end-users) & $\mathbf{x}$ & & $\mathbf{x}$ & & $\mathbf{x}$ & & \multirow[t]{2}{*}{ 'Player' } \\
\hline Acute care providers & $\mathbf{x}$ & & $\mathbf{x}$ & & $x$ & & \\
\hline Rehabilitation care providers & & $x$ & $\mathbf{x}$ & & $\mathbf{x}$ & & \multirow{4}{*}{$\begin{array}{l}\text { 'Context } \\
\text { setters' }\end{array}$} \\
\hline Home care providers & & $\mathbf{x}$ & $\mathbf{x}$ & & $\mathbf{x}$ & & \\
\hline Communal social services & & $x$ & $\mathbf{x}$ & & $\mathbf{x}$ & & \\
\hline Research community & & & $\mathbf{x}$ & $\mathbf{x}$ & $\mathbf{x}$ & & \\
\hline Technical support groups & & & $\mathbf{x}$ & & $\mathbf{x}$ & & \multirow[t]{4}{*}{ 'Subjects' } \\
\hline Content-near peer groups & & & $\mathbf{x}$ & & $x$ & & \\
\hline Ambulant service providers & & & $\mathbf{x}$ & & $x$ & & \\
\hline Project funding organisation & & & & & $\mathbf{x}$ & $\mathbf{x}$ & \\
\hline Health policy makers & & & & & $\mathbf{x}$ & & \multirow[t]{2}{*}{ 'Crowd' } \\
\hline Health cost providers & & & & & $\mathbf{x}$ & & \\
\hline
\end{tabular}

* 'Active participation' refers to the moral obligation to participate and act in the programme as an end-user or gatekeeper; 'occasional involvement' refers to the need of being professionally involved within a specific setting (e.g. rehabilitation care); 'context-specific knowledge' emphasizes the need to include stakeholders ' expertise; ' ownership 'clarifies the intellectual property of the programme; 'funding' refers to the need of financial contribution; and 'campaigning' highlights stakeholder-driven activities which advocate the programme. 
pative working approach, e.g. in interactive working groups.

'Context setters', possibly thought to have high power but low interest, demand satisfaction as they are only occasionally involved in the practical implementation process. This group should therefore be engaged with the programme, e.g. by installing feedback loops after referral or filed visits.

'Subjects', were considered to show high interest in the success of the implementation, but possess little power to influence, as they are not involved in practical implementation. The project funding organizations ' high interest was endorsed by the financial input, but they are thought to play a passive role during implementation. Likewise, the high interest of content-near-peer groups' was attributed to the fact that no stroke caregiver peer group exists in the region. They need to be constantly informed via a personalized approach, e.g. through invitations to project advancement.

'Crowd' possess marginal power and interest during implementation but may be influenced by or would gain interest in the programme for different reasons, e.g. political obligations during the progress of the programme. Little effort should be involved in monitoring them, but their explorative engagement may be required when finalizing the programme, e.g. during transferal.

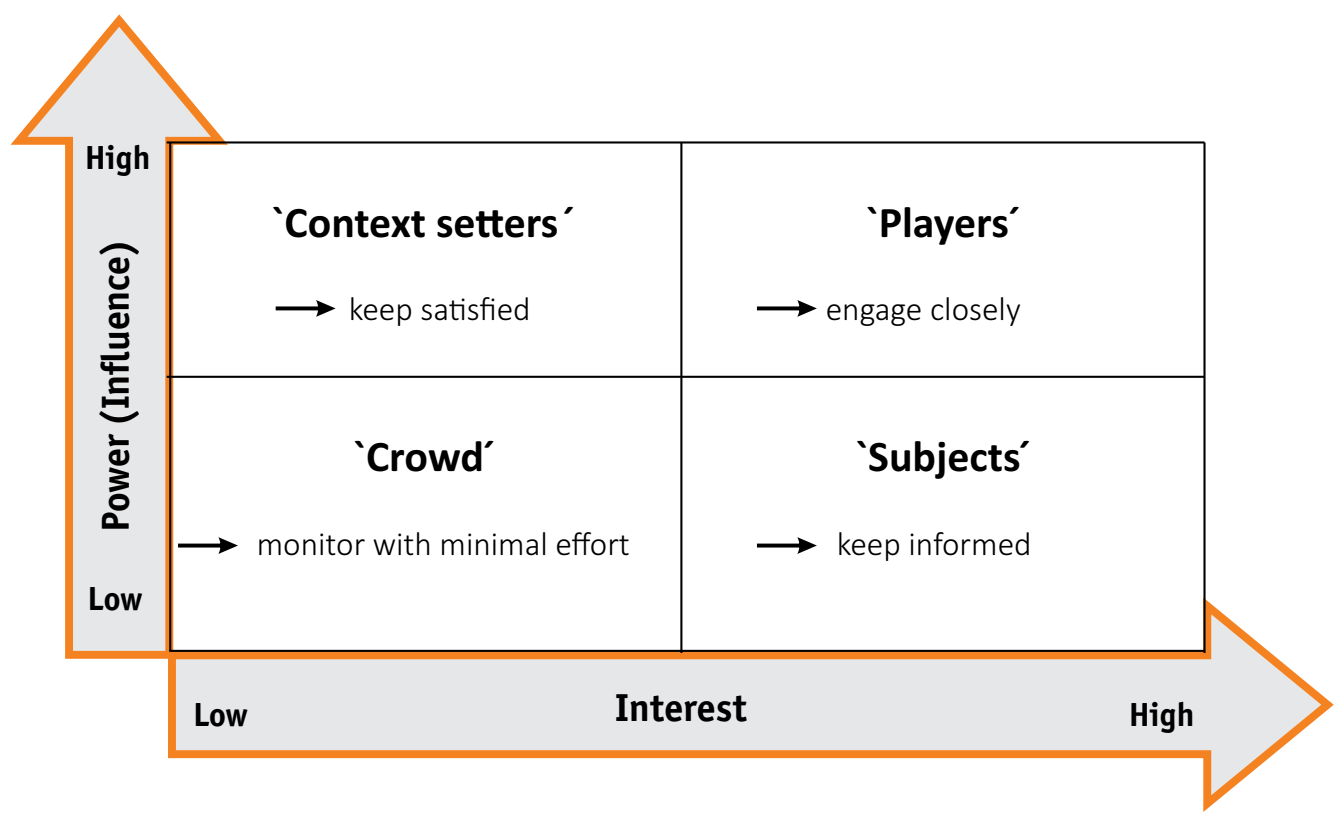

Figure 4: Results of activity 3: stakeholders' power and interest with corresponding engagement strategies (adapted from Ackermann \& Eden, 2011) 
Activity 4 and 5 - risk identification \& assessment: seventeen potential risks were identified by the participants during the stakeholder meeting, allocated to three overarching risk domains, and categorized according to their likelihood (Table 2).

The risk domain 'performance' was considered highly likely to occur, implying a high potential to jeopardise implementation, and therefore requires the most attention. In general, 'performance' was thought to be strongly influenced by the staff involved. Stakeholders pointed out that the entire project could be hindered or even terminated due to internal or external misunderstandings

\section{Table 2: Results of activities 4 \& 5 - potential project- or stakeholder-related implementa- tion risks, risk domains and their likelihood.}

\begin{tabular}{|c|c|c|c|}
\hline \multicolumn{2}{|c|}{ Potential implementation risks } & \multirow[b]{2}{*}{$\begin{array}{c}\text { Risk } \\
\text { domain }\end{array}$} & \multirow[b]{2}{*}{ Likelihood } \\
\hline Project-related & $\begin{array}{l}\text { Stakeholder- } \\
\text { related }\end{array}$ & & \\
\hline $\begin{array}{l}\text { - Weak leadership and management } \\
\text { skills, e.g. "bossy person" instead of } \\
\text { participative engaging working } \\
\text { approach } \\
\text { - Weak lines of communication } \\
\text { - A lack of communication skills } \\
\text { amongst the team members, e.g. } \\
\text { how to communicate on different } \\
\text { levels (client, staff, health } \\
\text { insurance) } \\
\text { - Inaccurate description of the } \\
\text { required resources, e.g. time } \\
\text { - Insufficient professional network } \\
\text { - Non-transparency within the } \\
\text { decision-making process } \\
\text { - Insufficient stakeholder } \\
\text { engagement }\end{array}$ & $\begin{array}{l}\text { - Insufficient } \\
\text { - } \text { Larticipation } \\
\text { (e.g. staff, time) } \\
\text { - Uncertain role } \\
\text { expectations } \\
\text { - Lack of stakeholder } \\
\text { motivation and } \\
\text { nonparticipation } \\
\text { - Interpersonal, } \\
\text { interprofessional, } \\
\text { intersectional } \\
\text { conflicts }\end{array}$ & Performance & High \\
\hline $\begin{array}{l}\text { - Weak project management } \\
\text { performance } \\
\text { - Slow or disruptive counselling } \\
\text { process }\end{array}$ & $\begin{array}{l}\text { - Slow or disruptive } \\
\text { recruitment }\end{array}$ & Schedule & Medium \\
\hline $\begin{array}{l}\text { Inflexible financial planning, e.g. } \\
\text { funding line allows only earmarked } \\
\text { money } \\
\text { - Insufficient calculation of urgent } \\
\text { investments, e.g. in communication } \\
\text { and networking activities }\end{array}$ & $\begin{array}{l}\text { The project is } \\
\text { completely funded by } \\
\text { the BMBF. No financial } \\
\text { investment is required } \\
\text { from the stakeholders. }\end{array}$ & Costs & Low \\
\hline
\end{tabular}


or emotional disharmony. Potential project-related risks were identified, e.g. weak leadership and weak communication skills. Stakeholders themselves may jeopardize the performance, e.g. through non-participation or interpersonal conflicts. Notably, the 'performance' domain would overlap with the other two domains.

'Schedule' was classified as medium likelihood. It can be negatively influenced by the project itself, e.g. deficient project management performance; as well as by the stakeholders, e.g. seasonal gaps.

'Cost' was considered with low likelihood, as the 'Caregivers' Guide is completely funded by the BMBF and the overall costing levels seemed appropriate. Adjustment of the preliminary project management plan might be necessary during implementation, e.g. networking activities. However, this could be problematic, as finances were fixed at the outset by the funding organisation.

\section{Step 2 - Developing implementation management instruments: generating outputs}

We produced two 'outputs' based on the stakeholder- and risk analysis 'inputs`: an individual 'stakeholder-risk atlas' and a project implementation strategy.

The `stakeholder-risk atlas`

Our instrument 'stakeholder-risk atlas` should facilitate the day-to-day interaction during implementation between the Caregivers' Guide counsellor and all stakeholders. It was developed top-down and was labelled `stakeholder-risk atlas' as it incorporates essential information from the stakeholder and risk analyses.

In the first stage individual stakeholder information was inserted in the atlas, including name, affiliation, contact person, role, contribution, as were stakeholder-specific expectations and perceived risks. Subsequently stakeholder-speci-

\section{Table 3: The outline of the 'stakeholder-risk atlas}

\begin{tabular}{|l|l|l|l|l|l|l|}
\hline $\begin{array}{c}\text { Stakeholder } \\
\text { name }\end{array}$ & $\begin{array}{l}\text { 1) Affiliation } \\
\text { 2) Contact } \\
\text { (focus person) }\end{array}$ & Role & Contributions & Expectations & $\begin{array}{l}\text { Perceived } \\
\text { risks }\end{array}$ & $\begin{array}{c}\text { Specific } \\
\text { engagement } \\
\text { activities }\end{array}$ \\
\hline Stakeholder 1 & & & & & & \\
\hline Stakeholder 2 & & & & & & \\
\hline$\ldots$ & & & & & & \\
\hline
\end{tabular}


fic engagement activities were formulated using the results of the project implementation strategy. Stakeholder engagement is a process characterised by a 'two way' exchange between the stakeholders and the research team, which empowers both to influence the programme (Evans et al., 2013). An outline of the atlas is provided in Table 3 and a real-world example is given in Appendix 1.

The project implementation strategy

Our project implementation strategy was outlined as a general instrument, facilitating the Caregivers' Guide implementation phase within the intricate stroke support system. This instrument was developed both bottom-up and top-down. First, as 'performance' was categorized to have a high likelihood of occurring, we focussed on this issue in the stakeholder meeting via brainstorming. Together with our stakeholders we generated ideas, considerations or perceptions, potentially reducing the performance risk domain. We converted the project-related 'performance' risks (Table 2) into practical solutions, which should manage, influence, or reduce the risks within the complex system, which led to the creation of 'general activities'. Second, the research team categorized the activities in 'performance domains', producing our project implementation strategy (top-down) in its final form.

Our instrument outlines four domains: communication, transparency, network building and professionalism, with eleven corresponding 'general activities' (Table 4).

Table 4: The Caregivers' Guide project implementation strategy

\begin{tabular}{|c|c|}
\hline Performance Domain & General Activity \\
\hline Communication & $\begin{array}{l}\text { - Apply participative working approaches } \\
\text { - Stimulate and assure active stakeholder engagement } \\
\text { - Assure constant communication flow } \\
\text { - Install regular feedback loops and empower stakeholders } \\
\text { to provide critical feedback }\end{array}$ \\
\hline Transparency & $\begin{array}{l}\text { - Invest in project marketing } \\
\text { - Assure multilevel dissemination } \\
\text { - Clarify terms of references and responsibilities }\end{array}$ \\
\hline Network building & $\begin{array}{l}\text { Develop, maintain and further develop a sustainable } \\
\text { professional network } \\
\text { - Connect different networks through activities within the } \\
\text { region }\end{array}$ \\
\hline Professionalism & $\begin{array}{l}\text { - Invest in project management } \\
\text { - Guarantee the accessibility of the project team }\end{array}$ \\
\hline
\end{tabular}


The research team and stakeholders agreed that the performance domain 'communication' will be the "Achilles' heel" of a successful implementation of the intervention in the real-world. It was explicitly considered as interrelating with the other three domains. Satisfactory internal and external communication could be assured by applying a participative working approach and investing in regular engagement activities with the 'players' and 'context setters', e.g. field visits and project advancement meetings are recommended to achieve empowerment of the stakeholders. Moreover it was considered to be critical to assure a constant communication flow and to provide and request feedback on a regular basis.

'Transparency' activities should help to announce the new intervention within the intricate multi-stakeholder setting during implementation. Marketing and dissemination activities, e.g. developing and maintaining a project-specific internet-page, were considered essential to secure transparency. In addition terms of reference and responsibilities must be clarified.

'Network building' denoted the constant change and uncertainty of the complex environment and its need for adaptation. Activities, e.g. engaging in working groups, should assure that communication flow and help actualise the knowledge within in the dynamic setting, resulting in up-to date information provision during the caregivers' counselling process.

'Professionalism' regarding project management was perceived as crucial for the implementation. A strong leadership, working according to the ethical requirements and careful monitoring of resources, e.g. schedule; and the team accessibility, e.g. per telephone; was highlighted as important.

\section{Discussion}

In the project development phase of the `Caregivers` Guide, a new complex stroke caregiver intervention, we developed two context-tailored implementation management instruments: (1) an individualized 'stakeholder-risk atlas' (Table 3), and (2) an overall project implementation strategy (Table 4). The design of these instruments ('outputs') was based on the knowledge of the systematic stakeholder- and risk analyses ('inputs') by applying a multi-methodological approach (Figure 2). These instruments should facilitate the implementation of the complex intervention in practice by guiding the interactions between the research team and the different stakeholders, and helping the team to strategically support the implementation within the current system. 
For this purpose, the project team first had to gain a comprehensive understanding of the multi-stakeholder setting and potential implementation risks. Likewise, contextual readiness within the dynamic setting was achieved. This stakeholder and risk-specific knowledge enabled the team to design two instruments. Most interventions for stroke family caregivers are complex, involving different stakeholders and possible implementation risks. Therefore, we are convinced that researchers, practitioners and policy makers will benefit from both investing in systematic stakeholders and risks analyses and the development of implementation management instruments before initiating implementation in practice. Meanwhile current stroke service providers and family caregivers will benefit from this procedure through being engaged and sharing their knowledge to develop a tailored intervention.

Implementation management instruments can contribute to a successful implementation of a project in practice (PMI, 2013; Jepsen \& Eskerod, 2009). They assist in planning or managing the general activities, and enhance the capability to manage and engage with different stakeholders (Jepsen \& Eskerod, 2009). Moreover, they may be used for monitoring and safeguarding the efficiency of the programme (Hjortso, 2010; Carden \& Egan, 2008). The availability of these instruments per-se may not necessarily create the difference between the success or failure of an intervention (Pandi-Perumal et al., 2015). However, we are convinced that our instruments address the stakeholders' complexity and implementation risks. This was important as the German stroke support system is considered to be very complex and fragmented (Figure 1). Early investment in these analyses and development of management instruments helped our team to familiarize themselves with the complex system (Figure 3, Table 1). Moreover, since the research team belongs to an academic institution rather than the stroke support system itself, we profited from personal engagement with the stakeholders and achieved acceptance for the new caregiver intervention and gained contextual readiness within the setting. Nevertheless, the dynamic contextual changes should be considered by constantly adjusting the instruments to the real-world during implementation, e.g. by conducting iterative analysing loops over the entire life cycle of the project (Ward \& Chapman, 2008).

Our individual 'stakeholder-risk atlas' integrates details from the stakeholder and risk analysing process in one instrument (Table 3). It will serve as navigation assistance for the daily interaction with our stakeholders by providing individual stakeholder information, as well as specific engagement activities (Figure 
1). Instruments developed from the results of stakeholders' analyses are frequently used in disciplines other than health, such as the field of development aid (Amstrong et al., 2007; Kennon et al., 2009; Department of International Development - DIFID, 2002). Moreover, the risk analysing process in the project management field results in the development of risk management instruments (PMI, 2013; Ammar et al., 2007). Our atlas may be perceived as a "lifebelt", when it comes to unexpected events, e.g. staff turnover, providing the potential to reduce immediate negative impact on performance. Integrating insights from both analyses in one comprehensive instrument emerged from the humanitarian aid experiences of the first author (TK). In the dynamic setting, humanitarian project teams are obliged to develop practical instruments, which safeguard their context-specific knowledge and assist the stakeholder management in the intricate multi-stakeholder settings, in order to accomplish the projects' objective (Loquericio et al., 2006).

Our project implementation strategy includes four domains: communication, transparency, network building and professionalism, and we set a focus on different communication activities, such as feedback loops or activities securing the communication flow (Table 4). Implementation strategies facilitate communication, knowledge transfer and the management of poor project performance (Proctor et al., 2013). Their complexity can vary, however, in complex interventions (Proctor et al., 2013), and stakeholders' communication needs must be met (Pandi-Perumal et al., 2014), as poor communication affects the relationship between the stakeholders and the project team and disturbs the implementation (Carden \& Egan, 2008). Therefore, communication plays a critical role in the projects' acceptability (Caron, 2014). Furthermore, activities promoting transparency, namely networking building and a transparent working approach are included, and are both considered to be successful procedures in project management and implementation sciences (Hjortso, 2018; Damschroder et al, 2009).

The implementation of a complex intervention in the real world is considered as a critical milestone, benefiting from efforts made in the development phase (Campbell et al., 2007; van Dele et al., 2012; Forster et al., 2011). As of yet only a few publications on complex interventions in health care have reported on their development phase (Datta \& Petticrew, 2013; Corry et al., 2013), and the reported examples often lack essential information (Möhler et al., 2012; Sheppered et al., 2009). A review by Brainhard and Hunter (2016) cited only three articles 
dealing with use of analysis methods to explore implementation barriers. We advocate early investment in exploring the complexity of the stakeholder landscape and potential implementation risks of a complex public health intervention, as this influences its implementation (Möhler et al., 2912; Hawe, 2015). Moreover, as Caron has suggested (2014), comprehensive analyses are essential for the development of instruments, navigating the stakeholder management and engagement during implementation.

Our stakeholder- and risk analyses and instrument development process was conducted in the development phase of the project, yielding a comprehensive knowledge base. Early stakeholder exploration is considered to have the highest potential to prevent misinterpretations regarding a projects's scope and stakeholders' role, expectations, power and interest (Jepsen \& Eskerod, 2009; Mustaro \& Rossi, 2013). Moreover, assessing potential barriers prior to implementation is recommended (Campbell et al., 2007), as this process helps to develop context-tailored strategies to prevent or diminish these barriers (Zabaleta-del-0lmo, 2015). The MRC guidelines for complex interventions also advocates stakeholder involvement, but only later in the project life cycle [7]. We have provided a practical example on how to explore the stakeholder landscape in an early stage by identifying, classifying and assessing their stakeholders. The WHO prioritizes the stakeholders' identification and convening in their systems thinking guideline (WH0, 2019). Unfortunately, both guidelines do not clearly explain the stakeholder identification process. Moreover, we believe that a stakeholder identification should be the first activity in a comprehensive analysis.

\section{Applying project management tools}

We used tools from the project management domain as a starting point to explore the complexity of the stroke rehabilitation support system (Figure 1). These tools provide a clear sequential phased approach and help initiate change due to their visualizing and participative characteristics (Carden \& Egan, 2008), and we believe that complex interventions' project teams will profit from improving their project management skills (Jepsen \& Eskerod, 2009).

Our stakeholders evolved as an essential source of information, providing new insights and critical considerations on the current practice of the support system. We agree with Walker et al. (Walker et al., 2008) that, particularly in complex interventions, stakeholders should not be perceived as an 'amorphous entity`. Stakeholders have different interests, expectations, knowledge and 
power to engage in or jeopardize the implementation process through potential resistance (Pandi-Perumal et al., 2015; Eskerod et al., 2016). Therefore, a sound exploration of the stakeholders is imperative for the success of a projects (Caron, 2014). By identifying all potential stakeholders at an early stage, we gained an orientation on 'who really needs to be engaged', as has been advocated by Burgha and Varvasovszky (2000). In literature, stakeholders are often assigned to a primary, secondary or tertiary role (PMI, 2013). After exploring each stakeholders' contribution, we assigned our stakeholders to one of the four roles, (Table 1) which were necessary for assessing their power and interest (Ackermann \& Eden, 2011). This activity (Figure 4) was useful in predicting the influence of a stakeholder during implementation, and to outline general stakeholder engagement strategies (Jeffery, 2009).

In the risk analyses we were able to apply a participative working approach, as recommended by Jeffery (2009). Our stakeholders were involved in identifying possible project implementation risks and in their further assessment. Three context-specific risk domains were identified: performance, schedule, and cost and their likelihood was assessed (PMI, 2013). Through this process it became obvious that 'performance' requires the most attention during implementation. Consequently, 'performance' indicated the starting point for developing our management instruments (Tables 3 and 4). We explicitly included multiple perspectives of different stakeholders, as has been suggested by different scientists and practitioners (Caron, 2014; Walker et al., 2008; Jeffery, 2009). We are convinced that had we not involved our stakeholders in this process, we would have missed critical information, e.g. perceived project-related risks (Table 2).

\section{Methodological considerations}

In general, stakeholder and risk analyses can be conducted top-down and bottom-up, and both approaches have advantages and disadvantages in terms of time, resources and outcome (Greenhalgh et al. 2016). We decided to combine these two different approaches of knowledge production, and incorporated the different views, opinions and experiences of experts and stakeholders, as advocated by Khadka \& Vacik (2012). This process aided in sharpening and completing the teams' perception of the intricate landscape, as well as possible implementation risks. Moreover, it enabled the team to develop context-specific implementation management instruments. 
Top-down stakeholder analyses are common and feasible in the development phase of a programme (Hjortso, 2010). We applied this approach as a starting point, and it allowed us to achieve a quick and clear orientation within the intricate multi-stakeholder setting. However, while this approach was helpful in finalizing the instruments, it also implies some limitations. For instance, it represents the perceptions of the team, whereas those of the stakeholders remained unseen (Burgha \& Varvasovszky, 2000; Schiller et al., 2013). Furthermore, an expert-led understanding can result in 'quick-fix' solutions or strategies, which may not sufficiently consider the contextual complexity and uncertainty of the different stakeholders (Khadka \& Vacik, 2012).

We applied a bottom-up approach when analysing the implementation risks and developing the management strategy, which could be perceived as time consuming (Wallerstein \& Duran, 2010). However, the co-creation of knowledge was an eye-opening experience for all parties involved, as predicted by Greenhalgh et al. (2016). Being linked with our stakeholders resulted in a process of bi-directional learning, capacity building, and encouragement, which may lead to increasing their sense of project ownership. We are persuaded that applying the participative approach during implementation is the right way to lead us from pure stakeholder management towards a holistic engagement (Abrahams et al. 2015), which is considered as essential for complex interventions (Caron, 2014; Moore \& Evans, 2017).

\section{Conclusion}

Complex interventions will benefit from early and comprehensive stakeholder and risk analyses. Insightful stakeholder knowledge and their early involvement enables the team to develop context-tailored implementation management instruments. These instruments will support the team during implementation and may positively impact on the outcome of the intervention. Knowledge can be generated by combining top-down and bottom-up working approaches. Moreover, the base for stakeholder engagement, which is imperative for the implementation phase, will be initiated through early stakeholder involvement. 


\section{Annex 1: Example on the acute health care providers of the "stakeholder-risk atlas}

\begin{tabular}{|c|c|c|c|c|c|c|}
\hline 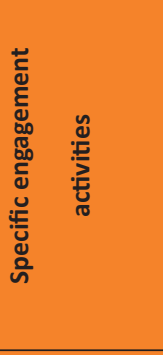 & 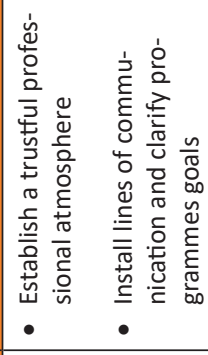 & 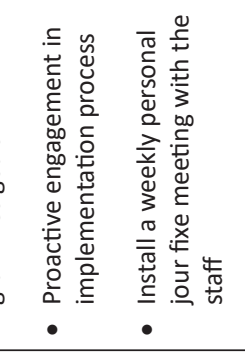 & 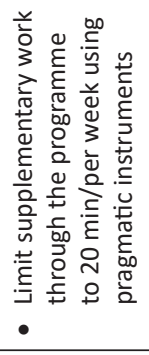 & 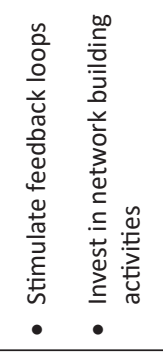 & 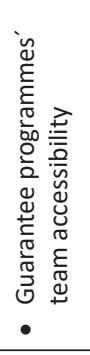 & 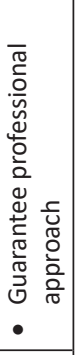 \\
\hline 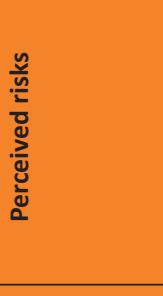 & 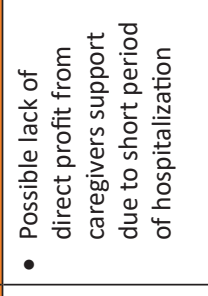 & 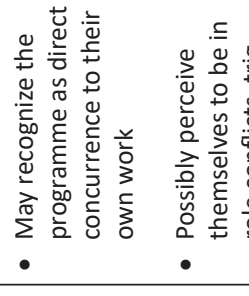 & 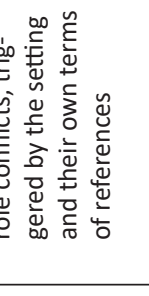 & 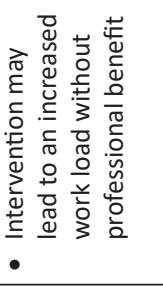 & & \\
\hline 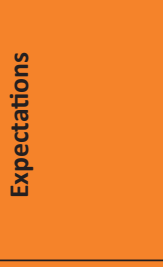 & 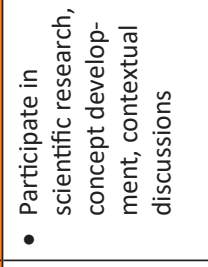 & 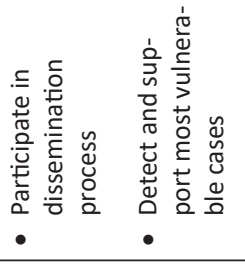 & 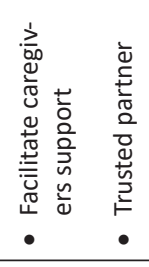 & 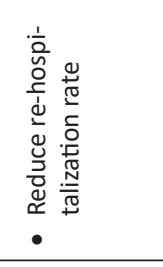 & & \\
\hline 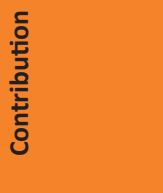 & 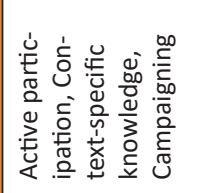 & & & & & \\
\hline$\frac{0}{0}$ & 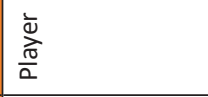 & & & & & \\
\hline 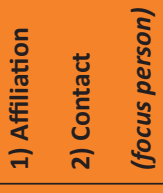 & 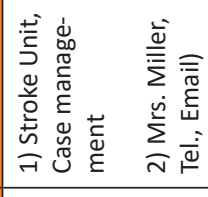 & & & & & \\
\hline 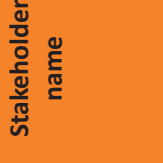 & 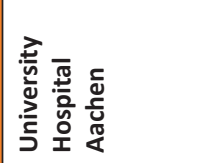 & & & & & \\
\hline
\end{tabular}


Chapter 3 
The stepwise development of a comprehensive family caregiver support programme. 


\section{CHAPTER 4 Optimising a complex caregiver support programme in practice: a participatory action research study}

Krieger T, Floren M, Feron F, Dorant E (2017) Optimising a complex caregiver support programme in practice: a participatory action research study. Educational Action Research (accepted for publication). 


\section{Abstract}

Complex public health interventions may suffer from "teething problems" when implementing in practice without appreciation of the importance of the system. Fitting a concept into practice, through early engagement with its stakeholders, may enhance its chance of success. Optimisation via participatory action research may help improve the concept.

We describe the conceptual optimisation process of the Caregivers ' Guide - a German primary prevention programme for stroke caregivers.

The optimisation process comprised three steps: (1) verifying and fitting the preliminary conceptual building blocks, (2) detecting, developing, verifying and fitting new blocks, and (3) prioritizing all blocks. Participatory action research, including iterative cycles composed of 4 phases: observe, reflect, plan and act, was applied. A multi-methodological design was chosen.

Optimisation resulted in the Caregivers' Guide matured concept, containing eight conceptual building blocks. The five preliminary building blocks: ' Content', 'Human resources', 'Personalised approach', 'Timing', and 'Setting', were prioritised to be the core blocks, providing the base for individual caregiver support. The three new building blocks: 'Network building', 'Communication', and 'Social safety-net' were selected to serve as facilitating blocks, safeguarding the programme within the complex everyday working environment.

Our complex intervention benefited from investing in optimisation by applying participatory action research. It helped us detect conceptual weaknesses, improve its feasibility and fit the concept to the needs in practice before implementing full-scale. Stakeholders' participation was crucial during the optimisation process, and their early engagement enhanced the interventions ' acceptance in practice. Optimisation may improve the interventions` effectiveness.

\section{Introduction}

Family caregivers play a key role in the day-to-day care of stroke survivors (Bakas et al., 2014) as they are the primary support system after discharge (Grant et al, 2014; Wetzstein et al., 2015. Family caregivers are relatives, partners, friends or neighbours, who provide voluntary physical, practical, and emotional care 
and/or support to a person with a chronic disability (adapted from Family Caregiver Alliance, 2006, p.5; Candy et al., 2011).

The abrupt onset of complex demands immediately after stroke differentiates stroke caregivers from other caregiver groups (Redfern et al., 2006; Bulley et al., 2009), where many caregivers feel uncertain and unprepared for their new role (Foster et al., 2013). Particularly in the beginning, stroke caregivers feel challenged due to individual deficits, e.g. lack of knowledge and skills; interpersonal concerns such as changes in their relationship with the stroke survivor, and role changing in the family (Grant et al., 2014). In a later stage, organisational issues such as identifying suitable support offers, financial stress and social isolation are recognized as additional caregiver burden (Adelman et al., 2014). Unmet caregiver support needs may negatively impact their health and social being (Adelman et al., 2014; Greenwood et al., 2010) Thus, comprehensive caregiver support programmes are required.

Stroke caregivers need informational, emotional, psychological and peer support (Wilz et al., 2007), as well as accompaniment and transition coaching (Egan et al., 2010), and these needs change throughout the care trajectory (Foster et al., 2013; Cameron et al., 2012; Plank et al., 2012). Personalized long-term interventions with a set of flexible components are identified as most promising (Cameron et al., 2012). Multicomponent interventions, including informational and psychosocial support, investing in caregiver skill training, stress-coping strategies, caregiver counselling and problem-solving are reported to be helpful (Grant et al., 2014; Plank et al., 2012; Cheng et al., 2014).

\section{Intervention optimisation}

Interventions which are strongly context-dependent are recognised by the UK Medical Research Council - MRC- as 'complex interventions' (Redfern et al., 2006). Their complexity lies in the number of interacting multifaceted components, organisational levels, stakeholders and outcomes (Craig et al., 2008). The development of this interventions should be perceived as an iterative process (Craig et al., 2008).

Successful implementation of public health complex interventions in practice is challenging (Sermeus, 2015), where many interventions fail due to insufficient investment in their development (Bleijenberg et al., 2018). Therefore, before 
full-scale implementation, investing in an optimisation phase is recommended (Craig et al., 2008). Optimisation aims to improve the interventions' effectiveness and can increase its acceptability and feasibility (Sermeus, 2015). 0ptimisation is a process, which may include verifying the intervention components and/or drafted interventions (Levati et al., 2016), completing and fitting the components to the practice, and prioritising the components according to the objectives of the intervention (Bleijenberg et al., 2018). Different RCT modelling tools: e.g. "Normalisation Process Model" and "Process Modelling in Implementation Research", are some of the tools applied in complex health interventions (Sermeus, 2015).

Involving the programmes' stakeholders in the optimisation may be helpful (Bleijenberg et al., 2018), whereas participatory action research - PAR -, requiring stakeholder engagement and participation (Caron, 2014; MacDonald, 2012), might be the right optimisation tool for non-experimental studies, especially for complex and multilevel interventions (0en \& Stromark, 2013).

PAR is a systematic, collaborative and empowering qualitative methodology (MacDonald, 2012), which works iteratively with feedback loops provided by the participants (Meyer, 2000). In the self-reflective inquiry process, researchers engage with service providers or end-users in order to generate new knowledge that triggers change in practice Meyer, 2000; Baum, 2006).

Cornwall's participation model (Cornwall, 1996), distinguishing six participation modes, is frequently used when conducting PAR in health related studies (Truman \& Raine, 2001), and was adapted to the needs of our study (table 1).

In the last decades many large-scale non-pharmacological intervention trials have been conducted, however none of them reported on a conceptual optimisation process. For instance, TRACS in UK or ATTEND in India, which have not shown the expected effectiveness. Both programmes did not follow the definition of complex interventions (Craig et al., 2008). In a process evaluation of the TRACS programme, contextual factors including service improvement pressures and staff perceptions (e.g. acceptability) were negatively impacting the implementation (Clarke et al., 2014). Winstein (2018) suggest that the collaboration between patient, professional and caregiver could not be achieved, which may be the reason behind ATTENDs' failure. Cameron and colleagues (2012) based their "Timing it Right Framework" on exploring the needs of the providers and end-users in a qualitative study before implementation. However, it was not reported whether there was an optimisation phase following the published study (Cameron et al., 2012). 


\section{The Caregivers' Guide: a new stroke caregiver support programme}

In Germany, the current patient-centred stroke rehabilitation process is fragmented, and characterised by multiple transition points and diverse bureaucratic, informational and logistical bottlenecks (Schuler \& 0ster, 2004). This situation poses several challenges for the support system, the patient, and the caregiver (Schuler \& 0ster, 2004).

A new primary prevention programme, the Caregivers' Guide, was recently developed in Aachen, by the Institute for Health Research and Social Psychiatry (igsp) - Catholic University of Applied Sciences North Rhine-Westphalia, Germany. This new programme aims to maintain the quality of life and reduce stroke caregivers' burdens by offering professional support parallel to the current rehabilitation trajectory. Caregivers are approached via outreach counselling as early as possible during the patients' acute phase in the hospital. Furthermore, support is offered by a specially trained counsellor until a stable home care situation is achieved. Psychosocial support and personalised information are the main ingredients of this intervention (Krieger et al., 2016). The Caregivers'

\section{Table 1: Participation, stakeholder involvement and research}

\begin{tabular}{|c|c|c|}
\hline $\begin{array}{c}\text { Participation } \\
\text { Mode }\end{array}$ & Character of stakeholder involvement & $\begin{array}{l}\text { Relationship } \\
\text { (researcher } \\
\text { and } \\
\text { stakeholder) }\end{array}$ \\
\hline 1. Co-option & Token; representatives are chosen, but no real action & On \\
\hline 2. Compliance & $\begin{array}{l}\text { Tasks are assigned, with incentives; researchers decide } \\
\text { agenda and direct the process }\end{array}$ & For \\
\hline 3. Consultation & $\begin{array}{l}\text { Stakeholders' opinions are asked, researchers analyse } \\
\text { and decide on a course of action }\end{array}$ & For/with \\
\hline 4. Cooperation & $\begin{array}{l}\text { Stakeholders work together with researchers to } \\
\text { determine priorities; responsibility remains with } \\
\text { researchers for directing the process }\end{array}$ & With \\
\hline 5. Co-learning & $\begin{array}{l}\text { Stakeholders and researchers share their knowledge to } \\
\text { create new understanding, and work together to from } \\
\text { action plans with researcher facilitation }\end{array}$ & With/ by \\
\hline $\begin{array}{l}\text { 6. Collective } \\
\text { action }\end{array}$ & $\begin{array}{l}\text { Stakeholders set their own agenda and mobilise to carry } \\
\text { it out, in the absence of outside researchers or facilitators }\end{array}$ & By \\
\hline
\end{tabular}


Guide support programme fits the definitions of complex interventions (Craig et al., 2008). It is strongly context-dependent and therefore, the ultimate intervention concept should fit the requirements of the three main actors: (1) stroke caregivers, being the end-users; (2) professionals, currently working in the stroke support system, and (3) Caregivers`'Guide counsellor as the intervention provider.

The Caregivers' Guide project life cycle comprises three phases: development, implementation and evaluation (PMI, 2013). The programmes' development phase was split in two parts.

First, the preliminary concept was developed using a top-down method. Three data sources were used: explorative interviews with experienced caregivers (end-user), semi-structured interviews with professionals (support system providers), and field observations in the acute, rehabilitation and home care settings. Data collection was performed by the principle investigator (first author) to gain insight of the current practice and needs. This process resulted in five preliminary Conceptual Building Blocks (CBB): 'Content', 'Approach', 'Timing', 'Setting' and 'Human resources' (Krieger et al., 2016).

Second, systematic stakeholder- and risk analyses were conducted by combining top-down and bottom-up approaches. We started identifying, classifying and assessing the programmes 'stakeholders, e.g. stroke caregivers and professionals with a top-down approach. Next, while identifying and assessing possible implementation risks, a bottom-up approach was applied to engage with the professional stakeholders. This process resulted in the development of two implementation management instruments: (1) a general implementation strategy, useful to support implementation on a programme level, and (2) an individualised 'stakeholder-risk atlas', assisting the Caregivers' Guide counsellor in their day-to-day interaction with the stakeholders (Krieger et al., 2018).

This article reports on the optimisation of the Caregivers' Guide using PAR in the practice. Our study aims to verify the completeness of our preliminary concept (Sermeus, 2015) as well as to understand the importance of the different components for the individual and system level during implementation in practice.

\section{Methods}

We applied an in-vivo optimisation strategy (Palmer et al., 2013) to systematically improve the Caregivers`'Guide preliminary concept in practice. 


\section{Study design}

We used a multi-methodological study design: interviews and focus groups, and merged two work approaches: top-down and bottom up.

\section{Participants}

Three type of participants contributed in the optimisation process: stroke caregivers, professionals from the current support system, and the Caregivers' Guide counsellor.

\section{Type 1 - stroke caregivers}

The first twenty experienced stroke caregivers, being the programme's endusers, who completed a whole counselling process with the Caregivers' Guide were interviewed. The professional counsellor (author 2) offered long-term counselling, on average 6 months, to stroke caregivers. Counselling started directly after the stroke occurred, and caregivers where supported throughout all phases of the patients' trajectory. Counselling could be terminated by the caregiver himself, approximately 4 weeks after transferal at home, when the desired caregiving routine was achieved.

In total, 15 female and 5 male caregivers, comprising 12 partners, 6 adult children, and one sister and one grandchild, contributed their personal experience with the new intervention (table 1, participation mode 3 ). The average age of the participants was 48 years (SD 29-75).

Type 2 - Professionals

Sixteen professionals, working in the patient-centred stroke support system, contributed as interviewees and co-researchers (table 1, participation mode 3-5) to improve the new intervention concept in practice. They represented the acute, rehabilitation, home care, and external support in the Aachen region (table 2). 
Professionals were iteratively interviewed on every encounter by the first or second author during the observation phase. They were asked to critically reflect on their experiences with the new intervention. Their feedback was used to verify the CBBs and to detect the strengths and needs for improvements by considering their internal system knowledge (table 1, participation mode 3).

During PAR's reflection and planning phase, professionals provided their input as co-researchers in focus groups, which were conducted during four reflection sessions in the inter-sectoral working group (IWG) as well as in three project advancement meetings (PAM). Hereby, a co-learning atmosphere was achieved, fostering mutual understanding for the needs of the system, the caregiver and the intervention provider (table 1, participation mode $4 \& 5$ ). This was considered to be an important step for improving the acceptability and feasibility of the intervention.

Table 2: Professionals participating in the participatory action research

\begin{tabular}{|c|c|c|c|}
\hline $\begin{array}{l}\text { Support } \\
\text { system }\end{array}$ & Setting \& place & Department & $\begin{array}{l}\text { Position \& professional } \\
\text { background }\end{array}$ \\
\hline \multirow{7}{*}{$\begin{array}{l}\text { Acute } \\
\text { Care }\end{array}$} & \multirow{4}{*}{$\begin{array}{l}\text { University Hospital, } \\
\text { Aachen }\end{array}$} & \multirow[t]{2}{*}{ Stroke unit, Neurology } & Case manager $1 /$ nurse \\
\hline & & & Case manager 2 / nurse \\
\hline & & \multirow[t]{2}{*}{ Neurosurgery } & Head of department / MD \\
\hline & & & $\begin{array}{l}\text { Case manager / nurse / } \\
\text { social worker }\end{array}$ \\
\hline & \multirow{3}{*}{$\begin{array}{l}\text { Rhein-Maas clinic, } \\
\text { Würselen }\end{array}$} & \multirow[t]{3}{*}{ Stroke unit, Neurology } & Social worker 1 \\
\hline & & & Social worker 2 \\
\hline & & & $\begin{array}{l}\text { Senior consultant / Medical } \\
\text { Doctor }\end{array}$ \\
\hline \multirow{3}{*}{$\begin{array}{l}\text { Rehabilit } \\
\text { ation } \\
\text { Care }\end{array}$} & $\begin{array}{l}\text { Inpatient Rehabilitation } \\
\text { Hospital, Bad Berleburg }\end{array}$ & $\begin{array}{l}\text { Patient \& caregiver support } \\
\text { services }\end{array}$ & Case manager / nurse \\
\hline & \multirow{2}{*}{$\begin{array}{l}\text { Ambulant Rehabilitation } \\
\text { Clinic, Aachen }\end{array}$} & Training and supervision unit & Nurse / supervisor \\
\hline & & Psychological support & Psychologist \\
\hline \multirow{3}{*}{$\begin{array}{l}\text { Home } \\
\text { Care }\end{array}$} & \multirow{2}{*}{$\begin{array}{l}\text { Home Care Service, } \\
\text { Aachen }\end{array}$} & \multirow[t]{2}{*}{ Home Care Service } & CEO / Nurse \\
\hline & & & Head nurse / Nurse \\
\hline & $\begin{array}{l}\text { Ambulant Intensive } \\
\text { Home Care Service, } \\
\text { Würselen }\end{array}$ & Home Care Service & Management team / Nurse \\
\hline \multirow[t]{3}{*}{$\begin{array}{l}\text { External } \\
\text { care }\end{array}$} & \multirow[t]{2}{*}{$\begin{array}{l}\text { Communal Social } \\
\text { Services, Aachen }\end{array}$} & $\begin{array}{l}\text { Home adaption counselling } \\
\text { services }\end{array}$ & Social worker \\
\hline & & $\begin{array}{l}\text { Care support and counselling } \\
\text { services }\end{array}$ & Nurse \\
\hline & $\begin{array}{l}\text { Medical Health } \\
\text { Equipment provider, } \\
\text { Aachen }\end{array}$ & Medical supply & Case manager / nurse \\
\hline
\end{tabular}




\section{Type 3 - The Caregivers`'Guide counsellor}

The Caregivers' Guide counsellor (second author) is a clinical social worker. She possessed four roles during optimisation: intervention provider (actor), interviewee, co-researcher and researcher. She offered the professional caregiver support during optimisation. In the PAR 's observation phase, she reflected on her personal working experiences after concluding each case during the explorative interviews with the scientific researcher (first author). Moreover, she contributed with conducting parts of the professional interviews. During PAR's reflection and planning phases she participated as co-researcher. Finally, she implemented the new improvements in the acting phase.

\section{Role of the professional researcher}

The scientific researcher (first author), with a background in nursing and public health, was assigned to be the facilitator, responsible for planning, leading, and directing the optimisation process. During observation phase, she conducted the interviews with the experienced caregivers' and professionals and took the lead in analysing the qualitative data. During reflecting and planning phases, she facilitated the focus groups. She was not involved in the acting phase.

\section{Optimisation process using PAR}

Optimisation was guided by a four-phase PAR cycles: observe, reflect, plan, and act (0`Leary, 2004). Cycles were concluded iteratively until all participants verified each $\mathrm{CBB}$ as perfectly fitting for the requirements in practice.

Phase 1 - observe -, implied top-down qualitative research. An individual perception concerning the intervention was gained from interviews with the stroke caregivers, professionals and counsellor. Data were studied using qualitative content analyses with an inductive theoretical stand, resulting in themes and subthemes (Graneheim \& Lundman, 2004). Qualitative strategies were applied to ensure trustworthiness of the results, e.g. method-, researcher- and data triangulation as well as member checking (Meyer, 2000; Friesen-Stroms et al., 2014).

In phase 2 - reflect-, and phase 3 - plan-, we gained a collective perspective. Therefore, the research team engaged with the professional stakeholders in a co-creative manner. We used focus groups to critically reflect on the findings of 
observation phase: themes and subthemes, and planned new actions. In phase 4 - act - new actions were implemented top-down by the Caregivers' Guide counsellor when starting a new counselling case.

The Caregivers' Guide preliminary concept consisted five CBBs, each included components, which characterised the CBB in detail (figure 1 - left side). Our optimisation process involved three steps: (1) verifying and fitting the preliminary concept, (2) detecting, developing, verifying and fitting new $\mathrm{CBBs}$, and (3) prioritising the $\mathrm{CBBs}$ (figure 1 - centre).

\section{Step 1}

Each preliminary CBB (figure 1, left side) was verified and critically reflected by the professional stakeholders and the research team concerning its feasibility in practice. When a need for adaption arose, new actions were planned and individual and collective ideas for improvements were integrated. Therefore new themes and subthemes, possibly leading to new CBBs or components, were incorporated in the new PAR cycles. Finally, when their feasibility was confirmed, improvements were introduced into the mature concept.

\section{Step 2}

New CBBs, each with their components, were detected, developed, verified and fitted by the research team and the professionals into practice. As a result of the qualitative content analyses in the observation steps, new themes with subthemes were detected. In order to develop new CBBs, we translated our findings

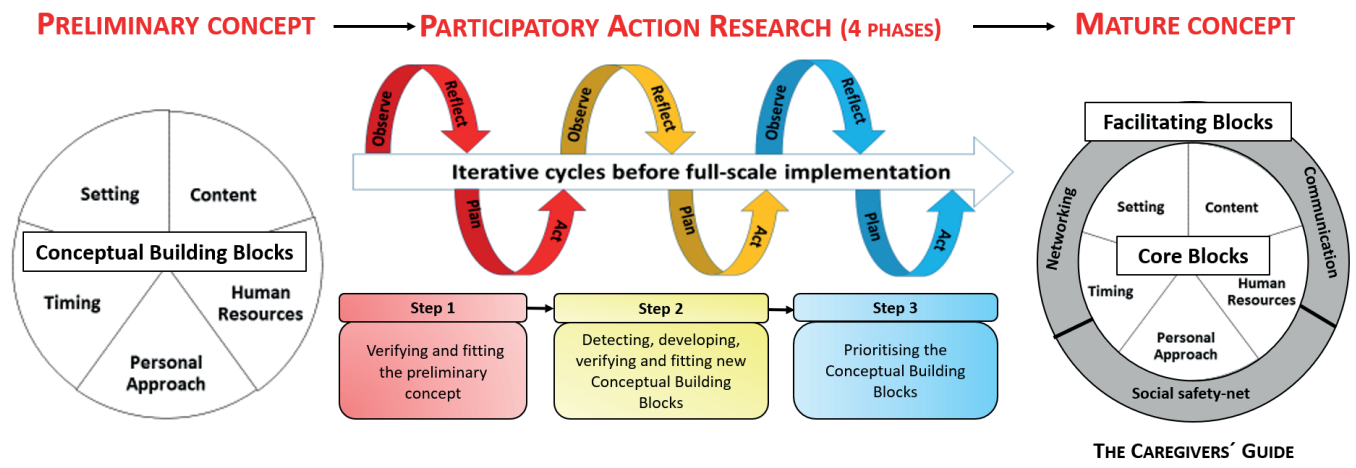

Figure 1: Optimising the Caregivers ' Guide preliminary concept via participatory action research. 
into practice by introducing them into the new PAR cycles. An iterative PAR process continued with verifying and fitting the new $\mathrm{CBB}$. The new $\mathrm{CBB}$ s were then included in the concept.

Step 3

All CBBs were prioritised according to their relevance to achieving the intervention`s goal, resulting in the mature concept (figure 1, right side). They were divided into core and facilitating blocks. We defined a 'core $\mathrm{CBB}$ ' as being compulsory for the individual caregiver counselling activity, whereas a 'facilitating $\mathrm{CBB}^{\prime}$ enables and safeguards the counsellors' work within the system, and sustains the intervention in practice.

\section{Ethics}

All participants, being the stroke caregivers, professionals, and the counsellor, received information about the study beforehand and provided consent for their participation. The COREQ research reporting guidelines were followed.

\section{Results}

In the following part, the outcomes of our optimisation are described per PAR cycle as well as per optimisation step. The optimisation process took started in June 2013 and lasted for 20 months.

\section{Step 1}

Our preliminary concept contained five CBBs (figure 1 - left side). While trying-out the programme in practice and at the same time applying PAR, all five CBBs were verified (annex 1). Moreover, needs for improvements were observed. As a result only four CBBs were fitted to the practice: 'Content, 'Personal Approach', 'Timing', and 'Setting', whereas 'Human resources' needed further development (table 3).

The preliminary $\mathrm{CBB}$ 'Content' contained 'psychosocial advices' and 'personalised information '. After its verification, only some fitting was needed resulting in adding three practical elements to the mature concept: extending the first counselling session with a personalised needs assessment, providing a first aid check list, and using an information tool box. 
The stepwise development of a comprehensive family caregiver support programme.

Table 3: Verifying and fitting the preliminary Conceptual Building Block`Human resources' using PAR

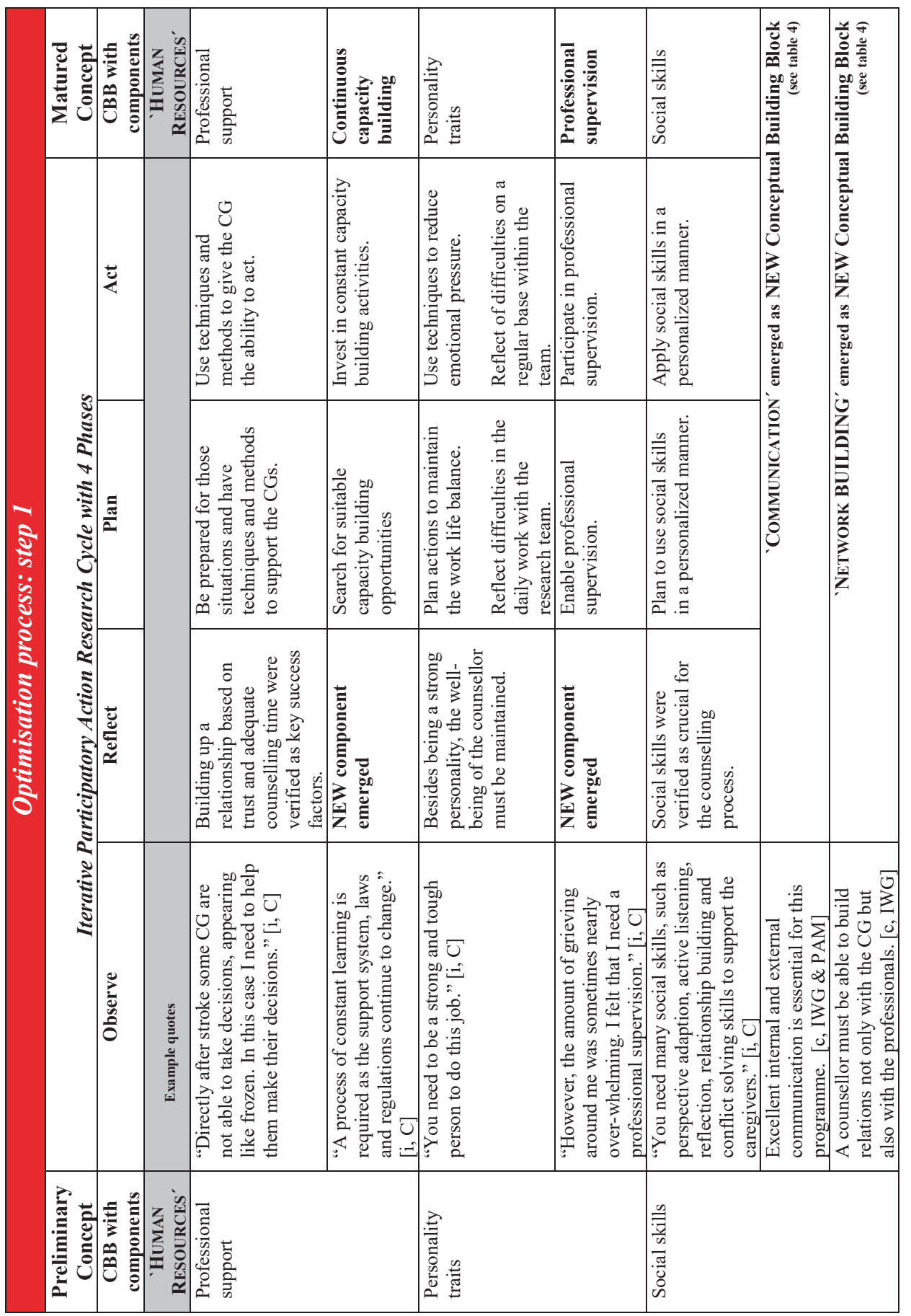

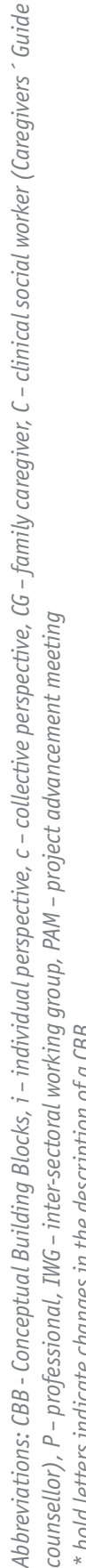


Before optimisation 'Personal approach' included four components: participation, outreach counselling, face-to-face communication, and focal person system (annex 1 - left side), all were verified as important. However, outreach counselling, face-to-face communication and participation had to be fitted to the practice (annex 1 - right side).

Outreach counselling was refined by adding the word 'flexible', to accommodate differences in professional viewpoints and working attitude between the two acute hospitals.

The component 'face-to-face' was broaden to 'direct communication'. Both co-researchers and the research team were convinced that face-to-face communication is the best counselling approach. However, they decided that telephone support should be offered when a face-to-face session is not possible.

Caregivers' have shown limited personal manageability directly post-stroke, which lead to adjusting the component 'participation' into 'active engagement'.

'Timing' contained 'long-term support through all phases', this needed to be specified to fit to the practice. Co-researchers and the counsellor indicated that caregivers need flexible long-term support, as the stroke rehabilitation trajectory differs from one case to the other. Professionals recommended that support should not be provided prior to the fifth day post-stroke. The first counselling session, requiring approximately 90-120 minutes, was perceived as the "most important" by both the counsellor and stroke caregivers, whereas the following sessions could be completed in 60 minutes.

Caregivers welcomed having the opportunity to decide when to end their personalized counselling process. However, it was verified that an average of seven-month counselling was needed in practice.

Before optimisation, 'Setting' included the component 'flexibility', which meant offering caregiver support in a place of the caregivers' convenience. This component appeared to be "too general" for the professionals and the counsellor, and was improved to 'flexible place of counselling'.

The preliminary CBB 'Human resources` described the Caregivers` Guide counsellors' requirements and included: 'professional support', 'social skills', and 'personality traits', which were verified to be crucial. However, from critical observation and reflection, important new insights emerged (table 3). Two additional components: 'continuous capacity building' and 'ongoing supervision ', were detected, verified and fitted into the mature concept. 


\section{Table 4: Detecting, developing, verifying and fitting the Caregivers' Guide new} conceptual building blocks using PAR

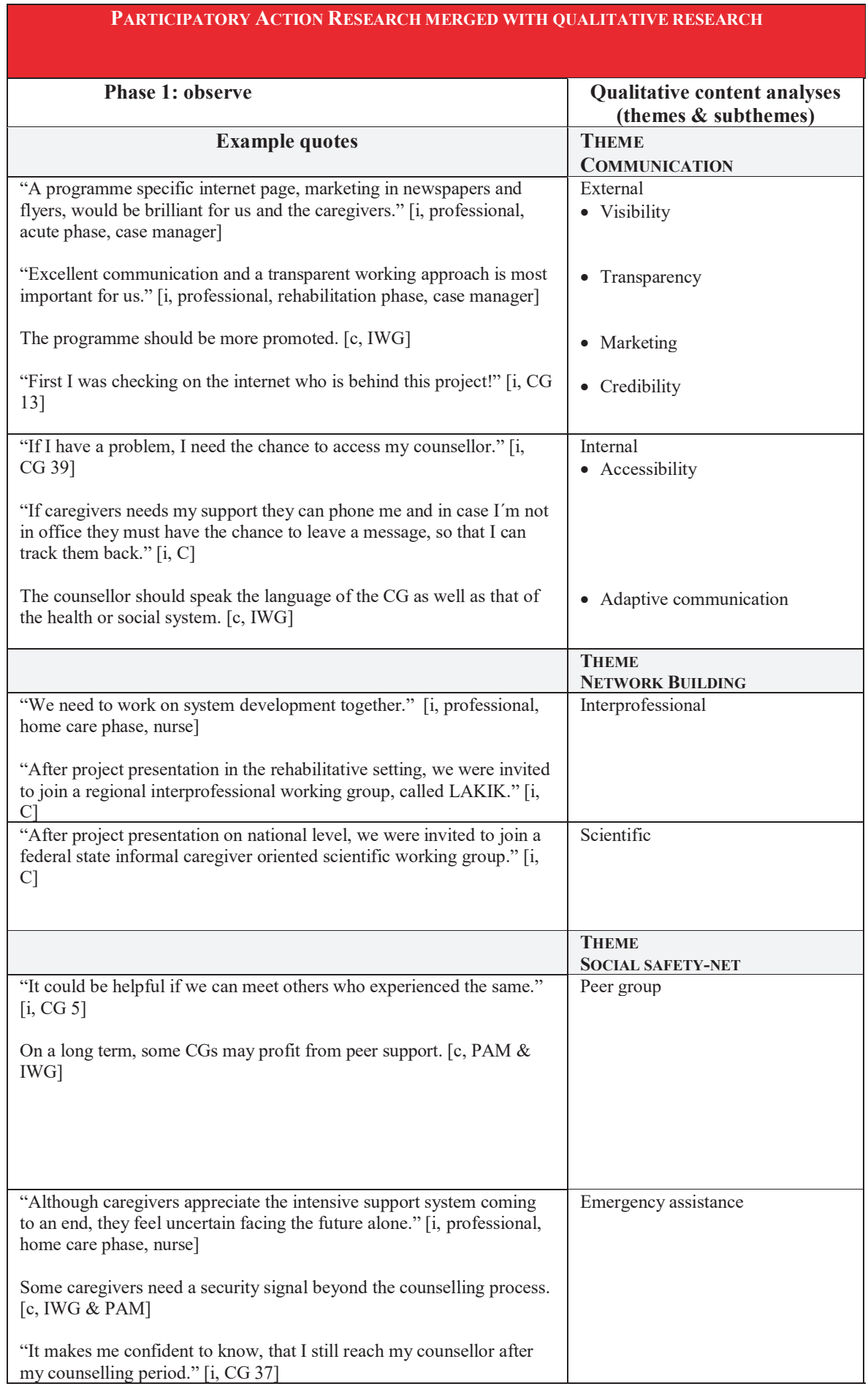


Abbreviations: CBB - Conceptual Building Block, $i$ - individual perspective, c - collective perspective, CG - family caregiver, C-clinical social worker (Caregivers ' Guide), P-professional, IWG - inter-sectoral working group, PAM - project advancement meeting

\begin{tabular}{|c|c|c|c|}
\hline PAR & ICIPATORY ACTION RE & AARCH & \multirow[t]{2}{*}{$\begin{array}{c}\text { New } \\
\text { CBB WITH } \\
\text { COMPONENTS }\end{array}$} \\
\hline Phase 2: reflect & Phase 3: plan & Phase 4: act & \\
\hline & & & $\begin{array}{l}\text { COMMUNI- } \\
\text { CATION }\end{array}$ \\
\hline $\begin{array}{l}\text { Investing in the internet page } \\
\text { was perceived as important } \\
\text { for CG and scientific } \\
\text { community. } \\
\text { Flyers distribution and press } \\
\text { releases were perceived as } \\
\text { important for transparency. }\end{array}$ & $\begin{array}{l}\text { Plan to invest in external } \\
\text { communication such as } \\
\text { internet page, flyers, and } \\
\text { press releases. }\end{array}$ & $\begin{array}{l}\text { Maintain the internet page with } \\
\text { CG relevant and scientific } \\
\text { information. } \\
\text { Distribute flyers. } \\
\text { Promote press releases. }\end{array}$ & External \\
\hline $\begin{array}{l}\text { The implementation strategy, } \\
\text { focussing on communication, } \\
\text { may help to navigate the } \\
\text { communication. }\end{array}$ & $\begin{array}{l}\text { Select activities from the } \\
\text { implementation strategy, } \\
\text { to improve } \\
\text { communication. }\end{array}$ & $\begin{array}{l}\text { Implement activities to foster } \\
\text { communication. }\end{array}$ & \\
\hline $\begin{array}{l}\text { Tracking system may support } \\
\text { the continuous counselling } \\
\text { process and provided a } \\
\text { security signal to the CGs. }\end{array}$ & $\begin{array}{l}\text { Plan to install CG } \\
\text { tracking system. }\end{array}$ & $\begin{array}{l}\text { Install and maintain CG } \\
\text { tracking system via telephone } \\
\text { and Email. }\end{array}$ & Internal \\
\hline $\begin{array}{l}\text { Individualised } \\
\text { communication may improve } \\
\text { mutual understanding and } \\
\text { reduced miscommunication. }\end{array}$ & $\begin{array}{l}\text { Plan to adjust } \\
\text { professional and } \\
\text { personal communication } \\
\text { skills. }\end{array}$ & $\begin{array}{l}\text { Communicate with different } \\
\text { stakeholders according to their } \\
\text { needs. }\end{array}$ & \\
\hline & & & $\begin{array}{l}\text { NETWORK } \\
\text { BUILDING }\end{array}$ \\
\hline $\begin{array}{l}\text { Becoming a member of the } \\
\text { interprofessional practical } \\
\text { network may stimulate } \\
\text { participatory knowledge } \\
\text { generation and reflection in } \\
\text { practice. }\end{array}$ & $\begin{array}{l}\text { Plan to become an active } \\
\text { member in the inter- } \\
\text { professional working } \\
\text { group (LAKIK). }\end{array}$ & $\begin{array}{l}\text { Acting as reflective and critical } \\
\text { member within the } \\
\text { interprofessional working } \\
\text { group (LAKIK). }\end{array}$ & Interprofessional \\
\hline $\begin{array}{l}\text { Joining the scientific network } \\
\text { will stimulate research, } \\
\text { interdisciplinary exchange } \\
\text { and foster dissemination. }\end{array}$ & $\begin{array}{l}\text { Plan to become an active } \\
\text { member within the } \\
\text { scientific working group } \\
\text { focusing on informal } \\
\text { CG. }\end{array}$ & $\begin{array}{l}\text { Acting as an official and active } \\
\text { group member. } \\
\text { Work on a joined federal state } \\
\text { proposal for informal CGs. }\end{array}$ & Scientific \\
\hline & & & $\begin{array}{l}\text { SOCIAL SAFETY- } \\
\text { NET }\end{array}$ \\
\hline $\begin{array}{l}\text { After the intensive } \\
\text { counselling process, offering } \\
\text { peer support may turn out to } \\
\text { be suitable as exit strategy } \\
\text { for some CGs. }\end{array}$ & $\begin{array}{l}\text { Plan to explore options } \\
\text { for establishing a peer } \\
\text { group within the } \\
\text { organized self-help } \\
\text { group system. }\end{array}$ & $\begin{array}{l}\text { Explore the needs for installing } \\
\text { a regional stroke CG peer } \\
\text { group and establish the group. } \\
\text { Promote group to experienced } \\
\text { CGs. } \\
\text { Insert a link of the group's } \\
\text { activities on the programme's } \\
\text { internet page, and interlink it } \\
\text { with the self-help group } \\
\text { system. }\end{array}$ & Peer group \\
\hline $\begin{array}{l}\text { To have the option to access } \\
\text { the counsellor may be } \\
\text { calming for most CGs. } \\
\text { Telephone support may be } \\
\text { sufficient in most occasion. }\end{array}$ & $\begin{array}{l}\text { Plan to offer telephone } \\
\text { support to discharged } \\
\text { CG. }\end{array}$ & $\begin{array}{l}\text { Promote the option to further } \\
\text { support discharge CG. } \\
\text { Offer telephone support to } \\
\text { discharged CG. }\end{array}$ & $\begin{array}{l}\text { Emergency } \\
\text { assistance }\end{array}$ \\
\hline
\end{tabular}




\section{Step 2}

Further observation cycles resulted in detecting, verifying and fitting three new CBBs (table 4). 'Communication' and 'Network building' were detected during step 1 of the optimisation phase within the CBB 'Human resources' (table 3), whereas 'Social safety-net' was first detected when the concept was verified in practice.

The new CBB 'Communication ' contains two components: external and internal communication. The former involves activities necessary to augment visibility, transparency, marketing, and credibility of the programme. The latter embraces activities aimed at assuring counsellor accessibility to caregivers, and establishing a personalised communication within the caregiver-patient dyad. Communication was perceived by all participants as vital, since it enables, supports and safeguards the programme on an individual, professional and societal level.

'Network building' includes three components: professional-, interprofessional-, and scientific network. It provides the base for disseminating knowledge and exchanging ideas. As well as safeguarding and connecting the intervention programme with the system. The implementation of the `stakeholder-risk atlas` (Krieger et al., 2018) was a helpful instrument in guiding the counsellor during their day-to-day interaction with the multiple stakeholders.

'Social safety-net' consists of two components: peer group and emergency assistance. It was perceived first by the caregivers, then by the professionals and the research team as essential to provide caregivers with the security needed to master their caregiving role. The possibility of establishing a stroke caregiver peer group was explored, resulting in a group foundation. At the end of each counselling trajectory, caregivers were encouraged to join this group.

After learning that caregivers were worried about the occurrence of a re-infarct, we agreed that emergency assistance should be offered after the client's discharge, f.i. via telephone counselling.

\section{Step 3}

Optimisation resulted in the mature concept, where all eight CBBs were prioritised by the professionals and the research team. 'Content', 'Human resources', 'Personal Approach', 'Timing', and 'Setting' were designated to 'Core blocks', whereas 'Communication', 'Network building' and 'Social safety-net' were chosen to serve as facilitating blocks (figure 2). 


\section{Discussion}

Before implementing full-scale, an optimisation process was conducted in practice by applying iterative PAR cycles in order to verify the maturity of the preliminary concept. Optimisation included three steps: (1) verification and fitting of the preliminary concept, (2) detection, development, verification and fitting of new CBBs, and (3) prioritising the CBBs. This resulted in the mature concept, comprising eight CBBs: five core and three facilitating.

PAR appeared to be the correct approach for optimising our concept. In four out of the five preliminary CBBs, few alterations were made to meet the requirements of both the system and the caregivers. The CBB 'Human Resources' had to be adjusted by adding two new components: continuous capacity building and professional supervision. Whereas the components 'Communication' and 'Network building' were moved from this CBB and developed into separate blocks, since their importance for the programme became increasingly apparent. 'Social safety-net' emerged as a new CBB (table 4), resulting in establishing a stroke caregiver peer group and offering emergency assistance for discharged clients. Optimisation resulted in prioritising the $\mathrm{CBBs}$, where the five preliminary CBBs were considered to be core elements for the individualised caregiver support. Furthermore, the three new CBBs were valued as 'facilitating' since they enable the counsellors' work and safeguard the programme's implementation within the intricate stroke support system (figure 2).

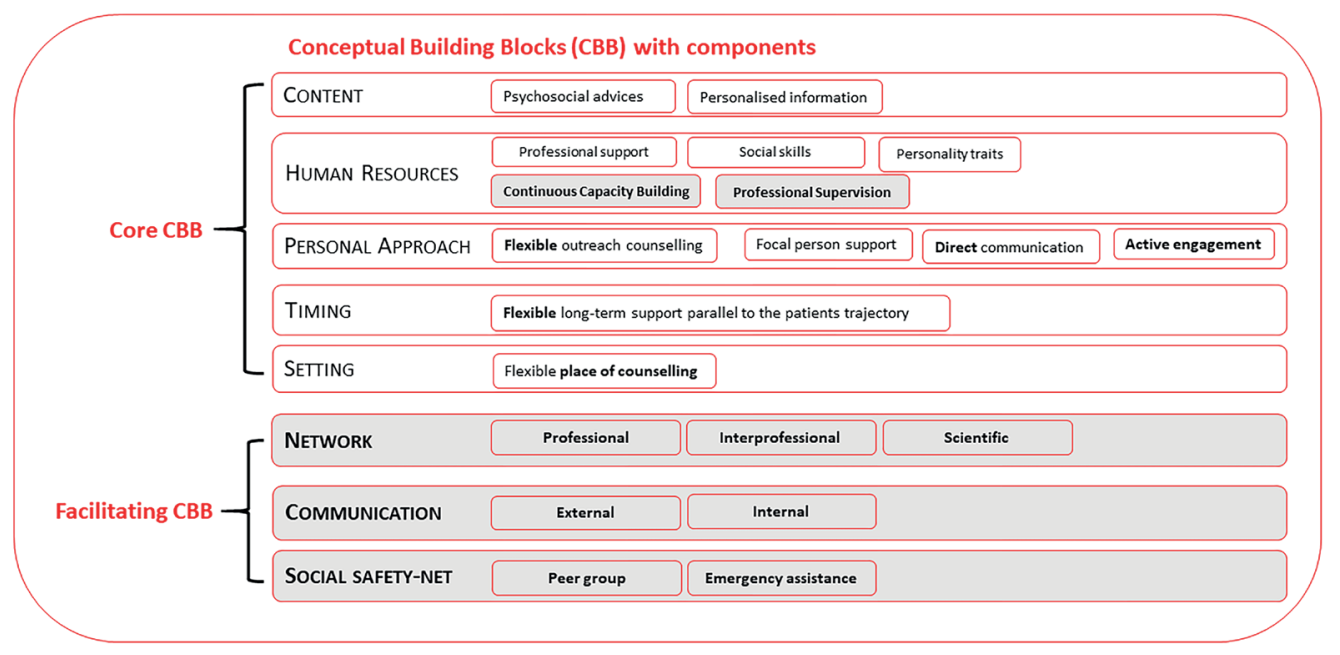

Adaptations in the components are illustrated using bold letters.

New CBBs and components are placed on a grey background and using bold letters.

Figure 2: The matured concept of the Caregivers' Guide 
Especially in public health, the implementation of a complex intervention in practice is considered a 'black box' (Sermeus, 2015). Insufficiently developed interventions, caused by conceptual weaknesses, may endanger the implementation and its effectiveness (Bleijenberg et al., 2018; Chalmers et al., 2009). However, due to the complex nature of the system, developing a mature concept without implementation in practice is still challenging (Greenwood-Lee et al., 2016). Our experiences during optimisation showed that developing a `stateof-art ' intervention concept in theory is not sufficient, and its feasibility and completeness needed to be verified in practice, also suggested by Bleijenberg et al. (2018). We benefited from in-vivo optimisation, not only by gaining real-life experiences and detecting "teething problems", but also by improving and completing the preliminary concept, resulting in a mature concept. It became obvious that our preliminary concept was not considering the systems' needs sufficiently, which may be attributed to the fact that the Caregivers' Guide counsellor was not part of the current stroke support system. This resulted in her having insufficient internal system knowledge needed to safeguard the intervention within the intricate stroke rehabilitation system.

However, investing in optimisation requires time, human resources, professional skills, and stakeholders' commitment. Due to the evolving complexity of our intervention, multiple iterative cycles were necessary. Twenty caregivers, sixteen professionals and two researchers contributed, and the three optimisation steps with iterative PAR cycles were completed in a 20-months timespan.

The MRC guideline highlights the value of modelling and optimising (Craig et al., 2008). Unfortunately, practical examples of complex interventions' optimisation processes are rarely published (Bleijenberg et al., 2018), even though they can add a clear value for the researchers, the professionals working in the practice and the interventions' end-users, e.g. stroke caregivers. Bleijenberg et al. (2018) suggest to focus on prioritisation while modelling the intervention, and Sermeus (2015) underlined the importance of "understanding the different components", however practical examples were not found in literature. This article provides a practical example of optimising a complex intervention.

Our experiences agree with those of Craig et al. (2008) in recognising the development of a complex interventions as an iterative process. The Caregivers' Guide preliminary concept was designed in the development phase with a top-down approach using a qualitative deign. We felt the necessity to verify 
the components in practice before full-scale implementation, which resulted in optimising our concept early in the projects' life-cycle. We used an in-vivo optimisation strategy (Palmer et al., 2013), allowing us to observe conceptual strengths and weaknesses (Levati et al., 2016) and to immediately respond to inadequacies. Our observations indicate that in-vivo optimisation may be a suitable approach for public health interventions with non-experimental designs (Spencer et al., 2013).

During optimisation, we gave much attention to the complex and dynamic stroke rehabilitation system, also suggested by Hoddinott et al. (2010). We applied a holistic and systems-thinking approach (WH0, 2010; Waldman, 2007), since a reductionist approach or silo-thinking (Quigley, 2002; Leischow et al., 2008) may not be sufficient when dealing with complexity. Systems-thinking and holistic approaches in public health emphasise the importance of transdisciplinary stakeholder engagement as well as relationship building between individuals and organisations (Leischow et al., 2008).

Our stakeholders exhibited the power to hinder or facilitate the implementation process (Caron 2014), we therefore invested in their engagement, which led to mutual understanding and trust, as proposed by Jeffery (2009) and Pandi-Perumal et al. (2016). We were constantly engaged in intensive stakeholder dialogues, advocated as 'best practice' by Caron (2014). Moreover, we considered both our stakeholders' and organisations' wants and needs (SWANS, OWANS, respectively) for the concepts' optimisation (Jeffery, 2009). Stakeholders constantly provided valuable feedback, which increased our perception of the dynamic and intricate support system, also observed by Burton et al. (Burton et al. 2008). Yet, engagement requires not only resources and skills from the researcher, but also an open atmosphere (Jeffery, 2009). Moreover, the capability of critically reflecting on the process is required from all participants, which may be incompatible with the rules of some organisations, societies or cultures (MacDonald, 2012; Hofstede, 2003). 


\section{Methodological considerations}

\section{Participatory Action Research}

PAR was experienced by both stakeholders and research team as interactive, encouraging, and leading to change, as suggested by Baum (2016). This methodology is increasingly used in public health and local projects (Koshy et al., 2011; Ehde et al., 2013), it is however seldom reported in academic literature (Baum, 2016).

PAR requires participation from both stakeholders and researchers. Our professional stakeholders were actively engaged and were empowered to provide critical feedback on the concept's maturity (MacDonald, 2012; Meyer, 2000). As professional researcher, we welcomed the opportunity to facilitate optimisation, allowing us to be involved as participants and learners, as suggested by MacDonalds (2012).

We used Cornwalls' participation model (1996) to indicate the different participation levels with our stakeholders during optimisation. Different modes of stakeholder-involvement with the researcher generate different types of knowledge. In our study participation ranged between consulting and co-learning (mode 3-5), depending on the stakeholder, e.g. caregiver or professional, and PAR's phase. A possible limitation is that the caregivers' participation mode was low (mode 3), since they were thought to be occupied with their new role. PAR has several strengths, including bridging the gap between theory and practice (Buul et al., 2014), providing the opportunity to generate new caregiver-specific, contextual and systemic knowledge in a co-creative way (Baum, 2016; Greenhalgh, 2016).

On the other hand, PAR is time- and resource-consuming (MacDonald, 2012; Young, 2006). Moreover, this methodology requires to be sufficiently communicated within the system, and the professional superiors must be convinced of applying PAR in a project, in order to guarantee stakeholder's commitment. Additionally, PAR-researchers need extended research abilities, interpersonal skills and the courage to work outside their professional comfort zone (Meyer, 2000; Denscomber, 2005). Finally, PAR might be criticised for being a 'soft' research methodology (Young, 2006).

\section{Methodological pluralism}

During PAR, we merged top-down and bottom-up approaches. This "methodological pluralism" (Baum, 2016) helped us gain a greater understanding of the 
actual needs in practice and produced a more detailed, multi-perspective picture, as predicted by Thurmond (2001). Through the collaboration between 'insiders' - professional stakeholders - and the 'outsiders' - academic researchers(Anderson \& Jones, 2000), we received critical and constructive feedback on the concepts' maturity.

For data collection, we applied a qualitative multi-methodological design (Morse, 2010) using two different data collection methods: interviews and focus groups. Using more than one method enabled us to take advantage of the strengths of both, as reported by Creswell (2009). Moreover, it augmented the trustworthiness of our study (Philips et al., 2014).

By first analysing each dataset separately, and then integrating and the findings in the CBBs, we achieved data convergence and complementarity (Greene et al., 1989). In order to assure rigor, we triangulated our data, which iprovided a multiperspective perception of the concept's maturity, as advocated by Morse (2010). Professional stakeholders were empowered to critically reflect on different findings, also known as "member checking" (Meyer, 2000). Finally, our study achieved high democratic validity as a result of early stakeholder engagement.

\section{Conclusion}

Our complex intervention concept benefited from the early and systematic optimisation process in practice. In-vivo optimization resulted in detecting "teething problems" in the preliminary concept, which needed to be addressed with practical solutions, to finally result in a mature concept. Our optimisation was guided by PAR, requiring stakeholders' participation and engagement. The mature Caregivers' Guide concept contains eight CBBs: five core, focussing on the individual caregiver counselling process; and three facilitating, safeguarding and connecting the programme with the current support system. Methodological pluralism was compulsory to incorporate the different perceptions and counterbalance the weaknesses of each method. Using PAR and merging top-down and bottom-up approaches was suitable for translating findings from theory into practice.

\section{Disclosure of interest}

All authors report no conflicts of interest. 
The stepwise development of a comprehensive family caregiver support programme.

\section{Annex}

Annex 1: Outcomes of the optimisation process of the preliminary concept's five conceptual building blocks using PAR.

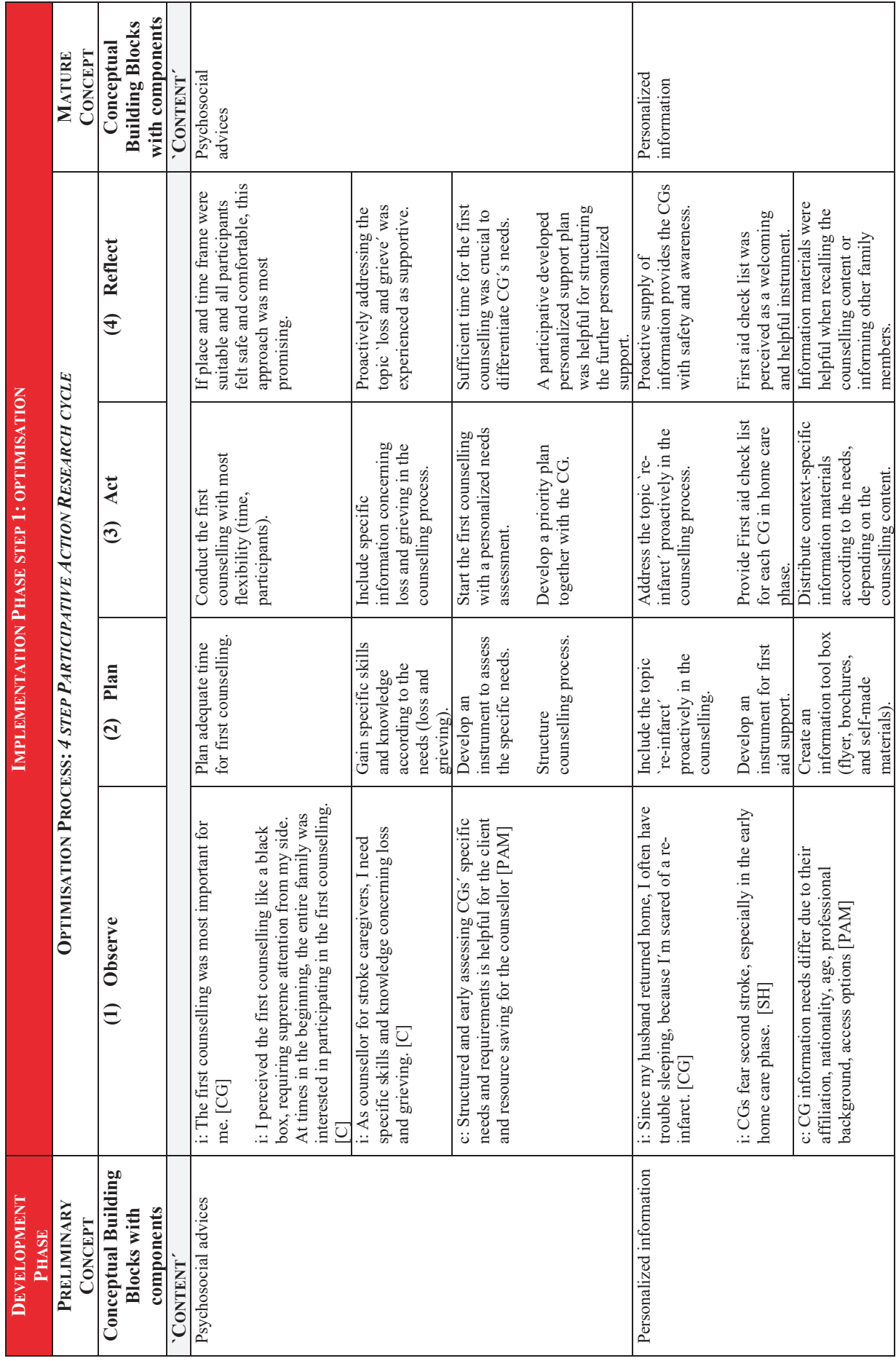




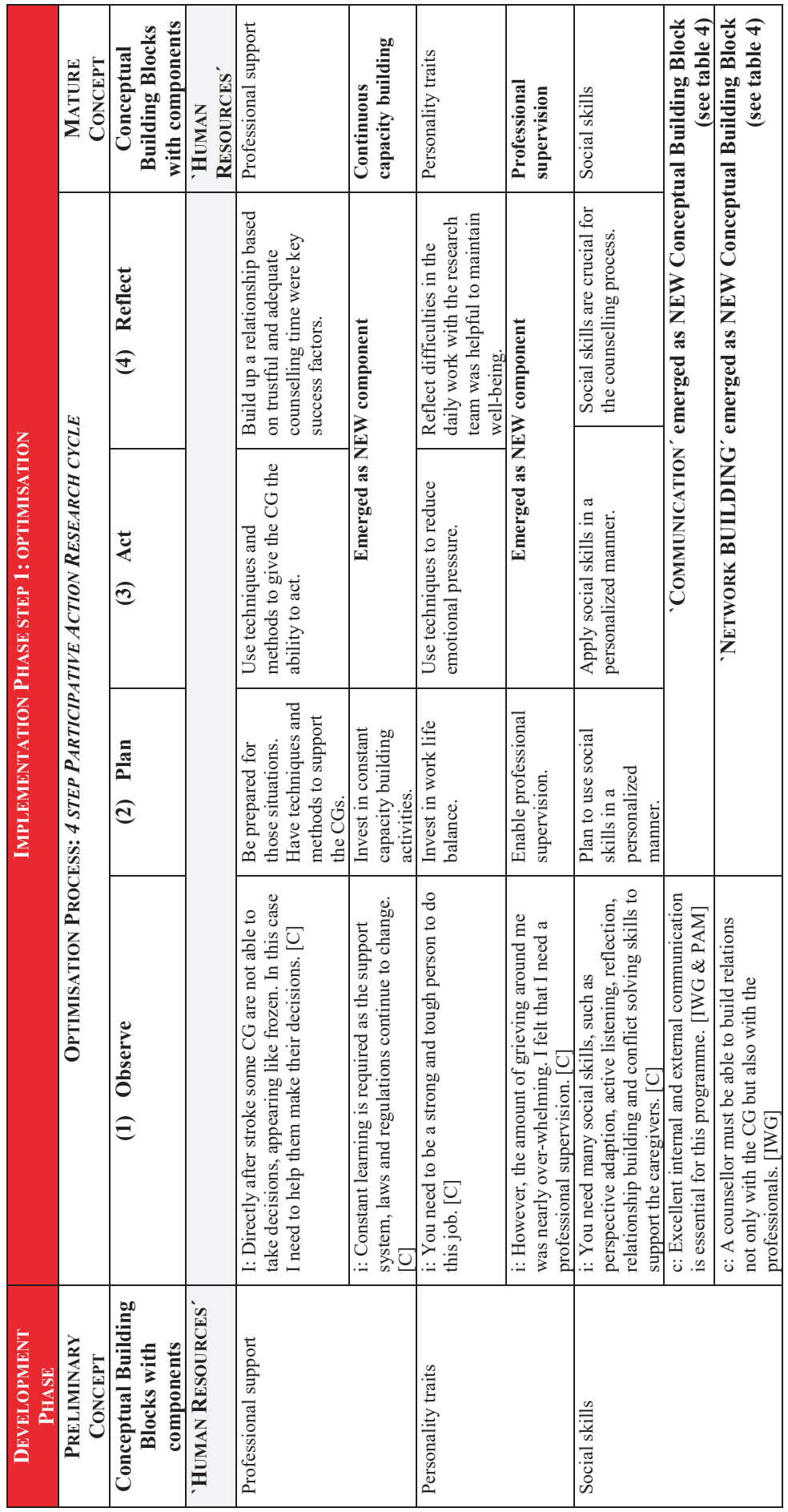

के

¿

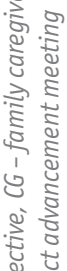

춀홍

. ¿ $\sum^{1}$

\%

1 은

๑. के

造立

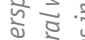
현 : $\therefore \mathrm{1}$ 的望 : 웡

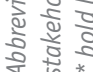


The stepwise development of a comprehensive family caregiver support programme.

\begin{tabular}{|c|c|c|c|c|c|c|c|c|}
\hline & 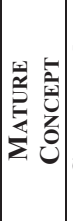 & 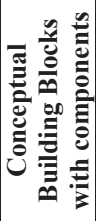 & 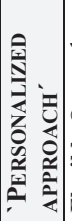 & 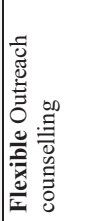 & & 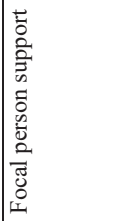 & 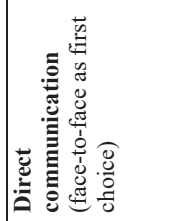 & 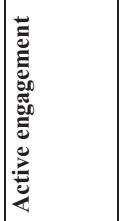 \\
\hline & $\stackrel{s}{0}$ & 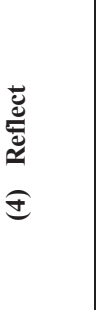 & & 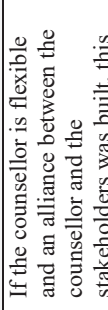 & 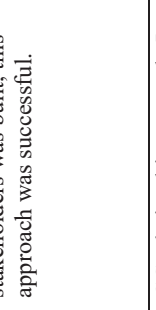 & 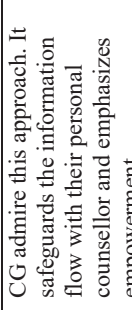 & 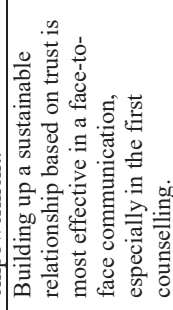 & 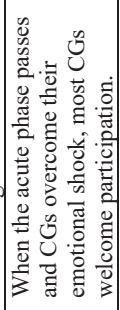 \\
\hline 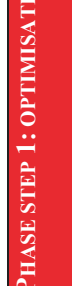 & 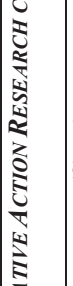 & $\frac{\vec{e}}{4}$ & & 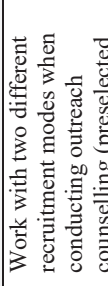 & & 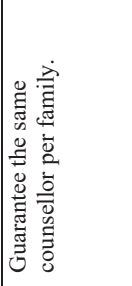 & 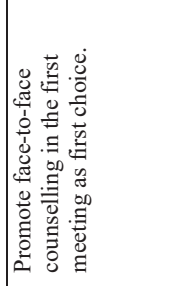 & 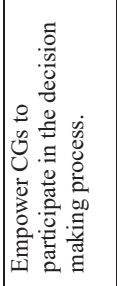 \\
\hline 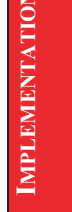 & 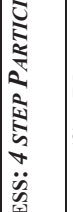 & 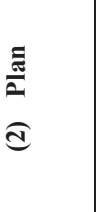 & & 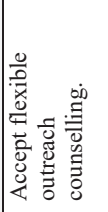 & & 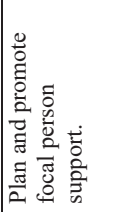 & 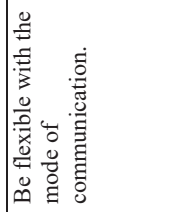 & 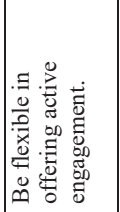 \\
\hline & 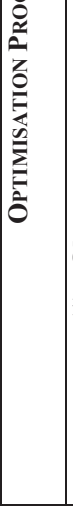 & 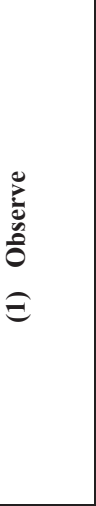 & & 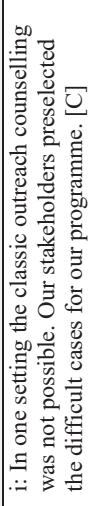 & 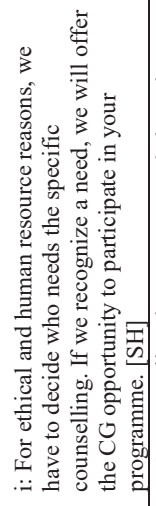 & 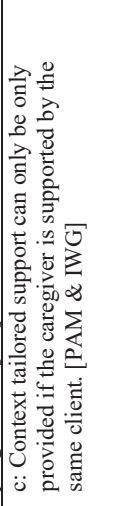 & 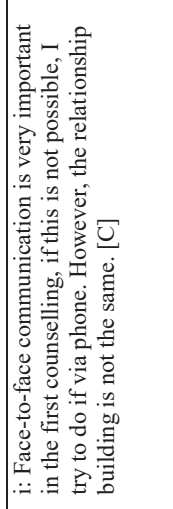 & 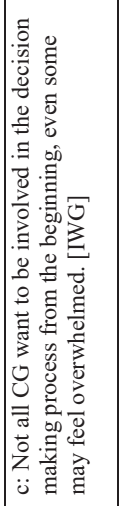 \\
\hline 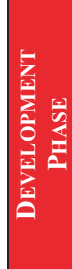 & 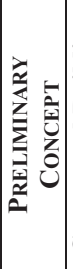 & 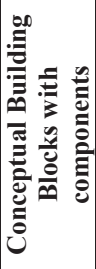 & 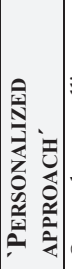 & 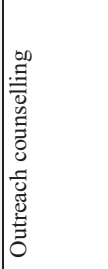 & & 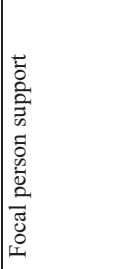 & 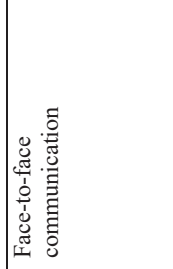 & 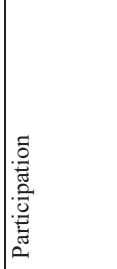 \\
\hline
\end{tabular}




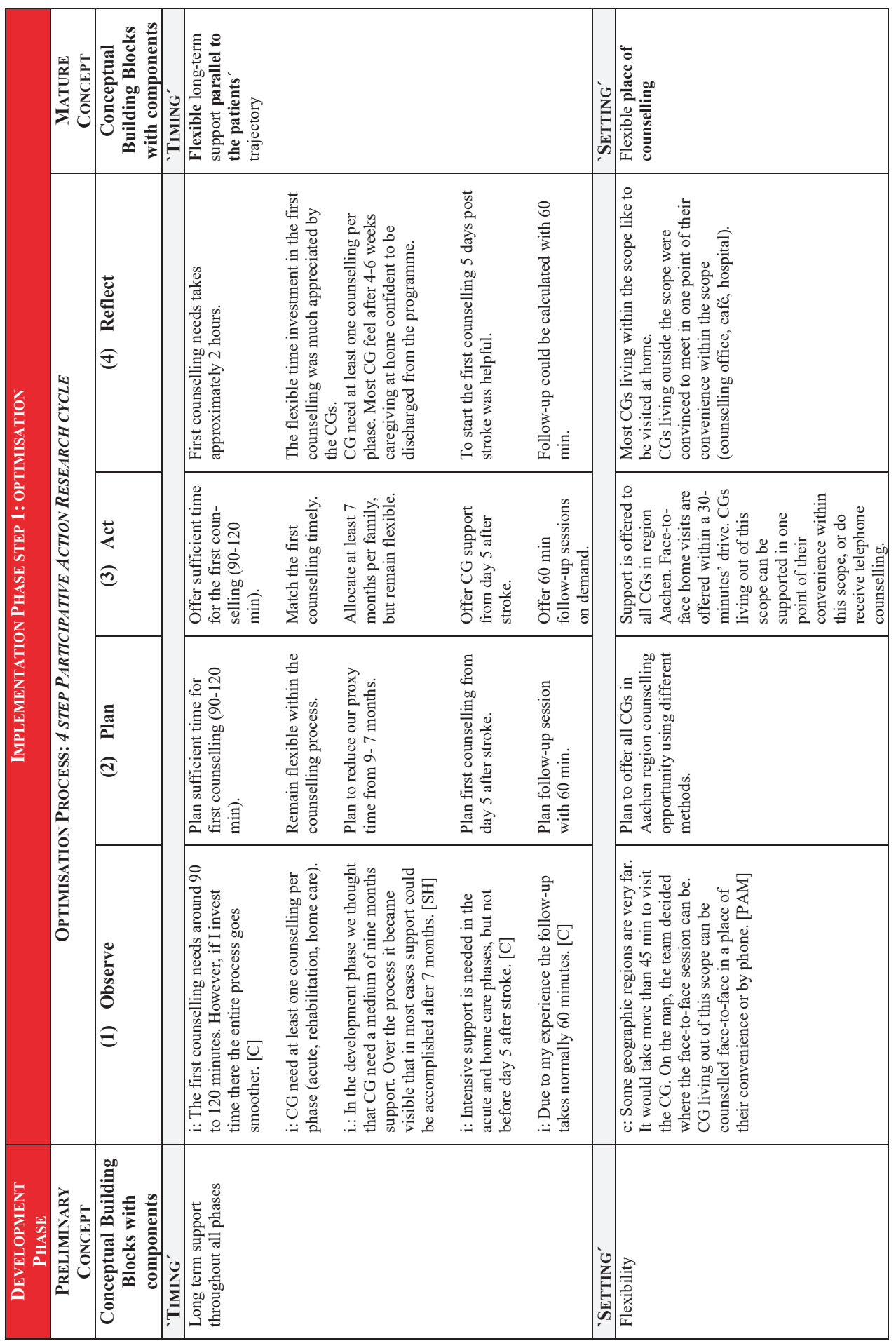


The stepwise development of a comprehensive family caregiver support programme. 


\section{CHAPTER 5}

\section{Evaluating a complex intervention for stroke caregivers on individual and system level: the Caregivers' Guide example}

Krieger T, Feron F, Dorant E (2019) Evaluating a complex intervention for stroke caregivers on individual and system level: the Caregivers' Guide example (submitted). 


\section{Abstract}

Background. Caregivers are the backbone of the long-term support system. The Caregivers' Guide, a primary prevention support for stroke caregivers, was developed, optimised in three activities and implemented. Caregivers received personalized information and psychosocial support by a professional counsellor. The programme invested in network-building and communication within the stroke rehabilitation support system.

Purpose. In this evaluation we aim to gain a comprehensive understanding of the interventions' impact on individual and system level.

Methods. A multi-methodological approach was used. Two interconnected studies: (1) quant-QUAL, and (2) QUAL-QUAL, with two groups of participants were conducted. Caregivers participated in a pre-post design with a quantitative questionnaire and a post-intervention qualitative design with a semistructured interview, reflecting on their individual experience with the support programme as end-user (individual level). Professionals participated ex-post with an interview, reflecting on the impact of the intervention on the supported endusers (individual level) and on their perceived impact of the intervention on the stroke support system (system level).

Results. Quantitative data showed that providing personalized information improved caregivers' health literacy significantly, and offering psychosocial support improved caregivers' psychosocial health. Qualitative data show health literacy enhancements of knowledge, capability to act and individual empowerment, and psychosocial stabilisation of self-confidence, life balance and emotional well-being.

The professionals perceived that communication and network-building helped optimising the system by positively influencing the daily work, institutional support, quality of care and inter-institutional cooperation.

Conclusion. A comprehensive understanding of the interventions impact was achieved on both levels. On the individual level caregivers' health literacy improved and their psychosocial health stabilized, whereas on system the level the support system was optimized by the intervention. 


\section{Introduction}

Stroke is the primary cause of disability worldwide (Thrift et al., 2014). After rehabilitation many survivors have to cope with significant physical, cognitive, and emotional deficits (Bonita et al., 2004). In the everyday care of stroke survivors at home family caregivers play a significant role (Bakas et al., 2014). Family caregivers are relatives, partners, friends or neighbours, who provide voluntary physical, practical, and emotional care and/or support to a person with a chronic disability in the home environment (adapted from Family Caregiver Alliance, 2006, p.5; Candy et al., 2011).

Stroke caregiver challenges and needs on individual and system level Compared with other caregiving situations, such as in cases of dementia, the sudden presentation of a stroke in a family, with the abrupt onset of complex demands, is challenging (Redfern et al., 2006; Legg et al., 2011). From the start caregivers are challenged by managing individual, interpersonal and organisational issues (Grant al., 2014). Moreover, they may experience emotional and social problems or communication weaknesses with the support system (Murray et al., 2003). Especially new caregivers demonstrate low health literacy in stroke, e.g. unfamiliarity with the support system or lack of knowledge and skills to master the care at home. Their needs are often ignored by the professionals within the system (Chen et al., 2015; Sanders et al., 2014). Caregivers may feel thrown in their new role without receiving training or having time to learn the necessary skills (Smith et al., 2004). The complex demands of family caregiving may impact negatively on the caregiver's physical, psychological, psychosocial, social health or financial situation (Adelman et al., 2014) and its well-being (Lutz \& Young, 2010). Many long-term stroke caregivers suffer from depression (Han \& Haley, 1999) and social isolation (Tooth et al., 2005). In addition, low educational attainment and the lack of choice in being a caregiver are acknowledged (Adelman et al., 2014).

Family caregivers might also suffer from marginalisation by the support services, insufficient communication with professionals from the system, lack of information provision, limited awareness of services and inadequate process involvement during transferals (Pindus et al., 2018; Chen et al., 2015; Ng, 2009). They feel insufficiently prepared to cope with the patients' impairment at home during the hospital's discharge management (Carlson et al., 2012), possibly fostering stroke associated complications which may require rehospitalisation of the survivor (Perry \& Middleton, 2011). 
Individual stroke caregivers require complex informational, emotional, psychological, psychosocial and peer support (Wilz et al., 2007; Li et al., 2017), as well as coaching during patient's transitions (Egan et al., 2010). Moreover, the provision of psychological first aid - PFA- seems to be essential (Gunderson et al., 2012). On the system level, caregiver interventions may result in building-up a professional support network, discovering new support offers and optimising the quality of care for the stroke survivor (Visser-Meily et al., 2005).

\section{Interventions for stroke caregivers}

During the last two decades many preventive stroke caregiver interventions were tested, and most of these interventions are complex, even though they are not explicitly outlined as complex interventions.

In a systematic review, four types of support programmes were identified: providing specialist services, (psycho-)education, counselling, and social support by peers (Visser-Meily et al., 2005). The authors could not confirm the efficacy of these interventions, however counselling was reported as most beneficial for caregivers (Visser-Meily et al., 2005).

Stroke caregiver interventions vary in content, approach, e.g. personalized or group support; and frequency, e.g. one or multiple sessions. Caregivers'support time varies from short-term, e.g. two hours (Aguirrezabal et al., 2013) to longterm, e.g. 12 weeks (King et al., 2012). No long-term offer parallel to all stroke care phase was reported. Some intervention do only provide information and education to the caregivers (Aguirrezabal et al., 2013), however most interventions are multicomponent, including information, education and counselling (Ostwald et al., 2013; Smith et al., 2012).

In the acute stroke phase, Foster et al. (2013) offered a structured caregiver training programme containing 14 components, however, this intervention did not impact on caregiver burden. During the rehabilitation phase, Aguirrezabal et al. (2013) provided a two hour group information session to caregivers, and participants were significantly more satisfied with the process of rehabilitation and the transferal at home. After discharge 0stwald et al. (2013) offered a home based personalized intervention containing information, skills training and counselling for 6 months with 16 visits/70min per session, that was significantly improving caregivers self-reported health and coping and improved cognitive functioning. 
Multiple instruments, e.g. Caregiver Burden Scale, SF-36, Frenchay Activity Index, Quality of Life, are utilized to measure the impact, realigning comparison almost impossible. However, caregivers seem to benefit most from longterm support (King et al., 2012) and personalized interventions (Ostwald et al., 2013). Bakas et al. (2014) reviewed 32 stroke family and dyad interventions. They reported that support is predominantly provided face-to-face or by telephone and rarely via web, and the frequency differs from 1-more than 15 session. In the majority of the interventions only the outcome on individual level was measured, where significant changes on caregivers' preparedness, knowledge, anxiety and depression, burden, stress and strain, quality of life, and social function were perceived (Bakas et al. 2014). On system level only caregivers' service use or satisfaction with the support were measured (Bakas et al. 2014).

\section{The German stroke rehabilitation process}

In Germany the current patient-centred stroke rehabilitation process is fragmented (figure 1).

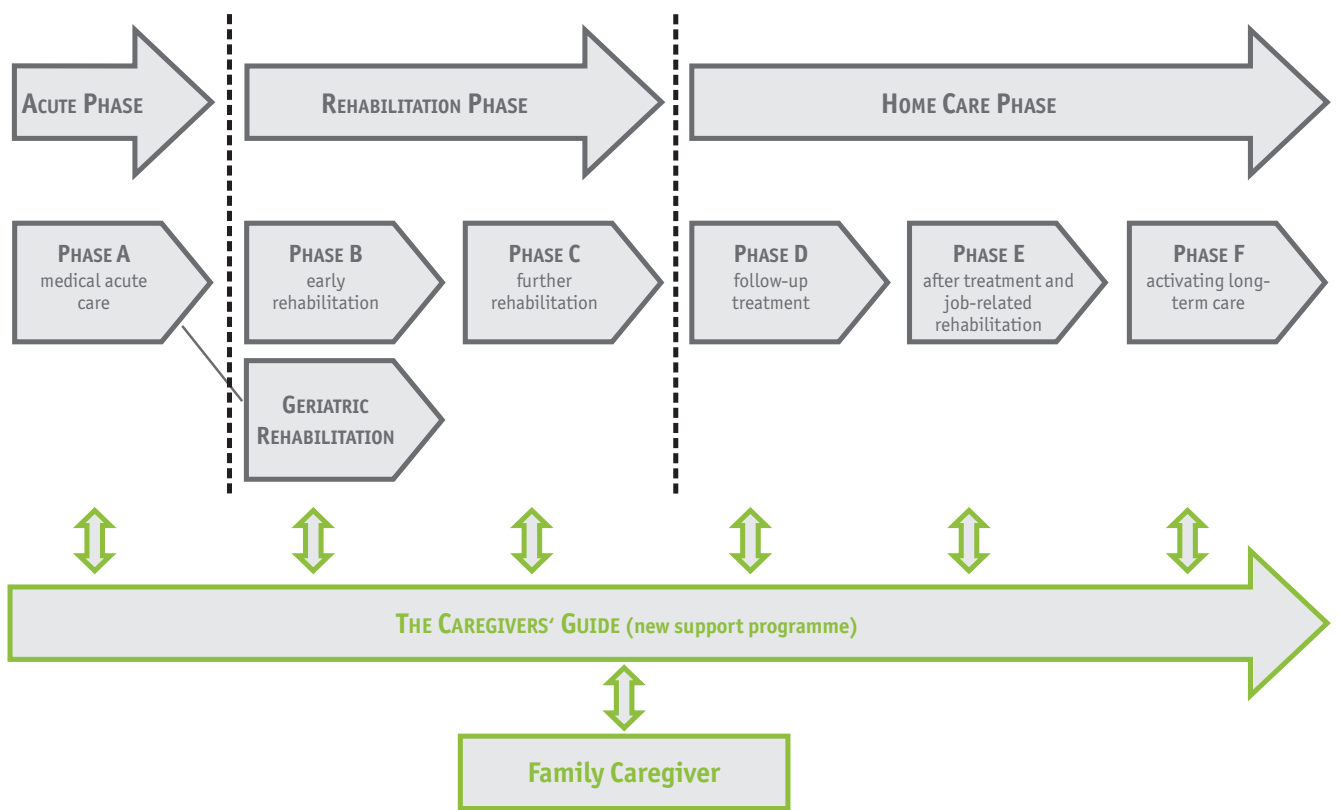

Figure 1: The German stroke rehabilitation support system (adapted from BAR, 2014) and the timing of intervention with the Caregivers' Guide 
It is characterised by multiple transition points and diverse bureaucratic, informational and logistical bottlenecks (Schuler \& 0ster, 2004), which poses challenges for the support system, the patient, and the caregiver. The current system lacks coordination, communication and navigation through the different phases and affiliated services on individual and societal levels.

In Germany, since the year 2000 many regional stroke units have been created, and most units implemented case management in order to support the discharge from acute to rehabilitation care (figure 1). However, in general family caregivers are still insufficiently invited to actively participate in the transferals and discharge process of the patient (Küttel et al., 2015). Even the good practice project of the German Stroke Association - Schlaganfall-Lotse- , puts its attention only on the patient and not on the caregiver-patient dyad (Manteufel, 2014). Some caregiver support is offered by health insurances, e.g. telephone counselling support (GKV, 2011) or the communal services, e.g. caregiver counselling. Comprehensive stroke caregiver support programmes are missing (GKV, 2011).

\section{The Caregivers`Guide programme}

The Caregivers' Guide, a new primary prevention programme, was recently developed and implemented by the multidisciplinary team of the Institute for Health Research and Social Psychiatry (igsp) in the Catholic University of Applied Sciences North Rhine - Westphalia in Aachen, Germany (2012-2015). The programmes' objective was to provide professional needs- and process-oriented support to stroke family caregivers (Jungbauer et al., 2014).

This multicomponent programme is a complex intervention (Craig et al., 2008). Personalised information as well as psychosocial support were offered in order to improve family caregivers ' health literacy and stabilize its psychosocial health. Caregivers were approached via outreach counselling by a specially trained counsellor, a clinical social worker, as early as possible after stroke and were supported as long as needed.

The Caregivers' Guide development phase was split into 2 steps: first, five preliminary Conceptual Building Blocks (CBB) were developed (Krieger et al., 2016), and second, two implementation management instruments were based on the input of a combined stakeholder and risk analysis (Krieger et al., 2018). Before full-scale implementation, an in-vivo optimization process was initiated, based on principles of Participatory Action Research - PAR - (MacDonald C 2012). This pre-implementation part resulted in a matured concept consisting of eight CBBs. The five core blocks: 'Content', 'Human resources', 'Personalized ap- 
proach', 'Timing' and 'Setting'; were essential for providing personalized caregiver support. The three facilitating blocks: 'Network building', 'Communication', and 'Social safety-net', served as a "lifebelt" for the programme within the current support system (Krieger et al., 2018). The CBBs were appointed as flexible and interconnected in order to address differences in individual and system needs.

In this paper we report on the Caregivers' Guide evaluation phase (figure 2) on both the individual and the system levels.

On the individual level, an increase of caregivers' health literacy and stabilization of psychosocial health is expected.

Health literacy - HL - is defined as 'the cognitive and social skills which determine the motivation and ability of individuals to gain access to, understand and use information in ways which promote and maintain good health ' (WH0, 1997). HL is a multidimensional concept (Batterham et al., 2016), which is considered as outcome in health promotion activities (Nutbeam, 2000). Stroke caregivers need HL for accessing and utilising services, interacting with health care service providers, participating in decision making and caring for one's own and the health of others (Pasche-Orlow \& Wolf, 2007; Nutbeam, 2008). Increased HL may positively impact caregivers' health and the quality of care (Yuen et al., 2018).

Psychosocial health - PH - is complex, encompassing a state of mental, emo-

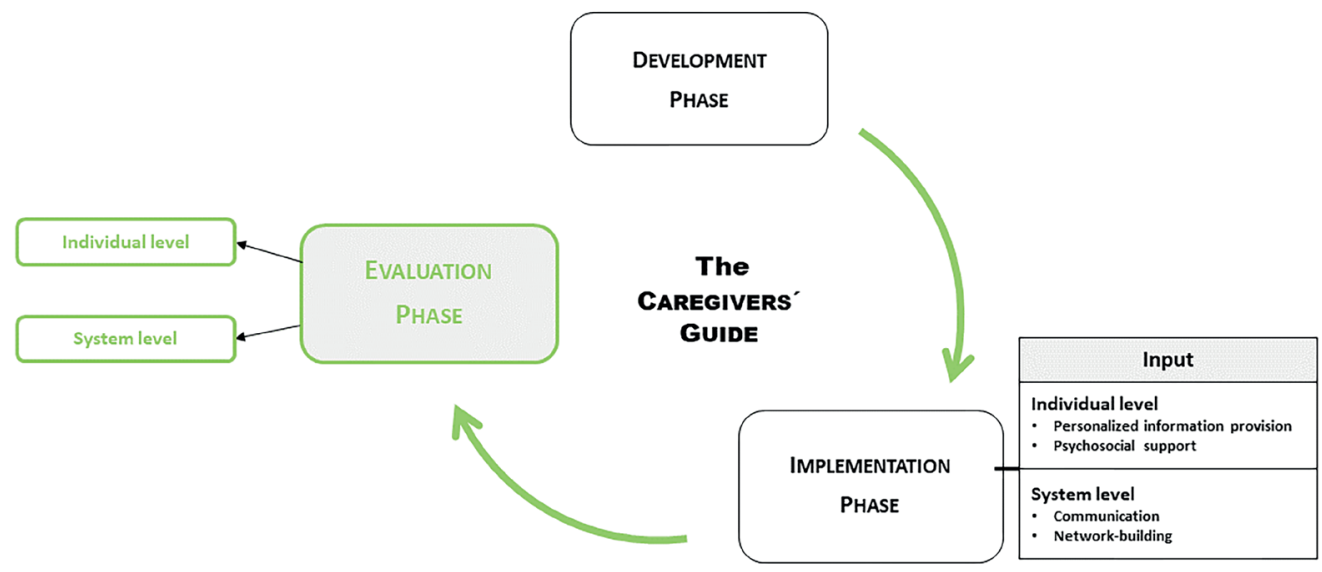

Figure 2: The Caregivers' Guide project life cycle with the inputs and focus on evaluation on individual and system level 
tional, social, and spiritual well-being, and can be destabilized through a sudden event, e.g. stroke. Circumstances embracing "both psychological and social factors" are described as psychosocial (Reber et al., 2009, p. 638), e.g. depression, stress. Psychosocial support is the provision of psychological and social resources to a person by a professional counsellor with the intention of increasing the receiver's ability to cope with certain problems (Silver Cardoso \& Chronister, 2009).

The Caregivers' Guide intervention is expected to improve the current caregiver support on the system level, which embraces all individuals and organisations within the current stroke rehabilitation support system.

By exploring the individual and system impact in one study we aim to gain a comprehensive understanding of the impact resulting from our intervention.

\section{Methods}

HL is a general, rather crude concept (Nutbeam, 2000) and PH is very complex. Therefore, a multi-methodological design was chosen (Morse, 2014; Creswell et al., 2004). Two interconnected studies were conducted, combining quantitative and qualitative methods. The quantitative part was the starting point, providing a first indicator for change attributed to our intervention. However, we aimed to gain a comprehensive understanding in the actual aspects of change that are important for stroke caregivers. Consequently, a qualitative study part was added: qualitative exploration the general HL concept for caregivers from

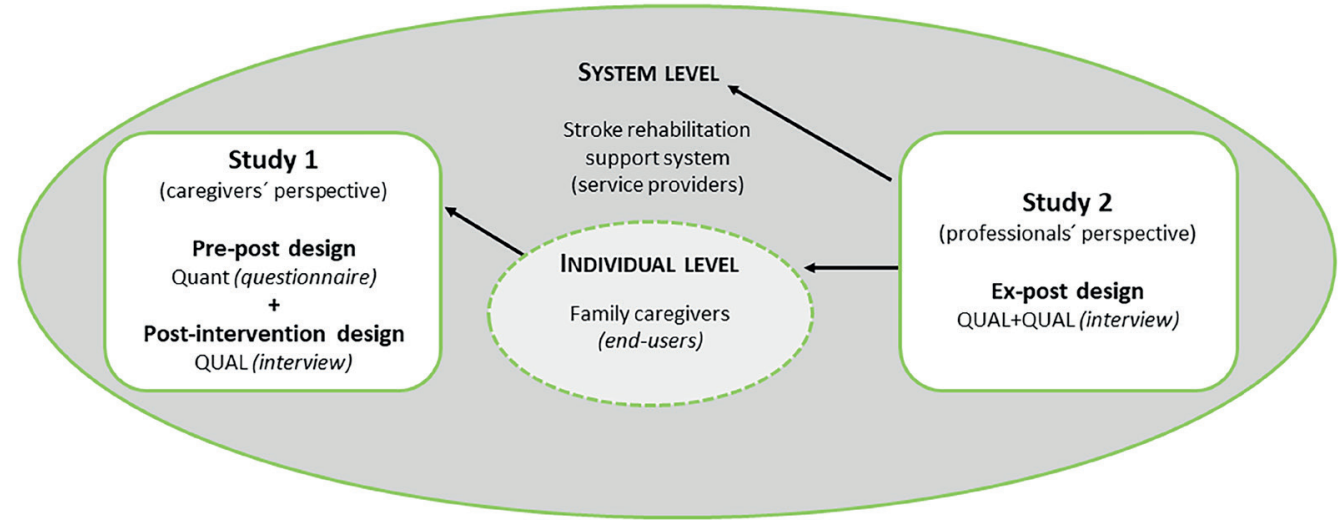

Figure 3: Research design of the Caregivers' Guide evaluation on individual and system level 
two viewpoints, (1) caregivers' perspective and support systems`' perspective (figure 3).

Two groups participated: (1) the programmes end-users, namely the family caregivers (study 1); and (2) the service providers working in the stroke rehabilitation trajectory within the acute, rehabilitation and home care phase (figure 1), namely the professional stakeholders (study 2).

In study 1, the interventions' impact on individual level was measured and in detail explored by combining a quantitative one-group pre-post design with a qualitative post-intervention design (quant-QUAL design).

In study 2, the interventions impact on the individual and societal level was explored by applying an ex-post qualitative design (figure 3).

The data collection instruments of both studies (questionnaire, interview topic list) were developed and piloted by participants from both groups regarding their feasibility, e.g. length, textual understanding, and logical flow.

Both quantitative data (study 1) as well as qualitative data (study 1 and 2) were collected by convenience sampling. All interviews were conducted by the first author, who was not involved in the counselling process. The semi-structured topic list allowed a dialogical way of communicating with both participant groups during the interview.

Quantitative data were analysed with statistical methods and qualitative data were analysed by their content.

\section{Study 1}

Participants

Sixty-two family caregivers completed a pre- and post-intervention questionnaire, between T0 and T1 were approximately six months. Caregivers were aged between 28-83 years (mean 56.4 years, $S D=12.0$ ), and the majority were females $(76 \%)$. They were spouses or partners $(\mathrm{N}=38)$, adult children or children-in-law $(\mathrm{N}=19)$, parents $(\mathrm{N}=2)$, sisters $(\mathrm{N}=2)$, or a close friend $(\mathrm{N}=1)$. The majority of these worked either full-time or part-time ( $27 \%$ and $26 \%$ resp.), whereas $34 \%$ were unemployed, and $13 \%$ were retired.

Thirty caregivers of this group participated additionally in interviews, lasting on average 50 minutes. They were approached within one month after completing 
T1. Fifteen spouses or partners and 15 adult children participated. The spouses or partners were on average 59 years old, the majority of them were females (73\%), only $20 \%$ were employed, and they required on average 6 counselling sessions. The adult children were on average 48 years old, $66 \%$ were female, $80 \%$ were employed and required on average 5 counselling sessions.

\section{Measures}

First, the quantifiable impact (quant) of the intervention was assessed among the family caregivers through a pre- and postintervention questionnaire. Caregivers self-reported once before the intervention commenced (T0), and again immediately after (T1). The self-developed instrument contained 21-items on a five-point Likert-type scale, from 1 as a very negative and 5 as a very positive result. The items measure two indicators: health literacy and psychosocial health (see Annex 1).

We used Freebody \& Lukes 's (1990) framework to measure caregivers' HL: (1) functional $\mathrm{HL}$ implies possessing the information to be able to function in the day-to-day life, e.g. ability to gain health related knowledge; (2) interactive HL refers to more advanced cognitive and literacy skills to actively participate in daily activities and to apply new information to changing circumstances, e.g. develop new practical skills, and (3) critical HL refers to most advanced cognitive skills which may be applied to critically analyse situations and to use these information to have greater control over life, e.g. role adaption skills.

For measuring $\mathrm{PH}$ we targeted on self-confidence and life balance.

SPSS 22 (Chicago, IL) was used for analyses. The means of the five indices in T0 and T1 were calculated. The internal consistence of the indices was assessed with Cronbach's Alpha, which ranged between $0.84-0.66$ (functional HL 0.84, interactive HL 0.75 , critical HL 0.66 , sense of certainty 0.82 , and life balance 0.78 ), what is a good result. The dependent T-test was used to determinate the statistical significance and the significance level was set at $\mathrm{p}<0.05$.

Second, the qualitative post-intervention design (QUAL) was applied in order to gain a deeper understanding of the actual changes on family caregivers' HL and $\mathrm{PH}$. Therefore, a caregivers' subgroup was invited to participate in an additional semi-structured face-to-face interview with open-ended questions (Annex 2 , topic list). They reflected retrospectively on their individual experiences with the programme and stated their individually perceived impact. 


\section{Study 2}

\section{Participants}

Eleven professional stakeholders, affiliated with the stroke rehabilitation support system, were invited to participate in semi-structured interviews (table 1).

\section{Measures}

A qualitative ex-post analysis design (QUAL+QUAL) was used in order to reflect on both the individual impact on the supported caregivers as well as on the system impact within the stroke support system. The first author interviewed the professionals face-to-face or via telephone after the programmes ' intervention phase was competed (Annex 3 topic list). The overall research question was: How was the Caregivers ' Guide support programme perceived by the professional stakeholders regarding its impact on an individual and societal levels? On individual level, professionals compared the caregivers receiving the interventions' support with those not being supported by the programme, e.g. before the programme started. On a system level, professionals reflected on their own experience as being part of the system. The heterogeneity of the system needed to be considered, which was possible by including multiple professions from different support domains.

\section{Table 1: Professional stakeholder participating in the qualitative study}

\begin{tabular}{|c|c|c|c|}
\hline $\begin{array}{l}\text { Support } \\
\text { system } \\
\text { domain }\end{array}$ & Setting \& place & Department & $\begin{array}{l}\text { Position \& professional } \\
\text { background }\end{array}$ \\
\hline \multirow[t]{2}{*}{ Acute Care } & University Hospital, Aachen & $\begin{array}{l}\text { Stroke unit, Neurology } \\
\text { Neurosurgery }\end{array}$ & $\begin{array}{l}\text { Case manager } \\
\text { Head of department / MD } \\
\text { Case manager / nurse / social } \\
\text { worker }\end{array}$ \\
\hline & Acute Hospital, Würselen & Stroke unit, Neurology & Social worker \\
\hline \multirow[t]{2}{*}{$\begin{array}{l}\text { Rehabilitation } \\
\text { Care }\end{array}$} & $\begin{array}{l}\text { Inpatient Rehabilitation } \\
\text { Hospital, Bad Berleburg }\end{array}$ & $\begin{array}{l}\text { Patient \& caregiver } \\
\text { support services }\end{array}$ & Case manager / nurse \\
\hline & $\begin{array}{l}\text { Ambulant Rehabilitation } \\
\text { Clinic, Aachen }\end{array}$ & Psychological support & Psychologist \\
\hline Home Care & Home Care Service, Aachen & Home Care Service & $\begin{array}{l}\text { CEO / Nurse } \\
\text { Head nurse / Nurse }\end{array}$ \\
\hline \multirow[t]{2}{*}{ External care } & $\begin{array}{l}\text { Communal Social Services, } \\
\text { Aachen }\end{array}$ & $\begin{array}{l}\text { Home adaption } \\
\text { counselling services } \\
\text { Care support and } \\
\text { counselling services }\end{array}$ & $\begin{array}{l}\text { Social worker } \\
\text { Nurse }\end{array}$ \\
\hline & $\begin{array}{l}\text { Medical Health Equipment } \\
\text { provider, Aachen }\end{array}$ & Medical supply & Case manager / nurse \\
\hline
\end{tabular}




\section{Qualitative data analyses}

The qualitative data from study 1 and 2 were analysed separately.

Data were examined top-down using qualitative content analysing. This method is suitable for the subjective interpretation of text data content through a systematic classification process, by coding and identifying themes and subthemes (Hseih \& Shannon, 2005). Deductive and inductive content analysing approaches (Graneheim et al., 2017) were combined.

The interviews were digitally recorded and transcribed verbatim. All transcripts were read line-by-line by the first author. The data were then analyzed by selecting and labeling themes emerging from the text.

Qualitative data reflecting on the individual level were analyzed by applying both a deductive and inductive approach. First, qualitative data of study 1 were initially analyzed with a deductive approach (Schreiner, 2012) using the indicators and indices of the quantifiable impact (table 2) as topics: 'health literacy' and 'psychosocial health', with corresponding subtopics. Next, we used an inductive approach for creating 'subthemes' with corresponding 'themes' from the text material. An inductive approach was also applied when a new `subtheme' emerged. Finally, 'subthemes' were illustrated with example quotes. The qualitative data from study were using first the 'themes' and 'subthemes' of study 1 (deductive), and if new findings emerged an inductive approach was applied.

Qualitative data reflecting on the societal level (study 2) were only analysed inductively (Krippendorff, 2013). After familiarizing with the data, an open coding process started, resulting in an inductive topic development (Mayring, 2000). The resulting codes were sorted into the topic 'stroke support system' and its corresponding themes and subthemes, which were then illustrated by example quotes. Data collection continued until no new themes were identified from the different support domains.

In addition, the second author analysed the data and refined the codes and coding manual. The variation of coding were discussed between the two authors until consensus was reached (Elo \& Kyngäs, 2008). The results were then presented to the professionals in the project's closing workshop for checking and feedback. 
Findings were triangulated within each study (case triangulation). Triangulating methods and sources lead to a comprehensive understanding of the perceived changes on the different levels (Pattom, 2001). This finally resulted in assessing the impact on both individual and system levels.

\section{Ethics}

Ethical approval was provided by the board of the University of Applied Sciences North Rhine Westphalia and the Ethic Committee of the University Hospital Aachen (study 1). All participants received information about the study and provided a written consent before data collection.

Study 2 did not fall within the scope of medical research in Germany and therefore no ethical approval was required, verbal consent was nevertheless obtained from all participants.

The researchers had no prior relationship with the participants.

\section{Results}

The intervention's impact was assessed on both individual and system level. Caregivers' perception (end-users) was collected with quantitative and qualitative instruments. Professionals' perception (service providers) was gained only qualitatively. The evaluation resulted in four outcomes: three outcomes on individual level, and one outcome on system level (Figure 4).

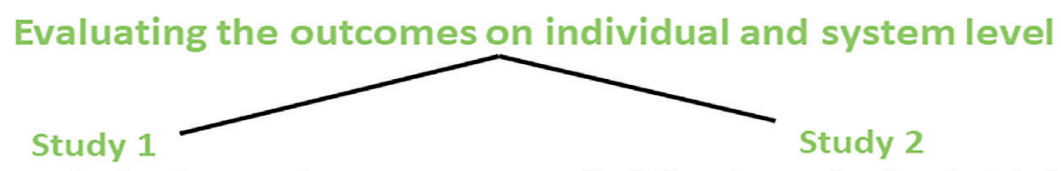

Participants: stroke family caregivers

Participants: professional stakeholder

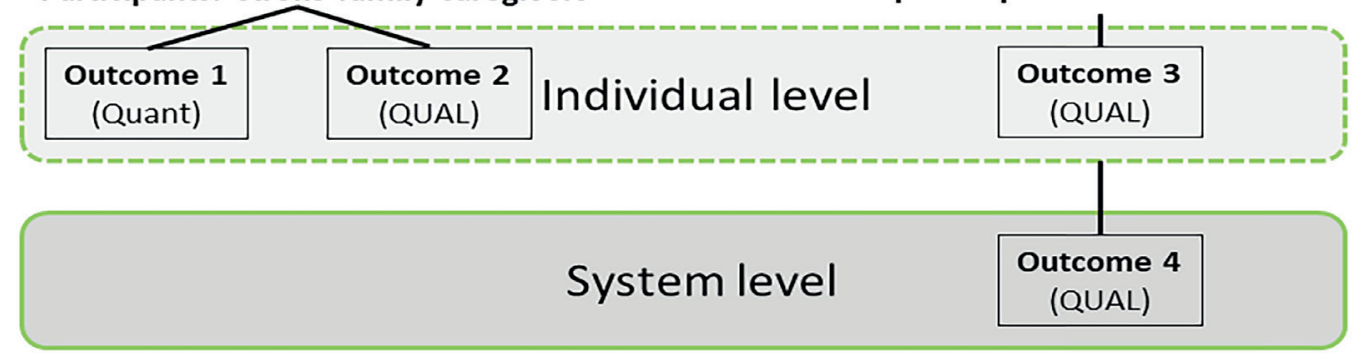




\section{Outcome 1}

The results of the quantitative part are presented in table 2.

As can be seen in table 2, HL improved during intervention on all 3 indexes. The functional and interactive HL even showed high statistical significance. Both PH indexes: self-confidence and life balance, improved. Caregivers' self-confidence showed statistical significance, whereas on life balance only marginal changes were perceived.

\section{Outcome 2}

The primary impact structure of findings of the quantitative part with $\mathrm{HL}$ and $\mathrm{PH}$ (table 2) was in-depth explored in this qualitative part of study 1 (figure 4). An overview of the results with corresponding quotes is provided in table 3.

Caregivers perceived a positive effect on their individual HL. Two subthemes emerged: knowledge (functional HL), and capability to act (interactive $\mathrm{HL}$ ), no material was found corresponding to critical HL (table 2).

Due to the personalized information provision, which was provided by the Caregivers`'Guide counsellor, caregivers gained new and important knowledge. They perceived a better understanding of the stroke and its consequences. Caregivers felt familiarized with the fragmented stroke rehabilitation process, e.g. the German A-F Phase rehabilitation system (figure 1) and informed about the regional stroke entire support system with its support options, e.g. communal services, financial support (table 3).

As a consequence of understanding the disease, the rehabilitation process and the support system, caregivers stated that their capability to act improved during the counselling process. Caregivers felt enabled to collaborate with the sys-

Table 2: Impact on caregivers' health literacy and psychosocial health, a quantitative pre\& post intervention study among 62 stroke caregivers supported by the Caregivers' Guide.

\begin{tabular}{lcccc}
\hline Indicator & T0 & T1 & T & p \\
& Mean (SD) & Mean (SD) & & \\
\hline Health literacy & & & & \\
$\quad$ Functional HL & $3.7(0.8)$ & $4.2(0.8)$ & -4.0 & 0.000 \\
Interactive HL & $3.3(1.0)$ & $3.7(0.8)$ & -3.7 & 0.000 \\
$\quad$ Critical HL & $3.0(0.9)$ & $3.2(0.8)$ & -2.5 & 0.015 \\
Psychosocial Health & & & & \\
Self-confidence & $3.0(0.8)$ & $3.2(0.7)$ & -2.6 & 0.012 \\
Life balance & $2.8(0.9)$ & $2.9(0.9)$ & -1.2 & 0.26 \\
\hline
\end{tabular}


tem for the patient's and their own purposes, e. g. finding a suitable home care service. They started to involve themselves actively in the rehabilitation and discharge process and/or searched for further support option within the system. "She (counsellor) explained that we may apply for a disability card. I would not think about this issue by myself" [Caregiver 53]. An early preparation for their new caregivers' role was perceived as, e.g. attending a communal caregiver course; personally approaching therapists in the rehabilitation clinic for handon training (table 3).

Findings indicated that providing psychosocial support stabilized caregivers' PH. Three subthemes surfaced: self-confidence and life balance (table 2) were further explored, and emotional well-being emerged as new subtheme (table 3). Caregivers highlighted that counselling helped to retrieve their self-confidence. They felt enabled to recapture their everyday life control and to take actions to plan their "new life", e.g. considering different future scenarios. Active listening and the "first aid guide", provided to each caregiver as a helpful instrument in case of a possible re-infarct, were both perceived to reduce anxiety. Counsellor accessibility was perceived to be crucial to feel tranquil within the intricate and instable new situation.

Caregivers mentioned that the intervention helped them to re-balance their new life. An awareness of overburdening due to new role was raised and practical solutions were found together with the counsellor. Especially in the end of the rehabilitation process, caregivers wanted to engage with peers. The programme granted this wish by establishing a caregiver peer group. „The meetings with other caregiver experiencing the same challenges give me so much power and joy" [Caregiver 35].

Caregivers perceived their emotional well-being as an important factor to take over their new role. "It was just too much. I guess if there is nobody to help, one may easily get their head stuck in the sand" [Caregiver 35]. Directly post stroke, the provision of psychological first aid, e.g. promoting hope, was perceived as helpful to alleviate negative emotions. Personalized counselling helped to get confidence to plan the future as a family. Caregivers felt supported during their grieving process. "It is a completely different life...! How often do we sit here and tell ourselves ' if we had our old life back...'; yes, the old life, we miss it already" [Caregiver 5]. Caregivers felt supported in resolving conflicts caused by having the stroke in the family. 


\section{Table 3: Impact on caregivers' health literacy and psychosocial health, a qualitative study among 30 stroke caregivers supported by the Caregiver's Guide.}

\section{IMPACT ON INDIVIDUAL LEVEL}

\section{Topic 1: Health literacy}

\begin{tabular}{|c|c|c|c|c|}
\hline $\begin{array}{l}\text { Subtopics* } \\
\text { (deductive) }\end{array}$ & Example quotes from caregivers & $\begin{array}{l}\text { Subthemes } \\
\text { (inductive) }\end{array}$ & $\begin{array}{l}\text { Themes } \\
\text { (inductive) }\end{array}$ & Outcome \\
\hline \multirow[t]{3}{*}{$\begin{array}{l}\text { Functional } \\
\text { HL }\end{array}$} & $\begin{array}{l}\text { "She (the counselor) explained to me in } \\
\text { a way I could understand the effects } \\
\text { and consequences of the stroke." [CG } \\
6]\end{array}$ & $\begin{array}{l}\text { Stroke specific } \\
\text { knowledge gain }\end{array}$ & \multirow[t]{3}{*}{ Knowledge } & \multirow[t]{7}{*}{$\begin{array}{l}\text { Health } \\
\text { literacy } \\
\text { enhancements }\end{array}$} \\
\hline & $\begin{array}{l}\text { „She knew the process and clarified } \\
\text { what we could expect and how the } \\
\text { rehabilitation process will be“ [CG 49] }\end{array}$ & $\begin{array}{l}\text { Familiarization } \\
\text { with } \\
\text { rehabilitation } \\
\text { process }\end{array}$ & & \\
\hline & $\begin{array}{l}\text { "She provided me with the necessary } \\
\text { facts and told me who to approach } \\
\text { when I face a problem" [CG 12] }\end{array}$ & $\begin{array}{l}\text { Support system } \\
\text { orientation }\end{array}$ & & \\
\hline \multirow[t]{4}{*}{$\begin{array}{l}\text { Interactive } \\
\text { HL }\end{array}$} & $\begin{array}{l}\text { „As a caregiver you have to get } \\
\text { involved in certain issues, you have to } \\
\text { be active and back-track things. The } \\
\text { Caregivers' Guide counselor helped me } \\
\text { in this aspect." [CG 55] }\end{array}$ & $\begin{array}{l}\text { Proactive } \\
\text { process } \\
\text { involvement }\end{array}$ & \multirow[t]{5}{*}{$\begin{array}{l}\text { Capability } \\
\text { to act }\end{array}$} & \\
\hline & $\begin{array}{l}\text { "The Caregivers Guide prepared me for } \\
\text { going to the communal social services } \\
\text { and applying for the necessary } \\
\text { support." [CG 33] }\end{array}$ & $\begin{array}{l}\text { Collaboration } \\
\text { with the support } \\
\text { system }\end{array}$ & & \\
\hline & $\begin{array}{l}\text { "Sometimes the applications for the } \\
\text { health insurance contained too much } \\
\text { administrative language which was } \\
\text { difficult to understand. I asked her (the } \\
\text { counselor) to clarify them before } \\
\text { submitting the application." [CG 3] }\end{array}$ & $\begin{array}{l}\text { Search for } \\
\text { further support }\end{array}$ & & \\
\hline & $\begin{array}{l}\text { "She (the counselor) told me that there } \\
\text { is a caregiver training programme in the } \\
\text { rehabilitation clinic in Bad Berleburg, } \\
\text { and she assisted me to get admitted } \\
\text { there, which was just great for me." } \\
\text { [CG 9] }\end{array}$ & $\begin{array}{l}\text { Early role } \\
\text { preparation }\end{array}$ & & \\
\hline Critical HL & \multicolumn{2}{|l|}{ No qualitative findings } & & \\
\hline
\end{tabular}




\begin{tabular}{|c|c|c|c|c|}
\hline \multicolumn{5}{|c|}{$\begin{array}{l}\text { IMPACT ON INDIVIDUAL I } \\
\text { Topic 2: Psychosocial Health }\end{array}$} \\
\hline \multirow[t]{3}{*}{$\begin{array}{l}\text { Self- } \\
\text { confidence }\end{array}$} & $\begin{array}{l}\text { "Every time she (the counsellor) was } \\
\text { here, she explained a lot to me and } \\
\text { answered all my sometimes confusing } \\
\text { questions. She was very patient and } \\
\text { overtime I gained confidence to manage } \\
\text { the situation at home." [CG 22] }\end{array}$ & $\begin{array}{l}\text { Recapture of } \\
\text { everyday life } \\
\text { control }\end{array}$ & \multirow[t]{3}{*}{$\begin{array}{l}\text { Self- } \\
\text { confidence }\end{array}$} & \multirow[t]{9}{*}{$\begin{array}{l}\text { Psychosocial } \\
\text { health } \\
\text { stabilization }\end{array}$} \\
\hline & $\begin{array}{l}\text { "In the acute phase, everybody takes } \\
\text { care of the patient. We as relatives with } \\
\text { our great fear and thoughts are not } \\
\text { taken in consideration. The Caregivers' } \\
\text { Guide counselor took time to listen to } \\
\text { me and my needs which reduced my } \\
\text { fears." [CG 35] }\end{array}$ & $\begin{array}{l}\text { Anxiety } \\
\text { reduction }\end{array}$ & & \\
\hline & $\begin{array}{l}\text { "I always had the feeling, even at } \\
\text { midnight, that I can call her. This is not } \\
\text { like contacting an office with limited } \\
\text { opening hours, there was always } \\
\text { someone who can help me. That was } \\
\text { incredibly important." [CG 49] }\end{array}$ & $\begin{array}{l}\text { Accessibility } \\
\text { of support }\end{array}$ & & \\
\hline \multirow[t]{2}{*}{ Life balance } & $\begin{array}{l}\text { „I could not sleep well in the nights } \\
\text { anymore since my husband turned back } \\
\text { home. My head was spinning. The } \\
\text { Caregivers' Guide counselor always } \\
\text { told me that I seriously need to take } \\
\text { time for myself. Finally, we involved a } \\
\text { home care service and I started to relax } \\
\text { a bit." [CG 46] }\end{array}$ & $\begin{array}{l}\text { Awareness of } \\
\text { overburdens }\end{array}$ & \multirow[t]{2}{*}{ Life balance } & \\
\hline & $\begin{array}{l}\text { „The meetings with other caregivers } \\
\text { experiencing the same challenges gives } \\
\text { me so much power and joy. [CG 35] }\end{array}$ & $\begin{array}{l}\text { New social } \\
\text { contacts } \\
\text { (peers) }\end{array}$ & & \\
\hline \multirow[t]{4}{*}{$\begin{array}{l}\text { No } \\
\text { qualtitative } \\
\text { findings }\end{array}$} & $\begin{array}{l}\text { „In the beginning I was in a state of a } \\
\text { shock. I was not able to think or to act. } \\
\text { It was so important to get professional } \\
\text { help.” [CG 22] }\end{array}$ & $\begin{array}{l}\text { Emotional re- } \\
\text { stabilisation }\end{array}$ & \multirow[t]{4}{*}{$\begin{array}{l}\text { Emotional } \\
\text { well-being }\end{array}$} & \\
\hline & $\begin{array}{l}\text { "My counselor was actively stimulating } \\
\text { us to decide what do when my father } \\
\text { returns home. We focused on practical } \\
\text { circumstances and I could start to plan } \\
\text { an achievable future for our family." } \\
\text { [CG 35] }\end{array}$ & $\begin{array}{l}\text { Future life } \\
\text { orientation }\end{array}$ & & \\
\hline & $\begin{array}{l}\text { „In counselling the most important part } \\
\text { was to talk about my grief and I } \\
\text { received professional grief processing.“ } \\
\text { [CG 69] }\end{array}$ & $\begin{array}{l}\text { Grieving } \\
\text { process } \\
\text { support }\end{array}$ & & \\
\hline & $\begin{array}{l}\text { "She resolved our conflicts in the } \\
\text { family.“ [CG 30] }\end{array}$ & $\begin{array}{l}\text { Conflict } \\
\text { resolution }\end{array}$ & & \\
\hline
\end{tabular}


The findings of the qualitative part suggest that the intervention was perceived as a great benefit by the caregivers. "I did not know where my head was! I was overwhelmed with fear and could barely think. Without the Caregivers' Guide I would have probably lost my head" [Caregiver 24].

\section{Outcome 3}

The professionals perceived also a positive impact on the caregivers' ${ }^{\prime} \mathrm{HL}$ and $\mathrm{PH}$ (figure 4, study 2). Findings were summarized in table 4.

In addition to the caregivers' perception of the two HL themes: knowledge and capability to act (table 3 ), professionals perceived additionally a positive impact on individual empowerment.

Due to the personalized information provision by the counsellor professionals observed that supported caregivers were better informed about the stroke and its consequences, as information was provided to their needs, e.g. user-friendly language, use of recall questions. During the counselling process caregivers were familiarized with the rehabilitation process, e.g. rehabilitation options, after acute care. "Caregivers in the programme understood the different responsibilities of each player in the rehabilitation process. The roles of the different professionals' were clear" [Case manager, rehabilitation care]. Supported caregivers gained a comprehensive orientation within the broader support system and knew existing support offers, e.g. communal services.

Professionals observed that due to the valuable and structured information provision by the counsellor, caregivers' capability to act enhanced during the process. Caregivers were perceived as collaborating with the support system. "Caregivers started to understand why it is important to think about the future situation already in the acute phase. Normally they are not ready for this and we have our struggles with them" [Case management 2, acute phase]. During the process professionals notified that caregivers increasingly intended to get involved in the decision making, e.g. discharge, and were searching actively for support. The home care services and the external support providers perceived that caregivers prepared themselves earlier for their new role, which was attributed to the stimulation of the counsellor.

Professionals observed that supported caregivers were individually empowered, which resulted in a better role adaptation. "Through the long-term counselling process, caregivers were better equipped to understand and actively manage the process" [Medical health equipment provider, home care phase]. Professionals 
also perceived an increased use of the support network, which may result in preventing overburden and social isolation. "Social isolation occurs often in family caregiving. The Caregivers' Guide counsellor assured with a systemic working approach that the work is not done by only one family member" [Social worker, acute phase].

Professionals equally perceived an impact on caregivers $\mathrm{PH}$ on three subthemes: self-confidence, life balance, and emotional well-being.

Professionals observed that due to psychosocial support caregivers self-confidence was reinforced. Counselling helped to plan a realistic future and gain control over the new life. Caregivers' anxiety caused by the event was reduced through having a focus person for personal conversation and support. "Caregivers had the counsellor as a frist contact person if something went wrong. They felt they were not abandoned and therefore safe" [Nurse, home care phase]. The accessibility of the counsellor via telephone or Email was also perceived as very important.

Professionals observed an improved life balance. Caregivers who were supported right from the start were more concerned of the possible risk of overburdening. Consequently, they started to search for preventive actions, e.g. organisational short-term care. Caregivers sustained their social contacts and appeared to be less isolated, in addition to having new contacts through the peer group "In the beginning it was so important that the Caregivers' Guide counsellor was available for personal support. Later in the process, some of the caregivers participated in the peer group and they were very content with it" [Social worker, acute care phase].

Professionals perceived the provision of psychological first aid as key element for the interventions' success, whereby the counsellor provided knowledge and a sense of security to the caregivers, which supported their emotional well-being. "Some caregivers are emotionally frozen, unable to act or take decisions. Thanks to the psychosocial support of the counsellor, caregivers were able to gain their decision-making skills back" [Case manager 1, acute care]. "When being after their shock status" (Case manager 2, acute care), caregivers started to plan their life within their new role. Caregivers are often overwhelmed by emotional waves, therefore, the offer of professional grieving support was perceived as very helpful. Caregivers' emotional well-being was also stabilized through systemic family counselling, resulting in conflict resolution. 
Table 4: Impact of the Caregivers' Guide intervention on caregivers ' health literacy and psychosocial health, a qualitative study among 11 professionals working as service providers within the stroke rehabilitation system.

\begin{tabular}{|c|c|c|c|}
\hline $\begin{array}{l}\text { Themes* } \\
\text { (deductive/ } \\
\text { inductive) }\end{array}$ & Example quote from professionals & $\begin{array}{l}\text { Subthemes* } \\
\text { (deductive/ } \\
\text { inductive) }\end{array}$ & Outcome \\
\hline \multicolumn{4}{|c|}{ Topic 1: Health literacy } \\
\hline \multirow[t]{3}{*}{ Knowledge } & $\begin{array}{l}\text { "The Caregivers' Guide counsellor provided valuable } \\
\text { health-related information in a caregiver-friendly } \\
\text { language. They were therefore well informed." [Head } \\
\text { of department, Neurosurgery, acute phase] }\end{array}$ & $\begin{array}{l}\text { Stroke specific } \\
\text { knowledge gain }\end{array}$ & \multirow[t]{9}{*}{$\begin{array}{l}\text { Health } \\
\text { literacy } \\
\text { enhance- } \\
\text { ments }\end{array}$} \\
\hline & $\begin{array}{l}\text { "Caregivers were informed about the process of } \\
\text { rehabilitation." [Case manager, rehabilitation care] }\end{array}$ & $\begin{array}{l}\text { Familiarization } \\
\text { with rehabilitation } \\
\text { process }\end{array}$ & \\
\hline & $\begin{array}{l}\text { "The structured information provision included issues } \\
\text { concerning financial infrastructural and caregiving } \\
\text { support. She (counsellor) explained everything and } \\
\text { distributed flyers which caregivers could read again." } \\
\text { [Nurse, care support, communal social services] }\end{array}$ & $\begin{array}{l}\text { Support system } \\
\text { orientation }\end{array}$ & \\
\hline \multirow[t]{4}{*}{$\begin{array}{l}\text { Capability to } \\
\text { act }\end{array}$} & $\begin{array}{l}\text { "When a caregiver was supported by this programme, } \\
\text { they were more intrigued to be involved. They asked } \\
\text { focussed questions and wanted to be involved in the } \\
\text { decision making process." [Nurse, home care phase] }\end{array}$ & $\begin{array}{l}\text { Proactive process } \\
\text { involvement }\end{array}$ & \\
\hline & $\begin{array}{l}\text { "The way of working and communicating together } \\
\text { improved. We (families and services) were now } \\
\text { working not against each other, but more together in } \\
\text { order to find the best solutions for the patient and the } \\
\text { family. [Head of home care service, home care phase] }\end{array}$ & $\begin{array}{l}\text { Collaboration } \\
\text { with the support } \\
\text { system }\end{array}$ & \\
\hline & $\begin{array}{l}\text { "They could contact the Caregivers' Guide counselor } \\
\text { any time and took advantage of it, it provided them } \\
\text { with confidence. They started to be more active." } \\
\text { [Medical health equipment provider, home care phase] }\end{array}$ & $\begin{array}{l}\text { Search for further } \\
\text { support }\end{array}$ & \\
\hline & $\begin{array}{l}\text { "Caregivers were stimulated by the counsellor to } \\
\text { participate in our training sessions already in the acute } \\
\text { phase. So they accompanied the patient during } \\
\text { rehabilitation and participated in this training. This was } \\
\text { very helpful for the patient, the caregiver and also for } \\
\text { us." [Case manager, rehabilitation care] }\end{array}$ & $\begin{array}{l}\text { Early role } \\
\text { preparation }\end{array}$ & \\
\hline \multirow{2}{*}{$\begin{array}{l}\text { Individual } \\
\text { empower- } \\
\text { ment }\end{array}$} & $\begin{array}{l}\text { "I had the impression that caregivers felt more } \\
\text { confident in their new role." [Nurse, home care phase] }\end{array}$ & Role adaption & \\
\hline & $\begin{array}{l}\text { "Some of the supported caregivers were able to get } \\
\text { some time off in the day-care programme. Normally } \\
\text { caregivers are not aware that this time can be financed } \\
\text { by the health insurance." [Nurse, home care phase] }\end{array}$ & $\begin{array}{l}\text { Support network } \\
\text { use }\end{array}$ & \\
\hline
\end{tabular}




\begin{tabular}{|c|c|c|c|}
\hline $\begin{array}{l}\text { Themes* } \\
\text { (deductive/ } \\
\text { inductive) }\end{array}$ & Example quote from professionals & $\begin{array}{l}\text { Subthemes* } \\
\text { (deductive/ } \\
\text { inductive) }\end{array}$ & Outcome \\
\hline \multicolumn{4}{|c|}{ Topic 2: Psychosocial Health } \\
\hline \multirow[t]{3}{*}{$\begin{array}{l}\text { Self- } \\
\text { confidence }\end{array}$} & $\begin{array}{l}\text { "As the counselling took place in their home } \\
\text { environment, caregiver were much more confident in } \\
\text { mastering the caregiving requirements." [Case } \\
\text { manager, rehabilitation phase] }\end{array}$ & $\begin{array}{l}\text { Recapture of } \\
\text { everyday life } \\
\text { control }\end{array}$ & \multirow{9}{*}{$\begin{array}{l}\text { Psycho- } \\
\text { social } \\
\text { Health } \\
\text { stabiliz- } \\
\text { ation }\end{array}$} \\
\hline & $\begin{array}{l}\text { "They had confidence in the Caregivers' Guide, who } \\
\text { offered a professional support to answer all their } \\
\text { questions. The initial anxiety was greatly reduced when } \\
\text { caregivers were engaged in the counselling process." } \\
\text { [Case manager, acute care phase] }\end{array}$ & Anxiety reduction & \\
\hline & $\begin{array}{l}\text { "Caregivers were aware of the possibility to contact } \\
\text { their professional counsellor at any time in case of } \\
\text { emerging issues, which was very comforting for the } \\
\text { caregivers." [Head of home care services, home care } \\
\text { phase] }\end{array}$ & $\begin{array}{l}\text { Accessibility of } \\
\text { support }\end{array}$ & \\
\hline \multirow[t]{2}{*}{ Life balance } & $\begin{array}{l}\text { "Caregivers themselves stimulated the programme to } \\
\text { initiate a caregiver peer group. This was really great." } \\
\text { [Psychologist, rehabilitation care] }\end{array}$ & $\begin{array}{l}\text { Awareness of } \\
\text { overburdens }\end{array}$ & \\
\hline & $\begin{array}{l}\text { "Overburdening is very frequent, especially for women. } \\
\text { I had the impression that the caregivers involved in the } \\
\text { programme were more aware of this problem and tried } \\
\text { to find individual solutions." [Head of home care } \\
\text { services] }\end{array}$ & $\begin{array}{l}\text { New social } \\
\text { contacts (peers) }\end{array}$ & \\
\hline \multirow[t]{4}{*}{$\begin{array}{l}\text { Emotional } \\
\text { well-being }\end{array}$} & $\begin{array}{l}\text { "Experiencing a stroke in the family is a traumatic } \\
\text { event. The Caregivers' Guide counsellor provided } \\
\text { psychological first aid." [Psychologist, rehabilitation } \\
\text { care] }\end{array}$ & $\begin{array}{l}\text { Emotional re- } \\
\text { stabilisation }\end{array}$ & \\
\hline & $\begin{array}{l}\text { "Due to the structured orientation process by the } \\
\text { counsellor, caregivers had realistic expectations." [Case } \\
\text { manager, rehabilitation phase] }\end{array}$ & $\begin{array}{l}\text { Future life } \\
\text { orientation }\end{array}$ & \\
\hline & $\begin{array}{l}\text { "There was time to grief and cry, time to live the } \\
\text { emotions. This was an important step for their } \\
\text { recovery." [Case manager 1, acute phase] }\end{array}$ & $\begin{array}{l}\text { Grieving process } \\
\text { support }\end{array}$ & \\
\hline & $\begin{array}{l}\text { "For some caregivers the interfamilial conflicts, even } \\
\text { with the patient themselves, were difficult to handle } \\
\text { and lead high levels of emotional stress. Here the } \\
\text { Caregivers' Guide counselled the entire family and } \\
\text { found together suitable solutions." [Case Manager, } \\
\text { rehabilitation care] }\end{array}$ & $\begin{array}{l}\text { Conflict } \\
\text { resolution }\end{array}$ & \\
\hline
\end{tabular}

* Themes and subthemes from the qualitative caregiver study (deductive), bold letters indicate a new theme and subtheme (inductive), CG: family caregiver 


\section{Outcome 4}

The impact on a system level was assessed by interviewing the professionals (figure 4, study 2), and resulted in a perceived 'support system optimization'. Four themes: (1) professionals` everyday work, (2) institutional support, (3) quality of patient care, and (4) interinstitutional cooperation, emerged from the findings (table 5).

The intervention impacted positively on professionals' daily work as it was attracting professionals' attention to the caregivers' needs. "We did not have sufficient knowledge to provide a holistic caregiver support" [Case manager 2, acute phase]. During regular meetings with the counsellor and the project team the counsellor was also acting as a system coach, and therefore, professionals expanded their overview of suitable support offers within the geographic region and learned about other suitable instruments, e.g. good practice proxy of the communal services.

Most professionals mentioned that they profited from the supported caregivers and experienced temporally less time pressure during their interaction with the caregiver. "As the psychosocial support and coordination was done by the caregivers' Guide, I could concentrate on my duty" [Nurse, home care services, home care phase]. However, the professionals in the acute care (case manager or social workers) invested time on client recruitment. "We had to invest $15 \mathrm{minu}$ tes per week for preparing the recruitment list, and 20 minutes for the handover to the Caregivers' Guide. This was sometimes a problem in our strictly scheduled working day" [Case manager 1, acute phase]. These professionals did not receive a direct profit on their investment, but felt nevertheless that the intervention was important for the caregivers.

Are the needs of the individual caregivers sufficiently addressed in the current economized and patient-centered stroke rehabilitation system? This intervention was welcomed by all professionals as "filling an important gap" (social services, acute clinic). "We do not provide a caregiver counselling offer in our clinic. However, caregivers need clear and precise information to get not lost or overburdened by the situation and someone who takes time for them from the start, and this is what the intervention did" [Psychologist, rehabilitation phase]. The necessary resources, e.g. time and staff, for long-term support were provided by the intervention, which resulted in enhancing the support within the institutions (table 5). "Many caregivers fear the situation when a patient is 


\section{Table 5: Impact of the Caregivers' Guide intervention on system level, a qualitative study among 11 professionals working as service providers in the stroke support system}

\begin{tabular}{|c|c|c|c|}
\hline \multicolumn{4}{|l|}{ IMPACT ON SYSTEM LEVEL } \\
\hline Example quote & Subtheme & Theme & Outcome \\
\hline $\begin{array}{l}\text { "The Caregivers' Guide coordinated and monitored all families } \\
\text { for a long time. She knew the system very well and helped us } \\
\text { orient ourselves in the dynamically changing system." [Case } \\
\text { Manager 2, acute phase] }\end{array}$ & $\begin{array}{l}\text { Professionals' } \\
\text { development }\end{array}$ & \multirow[t]{2}{*}{$\begin{array}{l}\text { Professionals' } \\
\text { daily work }\end{array}$} & \multirow[t]{13}{*}{$\begin{array}{l}\text { Support } \\
\text { system } \\
\text { optimization }\end{array}$} \\
\hline $\begin{array}{l}\text { "Due to the early, professional and structured information } \\
\text { provided by the Caregivers' Guide, I felt less time pressure } \\
\text { when receiving a new case." [Case manager, rehabilitation } \\
\text { phase] }\end{array}$ & Resource allocation & & \\
\hline $\begin{array}{l}\text { "A psychosocial support focal point was missing since we were } \\
\text { not trained for it, and the social services offered it only in } \\
\text { urgent cases. Therefore, this intervention was a strong } \\
\text { complement to our daily routine." [Case manager 2, acute } \\
\text { phase] }\end{array}$ & $\begin{array}{l}\text { Filling the gap } \\
\text { (offering caregiver- } \\
\text { centred support) }\end{array}$ & \multirow[t]{3}{*}{$\begin{array}{l}\text { Institutional } \\
\text { support }\end{array}$} & \\
\hline $\begin{array}{l}\text { "It was so helpful to have a focal person who knows the family } \\
\text { since the beginning. I was much better prepared when I took } \\
\text { over a new case." [Medical health equipment provider, home } \\
\text { care phase] }\end{array}$ & $\begin{array}{l}\text { Providing resources } \\
\text { (time, staff) }\end{array}$ & & \\
\hline $\begin{array}{l}\text { "The professional, flexible, structured and needs-oriented } \\
\text { guidance was very much appreciated." [Neurosurgical head of } \\
\text { department, acute phase] }\end{array}$ & $\begin{array}{l}\text { Comprehensive } \\
\text { orientation and } \\
\text { information provision }\end{array}$ & & \\
\hline $\begin{array}{l}\text { "The caregivers were prepared mentally and infrastructural for } \\
\text { home caregiving. The transferal did not interfere with the } \\
\text { success of the rehabilitation." [Nurse, home care services, } \\
\text { home care phase] }\end{array}$ & $\begin{array}{l}\text { Safeguarding the } \\
\text { rehabilitation } \\
\text { outcome }\end{array}$ & \multirow[t]{4}{*}{$\begin{array}{l}\text { Quality of } \\
\text { patient care }\end{array}$} & \\
\hline $\begin{array}{l}\text { "I believe that the re-hospitalizion rate was lower as the clients } \\
\text { could approach the Caregivers Guide with their questions after } \\
\text { the acute phase." [Case manager 1, acute phase] }\end{array}$ & $\begin{array}{l}\text { Reduction of re- } \\
\text { hospitalisation rate }\end{array}$ & & \\
\hline $\begin{array}{l}\text { "The transferal process was much different. We perceived a } \\
\text { better information flow about the rehabilitation process. } \\
\text { Consequently, patient security improved and we felt earlier and } \\
\text { increasingly involved." [Nurse, home care phase] }\end{array}$ & $\begin{array}{l}\text { "personalized " } \\
\text { transferal }\end{array}$ & & \\
\hline $\begin{array}{l}\text { "Caregivers were prepared for the next rehabilitation steps and } \\
\text { the programme reduced the transferal bottlenecks, which } \\
\text { resulted in an increased system confidence of both caregivers } \\
\text { and patients." [Case manager, rehabilitation phase] }\end{array}$ & System reliance & & \\
\hline $\begin{array}{l}\text { "We were always in contact with each other which made us } \\
\text { feel as companions. Our communication was characterized by } \\
\text { high level of trust and transparency. [Social worker, home } \\
\text { adaption counselling services, communal social services] }\end{array}$ & $\begin{array}{l}\text { Improved } \\
\text { communication } \\
\text { (quality and flow) }\end{array}$ & \multirow[t]{4}{*}{$\begin{array}{l}\text { Inter- } \\
\text { institutional } \\
\text { cooperation }\end{array}$} & \\
\hline $\begin{array}{l}\text { "Through the targeted approach of stakeholders within the } \\
\text { network, we professionals got engaged with some cases when } \\
\text { needed. This network was very supportive for my daily } \\
\text { business." [Social worker, home adaption counselling services, } \\
\text { communal social services] } \\
\text { "In many cases you can't solve the problem alone. So we } \\
\text { worked in a team with a common goal of finding the best } \\
\text { solutions for both patient and caregiver." [Case Manager, } \\
\text { Rehabilitation phase] }\end{array}$ & $\begin{array}{l}\text { Team \& network } \\
\text { building }\end{array}$ & & \\
\hline $\begin{array}{l}\text { "In complex cases during social and legal problematic } \\
\text { circumstances, the Caregivers' Guide initiated the interaction } \\
\text { between the different actors, which was very effective." } \\
\text { [Nurse, care support, communal social services] }\end{array}$ & $\begin{array}{l}\text { Support in the } \\
\text { transferal of complex } \\
\text { cases }\end{array}$ & & \\
\hline $\begin{array}{l}\text { "Without the Caregivers' Guide, many caregivers would have } \\
\text { come much later to our services if any. We had the chance to } \\
\text { help them early enough." [Nurse, care support, communal } \\
\text { social services] }\end{array}$ & $\begin{array}{l}\text { Increased use of } \\
\text { service offers }\end{array}$ & & \\
\hline
\end{tabular}


transferred from the rehabilitation phase to the home environment, which may result in a rapid change of the situation to the worse. Therefore the continuous support by the focal person until transferal to home was helpful for our work." [Nurse, Home care phase]. During hospitalization the Caregivers' Guide invested in communication between all actors and providing feedback, which safeguarded the communication between the caregivers and the staff.

Professionals perceived an impact on the quality of patient care. A constant information flow and good communication provided by the counselor helped to prevent a loss of information or false information and helped to safeguard the rehabilitation outcome, e.g. having the appropriate medical equipment at home. Investing in caregivers' knowledge and psychosocial health resulted also in a perceived decrease of avoidable acute re-hospitalization. The "personalized" transferals and the trust of the patient-caregiver dyad in the support system were perceived as positively impacting.

The intervention was a main driver to build up and maintain an inter-organizational professional network within the region at this time, which reduced bottlenecks during transferal. An interprofessional team building process started, where feedback loops provided a stimulating and positive working atmosphere. "Our communication was characterized by high level of trust and transparency."

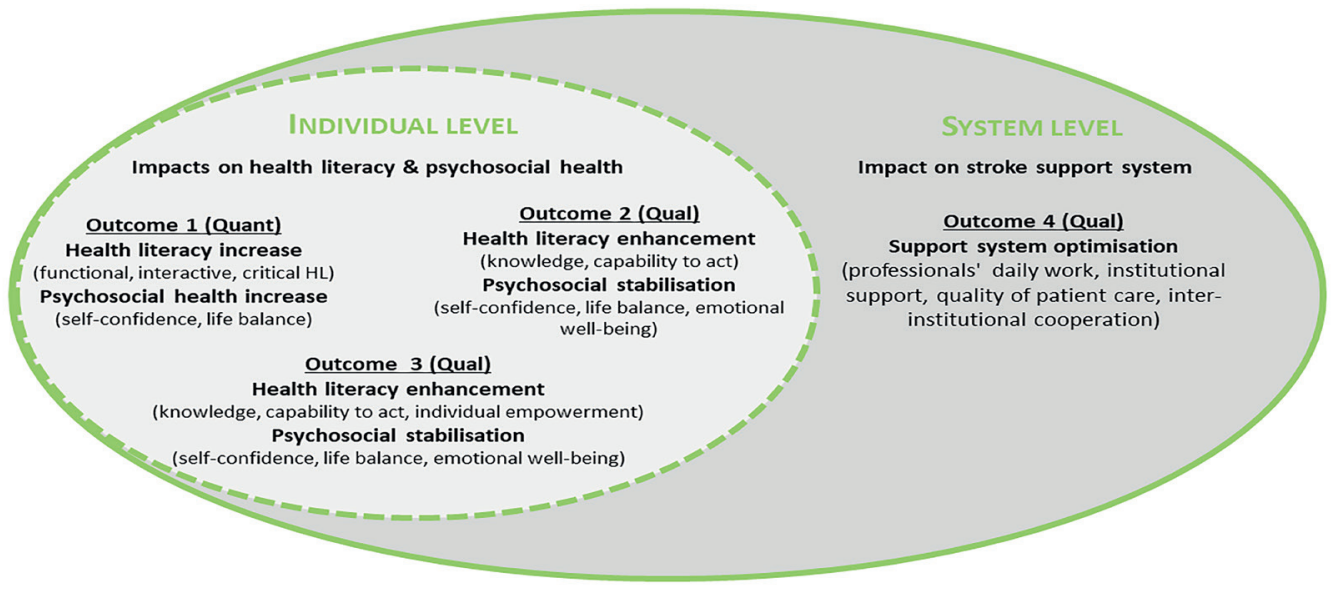

Figure 5: The Caregivers' Guide impacts and outcomes on individual and system level 
[Social worker, home adaption counselling services, communal social services] The new network improved the flow and quality of the communications, which was especially useful in the transferal of complex cases. "Many administrative issues were solved by using shortcuts within the system, which was beneficial for all" [Medical health equipment provider, home care phase]. The inter-institutional cooperation also resulted in triggering caregivers appropriate support system use within the region.

The findings from both studies resulted in a comprehensive picture of the impact on individual and system levels. We demonstrated that both caregivers and professionals within the system benefited from the intervention programme. The neurosurgeon head of department (acute phase) summarized: "The structured, practical, flexible and professional guidance of the caregivers as supplement offer to the current support system was a big advantage for us and the caregivers."

\section{Discussion}

\section{Concluding the results}

The Caregivers' Guide impact was evaluated on both individual and system levels. Stroke caregivers, being the programmes' end-users, and professionals, being the service providers within the stroke rehabilitation trajectory, participated. Our evaluation included two studies and each study contributed with new knowledge based on their different perspectives and designs (figure 3). The evaluation resulted in four outcomes (figure 5), three of which demonstrate the positive impact on caregivers' $\mathrm{HL}$ and $\mathrm{PH}$ on an individual level, whereas the fourth outcome shows that the input of the Caregivers' Guide initiated changes in the system that were perceived as positive. This evaluation provided a comprehensive understanding of the complex stroke caregiver intervention's impact.

The results from the quantitative part of the caregiver study showed a significant increase of caregivers' $\mathrm{HL}$ (functional, interactive, and critical HL) and an increase on $\mathrm{PH}$, with focus on self-confidence and life balance (table 2). These findings were the starting point of exploring the perceived changes in HL and $\mathrm{PH}$ deeper. 
The impact on HL and PH on an individual level was explored in-depth in the qualitative part of caregivers' study, which resulted in gaining a deeper understanding of the actual perceived changes from the end-user's perspective (table 3). First, an enhancement on HL was observed, as caregivers perceived a knowledge gain regarding stroke and its consequences, the rehabilitation process and the current support system. Moreover they noticed improvements on their capability to act, such as proactive process involvement, collaboration with the support system, search for further support, and early role preparation. Second, a stabilisation of $\mathrm{PH}$ was observed. Caregivers perceived that their self-confidence was strengthened by: recapturing their everyday life control, anxiety reduction and accessibility of support. Additionally, having new social contacts and being aware of the risk of overburdening due to caregiving helped to stabilize their lives. 'Emotional well-being' appeared as a new subtheme and was considered crucial for their $\mathrm{PH}$ stabilisation. Providing psychosocial support resulted in caregivers' emotional re-stabilisation, future life orientation, grieving process and conflict resolution.

The impact on $\mathrm{HL}$ and $\mathrm{PH}$ on an individual level was also explored in the professionals' study (figure 4). This resulted in a deeper understanding of the perceived changes from the service providers ' perspective (table 4). Enhancements in caregivers' HL and stabilisation of $\mathrm{PH}$ was also observed by the professionals. Interestingly they perceived an individual empowerment of the supported caregivers, which corresponds to findings of the quantitative part of study 1 of an increase in critical HL.

The impact on the system level was explored by the professionals, being part of that system. They concluded that investing in communication and network building activities helped in optimizing the current stroke support system (table 5). Professionals perceived a positive change in their daily work, within their own institution, the quality of patient care, and in the inter-institutional cooperation.

\section{Impact on an individual level}

On an individual level caregivers` HL was improved and PH was stabilized.

We assume that enhancements in HL helped caregivers to better and earlier prepare for their new role. Receiving validated personalized information was perceived by both caregivers and professionals as fundamental for enhancing their stroke related HL. In our opinion HL is crucial for caregivers' empowerment 
as these knowledge and skills are required to meet the health-related goals of both patient and caregiver (Institute for Medicine, 2004). First of all, caregivers need a tailored timing of information acquisition as well as an adaption of the information to their specific situation (Ghazzawi et al., 2016). Second, caregivers must develop new skills, e.g. practical skills, problem-solving, in order to interpret and analyse health information, navigate the health care system, and actively participate in encounters with the support system (Institute for Medicine, 2004). Finally, caregivers should develop critical HL skills, e.g. stress-coping skills, to cope with the new life and its unpredictable challenges.

Carlson et al. (2012) reported that especially new caregivers lack information, knowledge and skills needed to cope with the physical, cognitive and social aspects of caregiving. Moreover, insufficient HL may result in role adaption problems, caregiver stress and strain (Yuen et al., 2018). Family caregivers have a key role in exchanging health information and are requested to participate in health decision-making (Adelman et al., 2014). Therefore, investing in caregivers' HL will help them when communicating with service providers, co-ordinating support services, participating in health-decision and problem solving (Yuen et al., 2018). When searching for instruments assessing the impact of 'personalized information provision', we were attracted by the work of Freebody and Luke (1990), who described HL as a development process with three levels: functional, interactive and critical.

In study 1, our statistical results show that caregivers' HL was improved on all levels, whereas the qualitative data suggest that only their knowledge and ability to act were enhanced. Moreover, the qualitative results of study 2 indicate that the professionals' perceived further enhancements on individual empowerment, which corresponds to the last level. This might be attributed to the following reasons: (1) as caregivers' reflect only on their own case and therefore find it difficult to perceive an individual empowerment, (2) we should have reflected more on this issue in early interviews, or (3) the interviews were conducted approximately 4 weeks after the individual intervention was completed, and this might have been too early for the caregivers to perceive an individual empowerment.

Despite the fact that 'information provision" is almost an "obligatory ingredient" in all stroke intervention programmes, studies and instruments, assessing caregivers' HL pre- and - post intervention were not found. Only two studies examined the impact of inadequate caregiver's HL on the adult cancer care recipient (Bevan \& Pecchioni, 2008, Sparks \& Nussbaum, 2008). Moreover, two studies reported HL post-intervention: the first concluded no HL improve- 
ments in caregivers who attended a diabetes class (Gibson, 2013), and the second stated that caregivers participating in an online hip fracture intervention showed significant improvements in knowledge and eHealth literacy (Nahm et al., 2012).

Our findings show that providing psychosocial support improved and stabilized caregivers' PH. From the start caregivers experience high emotional stress levels (Grant et al., 2014). Therefore, our intervention offered psychological first aid (PFA), which entails a humane, supportive response to a fellow human being who is suffering and who may need support (WH0, 2011). This element was perceived by both caregivers and professionals as a key element when starting the counselling process. PFA was provided by a professional clinical social worker (counselor), which was seen as obligatory by all participants. Moreover, we were able to regain caregivers' self-confidence by emphasizing the accessibility of the available services, also advocated by $\mathrm{Ng}$ (2009). Counselling also assisted in developing stress-coping and problem-solving strategies, which is acknowledged as important for caregivers' well-being (Cheng et al., 2014).

\section{Impact on a system level}

We focused on improving inter-institutional cooperation by investing in network building and communication between professionals (figure 1). To support caregivers, Cameron et al. (2008) promote interdisciplinary coordination within an organisation. The German stroke units operate interdisciplinary (Hillmann et al., 2017). However, they do not apply a system thinking approach as caregivers lack to be systematically included in processes (WH0, 2009). Caregivers are not perceived as an integral part of the support system and consequently they feel "left in the lurch" and abandoned due to the lack of knowledge and skills (Pindus et al. 2018).

We perceived the stroke rehabilitation process with a holistic approach, also recently advocated by Chen et al. (2015). Therefore, we were intervening not only on an individual caregiver level, but also on a system level in the current stroke support system (figure 2) by invested in communication and network-building since the beginning (Krieger et al., 2016; Krieger et al., 2018). As the intervention progressed, professionals involved in the service provision started to perceive caregivers as part of the rehabilitation team, which was acknowledged as a first step of the system optimization. The intervention supported the affiliated institutions and organisations by providing the necessary resources for comprehensive caregiver support. Network-building activities initiated or enhanced interinstitutional cooperation, and communication strategies helped to 
safeguard the quality of patients' care in the home care phase (figure 2). Due to these circumstances, our additional support offer was welcomed by professionals in all phases of the trajectory.

Professionals did not feel sufficiently trained for providing caregiver counselling. Our findings agree with those of $\mathrm{Ng}$ (2009) that professionals could reduce caregivers' barriers of service use by improving their own system knowledge and using their network for navigation, which in our case helped in facilitating the professionals' daily work.

The Caregivers' Guide counsellor started her support by exploring caregivers' individual needs, which was helpful for both caregiver, e.g. meeting caregivers' expectations, and professionals, e.g. guarantee early service utilization. Coordinated discharge planning and case management with focus on the needs of both patient and caregivers is important (Cameron et al., 2008). However, in Germany, caregivers' needs are hardly assessed during the patients' rehabilitation trajectory. Many caregivers experience organisational issues, e.g. identifying and assessing services (Wetzstein et al., 2015). In our setting, case management and social services focus on transferal and discharge under economic aspects. Ghazzawi et al. (2016) suggested providing an electronic system navigator, e.g. as mobile application or assigning a case manager to improve communication and coordination between the different actors. We agree with Lutz et al. (2010) that the conduction of comprehensive caregiver assessment should be started early by exploring caregivers' needs, skills and resources to be of benefit for both caregivers and the support system. Moreover, stroke rehabilitation guidelines should also address caregiver needs on a long-term, (Grant et al., 2014).

Especially the professionals in the home care phase observed that the quality and continuity of care in the home environment optimized due to "personalized" transferals, e.g. getting detailed information of the caregivers' needs. Pindus et al. (2018) stated that the limited access to support, the lack of information and communication may lead to a discontinuity of care for the survivor. We believe that through the caregivers' enhanced HL and stabilized PH and openness from the professional supported system for caregivers' needs facilitated patients' return home.

\section{Reflections on the intervention}

We offered long-term support to stroke caregivers, as recommended by Murray et al., 2003; Visser-Meily et al.; 2005; Grant et al., 2014), which was compulsory in order to achieve an impact on individual and system level.

On individual level our aim was to improve caregivers HL and stabilize their psychosocial health. Therefore, a combination 'personalized information pro- 
vision' and 'psychosocial support' was offered, which is perceived as most promising (Wilz et al., 2007; Lutz \& Young, 2010). Our outcomes show that this combination improved caregivers' HL and improved or stabilized PH. Bakas et al. (2014) showed that combining 'skill-building' with 'psycho-educational' strategies results in positive caregiver outcomes. Both elements were included in our intervention, resulting in a multicomponent intervention, as advocated by Visser-Meily and colleagues' (2005). However, we contemplate that our intervention not only showed a positive impact on individual and system level due to the delivery of the appropriate 'content', but also to the 'who' (human resources), 'when' (timing), 'how' (personalized approach) and the 'where' (setting) CBBs (Krieger et al., 2016).

The Caregivers' Guide was offered as an addition to the current system, which was perceived as very helpful by both end-users and service providers. However, on a long term achieving sustainability might be difficult with an "addition". We were able to offer an "exit strategy" for caregivers after the counselling process was finished. Our caregivers could join a peer group which was initiated by the programme. This opportunity was perceived as important for maintaining their $\mathrm{PH}$.

In order to successfully implement the intervention on the system level, the facilitating CBBs 'communication' and 'network building' were crucial (Krieger et al., 2018). Our findings indicate that these CBBs together with the core CBBs lead to a comprehensive intervention which supported both caregivers and professionals needs.

\section{Methodological considerations}

In this evaluation we aimed to gain a comprehensive understanding of the Caregivers' Guide impact on both individual and system levels, which is a non-pharmacological complex intervention in the field of public health. Therefore, a multi-methodological design with two interconnected studies was applied (Cresswell, 2004; Morse, 2010). We were consistent in searching for heterogenity, and therefore included the programmes end-users (the caregivers) and the service providers (professionals working in the system) in our evaluation. In the caregivers' study we used a pre-post design for the quantitative part and a post-intervention design for the qualitative part; and in the qualitative professionals`study an ex-post design was applied (Leiber et al., 2015).

We used mixed methods data collection methods: quantitative data were col- 
lected with questionnaires and qualitative data were gathered via interviews, which is required for complex interventions (Campbell et al., 2000) and triangulated our findings (Springett \& Wallerstein, 2008). The methodological pluralism (Morse, 2010) and combining a deductive-inductive approach (Graneheim et al., 2017) during data analyses enabled us to explore the impact of the complex intervention in-depth. The quantitative part of study 1 was the starting point for further exploring the impact on individual and societal levels. Qualitative data were analysed top-down using a qualitative content analysing approach (Hseih \& Shannon, 2005; Graneheim et al., 2017), which helped clarify on the detailed outcomes and impacts on both levels in detail.

On the individual level we were aiming to assess changes on caregivers ' $\mathrm{HL}$ and $\mathrm{PH}$. As no instrument was available, we used a self-made questionnaire, what may be seen as a limitation. However, it was tailored to the context, piloted and validated through pre- and post-application. We agree with Nutbeam (2008), proposing that a comprehensive measurement for assessing HL on different levels is needed. Comprehensive instruments, suitable for assessing HL in general populations, are available, e.g. Health Literacy Questionnaire (0sborne et al., 2013), European Literacy Questionnaire (Soersen et al., 2013). Yuen et al. (2014) developed a HL of Caregiver Scale Cancer, however it was not applicable for other caregiver groups. Moreover, Yuen et al. (2018) specified that the current instruments do not capture the challenges within the current health care system, e.g. lack of adequate communication. To our knowledge, a tool for assessing family caregiver's HL does not exist and we agree that there is a need to develop adequate measures for caregiver HL, as proposed by Yuen et al. (2018). Therefore, our current questionnaire could be perceived as a starting point for assessing stroke caregivers' HL. We believe that assessing caregivers' HL pre-/post intervention may help to stimulate improvements in practice, e.g. perceiving caregivers as part of the system, recently advocated by Batterham et al. (2016).

In order to allow a comparison with other stroke caregiver intervention studies, it might have been useful to include one of the frequently used instrument, e.g. Caregiver Burden Scale (Zarit, 1980), Caregiver Strain Index (Robinson 1983), Caregiver Reaction Scale (Qualls \& Kenny, 2008), Caregiver Self-Assessment Questionnaire (Epstein-Lubow et al., 2010). As coping skills are required for achieving critical HL, the revised Scale of Caregiving Self-efficacy (Steffen et al., 2002) or the Utrecht Coping List (van den Heuvel et al., 2002) might have been worthwhile. 


\section{Strengths and limitations}

To our knowledge, this is the first evaluation of a caregiver support programme exploring the impact of a stroke caregiver intervention on both individual and system levels. However, the generalisation of the findings may be restricted due to: the nature of the qualitative research in studies 1 and 2, the participant recruitment using convenience sampling, and the relatively small sample size in the quantitative part. Moreover, as complex interventions are strongly context dependent, and even within Germany, the stroke trajectory differs partly from state to state, replication may be challenging.

An important prerequisite for enabling a comprehensive evaluation is the continuous stakeholder engagement during development and implementation, which should be supported by funders and policy makers.

Our intervention was funded by the BMBF with an internal evaluation, which had some advantages, e.g. internal system knowledge, time saving; and some disadvantages, e.g. limited objectivity due to personal involvement.

Applying a multi-methodological approach and involving both groups: the programmes' end-users (caregivers) and the stroke service providers (professionals in the support system) was important in order to answer out research question in detail.

It was innovative to assess the impact of providing 'personalized information' on caregivers' HL with quantitative and qualitative measurements.

Psychosocial support was provided in order to stabilize $\mathrm{PH}$. In the questionnaire only 'life balance' and 'self-confidence' was assessed, however 'emotional well-being' was not considered.

Finally, the timing of the post-intervention interview might have been too early, as individual empowerment was not perceived by the caregivers.

\section{Conclusion}

As complex interventions may have an impact on different levels, a comprehensive evaluation is required. This paper provides a unique and comprehensive view of the interventions 'impact on individual and system levels, which includes the perceptions of both programmes' end-users and the service providers. Hereby, the qualitative studies added significantly to our understanding of caregiver and professionals experience with the new programme.

On the individual level, by providing personalized information (mean of 6 ses- 
sions during 7 months), caregivers' stated that the intervention significantly increased their functional, interactive, and critical HL and enhanced their knowledge and capability to act. Additionally, professionals perceived enhancements in caregivers ' individual empowerment. Moreover, providing psychosocial support was perceived by both caregivers and professionals as stabilizing the caregivers' $\mathrm{PH}$ by recovering self-confidence, strengthening its life balance and enhancing their emotional well-being.

On the system level, by investing in communication and network-building, professionals observed that the intervention optimized the current stroke support system. It had an influence on the professionals' daily work, institutional support, quality of patient care and inter-institutional cooperation.

Including both end-users and professionals and applying a multi-methodological approach helped to gain a comprehensive understanding of our interventions'impact.

Further research evaluating a caregiver interventions' impact on both individual and system levels, is required to allow comparisons of results from different settings and provide suggestion for improvements. 


\section{ANNEX 1: Pre- and Postintervention questionnaire of the Caregivers' Guide (Adapted English version)}

\begin{tabular}{|c|c|c|}
\hline Indicator & Index & Questions (specific variables) \\
\hline \multirow{11}{*}{$\begin{array}{c}\text { Health } \\
\text { Literacy } \\
\text { (functional, } \\
\text { interactive, } \\
\text { critical) }\end{array}$} & \multirow{3}{*}{$\begin{array}{c}\text { Functional } \\
\text { HL } \\
\text { (3 variables) }\end{array}$} & Regarding the stroke disease of my relative, I feel well informed. \\
\hline & & $\begin{array}{l}\text { I know what happens during my relative's treatment or rehabilitation and how } \\
\text { I can support the recovery process after stroke. }\end{array}$ \\
\hline & & I know who to contact if I need help. \\
\hline & \multirow{3}{*}{$\begin{array}{c}\text { Interactive } \\
\text { HL } \\
\text { (3 variables ) }\end{array}$} & Lately, I feel like I'm powerless and helpless. \\
\hline & & In the face of post-stroke problems, I feel totally overwhelmed. \\
\hline & & $\begin{array}{l}\text { I am confident that I am well prepared to meet the challenges related to my } \\
\text { relative's care and support after stroke. }\end{array}$ \\
\hline & \multirow[t]{5}{*}{$\begin{array}{l}\text { Critical HL } \\
\text { (5 variables) }\end{array}$} & $\begin{array}{l}\text { To better cope with the situation after the stroke, I ask other people for } \\
\text { advice and help. }\end{array}$ \\
\hline & & I thought in detail about what I can do to improve the situation. \\
\hline & & I did something to relieve or distract myself. \\
\hline & & I also try to find something good in what has happened lately. \\
\hline & & I try to find hold in my faith. \\
\hline \multirow{10}{*}{$\begin{array}{c}\text { Psycho- } \\
\text { social } \\
\text { Health }\end{array}$} & \multirow{4}{*}{$\begin{array}{l}\text { Life balance } \\
\text { (4 variables) }\end{array}$} & My own needs are currently missed out. \\
\hline & & Currently, I have too few opportunities for rest and relaxation. \\
\hline & & $\begin{array}{l}\text { At the moment I have barely time for social contacts and activities (friends, } \\
\text { colleagues etc.) }\end{array}$ \\
\hline & & $\begin{array}{l}\text { Despite all the problems caused by the stroke, I also experience positive } \\
\text { feelings in everyday life (for example joy, contentment, gratitude). }\end{array}$ \\
\hline & \multirow{6}{*}{$\begin{array}{c}\text { Self- } \\
\text { confidence } \\
(6 \text { variables })\end{array}$} & When I think about the future right now, I'm afraid of the worst. \\
\hline & & $\begin{array}{l}\text { I'm very worried that my loved one might need continuous help and care } \\
\text { after the stroke. }\end{array}$ \\
\hline & & At present, I often ponder, and my thoughts turn in circles. \\
\hline & & $\begin{array}{l}\text { I also feel my fears and worries physically (e.g. shaking, palpitations, } \\
\text { abdominal pain). }\end{array}$ \\
\hline & & $\begin{array}{l}\text { I am afraid that due to the health situation of my relative we will face financial } \\
\text { bottlenecks. }\end{array}$ \\
\hline & & I fear that my relative will change its personality a lot because of the stroke. \\
\hline
\end{tabular}

ANNEX 2: Topic list semi-structured interviews with stroke family caregivers

Warming up Can you briefly describe the situation after the stroke happened for you? (feelings, thoughts, questions)

Reflecting What changed when the Caregivers' Guide was approaching you for the first on the time?

intervention What did the Caregivers' Guide offered you in the counselling, and what exactly was helpful for you? (information, psychosocial support, emotional strengthening, security, orientation)

How would you describe the work of the Caregivers' Guide?

When did you require the most support from the Caregivers' Guide? Why?

Closing down What could be improved in the future? (Scope, sustainability)

Would you recommend the Caregivers' Guide?

ANNEX 3: Topic list semi-structured interviews with professional stakeholders

$1 \quad$ How did you experience the work of the Caregivers' Guide in your practice?

(critical reflection concerning the interventions' conceptual building blocks: content, human resources, timing, approach, setting, communication, networking, social safety-net)

$2 \quad$ What effects did the Caregivers' Guide intervention have in your daily work?

(own profession, department, support system, stroke survivor)

3 What effects did you perceive on family caregivers when these were supported by the intervention?

4 Are there any suggestions for improving the current intervention? 
Chapter 5 
The stepwise development of a comprehensive family caregiver support programme. 


\section{CHAPTER 6 \\ Contextual exploration of a new family caregiver support concept for geriatric settings using a Participatory Health Research strategy}

Dorant E, Krieger T (2017) Contextual exploration of a new family caregiver support concept for geriatric settings using a Participatory

Health Research strategy. International Journal of Environmental Research and Public Health, 14:1467; doi:10.3390/ijerph14121467. 


\section{Abstract}

Background. Family caregivers are the backbone of the long-term care support system within the home environment. Caregiver support programs require collaboration and coordination within the system. A new public health concept, Vade Mecum, aims to harmonize and professionalize family caregiver support initiatives in geriatric care settings in the Euregion Maas-Rhine. Exploration of the new concept was recently started in Germany to gain in-depth insight into current supports and needs of the geriatric care team and family caregivers.

Methods. Within the context of an exploratory qualitative study a Participatory Health Research (PHR) strategy was applied to make optimal use of experiences and knowledge from the system. Care professionals, engaged as co-researchers, were responsible for decisions about the research question, data collection methods and procedures of engaging family caregivers.

Results. A research team representing all professions within the geriatric department was formed. Research objectives were formulated and an appropriate mix of qualitative data collection methods consisting of interviews, focus groups and story-telling, was chosen. Needs and expectations towards the new concept, and practical solutions for involving family caregivers, were discussed.

Conclusion. PHR strategy resulted in the start of a qualitative study in a geriatric care setting carried out by care professionals. Knowledge was generated in a co-creative manner, and co-researchers were empowered. Comprehensive understanding of the system serves as starting point for advancement of the new family caregiver concept.

\section{Introduction}

A vast majority of Europeans prefer to be cared for at their own home or the home of their family when in need for long-term care (European Comission, 2007). Family caregivers are the backbone of the long-term care support system. Family or informal caregiving is a 'free of charge' service, provided by a relative, partner, friend or neighbor to a person with a chronic disability (Family caregiver Alliance, 2006).

Recent figures show that in Germany $69 \%$ of all people requiring long-term care are cared for at home, with over $90 \%$ receiving care from family members. More 
than 70 percent of home care is provided by family members alone, without assistance of care professionals (Statistisches Bundesamt, 2015). Especially elderly people rely on their family for day-to-day care or support. In Belgium almost $10 \%$ of persons aged 15 or over provide informal care, with the most intensive informal care (more than 4 hours per day) concentrated in older age groups (65+) most of who care for their spouse (Willemé, 2010). In The Netherlands more than 50 percent of all adults over 75 years of age living in the community receive care and support, $22 \%$ receive care only from a family caregiver (Putman et al., 2014).

Although caregiving can have positive consequences as well, there is ample evidence that family caregiving has a negative impact on the physical, mental and social well-being of the caregiver (Adelman et al., 2014; Broese et al., 2013; Garlo et al., 2010; Kummer et al., 2010). The scale of these consequences is related to both the patient's condition and the amount of time needed for their care, as well as to their own needs. Caregiver's characteristics, like their own age, health, being employed, and presence of resources, influence the impact of caregiving (Adelman et al., 2014; Broese et al., 2013; Pinquart \& Sörensen, 2007). Caregivers can feel overburdened for different reasons, f.i. to be on " 24 hours on call" or to have to manage the bureaucratic work that is involved to get the care organized and running (Adelman et al., 2014; Kunz \& Wilz, 2011). When family caregivers are not involved by care professionals as partner in the patient care trajectory they may not have sufficient knowledge about practical aspects of the care that has to be provided (Adelman et al., 2014). They may also experience that formal health care providers give little structured guidance to them and their prospective role as caregiver (Burcher et al., 2001; Scherbring, 2002; Schumacher et al., 2000), or that professional caregivers have not enough understanding regarding the next of kin 's worries and stresses towards caregiving (Liedström et al., 2014).

Caregivers of older adults experience burdens different from those of other caregiver populations Ringer et al., 2017). Problem behavior of elderly care recipients may be the underlying source of increased burden (Broese et al., 2013). Also, the high prevalence of multimorbidity among elderly persons may influence the complexity of the role of caregivers in the home environment (Giovannetti et al., 2012), and thus increase the support needs for their family caregivers (Meranius et al., 2017).

Family caregiving for elderly persons at home may be especially demanding in situations when the family member who is taking up the role as caregiver has no experience, or when there is a sudden demand. They may feel unprepared for 
their role (Adelman et al., 2014; Lutz et al. 2011). In these situations the caregiver, at the same time, has to be prepared for the practical aspects of their caregiving task and to deal with the unexpected emotional strains resulting from the care receiver's condition. Family caregivers need personalized information, psychological support, effective communication and financial and legal support (Silva et al., 2013; Corry et al., 2015). Timing of support and the way of approaching caregivers is crucial (Cameron \& Gigniac, 2008). Long-term support and outreach counselling may be needed (Wetzstein et al., 2015). Remarkably however, the overall effect of current tailored caregiver support programs for elderly living in the community seems to be small, as was concluded in a recent systematic literature review. This disappointing outcome was attributed to inconsistencies between the included studies, but the main recommendation was that support for family caregivers of the elderly requires intense collaboration and coordination between all stakeholders (Lopez-Hartmann et al., 2012).

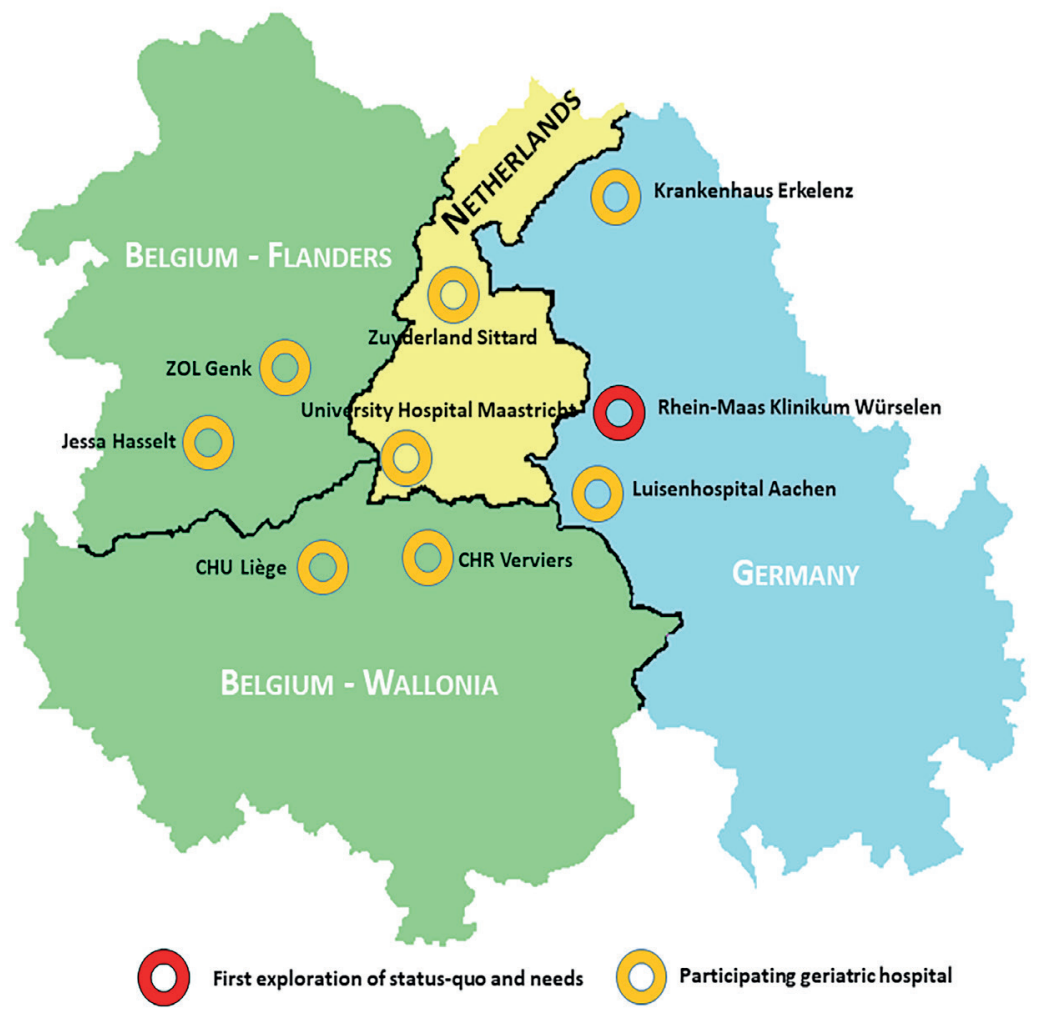

Figure 1. Cross-border orientation of Vade Mecum: hospitals in three countries in the Euregion Maas-Rhine joining the project 
In this article we describe an initial step in the advancement of a new and innovative family caregiver support concept for elderly persons called Vade $\mathrm{Me}-$ cum. Vade Mecum is a complex public health intervention specially designed to harmonize and professionalize current caregiver support initiatives in geriatric care situations, with special attention for cross-border continuity of support. Vade Mecum is situated in the Euregion Maas-Rhine (EMR), an area where three countries (Germany, Belgium, and Netherlands) are closely connected and health services operate cross-border. This specific geographical configuration is adding to the complexity of family caregiver support in case of cross-border hospitalisation or rehabilitation of the care receiver. Nine hospitals with geriatric departments spread over the EMR participate in the project (figure 1).

The Vade Mecum concept builds on prior knowledge and experiences from a recent innovation project, The Caregivers' Guide, a professional stroke caregiver support program executed from 2012-2015 in Aachen, Germany (Jungbauer et al., 2016). The Caregivers' Guide concept consists of eight conceptual building blocks: five core building blocks encompassing an individualized caregiver counselling programme and three facilitating building blocks safeguarding and interconnecting the program with the practical, real-world, system. One specially trained counsellor guides the family caregiver through the entire stroke trajectory of the care receiver and provides tailored family caregiver support from as early as possible after stroke to as long as needed in the home environment. The concept of the Caregivers' Guide was aligned with the real-world system before implementation using participative action research. The programme's stakeholders played a crucial role in this process (Krieger et al., under review Krieger et al. under review).

The new Vade Mecum concept is based on the Caregiver's Guide concept: care professionals, employed in one of the hospitals joining the project, will receive special training to become a specialized 'Geriatric Family Companion', a new job profile. As a group they will form a cross-border network of support experts, offering personalized counselling, information provision, empowerment and resource allocation to first-time informal caregiver - geriatric patient dyads. Family caregiver support will start already in the hospital, as early as possible after hospitalization of the care receiver, and will last until at least a secure situation in the home environment is reached. The ultimate objective of Vade Mecum is to sustain health and wellbeing, and prevent social exclusion and health inequality of geriatric patient-caregiver dyads. The focus of the primary prevention support program is put on the family caregiver. 
Early engagement of the system in which Vade Mecum will be operating, is paramount to achieve the goals of this new complex public health intervention. The Meikirch model of Health will serve as framework to keep focus on the interconnectedness in the system (Bricher \& Kuruvilla, 2014). The management of the entire project as well as all research associated with it, is guided by tools from project management and a design thinking approach (Project Management Institute - PMI -, 2013; Gruber et al., 2015). The project is divided in 5 consecutive steps: 1) $360^{\circ}$ exploration, 2) concept and curricullum development, 3) training of Geriatric Family Companions, 4) implementation and supervision, and 5) evaluation.

For the first $360^{\circ}$ exploration the Participatory Health Research (PHR) paradigm was considered as most appropriate, since it involves exploration of local knowledge and perceptions from key stakeholders who are affected by the intervention or provide a service to the family caregivers (Cornwall \& Jewkes, 1995; Wright et al., 2013). PHR, which has its roots in participatory action research, adult education, medical anthropology, agricultural and community development (Cornwall \& Jewkes, 1995), is a research strategy broadly defined as "systematic inquiry, with the collaboration of those affected by the issue being studied, for purposes of education and taking action or effecting change" (Green et al., 1995). The bottom-up PHR strategy is characterized by a reflective and open minded attitude of the research team and an open process-oriented outcome (Wright, 2013). It targets two goals: co-creation of knowledge towards a practical question and empowerment of the co-researchers (Cornwall \& Jewkes, 1995; Cargo \& Mercer, 2008).

In this article we describe the initial step in the development of a new holistic family caregiver concept applying a PHR strategy. The results of this first exploration will serve as starting point for further concept development.

\section{Materials and Methods}

\section{Research design and strategy}

Within the context of the first step in the development of Vade Mecum, the qualitative $360^{\circ}$ exploration, a PHR strategy was applied to gain a deeper understanding of the current family caregiver support system and of the support offers and needs in the geriatric setting.

PHR enables proactive stakeholder involvement and empowerment. 'Information rich' stakeholder groups who have a depth of experience towards family 
caregiver issues in a geriatric setting contribute to the research process, thus ensuring that the research is conducted not just on, for and with people, but also by people from this setting (Cornwall \& Jewkes, 1995).

\section{Setting and research team}

The PHR started in February 2017 in the Rhein-Maas-Klinikum (formerly known as Medizinisches Zentrum Würselen), Germany. Since 1998 this hospital has a geriatric department. Today it contains 64 acute geriatric beds and 28 rehabilitation beds spread over three wards. The department has a high reputation within the community.

Presently the multidisciplinary professional team on the geriatric department consists of more than 70 members: 10 medical doctors, 44 nurses, 12 therapists (ergo- and physio-), 2-3 neuropsychologists, 2 case managers, and 2 social workers. Care and medical support is provided with a patient-centred approach (professional-patient dialog).The department is characterised by a low staff turnover.

In 2016, 1550 patients, on average 82.7 years old, were admitted at the geriatric department with diagnoses varying from heart- and vascular diseases to neurologic disorders, severe accidents, pneumonia, Parkinson's disease, and hip fractures. Co-morbidity with dementia or delirium was estimated at 50\%. After a mean stay of 17.8 days, about half of the patients returned home where approximately $60-70 \%$ needed daily assistance. The rehospitalisation rate within 3 months after hospital discharge is estimated at $10 \%$.

Members of the multi-professional care team working at the geriatric department, as well as professionals with a broader perspective working elsewhere in the hospital will be engaged as co-researchers. The research project is supported by two external impulse providers: 1) a critical friend with experience as nurse and health manager, and 2) an academic research impulse provider facilitating and stimulating the research process and providing the scientific and technical knowledge.

\section{Project realization and data collection}

The project life cycle for this early $360^{\circ}$ exploration contains six consecutive phases: 1) orientation, 2) setting-up, 3) planning, 4) data collecting, 5) analysing \& concluding, and 6) reporting (figure 2). 
Care professionals will be engaged as co-researchers in all phases of the study. They will define the research problem and the project goals, formulate the research question, choose the methods of data collection, conduct the research and analyze the data. The type of participation of the co-researchers, defined using an adaptation of Cornwall 's participation model (see figure 1), will change through the process of active engagement and empowerment while the project is progressing.

The perceptions, insights and experiences of the professional care team (as service provider), the family caregivers (as service receiver) and a broader perspective from the co-researchers working in the hospital will create the projects' knowledge base'. To enable triangulation a mix of different data collection and analysis methods will be used.

\section{Results}

Results of this ongoing PHR study will be presented for the first four phases of the 6-phase PHR life cycle (see figure 2).

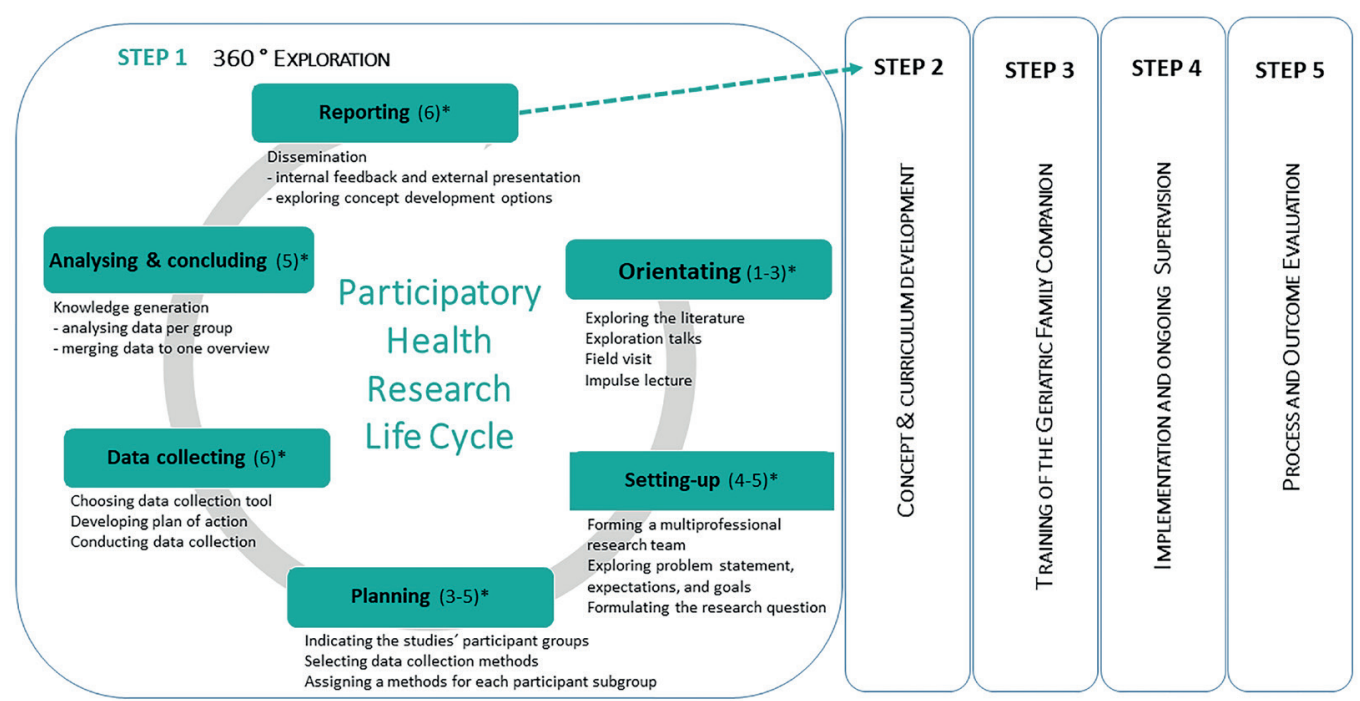

*: Type of participation (Cornwall, 1996]: 1-co-option, 2 - compliance, 3 -consultation, 4-cooperation,

5 - co-learning, 6 - collective action

Figure 2. Project management life cycle and type of participation 


\section{Phase 1: Orientation - March 2017}

The orientation phase started with a brief inspection of the literature to gain insight in current state of knowledge concerning caregiver support initiatives in geriatric settings.

Next, two explorative conversations with the head of department were held by the external impulse provider followed by a two-day field visit (TK, second author), both with special focus on family caregiver support. Initial personal impressions were that care professionals perceive family caregivers as important for the rehabilitation process, but that their role was not specified within the current rehabilitation process. Support offers were perceived as fragmented, uncoordinated and lacking a holistic approach. A trialog, involving caregivers as partners in the care process, was offered on request but was principally patient-centred. Caregiver burdens or needs were not assessed systematically. However, family caregivers might have received some support within the system from different professionals on the department, e.g. nurses, physiotherapists, or from external support providers, e. g. from communal social services (Pflegestützpunkt), if they requested this support.

Next, an impulse lecture was offered by the external impulse provider, where the idea of conducting a PHR project with focus on family caregivers of geriatric patients was presented to members of the current multidisciplinary care team as

\section{Table 1. Participation type, stakeholder involvement and research relationship *}

\begin{tabular}{|l|l|l|}
\hline \multicolumn{1}{|c|}{$\begin{array}{c}\text { Participation } \\
\text { type }\end{array}$} & \multicolumn{1}{|c|}{ Character of stakeholder involvement } & \multicolumn{1}{|c|}{$\begin{array}{c}\text { Relationship } \\
\text { (researcher } \\
\text { and } \\
\text { stakeholder }\end{array}$} \\
\hline 1. Co-option & Token; representatives are chosen, but no real action & On \\
\hline 2. Compliance & $\begin{array}{l}\text { Tasks are assigned, with incentives; researchers decide } \\
\text { agenda and direct the process }\end{array}$ & For \\
\hline 3. Consultation & $\begin{array}{l}\text { Stakeholders' opinions are asked, researchers analyse and } \\
\text { decide on a course of action }\end{array}$ & For/with \\
\hline 4. Cooperation & $\begin{array}{l}\text { Stakeholders work together with researchers to determine } \\
\text { priorities; responsibility remains with researchers for } \\
\text { directing the process }\end{array}$ & With \\
\hline 5. Co-learning & $\begin{array}{l}\text { Stakeholders and researchers share their knowledge to create } \\
\text { new understanding, and work together to from action plans } \\
\text { with researcher facilitation }\end{array}$ & With/ by \\
\hline 6. Collective action & $\begin{array}{l}\text { Stakeholders set their own agenda and mobilise to carry it } \\
\text { out, in the absence of outside researchers or facilitators }\end{array}$ & By \\
\hline
\end{tabular}

*: Adapted from [Cornwall, 1996) 
prospective co-researchers. The professionals present at this first meeting were actively invited to take part in the project as co-researcher. Nine professionals expressed their interest spontaneously and joined the research team. To further expand the team, and to make sure that all professions will be represented in the research team, a form for completion was placed centrally in all three wards for three weeks, accompanied by a flyer.

\section{Phase 2: Setting-up - April 2017}

The second phase started with setting-up the project research team. Eventually, the research team consisted of 16 members: medical doctors $(n=2)$, case managers $(n=2)$, social workers $(n=2)$, therapists (physiotherapy, logo-therapist) $(n=2)$, and nurses $(n=4)$. Moreover, one nurse teacher from the nursing school, and the pastor working for the geriatric department decided to join the research team. The two external impulse providers facilitate the research process. All team members were experienced in their own field, expressed open-mindedness and interest in the topic and the participatory working approach.

In a first workshop the research team contemplated on: 1) the problem statement, 2) the goals and expectations concerning the family caregiver support facility, and 3) the research question.

1) Problem definition. Using the brainstorming method, all team members reflected upon their daily challenges in providing caregiver support. This interactive process resulted in formulating the problem statement. System-related problems, such as knowledge gaps, lack of resources, coordination deficits, as well as caregiver-related problems, such as non-compliance, overburdening, and communication deficits, were identified. Important individual contributions from members of the research team concerning potential problems were combined in a word cloud and presented as overview to the research team (figure 3).

2) Expectations. The expectations concerning the new job description of Geriatric Family Companion were explored for the professionals as a group as well as for each individual team member personally, and for the caregiver-patient dyad as perceived by the care professionals. Discussions took place in small groups of 3-4 professionals ("Murmelgruppen") after which the results were presented to the entire research team. The team then structured and prioritized the findings. Individual care professionals expect to: have more time personally to support caregivers individually according to their different needs when support 
is scheduled in the normal working hours and not in extra time, benefit from task simplification, make personal improvements and get appreciation. For their own profession they also expect improved time-allocation, a better infrastructure, and improved competence. The project might help to give caregivers and patients more consultation time, individualized and improved support, as well as more satisfaction with the services.

Expectations were listed per group in a table, which was send to the entire research team after the workshop (table 2).

3) Research question. As most participants indicated to be inexperienced in formulating a research question, they asked for moderation by the external impulse providers. Triggering questions such as: Who is in the focus of interest? What do we want to know? Where takes the study place?, helped the research team in formulating as research question: "How does the multidisciplinary research team of the Rhein-Maas Klinikum currently supports family caregivers, and what is needed to provide tailored support to caregivers?".

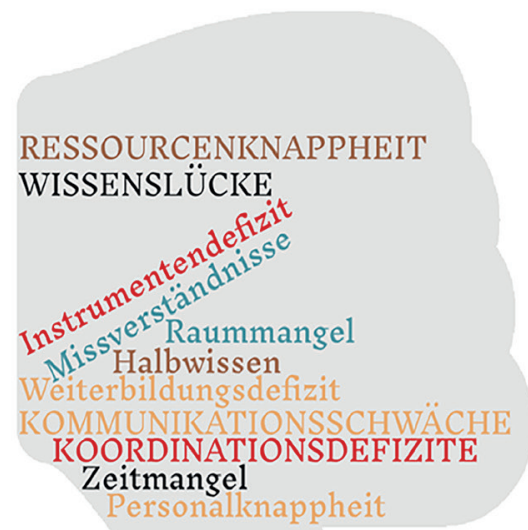

Systembedingte Probleme

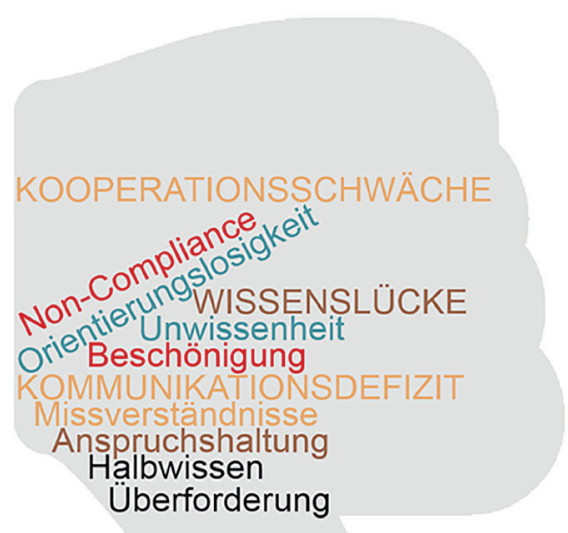

Angehörigenspezifische Probleme

Figure 3. System and caregiver problem identification in the geriatric setting: word clouds as presented to the research team (German language) 


\section{Table 2. Overview of personal and group expectations of participation in the PHR project}

\begin{tabular}{|c|c|c|}
\hline \multirow[t]{3}{*}{$\begin{array}{l}\text { Personal } \\
\text { coresearcher }\end{array}$} & time & $\begin{array}{l}\text { - to provide the adequate caregiver support in the time it } \\
\text { needs } \\
\text { - to do no over-time, when supporting caregivers }\end{array}$ \\
\hline & $\begin{array}{l}\text { personal } \\
\text { development }\end{array}$ & $\begin{array}{l}\text { - to improve skills in communication, stress and conflict } \\
\text { management } \\
\bullet \text { to develop further social skill (empathy) }\end{array}$ \\
\hline & $\begin{array}{l}\text { individual } \\
\text { appreciation }\end{array}$ & $\begin{array}{l}\text { - to gaining societal appreciation for working in the } \\
\text { geriatric ward } \\
\text { - to do something to improve the situation } \\
\text { - to Foster the individual awareness and intrinsic } \\
\text { motivation }\end{array}$ \\
\hline \multirow[t]{6}{*}{$\begin{array}{l}\text { Service } \\
\text { provider } \\
\text { (professional } \\
\text { group) }\end{array}$} & time & $\begin{array}{l}\text { - to understand the counselling needs of different } \\
\text { caregivers } \\
\text { - to offer structured support (individual information, } \\
\text { empowerment) }\end{array}$ \\
\hline & resources & $\begin{array}{l}\text { - infrastructural resources (counselling room) } \\
\text { - adequately trained and sufficient staff }\end{array}$ \\
\hline & $\begin{array}{l}\text { professional } \\
\text { improvements } \\
\text { (knowledge, skills) }\end{array}$ & $\begin{array}{l}\text { - } \text { communication skills } \\
\text { - } \text { practical skills transmission to informal caregivers } \\
\text { capacity building for all staff focusing on caregiving and } \\
\text { - } \text { home care }\end{array}$ \\
\hline & communication & $\begin{array}{l}\text { - to improve the work within the multi-professional team } \\
\text { - to improve the interdisciplinary teamwork } \\
\text { - to foster the professional image } \\
\text { - } \text { to improve the public image }\end{array}$ \\
\hline & $\begin{array}{l}\text { structured } \\
\text { caregiver support } \\
\text { (concept) }\end{array}$ & $\begin{array}{l}\text { - } \quad \text { early caregiver needs assessment } \\
\text { - } \quad \text { professional caregiver support focus person } \\
\text { - } \quad \text { cynergize and structure individualised support } \\
\text { - } \quad \text { structured information flow }\end{array}$ \\
\hline & $\begin{array}{l}\text { obtain } \\
\text { professional } \\
\text { satisfaction }\end{array}$ & $\begin{array}{l}\text { - to experience the professional efficiency when supporting } \\
\text { caregivers }\end{array}$ \\
\hline \multirow{5}{*}{$\begin{array}{l}\text { Service } \\
\text { receiver } \\
\text { (caregiver- } \\
\text { patient } \\
\text { dyad)* }\end{array}$} & time & $\begin{array}{l}\text { - to understand the process of the rehabilitation timely } \\
\text { planning to get clarification on own responsibilities } \\
\text { - to identify the right person in charge in the different } \\
\text { settings (acute-, rehabilitation-, home care) }\end{array}$ \\
\hline & $\begin{array}{l}\text { individualized and } \\
\text { improved support }\end{array}$ & $\begin{array}{l}\text { - } \text { psychosocial preparation for the new role } \\
\text { - early inclusion in planning and treatment processes } \\
\text { - training regarding the key competences of informal } \\
\text { caregiving }\end{array}$ \\
\hline & resources & - adequate counselling facility and fixed counselling hours \\
\hline & $\begin{array}{l}\text { communication } \\
\text { improvements }\end{array}$ & 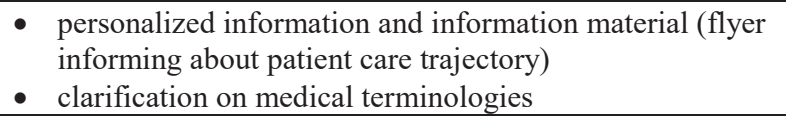 \\
\hline & satisfaction & - due to adequate, empathic, and professional support \\
\hline
\end{tabular}

*: as perceived by care professionals 


\section{Phase 3: Planning - May/June 2017}

In the planning phase, first a decision had to be made concerning data collection methods suitable for the care professionals as service providers, and for the caregivers as service receivers. The team had also to decide on the timing of the actual data collection within their respective settings.

At the start of the second workshop the external impulse provider briefly presented five frequently used qualitative data collection methods, addressing their advantages and disadvantages: interview, focus group, structured interview matrix (0'Sullivan et al., 2014), story-telling (Labonte et al., 1999), and community mapping (Amsden \& v. Wynsberghe, 2005). It was recommended to choose a mix of different data collection methods to enable triangulation. Next, the presented data collection options were discussed with regard to their feasibility and potential for knowledge generation for each professional group. Since in this planning phase of the PHR process family caregivers were not included yet, it was contemplated who best to approach and which data collection method would be suitable to use. One of the nurses proposed to invite "returners", i.e. family caregivers with experience as caregiver on the geriatric ward, to join in a story-telling activity. The social worker suggested that new, i.e. first-time, caregivers may be open for an interview. The group agreed with these ideas. Finally, it was decided by the entire research group to use interviews, focus groups, and story-telling for generating new knowledge (figure 4).

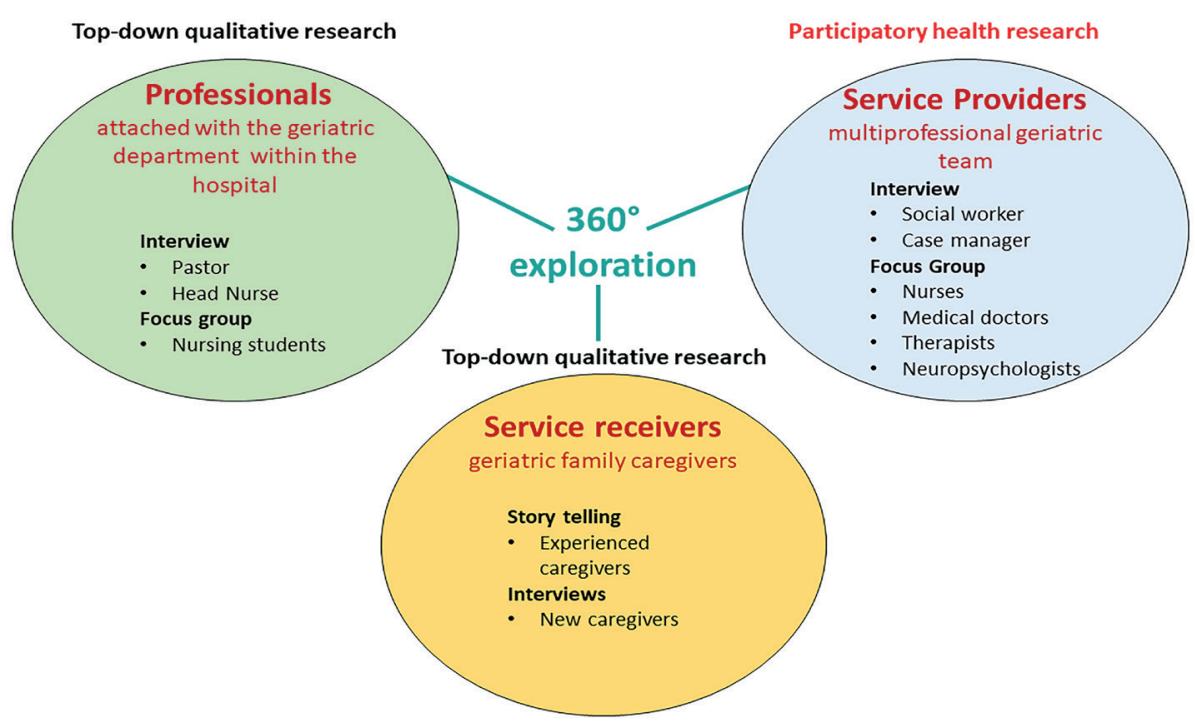

Figure 4. Qualitative data collection methods per participating professional group 
In a third workshop (June 2017) the timing of data collection was scheduled, responsibilities were clarified within the geriatric department, and a plan of action was drawn. All information was inserted in a Gantt chart and distributed to the entire research team. An example of this chart is provided in table 3.

It became apparent that it was necessary to structure, guide and synthesise the process of data collection, and to empower the co-researchers for gathering the data. For this a 'question catalogue' including 53 questions was developed by the research team and the external impulse providers. It targets the themes caregiver needs, information, knowledge, skills, resources, mandate, and support offers in 28 status quo and 25 needs questions. This instrument can be used by each profession and adapted to the needs of the group of participants when conducting interviews, focus groups, and storytelling. The questions were tested for their general understanding in a team discussion led by the external impulse provider. The external impulse provider also provided a 'checklist' for preparing and conducting interviews and focus groups in a participatory manner. One professional group (case management) needed further explanation before starting their data collection process, the other groups felt empowered with these two instruments.

For recruiting the service receiver group a flyer was developed and distributed to potential caregivers within the geriatric department.

Table 3. Gantt-chart presenting the data collection process in the geriatric department in 2017

\begin{tabular}{|c|c|c|c|c|c|c|c|c|c|c|c|c|c|c|c|}
\hline \multicolumn{16}{|c|}{ Year 2017} \\
\hline Month & \multicolumn{2}{|c|}{ June } & \multicolumn{4}{|c|}{ July } & \multicolumn{5}{|c|}{ August } & \multicolumn{4}{|c|}{ September } \\
\hline Week & 25 & 26 & 27 & 28 & 29 & 30 & 31 & 32 & 33 & 34 & 35 & 36 & 37 & 38 & 39 \\
\hline \multicolumn{16}{|c|}{ Multidisciplinary team (service provider) } \\
\hline Medical doctors & & & & & & & & & & & & & & & \\
\hline Nurses & & & & & & & & & & & \multicolumn{2}{|c|}{ FG } & & & \\
\hline Therapists (physio-, ergo-, speech-) & & & & & & & & & & & \multicolumn{2}{|c|}{ FG } & & & \\
\hline \multicolumn{16}{|l|}{ Neuro-psychologist } \\
\hline Social workers & & & & & & & & & & I & & & & & \\
\hline Case Managers & & & & & & & & & & \multicolumn{3}{|c|}{ I } & & & \\
\hline \multicolumn{16}{|l|}{ Family caregiver (service receiver) } \\
\hline Experienced caregivers & & & & & & & & & & & & \multicolumn{3}{|c|}{ ST } & \\
\hline New caregivers & & & & & & & & & & & & \multicolumn{3}{|c|}{ I } & \\
\hline \multicolumn{16}{|l|}{ Broader perspective (hospital-intern) } \\
\hline Nursing students & FG & & & & & & & & & & & & & & \\
\hline Pastor & I & & & & & & & & & & & & & & \\
\hline Head nurse & & & & & & & & & & & & I & & & \\
\hline
\end{tabular}

Note. FG: Focus group; I: Interview; ST: Story telling 


\section{Phase 4: Data collection - June/September 2017}

The participatory data collection process is planned to be conducted by the co-researchers between June and September 2017 (table 2). The family caregiver perspective will be gained in September 2017. The perspective beyond the geriatric ward (nursing students, pastor, and head nurse) will be explored by the external research impulse provider between June and September 2017.

Phases 5: Data analyses and conclusion - 0ctober/November 2017. For this part of the research project co-researchers will be assisted by the critical friend and the external research impulse provider. Qualitative data will be analysed using thematic content analysis

Finally, in Phase 6 (December 2017) findings will be disseminated internally by members of the research team within their own geriatric setting, and externally e.g. through scientific publications or on conferences.

\section{Discussion}

Two important goals were reached in this first exploration of the current family caregiver support system in the German geriatric setting applying a PHR strategy: knowledge was generated in a co-creative manner, and co-researchers were empowered within their setting. In PHR researchers are assigned to two roles: facilitators and learners (Cornwall \& Jewkes, 1995). In our $360^{\circ}$ exploration the two researchers, both external impulse providers, supported the co-researchers to grow in their new role, build up confidence as well as knowledge to be able to conduct PHR, and facilitated, structured and guided the entire process.

In our study the application of PHR as research strategy had several advantages: the problem was illuminated from different perspectives, research objectives were developed from the real-live experiences of the professionals within the setting, and data collection methods were chosen on the basis of feasibility and requirements within the setting. Also, co-researchers already came up with practical solutions for unforeseen problems (e.g. how to approach the caregivers). PHR gave us the insight in local practices and possibilities for change.

PHR concentrates on knowledge for action with emphasis on a bottom-up approach (Cornwall \& Jewkes, 1995). Participation requires reflexive stakeholder engagement, which can help identify problems, and systematically implement, monitor and reflect the outcome of change Meyer, 2000). PHR must be understood as a process, requiring time to build up relationships and trust, which are necessary to work in a creative way. Investing in communication and informa- 
tion sharing is a key requirement for success (Cornwall \& Jewkes, 1995; Wright et al., 2013). Throughout the course of our project's life cycle we could increase our grades of participation from consultation to co-learning (Cornwall, 1996).

A 'deep' participatory process engages different participants in all stages of a given activity, from identification to decision-making. However, this is time consuming as we experienced in our PHR project. Since our approach was used for the first time in this geriatric department, the newly appointed co-researchers needed time to adapt to their role.

Compared with conventional top-down research we also experienced that PHR requires extra time investment from the researcher's side (Cornwall \& Jewkes, 1995). The co-researchers also needed to invest considerable time, which was by some described as "on top of the other work", as the research activities were not perceived as priority in the department.

PHR also requires the ability for critical reflection and knowledge about research methods. As most of them had no experience and were not involved or trained earlier in research, they needed extra guidance and facilitation by the external impulse provider.

The open-ended, less controllable outcome, typical of a PHR project, may have tested some participants as well. However, in our case the co-researchers felt not stressed by the chosen methodology of the study and could work with an open mind. As the decision process in PHR is democratic team dynamics can appear to be challenging as well (Seidel \& Fixson, 2013).

During our research we took the validity criteria of the ICPHR as guidance, acknowledging participatory, intersubjective, contextual, catalytically, ethical, and empathic validity (Wright et al., 2013).

We decided to start in one of the larger hospitals joining the Vade Mecum project by consulting those people, i.e. key stakeholders, that work with and experience on a daily basis the family caregiver - geriatric patient dyad. We felt that it is important to obtain the commitment of the organisation's management although this was only partly reached in this project. Despite multiple attempts the head of nurses could not be involved in the study. Overall, establishing a stable research team in a setting of scarce resources took perseverance. Nevertheless, we were able to show that applying a PHR methodology was feasible in the hierarchical setting of the participating hospital.

We have chosen to show, in detail, the outcomes of a first explorative step using PHR in the advancement of an innovative complex public health intervention, 
Vade Mecum. In our view it demonstrates the feasibility and values of taking a systems approach and include key stakeholders as collaborative research-partners. Recent examples of research applying similar methodologies show the potential benefits of starting with a participatory methodology in the exploration phase of a new (public) health intervention. For instance, a family-support strategy for family members of people with traumatic brain injury was developed using participatory methods (Forster et al., 2012). In their article the researchers provide a thorough description of the participatory process they used to develop their program by involving clinical teams, hospital management teams, and a large number of client-family groups. Co-creation resulted in an eight-tiered approach to change support practices for family members (Forster et al., 2012). In another innovation project, about inpatient mental health services for young people with psychosis admitted to a mental hospital, a detailed description was given of the successful identification of areas for service improvement by incorporating practical knowledge and expertise of service users, carers, community, inpatient staff as well as management (Larkin et al., 2015). While planning the development, implementation and evaluation of our new complex geriatric caregiver support concept in the EMR, we acknowledged the importance of contextual exploration as a distinct first step in the process of service development, as it allows requirements and specifications to emerge (Atkinson et al., 2006). The Meikirch model we chose as guidance enables us to deconstruct and make sense of the different levels of the health care system around the family caregiver - geriatric patient dyad, and to be aware, on forehand, of the potential interactions between the different levels (Bircher \& $\mathrm{Ku}$ ruvilla, 2014).

Recommendations of first explorative steps in the development of new complex interventions in public health sometimes lack a focus on systems thinking. Prominent guidelines on development of complex interventions like the Medical Research Council UK - MRC Craig et al., 2008), or textbooks on the subject (e.g. Richards, 2015), primarily build on knowledge from Evidence-Based-Medicine, and focus almost entirely on translation of already tested, mostly under highly controlled conditions, interventions for implementation in public health settings. However, conventional approaches commonly used in medical research to design and evaluate interventions may not be advanced enough to understand the context and connections between the parts, the actors and the processes of the system (Cornwall \& Jewkes, 1995; De Savigny \& Taghreed, 2009). Integration of expertise from the field is crucial to the success of innovation (Lenfle, 2008), and collaboration with key stakeholders, forming joint and equal wor- 
king partnerships, is critical to build the political context in which the project will develop (Eskerod et al., 2015). Partnerships with stakeholders can also bring alternative perspectives as we experienced in our project. Stakeholders may own personal skills, knowledge, experiences and abilities complementing the expertise of the researcher, which can contribute in the divergent generation phase of concept development as well as in the convergent selection phase of new interventions (Seidel \& Fixson, 2013).

We decided to apply conventional project management tools for operational planning and control, in combination with a design thinking approach as an innovation strategy. Traditionally, project management is a performance oriented practice aiming at the constitution, coordination, and control of activities within a project (Blomquist et al., 2010). Design thinking refers to a human-centred approach to innovation that puts the observation and discovery of human needs at the forefront of an innovation process and starts with observing the users and the system's context and constraints (Gruber et al., 2015). Design thinking, with its emphasis on learning and knowledge creation, can be viewed as a novel methodology and a potentially valuable practice for improving innovation outcomes, whether those outcomes are products, services, or strategies (Seidel \& Fixson, 2013). Combining project management with a design thinking approach can provide significant contributions with respect to problem as well as solution formulation encountered in complex projects (Seidel \& Fixson, 2013; Ben Mahmoud-Jounini et al., 2016).

\section{Considerations}

Composition and social dynamics of the team engaged in PHR may have influenced the results of this first exploration. It is not clear to what extent reflections on the group's objectives, strategies and processes took place and how that influenced the outcomes of their task. However, it is uncertain if this has led to a different perception of the problem or a different problem statement. Furthermore, participants in the system, such as our participating hospital, need adequate resources, also long-term, to be able to make sustainable changes. They also need to build capacity to deliver the intervention. Time, effort and resources, and staff skill development need to be secured, which may be a challenge. During the research process a stable team without member turnover, as well as organizational commitment is required to maintain effective research relationships. Mutual respect and partnership working, effective communication, financial support and accessible information are important ingredients for continued stakeholder engagement (Read \& Maslin-Prothero, 2011). 
Further challenges in the future of the Vade Mecum project will be the identification and engagement of other or new relevant stakeholders to sustain the project's realization and advance the large and complex Vade Mecum project. However, we are encouraged by this first exploration using PHR and feel that this approach will lead to in-depth contextual understanding and engagement of all stakeholders before moving to the next phase of Vade Mecum, the concept and curriculum development.

\section{Conclusion}

During this first exploration applying a PHR strategy we reached high degrees of participation, our co-researchers were empowered, and new knowledge was generated in a co-creative manner. In this early explorative step in the development of the innovative family caregiver support concept, individuals of the multidisciplinary geriatric care team became co-researchers; the problem statement, goals and expectations as well as the research question were formulated; practical solutions for getting access to the support receivers were found; suitable data collection methods were chosen in a democratic way. In forthcoming steps in the current PHR process data will be collected by the co-researchers, analyses will be conducted by the entire research team, and the co-researchers will be empowered to disseminate their findings.

Acknowledgements: We thank Regina Specht for support as critical friend during the PHR. Our special appreciation goes to the multidisciplinary team of the geriatric department in the Rhein-Maas-Klinikum. As co-researcher participated: Dr. Oliver Franz, Dr. Ignaz Steiger, Dr. Maria Utschig-Sprenken (medical doctors); Petra Schneider, Babett Errens, Deniz Erkentzis, Jennifer Fehrling, Sabrina Grosse (nurses); Ingo Rieger (physiotherapy); Jasmin Tischkin (ergotherapy); Anne Theilig (speech therapy); Ulrike Hagen, Rosemarie Wolff (social services); Carmen Goeken, Sonja Palm, Julia Rüffer (case management); Heike Bergamo (deputy principal of the nursing school); Pastor Theodor Maas (psychosocial support and patient ombudsman).

Author Contributions: ED and TK conceived and designed the study; TK performed the practical part described in Methods and Results; ED and TK wrote the paper.

Conflicts of Interest: none 
The stepwise development of a comprehensive family caregiver support programme. 
Chapter 7

\section{CHAPTER 7 \\ General discussion}


This chapter discusses the main outcomes of the Caregivers' Guide programme's development and the preliminary steps of the Vade Mecum programme. In addition, it provides methodological considerations and recommendations for future research and policy development.

\section{Aims}

The aims of the studies included in this dissertation were: (1) to contribute to scientific knowledge with regard to family caregiver support within an actual support system, and (2) to provide a practical example of the stepwise development of a new and comprehensive family caregiver support programme, by reflecting on the entire project management life cycle (initiation, development, implementation and evaluation).

In order to achieve these aims, two projects were incorporated: the Caregivers ' Guide and Vade Mecum. The purpose of the Caregivers' Guide was to develop a new stroke-specific family caregiver support programme, whereas Vade Mecum was intended to develop a new support programme that assists family caregivers of elderly people. A practical and thorough example on how the new support programme was developed, optimized and evaluated has been given in the Caregivers' Guide (chapters 2-5). An example on the very first step of the Vade Mecum project's management life cycle - the initiation phase - was presented in chapter 6.

\section{Outcomes of the stepwise development process}

The new and comprehensive stroke caregiver support programme is the product of a systematic, multiperspective and methodologic development process.

The Caregivers' Guide project management life cycle contained three phases: development, implementation and evaluation.

The development phase included two steps: 1) development of the preliminary Conceptual Building Blocks (CBBs) (chapter 2), and 2) design of implementation management instruments (chapter 3).

First, the needs for a family caregiver support programme in the Aachen region (Germany), were explored (chapter 2). Prospective end-users (experienced stroke family caregivers) and actual service providers (professionals) representing the different rehabilitation phases of the current stroke support system, e.g. 
acute phase, participated in this exploration. The need for a personalized, holistic and multicomponent caregiver support programme emerged in both groups. The proposal 's initial conceptual ideas: professional diachronic support through all phases of rehabilitation, individual support with outreach counselling option, and information and psychosocial support; were: 1) explored regarding their feasibility, and 2) adapted to the context-specific needs for comprehensive caregiver support. This resulted in the Caregivers' Guide preliminary concept containing five CBBs: 'Content', 'Human resources', 'Timing', 'Approach', and 'Setting', which focussed on the individual caregiver-counsellor interaction (individual level).

Second, project management techniques were applied to systematically analyse the new programme's stakeholders and possible implementation risks in the actual stroke support system within the Aachen region (chapter 3). Two implementation management instruments were designed on the basis of these findings,: (1) the general project implementation strategy, emphasizing communication, transparency, network-building and professionalism; and (2) the comprehensive 'stakeholder-risk atlas' containing individual stakeholder information: role, access, contribution, power \& interest, expectations, perceived risks, and specific engagement activities.

The preliminary concept was optimized in practice before full-scale implementation (chapter 4). Using Participatory Action Research (PAR) strategy: (1) the preliminary CBBs were tested, verified, and adapted, (2) new CBBs were developed, and finally (3) all CBBs were prioritized in order to achieve the overall goal of the intervention. Optimization resulted in a matured concept with eight CBBs, addressing the needs on both individual (end-user) and system (service provider) levels. The five preliminary CBBs, 'Content', 'Human resources', 'Approach', 'Timing', and 'Setting', were fine-tuned and prioritised to be the 'core blocks' for providing individual caregiver support. The three new blocks, 'Network building', 'Communication', and 'Social safety-net', were selected to serve as 'facilitating blocks', intended to integrate and interlink each individual intervention within the actual support system, and to safeguard the new support programme within the complex everyday working environment.

The Caregivers' Guide was evaluated on both individual and system levels (chapter 5). On an individual level, quantitative data showed that providing personalized information and offering psychosocial support improved the caregiver's health literacy and stabilised psychosocial health; whereas qualitative data demonstrated health literacy enhancements in terms of knowledge, capability to 
act and individual empowerment. Psychosocial stabilisation enhanced self-confidence, life balance and emotional wellbeing. On a system level, professional service providers perceived a positive impact of the efforts in communication and network-building (facilitating CBBs) on the actual stroke support system, as the programme enhanced their routine interaction with caregivers, quality of care, support within their own organisation, and inter-institutional cooperation within the region.

The Caregivers' Guide was followed by Vade Mecum 's initiation phase (chapter 6). The current caregiver support and the needs for comprehensive caregiver support in the geriatric department were explored with the Participatory Health Research (PHR) strategy. The preliminary steps of this process resulted in: (1) discussion of the needs and expectations of the new support concept, (2) formation of a research team representing all professions within the geriatric department and involving them as co-researchers, (3) formulation of research objectives, (4) exploring practical solutions for involving family caregivers in the study, and (5) selection of an appropriate mix of qualitative data collection methods consisting of interviews, focus groups and story-telling. Co-researchers underscored that family caregivers would benefit from systematic caregiver support that is offered by the geriatric multidisciplinary support team. However, they postulated that in order to provide comprehensive support the team must be equipped with the resources, e.g. training material, and the skills, e.g. counselling skills (chapter 6, table 1). In Vade Mecum's initiation phase, participation degrees were achieved (chapter 6). In the closing-down workshop of the initiation phase both co-researchers and external impulse providers declared that PHR contributed to their individual and professional empowerment.

The key outcomes of the development process of a new caregiver support programme are illustrated per project and phase in Figure 1.

\section{Reflections on the outcomes}

The Caregivers' Guide contains eight CBBs that address the context-specific needs for caregiver support on both individual and system levels (Figure 1, centre). This new caregiver support programme was developed with a stepwise approach that includes: the initial exploration of the context-specific needs and the multi-stakeholder setting (Chapter $2 \& 3$ ); the maturation in practice (Chapter 4); and the confirmation (Chapter 5). This programme is based on both international scientific and actual context-specific knowledge and experience. 

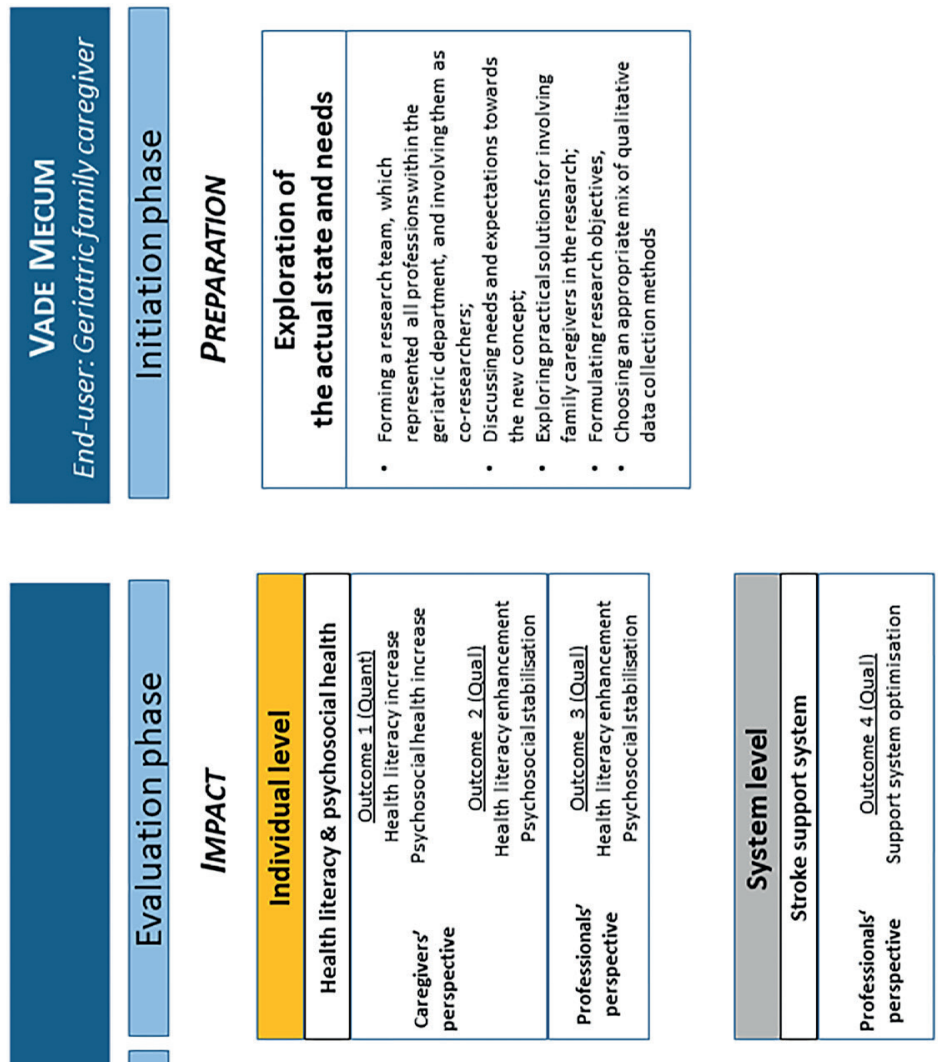

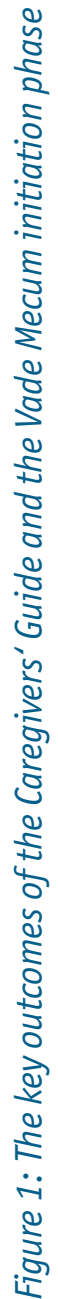


Our new programme answered in detail the essential conceptual questions for providing stroke caregiver support at an individual level (Figure 1, centre). The five core CBBs respond to the following questions: What support will be offered? ('Content'); Who will support the end-user? ('Human resources'); When and how long will support be offered? ('Timing '); How end-users will be approached and supported? ('Approach'), and Where support will be offered ('Setting '). The research team experienced that both end-users and service providers benefited from explanation of the complex support offer at an individual level with the core CBBs.

To the best of our knowledge, this is the first stroke caregiver support programme applying a systems thinking approach early in the programme, which helped to address the programme's complexity (WHO, 2009). The needs of the system are addressed in the three facilitating blocks: 'Communication', 'Network-building', and 'Social safety-net' (Figure 1, centre). These blocks are compulsory in order to support, integrate, safeguard and interconnect the new individual caregiver support programme with the actual support system, and therefore may be perceived as the programme's 'lifebelt'.

Designers and researchers of complex intervention programmes may profit from the 'block' approach, subsuming detailed components. This approach may support teams in systematically addressing the needs at individual and system level, and to reflect on the programme's completeness. Moreover, explaining the complex programme with the 'block' approach to caregivers, service providers or outsiders was experienced as convenient and helpful.

A conceptual review was conducted in order to critically reflect on the concept of our stroke-specific caregiver support programme. Detailed conceptual information from the existing scientific knowledge from other stroke caregiver programmes was compared to the Caregivers' Guide CBBs.

Up until now the only existing scientific reports are based on two German stroke-specific caregiver support programmes: 1 ) a psychosocial support programme that was offered to spouses in the home-care phase in Saxony (Wilz \& Barskova, 2007), and, 2) a problem solving programme offered to caregivers directly after rehabilitation discharge in Baden-Wuerttemberg (Pfeiffer et al. 2014). However, neither of these were developed and executed in the federal state of North Rhine-Westphalia and neither reported specifically on the development of the programme.

Unfortunately, only a few programmes have described their development phase 
in detail, e.g. Cameron et al. (2013). Recently, Forster et al. (2015) intended to describe the development of the TRACS programme, yet, it remains unclear from which knowledge base the different elements of the individual caregiver training course (curriculum) were evolved. None of the reviewed articles reported in detail on the entire project's life cycle. However, some information was found concerning our five core CBBs: 'Content', 'Human resources', 'Approach', 'Timing', and 'Setting' (Fig 1, centre). None of the stroke support programme publications reported on any of our facilitating system blocks: 'Communication', 'Network-building' and 'social safety-net'.

The Caregivers' Guide CBB 'Content' includes two elements: ‘personalized information' and 'psychosocial advice' (chapter 4). In the scientific literature 'Content' is considered as 'support type'. Four main types were recognized by Visser-Meily in 2004 (see general introduction), and if two or more of these types are combined, they are considered as 'multicomponent' (Wilz \& Böhm, 2007). Most of the reviewed programmes applied a multicomponent approach. Bakas et al. (2009), for example, combined information provision with counselling, and Schure et al. (2005) combined education with counselling. Some programmes have offered a single component, e.g. Larson et al. (2005) provided education. Forster et al. (2014) and Cameron et al. (2008) have shown, in agreement with our results (study $2 \& 4$ ), that both of the elements: 'personalized information' and 'psychosocial advice' are necessary to address the various needs of caregivers. The reviewed programmes vary in content, and have a varying number of elements, which might be attributed to the context, e.g. availability of other programmes.

The CBB 'Human resources' containing 'professional support', 'social skills', 'personality traits', 'continuous capacity building', and 'professional supervision', emphasizes the characteristics and needs of the professional for providing support. All reviewed programmes offered professional support, which is typically provided by professionals with a medical or therapeutic background: e.g. (specialized) nurses, medical doctors, psychologists, physiotherapists, occupational therapists or speech therapists (Bakas et al. 2009; Wilz \& Böhm, 2007). Some programmes provided multidisciplinary support (Forster et al., 2013; Ostwald et al., 2013), and in two programmes social workers were part of the multidisciplinary team (Glass et al. 2004; Marsden et al. 2010). In our programme, a clinical social worker was appointed as the support provider (chapter $2 \& 4)$. This was found to be practical, as a clinical social worker possesses the 
knowledge (health and support system) and the skills (counselling and network building) to fulfill this new job profile.

Only one earlier publication has reported on a combination of professional and peer support in a web-based support (Smith et al., 2012) that resulted in a better understanding of the emotional needs of both the caregiver and the stroke survivor. This is not comparable with our programme, which offers face-to-face support and peer support as 'add-on' element.

No publication has yet emphasized the 'skills' and 'personality traits', which emerged as one the outcomes in our study seen as necessary for offering adequate support to the caregivers. Both components were considered by the caregivers to be fundamental in offering adequate 'psychosocial advice' (Chapter 4). Moreover, it became evident during the optimization phase that providing stroke caregiver support is also professionally and emotionally demanding for the counselor. In order to prevent overburdening, 'continuous capacity building' and 'professional supervision' seems to be necessary, and should be offered. None of the reviewed publications have reported on these issues. However other German support programmes for pediatric family caregivers have used these components successfully to protect and empower their professional counselors and support teams (Bunter Kreis, 2017).

The CBB 'Approach' includes 'flexible outreach counseling', 'focal person support', ' direct communication', and 'active engagement' (chapter 4). During the optimization phase, both end-users and service providers highlighted 'flexible outreach-counselling' as a fundamental component. This proactive and personalized component encouraged caregivers to seek and receive support, and likewise contributed in early detection of and support for the most vulnerable caregivers, which is a public health concern. None of the reviewed stroke programmes applied 'outreach counselling' that is otherwise seen in public health programmes, e.g. HIV/Aids prevention, where it is frequently and successfully applied for the same reasons (Ahmeda et al., 2013). We are convinced that stroke support programmes will also benefit from this approach.

In our programme, continuous support to the caregiver is offered across the stroke survivor's rehabilitation by the same counselor (focal person support) trajectory. During the maturation process, this component was especially appreciated by the end-users, as it allows the development of a stable relationship and augments their sense of security. The system benefited from the maintenance of the communication flow during transitions that was guaranteed by this component. 
We have identified four modes of support provision in the literature: 1) faceto-face in an individual meeting, e.g. Lincoln et al. (2004); 2) face-to-face in a group meeting, e.g. Foster et al. (2013); 3) indirect support via web-based /telephone in an individual session, e.g. Bakas et al. (2009); and 4) indirect support via web-based /telephone in a group session, e.g. Smith et al. (2012). Most programmes approached caregivers face-to-face in individual or group sessions. Our programme applied the term 'direct communication' (mode 1), as in the optimization phase individual face-to-face support was promoted as being most effective, an approach also advocated by Bakas et al. (2014). However, we promoted flexibility regarding the mode, as for a variety of reasons, such as geographical distance, face-to-face support might be difficult at certain times. During optimization, caregivers and the counselor stated that 'direct communication ', including personal communication via telephone or mail, was also experienced as supportive.

As outlined in Chapter 2, caregivers requested to be more involved in the transition and discharge processes of their patient, and this has also been reported in other research, for example Creasy et al. (2013). As a result 'active engagement' was included in the CBB. However, during optimization one of the outcomes in the PAR process was that caregivers presented very different views regarding the degree and the moment of engagement and that the desire for participation in the caregivers was enhanced during its emotional stabilization process. We would, therefore, promote flexibility in regard to the degree of participation (Cornwall, 1986).

The CBB 'Timing' specifies that flexible caregiver support should be offered 'through all phases' and 'as early and for as long as needed', which might be the best possible support in our setting. In the literature, we observed variation regarding the onset, duration and intensity of the support. Some programmes already supported caregivers in the first month post stroke, i.e. the acute phase (e.g. Forster et al., 2013), but in all of them support lasted no longer than the second month post-stroke. In most publications the programmes started in the second month post stroke, which can be considered as the rehabilitation phase (e.g. Ostwald et al. 2013), or even later. For instance Schure et al. (2006) and Lincoln et al. (2004) started a support programme from month six post-stroke, in what might be considered as the home care phase. The shortest intervention only lasted for two hours (Aguirrezabal et al., 2013), whereas the longest interventions lasted twelve months (0stwald et al., 2013). The intensity varied from a single session (Aguirrezabal et al., 2013) up to 15 bimonthly sessions, each 
lasting 90 minutes (Wilz \& Barskova, 2007). A long-term intervention, offering flexible support across the entire rehabilitation trajectory of the patient (acute, rehabilitation and home care phase), has not been presented in the literature.

On our case the $\mathrm{CBB}$ 'Setting' promotes a flexible place for counselling in a trustful, private and convenient atmosphere. Both end-users and service providers have emphasized that additional support should be offered in the home environment (chapter 2). End-users in particular appreciated home visits when the patient returned home, as it helped them to feel certain with the new situation (chapter 5). Service-providers valued the home visits of the counselor as it helped to assess the actual home environment and to better prepare transition, for example by initiating adaptations in the bath room. In the reviewed programmes, support was mostly offered in counseling or training rooms which belonged to the organizational setting (Forster et al., 2013), and only some programmes offered individual home visits as a follow-up to the original group support (e.g. Schure et al., 2006). In telephone support (e.g. Bakas et al., 2009) or web-based support (e.g. Lutz et al., 2009) the 'setting' was not of concern. We discovered that offering at least one counselling session in the caregivers' home environment during the PAR part of the development was perceived as enhancing the counselling process by caregivers and service providers, as well as by the counselor. Therefore, it was decided that the aspect of flexibility should be integrated in the matured concept.

In our matured concept the facilitating $\mathrm{CBB}$ 'communication' contains two components: external and internal communication, and promotes activities necessary to augment visibility, transparency, marketing, and credibility of the programme (Chapter 4). 'Communication' is the connecting CBB of the entire program, which was perceived as vital, since it facilitates, supports and safeguards the programme at the individual and system levels. Investing in different 'communication' activities helped to ensure accessibility to the counsellor for the caregiver, and established clear communication lines with the different service providers during the trajectory, resulting in ensuring a constant communication flow at all levels. Effective 'communication' is a key element for enabling change in complex systems (Grol et al., 2013). In order to manage the multilevel communication needs, we developed a general implementation strategy (Chapter 3). However, for a complex intervention in health a communication plan would be an asset, as advocated by the Center for Disease Control (2018). 
The CBB 'Network building ' includes three components: professional, interprofessional, and scientific networking, which built the fundaments for knowledge exchange and dissemination (Chapter 4). The service providers appreciated 'Network building' as an important factor in connecting and safeguarding CBB within the system. Investing in building up personal relationships between different stakeholders also resulted in understanding the complexity of some cases and resulted in improving communication during transferals. Sustainable networks may impact positively on the service provider's intrinsic motivation and quality of support (Grol et al., 2013). As caregiver support programmes do not operate in a vacuum, new programmes in particular will profit from building up networks, as this helps to generate new context-specific knowledge and experience.

As a final step the CBB 'Social safety-net' was added to the concept. This consists of two components: emergency assistance and peer group. Both were considered as necessary to safeguard the family caregiver in their role after discharge from our programme. In the optimisation phase, the opportunity to receive emergency assistance after discharge was highlighted as emotionally stabilising for the caregiver by both the caregivers and home care service providers. Some caregivers specified their interest in peer support. In general, peer support is a potentially low cost way to enhance well-being (Kessler et al., 2014), by offering an opportunity to socialize with, learn and listen to others (NSA, 2018). Contrary to, for example the UK, the benefit of peer group support is not as widely acknowledged in the German society, especially amongst the older generations. As a consequence stroke caregiver groups are scarce. However, some stroke caregivers may benefit from peer support, especially in the home care phase (Cameron et al. 2008, Visser-Meily 2004). On the basis of these preconditions, the possibility of establishing a stroke caregiver peer group was explored, and an actual peer group was founded in the Aachen region. At the end of each counselling trajectory, caregivers were encouraged to join this group. The final CBB `Social safety-net' interlinks the individual caregiver and the system, for example by referring caregivers to the communal caregiver support services.

\section{Reflections on the research process}

The development process of this new stroke caregiver programme differed from that of other programmes. Our programme's development implied four research highlights: 1) the new programme was considered as 'complex' from the begin- 
ning, and therefore a systems thinking approach was applied; 2) the project management approach and affiliated techniques were utilized for the development process; 3 ) the matured concept is based on a comprehensive context-specific understanding and optimization in practice; and 4) both end-users and service providers contributed in the programme's development over the entire project life cycle.

\section{Complexity and systems thinking}

The needs of family caregivers are complex (Bakas et al., 2014). In order to address these needs different components, intervention levels and stakeholders might be involved, and therefore the caregiver support programme might also be complex. In order to achieve the Caregivers' Guide overall aim, namely to maintain the quality of life of stroke caregivers and reduce their burden, the research team was attracted by the UK framework for complex interventions that considers the complexity of an intervention (Craig et al., 2008). The Caregivers' Guide is the first (published) stroke caregiver support programme that was developed from the start with a complexity perspective (chapter 2).

Caregivers support needs are context-specific and depend on the availability of support (Redfern et al., 2006). Caregiver support programmes are not implemented in a vacuum but within an operating system. Consequently, achieving an in-depth contextual understanding was considered as compulsory for the development of a new stroke caregiver support programme within the Aachen region (Germany). Through the Caregivers' Guide experiences in all phases, it became apparent that comprehensive caregiver support programmes are interlinked with the system, requiring the collaboration with the system. We demonstrated how complex caregiver interventions could benefit from a systems thinking approach. Systems thinking elements were addressed in all phases of the programme by promoting stakeholder's participation (chapter 2-6), network-building, communication and feedback loops (chapter 4), and by applying the complex system perspective during research (WHO, 2009; Arnold \& Wade, 2015; Waldman, 2007). Systems thinking helped the team to develop the eight CBBs, addressing the needs for caregiving support not only at an individual but also at a system level. Early consideration of the importance of the support system and application of the systems thinking approach seems to have a positive effect on the comprehensive development of a new programme. 
The stepwise development approach used in the project management life cycle qualified the team to specifically address potential complexity and contributed to the concept development, finally resulting in a matured concept. We demonstrated that carefully developing and testing the CBBs in practice resulted in meeting the needs of both the individual caregivers and the system (chapter 4), as confirmed in the programme's impact evaluation (chapter 5). When initiating Vade Mecum, the complexity of the problems regarding the current caregiver support was also addressed at both caregiver and system levels (chapter 6). Understanding and addressing the complexity early in the project life cycle might be diminish "teething problems" during the programme's progress and enhance the outcomes at both individual and system levels.

Redfern and colleagues (2006) reported that interventions in stroke care are complex. Surprisingly, none of the publications we found on this subject that have appeared since then have reported on the incorporation of a systems view, or even mention the complexity of the system. Our research team considered the importance of the actual support system for the new support programme early in the project's life cycle. Besides focusing on the individual level, the system, with its stakeholders, was also explored, and needs were assessed and addressed in the facilitating CBBs (Chapter $3 \& 4$ ). This was perceived as positively impacting on the actual support system (Chapter 5). Due to our investments, the research team was qualified to evaluate the programme's impact on both levels.

\section{Translating knowledge from the project management}

When aiming to develop, implement and evaluate a complex intervention such as the Caregivers' Guide, it would appear indispensable to have a profound understanding of its complexity regarding the multi-stakeholder landscape within the stroke rehabilitation trajectory and possible factors jeopardizing the implementation of the programme. My previous working experience in the field of Humanitarian and Development Aid triggered me to recognize this complexity and its challenges and to search for possible solutions that help in achieving contextual readiness, as well as in navigating and assisting the intervention's implementation and evaluation phases. Tools originating from the project management - PM-, that is "the application of knowledge, skills, tools, and techniques to project activities to meet the project requirements", were considered to be a good choice to achieve our requirements (Project Management Institute - PMI, 2013). The new programme's development was framed in a PM life cyc- 
le, which helped to structure, monitor and control the necessary steps (PMI, 2013). Exploring in detail the new programme's stakeholders and the possible implementation risks, both well-known techniques in project management (WH0, 2009; Dogherty \& Estabrooks, 2015), was integral part of the development (Chapter 3).

Stakeholder and risk analyses helped to gain insights into the characteristics of the current care provision and involved organisations within the Aachen region, which can be considered as crucial for the development of a complex programme (Campbell et al., 2007). The research team benefited from identifying the primary stakeholders and considering these as main contributors, possessing the power to promote or hinder implementation, which resulted in their systematic engagement in the further development process (chapter 4, chapter 5). Furthermore, analyses helped to identify and include all the important stakeholders in the programme, for example the University Hospital Aachen, with its stroke unit and specialized neurosurgery department. As result, all acute hospitals were included as primary stakeholders in the new programme. End-users, service providers in the system, and also the research team all reported that including all acute care providers had a positive influence at both the individual and system levels (chapter 5), as caregiver support aimed to start in the acute phase. Nowadays, stakeholders are recognized as an important factor in the field of complex public health interventions, implementation sciences and health system development (Dogherty \& Estabrooks, 2015; Wensing et al. 2013, WH0, 2009), and our experience confirmed this.

Furthermore, we invested in achieving a clear understanding of possible implementation risks, as advocated by Dogherty \& Estabrooks (2015). For this purpose the programme's stakeholders were engaged in the risk analysing process, resulting in the gain of an insightful, context-specific and multi-perspective understanding. Risks were identified and categorized in project-related and stakeholder-related risks, and further assessed on their likelihood (table 2, Chapter 3 ). This process enabled the team to develop context-specific risk mitigation strategies.

The new programme's stakeholders and potential implementation risks were explored early on and systematically, as recommended by Möhler et al. (2012) and Hawe (2015). Systematic analyses enabled the team to design two project management instruments: the general implementation strategy and the individual stakeholder-risk atlas (chapter 3). Both instruments helped to plan the general activities and enhance the projects team's capability in managing the implementation process within the existing support system structured through 
systematic stakeholder engagement, as promoted by Jepsen \& Eskerod (2009) and Handley et al. (2016).

\section{Optimization in practice and design thinking}

During the development of the new programme we invested in a optimization phase, as Semeus et al. (2015) have reported 'implementation of a complex intervention is often a black box', as it remained up until this moment unclear if the preliminary CBBs were mature enough and complete enough to addressing the comprehensive needs. Therefore, we expressly applied PAR that is considered to bridge the gap between theory and practice (Buul et al., 2014). Iterative PAR cycles (Baum, 2016) and three optimization steps, including: (1) verifying and fitting the preliminary concept, (2) detecting, developing, verifying and fitting new CBBs, and (3) prioritizing all CBBs, were applied to mature the programme in practice (Chapter 4, Fig 1). By doing this we were attracted by the design thinking approach (Brown \& Wyatt, 2010), where trying out and improving the prototype is considered as obligatory for the development of a new programme. New knowledge was generated in a co-creative way, as advocated by Greenhalgh (2016) and Baum (2016). The needs of the system became more evident through practical trial, and resulted in three new CBBs: 'Communication', 'Network-building' and 'Social safety-net' (Figure 1, centre). Both the endusers and system providers stressed that new caregiver support programme's teams would benefit from investing in 'Communication' and 'Network-building'. These will help in awareness of possible obstacles within the system, for example staff turnover or modifications within the support system, such as new support providers. Both elements were considered as important in initiating change within the system, for example the inclusion of caregivers in transferal activities. Stakeholders advocated that the new programme should offer an ' exit strategy' for caregivers after programme discharge. A 'Social safety net', including emergency response and creation of a peer group, was part of this process. All in all, our optimization resulted in maturing the programme on both individual and system level, which possibly enhanced the impact at both levels.

\section{Participation of end-users and service providers}

We included both groups of stakeholders: end-users (stroke caregivers) and current service providers (e.g. nurses, social workers), in the development process of the Caregivers' Guide. They contributed with context-specific knowledge and experience from different perspectives, resulting in an in-depth contextual un- 
derstanding of the actual needs.

In our case an early and personal engagement with these stakeholders, who have face-to-face contact with family caregivers in their daily work (service providers), was compulsory. This was because in the project's initiation phase in 2011 only the heads of the departments of some support stroke organizations within the system were approached and asked for their commitment, which did not prove ideal. Subsequently, when starting our new programme at the end of 2012, we noticed that professionals at the periphery of the departments, e.g. social workers or case managers, were not informed of the new initiative, resulting in uncertainty and resistance within the system. Retrospectively, it would have been better to involve some representatives, of, for example, the nurses or social workers, in the initiation phase, for example via focussed discussion. Based on my experiences in initiating other public health programmes, e.g. maternity health, as well as on Vade Vecum 's initiation phase, complex health programme teams will benefit at this moment from stakeholders internal system-knowledge, institutional memory and experience. Moreover, expectations, possible implementation risks and contributions can be clarified and will contribute to the quality and feasibility of the project proposal. Investing time to personally explain in detail the project's scope to the potential contact persons within the organization, and at the same time inviting service providers to actively participate in the development process resulted in a proactive working atmosphere, professional relationships and network-building, as we experienced during the development of the preliminary concept. Moreover, early engagement with the service providers (chapter 2, \& 3) resulted in contextual readiness for the new programme within the system. This, we found, was fundamental, as the Caregivers' Guide team members, including the clinical social worker offering personalized caregiver support, were not a part of existing stroke support system, but all affiliated with the external academic research institute (KatHO). These conditions implied a potential for conflicts between both professional groups, the system 's service providers and the external counselor, which might negatively affect the implementation of the new support programme. Early and systematic stakeholder engagement may enhance the feeling of ownership and the acceptability of a new support programme within the support system, as was suggested by Caron (2014). Exploring the ground with stakeholders' engagement will help lead to a multi-perspective and detailed contextual understanding. Moreover, high participation grades may lead to the individual and professional empowerment of both co-researchers and professional researchers (chapter 6). In the optimization phase, participation empowered stakeholders to provide cri- 
tical information, and internal system knowledge to better fit the new programme into the existing system and to give constant feedback during the maturing process. Participation of external stakeholders was found to be a crucial to the research team for the development of the new programme. It was the base for a supportive, transparent and positive working atmosphere between the research team and the service providers. Moreover, participation enhanced the communication flow, enabled the early access to the end-users, helped to establish professional networks, and encouraged the foundation of the peer support group. End-users and service providers were both included in the Caregivers' Guide programme evaluation. Results were presented in the project's closure workshop, and this was especially appreciated by the service providers within the support system.

In contrast to the approach used in the Caregivers' Guide initiation phase, which took place before the start of the actual project presented in this dissertation, the second project, Vade Mecum, started with a PHR-based initiation phase (chapter 6). Professionals from the multidisciplinary team were engaged as co-researchers from the beginning. Our findings show that working with high levels of participation leads to professional and personal empowerment of the research team (co-researchers and professional researchers). Participation of the different professions helped to gain a rich picture of the actual needs. Working with high participation degrees seems to be promising when initiating a new, complex support offer in an intricate and fragmented multi-stakeholder landscape, for example in geriatric care (Cornwall, 1996).

Service providers and end-users felt appreciated in their role. The explicit involvement in the new programme's development was perceived by the end-users as a "privilege". The service providers considered participation as "necessary feedback-loop" for improving the quality of support for the patient-caregiver dyad.

Only a few publications have reported on the inclusion of the caregivers' perspective in the development of the stroke caregiver support programme(Brereton et al., 2007; Funk \& Stajduhar, 2009), and only recently have the service providers' views been gathered for the programme's development (Cameron et al. 2013; 0 'Brien et al. 2014). Only one qualitative study from Canada (Cameron et al., 2013) has reported on the inclusion of end-users and service providers during the development of the 'Timing it Right' stroke family education programme. Our findings show that research teams can benefit from stakeholders' participation during all phases of the project's life cycle. However, participation 
requires flexibility in terms of time, resources, and the willingness of all participants to learn from one another.

\section{Methodological considerations}

\section{Design}

A variety of research designs were applied for the development of the new and complex caregiver support programme, most of which were qualitative. The Caregivers'Guide's project management life cycle encompassed four sub-studies with different designs: (1) a QUAL-QUAL design was applied in order to gain a context-specific understanding and to build on this for the preliminary concept (Chapter 2); (2) systematic stakeholder and risk analyses, followed by a qualitative design, were used to understand the multistakeholder landscape and to develop implementation management instruments (Chapter 3); (3) a qualitative research design with integrated PAR strategy was applied to optimize the preliminary concept in practice (Chapter 4); and finally (4) an integrated quant-QUAL and a QUAL-QUAL design was applied to evaluate the outcomes of the programme at both individual and system levels (Chapter 5). In the Caregivers' Guide the same organisational groups and, in part, the same participants (service providers) were involved in different steps of the programme's development. This was helpful as researchers were aware of their expectations and therefore addressing their needs was possible.

In the Vade Mecum's initiation phase PHR strategy was applied to explore the context-specific needs and to empower co-researchers for qualitative data collection and analyses within their setting.

Using more than one data collection method was stimulated by the positive experience of the primary researcher when exploring other complex public health issues. For instance in 2004, in West-Darfur (Sudan) during the humanitarian crises, it appeared to be insufficient to only conduct quantitative surveys when monitoring the nutritional status of certain refugee populations. In order to gain an in-depth understanding of the nutritional situations of the vulnerable groups, qualitative methods where applied: focus groups, qualitative household surveys, observation, security walks. The combination of different qualitative data collection methods, so-called methodological pluralism (Morse, 2003), achieved a rich and comprehensive understanding of nutritional situation in these refugee camps. This knowledge qualified our teams to adapt the nutritio- 
nal support programmes according to the real needs, e.g. changing the schedule for food distribution for malnourished children. Finally, this investment enhanced the outcomes of our programme: reduced U5 mortality, decline in rehospitalisation in the Therapeutic Feeding Programme, and increased food security for vulnerable groups.

In the Caregivers' Guide the application of methodological pluralism (Morse, 2003) resulted in the gain of an enriched and more complete picture of the stroke caregiver landscape in Aachen. Collecting mixed methods data might be considered by the research team to be overwhelming or time consuming (Stange et al., 2001). However, our findings illustrate that methodological pluralism contributed in gaining rigorous understanding of the complex needs, as predicted by Borglin (2015) and Phillips et al. (2014). Gathering knowledge from different perspectives assisted in gaining a more holistic understanding of the complexity, as predicted by Morse and Cheek (2014) and Graneheim et al. (2017), which was considered as crucial for the new programme's development in the Caregivers' Guide and Vade Mecum.

The impact of the Caregivers' Guide programme at an individual level was evaluated using quantitative and qualitative evidence (quant-QUAL), which has been promoted as obligatory by Campbell et al. (2000). The relatively small and limited quantitative part served to navigate the further exploration with more extensive qualitative research on an individual level. Utilizing quantitative instruments at a system level was considered as unsuitable for the purpose of the research question on methodological grounds, for example because of the diversity of participants on different levels, e.g. acute care or home care support.

Qualitative research aims to gain a complete and detailed description of a phenomenon (Denscombe, 2005). It is increasingly used in health care development and nursing sciences. In the public health domain, however, it is difficult to find examples of qualitative research. Qualitative methods may provide several advantages: 1) it is 'grounded' on reality and flexibility, e.g. in terms of setting and timing; 2) it provides a 'thick description' of a phenomenon which helps to understand and deal with complex and intricate circumstances; 3 ) it implies the space for alternative explanations from different perspectives, e.g. endusers and service providers; 4) it may help to explore possible implementation risks or reflect on a intervention's maturity (Denscombe, 2005, p. 281; Campbell et al., 2000; Anderson 2010). Its disadvantages may be that: 1) data may be less representative for all caregiver groups, due, for example, to its strong context-dependency, 2) its interpretation is bounded with researcher's identi- 
ty, background and beliefs, the so-called researcher bias, and 3) data analyses and interpretation is time consuming (Denscombe, 2005; Silverman 2005; Anderson 2010). Our findings demonstrate that the entire development process of the Caregivers' Guide programme benefited from qualitative research. Through qualitative research we gained a comprehensive understanding of the complex issues attributed to family caregiving. Qualitative research helped to manage our data without destroying complexity and context, as predicted by Atieno (2009). It enabled the data collection and analysis of rich data from different perspectives and on different levels. However, it was resource consuming and required advanced methodological skills.

Qualitative research outcomes depend on the participants of the study. In our case, sampling was determined by the aim of study, and therefore both endusers and service providers were invited to contribute their knowledge and experience in each step of the development. Maximum variation sampling and convenience sampling was applied with the service-providers in order to gain a multi-perspective and in-depth understanding. Professionals from the health and social services, representing the real world support system, including the acute, rehabilitation and home care phases, were included, and this was experienced as helpful.

Convenience sampling was applied with the end-users for ethical reasons, as some caregivers felt emotionally overburdened in the beginning of the counselling process and therefore did not wish to participate in the research. Participants with different caregiver affiliations, e.g. partners or adult children, were included. The sample sizes of the different studies were relatively small and saturation may not have been reached. Nonetheless, in qualitative research sample sizes are not determined by fixed rules or duration of an interview (Patton, 2001), but concern a multi-perspective and context-specific understanding of the phenomena.

The quality and rigor of qualitative data allows reflections on its trustworthiness and authenticity (Guba \& Lincoln, 1985) Qualitative research is still criticized by some part of the scientific community as being biased, anecdotal, and for lacking rigor, however the opposite is the case if it is conducted with high quality (Anderson 2010). In our study trustworthiness was achieved by careful reporting and long-term engagement (Phillips et al. (2014), resulting in credible, confirmable and defendable data. Credibility and confirmability benefited from applying bottom-up approaches during data collection, as promoted by Sprin- 
gett \& Wallerstein (2008). However, transferability is provided to some extent only due to its context-dependency. We triangulated our findings from different levels: individual level vs systems level; from different perspectives: service providers in the acute, rehabilitation, home care phase vs end-users; as well as within different methods: interviews vs. observation. Triangulation helped to achieve a balanced perspective of the results and gained a rich picture, which resulted in enhancement of the trustworthiness (Morse, 2009).

We consider our data as authentic because: (1) multi-perspective information was gathered (fairness), (2) participants were given a true 'voice' (ontological authenticity), (3) preliminary and final outcomes were discussed and disseminated (educational authenticity); (4) our research stimulated change on individual and system levels (catalytic authenticity), and finally, (4) participants felt empowered though the research (tactical authenticity).

The role of the researcher in qualitative research can be both a strength and a weakness, as it is strongly dependent on the skills, experience, intellect, and creativity of this person (Patton, 2002). In our case, the skills and experience, as well as critical thinking, increased during the programme's development process. In order to reduce interviewer bias results were cross-checked by an independent researcher, and member checking was applied when interpreting focus group results (Chapter 3, Chapter 4, and Chapter 6).

Qualitative research is an umbrella term (Silverman, 2005), which incorporates different methodological approaches, for example PAR, that focus on co-creation of knowledge. In our study PAR was found to be helpful in testing and optimizing the preliminary concept in practice, before full-scale implementation, resulting in a matured concept (chapter 4). The research team benefited from engaging with stakeholders in order to generate new knowledge, as promoted by Meyer (2000) and MacDonald 2012. Feedback from participants was requested in iterative cycles, which also led to change in practice, e.g. improved communication between different organisations, as promoted by Meyer (2000) and Baum (2016).

Due to its cyclic nature, insider knowledge can be generated in a co-creative way with the stakeholders. Potential conceptual weaknesses might be detected and options for improvement can be explored and tested in practice. Participants and researchers benefit from professional development, and participation might lead to greater respect, acceptance and a better working atmosphere (Denscombe, 2005). On the over hand PAR is time consuming, context-dependent and 
therefore has limited representativeness, and often involves extra work for the participants (Denscombe, 2005). In our case stakeholders' motivation to contribute with their knowledge and experiences was high, as this process impacted positively in their daily work. However, true participation requires power sharing, and therefore research teams must be skilled and open to new thinking (Baum, 2016).

PAR is growing in popularity in social sciences, organisational development and health and social care (Descombe, 2005). However, PAR is not often reported in public health's academic literature, despite reporting on small, context-specific programmes, for example a preventive obesity study (Baum, 2016; 0en \& Stormark, 2013). Research teams and practitioners may benefit from PAR when aiming to systematically test and optimise a new family caregiver support programme.

\section{Modes of knowledge generation}

We utilized both top-down and bottom-up modes of knowledge generation, also labeled as mode 1 and mode 2 research (Gibbons et al., 1994). In the Caregivers' Guide project the contextual needs for caregiver support were explored top-down, the preliminary five CBBs were developed top-down (study 1, Chapter 2), and stakeholders were analyzed top-down., Implementation risks, however, were analyzed bottom-up, whereas implementation management instruments were designed top-down (study 2, Chapter 3). The preliminary CBBs were optimized in practice bottom-up by (study 3, Chapter 4), while the impact in the evaluation phase of the study was evaluated top-down (study 4, Chapter 5). When initiating Vade Mecum, Participatory Health Research, a bottom-up working strategy was applied (study 5, Chapter 6).

In public health both approaches of knowledge generation: top-down and bottom-up, can be applied and each working approach has its strengths and weaknesses (Pearce, 1996). Traditionally, new knowledge is generated by `ballooning over ' the scientific (international) landscape without getting involved with the people who would be actually affected by the research or the programme. The top-down approach is predictable in terms of required time and resources. However, is likely to generate mono-perspective knowledge, which limits the indepth understanding of the specific context obligatory for complex interventions (Campbell, 2007).

Bottom-up approaches are increasingly applied in health system development and nursing sciences (Baum, 2016; 0en \& Stormark, 2013). Bottom-up is `engaging with ' the people and involving them in a democratic manner, for example 
in research activities or programme development (Cornwall \& Jewkes, 1995). In the new generation of project management, bottom-up approaches are considered as flexible, for example in terms of methods or team compositions, and collaborative, involving, for instance, different organizational levels (Cordella, 2018). However, bottom-up approaches of knowledge generation require flexible research and communication skills and more openness from both participants and researchers. Bottom-up research is less predictable but provides the context-tailored solution. We benefited from the top-down approach when exploring the general needs, developing the preliminary CBBs and in evaluation of the programme (Chapter 2 \& 5). Applying bottom-up strategies helped to gain multi-perspective understanding, increased motivation of the participants and assisted in reducing the gap between theory and practice (Cornwall, 2008; Baum, 2016; WH0, 2009). In the development of the Caregivers' Guide programme on an individual level, bottom-up strategies helped to understand the complexity of the problem in the real world, to assess the implementation risks and to optimize the CBBs (Chapter $3 \& 4$ ). On the system level, bottom-up strategies enhanced the feeling of ownership and acceptability. Combining both top-down with bottom-up approaches seems worthwhile during the development of a new caregiver support programme.

For initiating Vade Mecum we explicitly decided to apply PHR strategy. In PHR, a bottom-up direction and active participation are acknowledged as central elements. Participants from the service provider group were engaged as co-researchers and during the project's live cycle high participation degrees were achieved (Cornwall \& Jewkes, 1995). PHR has a flexible nature, for example in terms of time, resources and outcomes (Wright, 2013), which enables the team to choose data collection methods that met the context-specific requirements for each professional group, e.g. resources or professional's group size; and to develop from this their schedule for data collection. However, PHR was perceived as time-consuming, for example in data collection and analyses, and unpredictable in its outcomes. In our case, meeting with co-researchers were scheduled during their working hours, although some homework was necessary for each co-researcher, for example in preparing the next research steps. But overall, PHR led to generation of new, context-specific and practical based knowledge from different perspectives, which was based on real-life experience, as predicted by Wright (2013). Each professional group contributed to the mosaic of the context-specific needs. Moreover, co- researchers were empowered by PHR strategy, which impacted on their intrinsic motivation and professional development. 
In the Vade Mecum project time was invested in team-building activities, with a focus on building trust, mutual understanding and development of a collective goal. On the one hand this was found to be helpful for equipping and empowering co-researchers for their new role, which was especially important because of the fact that the German health system is organized top-down. None of the co-researchers had been engaged in research with a bottom-up strategy before, and consequently it took some time to grow into this role. While the study progressed, the participation degrees (Cornwall, 1996) could be increased from consultation (degree 3 ) to co-learning (degree 5). Co-researchers felt appreciated by their professional peer group, the head of the department and the external impulse provider, which resulted in a high intrinsic motivation and feeling of ownership. As a consequence, the professional impulse provider gained detailed contextual understanding of the actual geriatric support system with its strengths and weaknesses. Overall, PHR was perceived as a very interactive, creative and effective strategy for generating new and practical based knowledge in this specific setting. However, as the decision making process is democratic (Seidel \& Fixson, 2013), PHR requires tolerance and critical reflection skills when aiming to initiate bottom-up change within the system.

Most published stroke caregiver programmes apply traditional top-down designs, and no programmes have reported on the application of bottom-up approaches during their development phase (see, for example, 0stwald et al. 2013). Reports on initiating a new programme with PHR were also not found.

\section{Measurements}

Interviews, focus groups, and observations were used as qualitative measurements. These instruments were adapted to the context and the background of the participants.

However, in the evaluation phase, only one quantitative instrument, a self-developed questionnaire focusing on $\mathrm{HL}$ and $\mathrm{PH}$, was used to assess the impact on individual caregivers (Chapter 5), which may be seen as a limitation. However no context-specific instrument focusing on caregivers' HL and psychosocial support was available in the German language. General instruments for assessing $\mathrm{HL}$ in populations are existent, e.g. the Health Literacy Questionnaire (Osborne et al., 2013), or the European Literacy Questionnaire (Soersen et al., 2013). In order to allow a comparison with other stroke caregiver programmes, it might also have been useful to include one of the frequently used instrument to measure burden, e.g. Caregiver Strain Index (Robinson 1983), or a resource oriented instrument Utrecht Coping List (van den Heuvel et al., 2002). However, 
these would first have to be translated and validated, which was unfortunately not foreseen in our project.

\section{Data analyses}

Qualitative content analyses were used for examining the qualitative data. The structured and systematic approach was experienced as being helpful for gaining an in-depth understanding and for developing the new programme, as promoted by Hseih \& Shannon (2005), Graneheim (2017) and Krippendorff (2013). Content analyses is a relatively cheap, low tech and fast method to analyze data, and is considered as highly reliable due to its systematic analyzing process, which allows replication. Moreover, it is important to present trustworthiness by reflecting on the credibility, dependability, confirmability, transferability and authenticity of the findings (Graneheim \& Lundman, 2004; Elo et al., 2014). Therefore, content analyses benefits from an independent coding process, for example by a second researcher that may diminish methodological weaknesses. In addition, efforts on systematic reporting on the data analyzing process are crucial.

The limitation would be that our programme is, to the best of our knowledge, the first published complex caregiver programme operating at both individual and system levels, and therefore our findings are foundational and exploratory. Comparison with other caregiver programmes was impossible due to its unique and complex nature, as well as to its context-dependency.

The flexible CBBs are tailored to the actual needs of caregivers and the system in the Aachen region, and therefore transferability to other settings or other caregiving groups is limited, which is normal for complex programmes.

\section{Implications for further research, funders and policy makers}

\section{Further research}

\section{Complexity}

Caregiver support programmes fit the definition of complex interventions (Craig et al., 2008), and consequently, exploring and addressing complexity seems to be obligatory for the development of a new programme. Our findings show that it was fundamental to invest in activities, which assist in gaining an in-depth understanding of: 1) the context-specific needs, 2) the current support system with its stakeholders, and 3) possible levels of interactions. 
We have shown that investing time and efforts in understanding the needs for a new programme at individual (end-user) and system (service provider) levels was worthwhile. This new generated knowledge qualified researchers to address the context-specific needs in the new concept. Although we did not measure this directly, it might possibly contribute in reducing "teething problems" during implementation and might enhance the programme's transferability and sustainability. Our stroke specific caregiver support programme was the first report to address the needs on both levels in one programme. Further research on addressing the needs on both individual and system levels is required, in order to enhance the outcomes of a program on both levels.

We applied project management techniques (e.g. stakeholder \& risk analyses), system thinking and design thinking approaches to address complexity, which proved to be very helpful in our situation. Other researchers might also benefit from knowledge and skills stemming from other disciplines than health or public health. Additional approaches to explore and address complexity would contribute to enhancement of the scientific knowledge and in-depth understanding of the complexity in caregiver support programmes.

In public health there if a requirement for more practical examples and guidelines, explaining in detail stakeholders 'identification, classification and assessment. These would equip researchers with the required knowledge and skills to understand the multi-stakeholder landscape as well as to manage and engage with the programme's stakeholders. Henceforth, academic institutes may offer capacity building activities for researchers, e.g. stakeholder and risk analysis workshops.

In the Caregivers' Guide programme we addressed the different needs of the individual caregivers and the system in eight CBBs: five core CBBs on the individual needs and three facilitating CBBs, interconnect and safeguard the programme within the system. Using a 'blocks' approach was considered adequate for explaining the different components in a structured order to stakeholders or outsiders, e.g. public relations, and is also used in industrial development (Dahmen, 1989). Other researchers at conferences, for instance Forschungswelten 2018, have pointed out that the 'block' approach was a structured way to comprehend the programme's complexity on both levels. Therefore, the actual block approach might be valuable for other researchers as a methodology from the project management field. 


\section{Stepwise and iterative development process}

The development of a complex caregiver support programme should be not considered as a linear process (Richards, 2015). Our findings illustrate that the maturity and appropriateness of the new caregiver support programme benefited from an iterative and stepwise development process. Obviously a stepwise development requires resources and skills, however the outcomes are promising. Our programme was the first explicit report on the stepwise development of a stroke caregiver support programme. More public health examples using this approach, might contribute to scientific knowledge of complex programmes.

\section{Systems thinking}

We applied system thinking during the new programme's development process, as it seems imperative to consider that individual caregiver support programmes are not implemented in a vacuum but within an existing system. The World Health Organization (WHO, 2009) promotes system thinking in order to strengthen health systems. However, this approach does not seem to be frequently applied in caregiver support programmes. We found no publication reporting on or promoting the application of systems thinking for the development of a new caregiver support programme. Our experiences during the programme and also when presenting our work at scientific conferences, for example the European Conference for Public Health (EUPHA, Stockholm 2017) showed that many researchers are probably unfamiliar with system thinking, and consequently also lack the required skills. However, complex program researchers and designers may benefit from applying systems thinking skills (WH0, 2009) when aiming to understand and engage with the system.

\section{Context-specific and practice-based understanding}

As caregiver needs are context-specific, the impact of a programme is dependent on how far the real needs were understood and addressed by their designers (Campbell et al., 2007). Our new programme is based on multi-perspective context-specific insights and in-depth practice-based understanding of the complex contextual needs within the existing multi-stakeholder support system. As indicated by our findings and my previous experience in other programmes, it is almost impossible to gain a comprehensive context-specific understanding from a desk study alone. Our programme benefited from physically exploring the intricate multi-stakeholder support system and engaging personally with key 
stakeholders (end-users, service providers). Other research teams may benefit from this approach.

One other stroke caregiver support study (Cameron et al. 2008) has reported a similar approach, which was considered as helpful in their new programme development. Further research and critical reporting on how a context-specific understanding can be achieved and how it contributes to the development of the new programme would be advantageous.

\section{Multiperspective knowledge and participation}

The development of most caregiver support programmes involves more than one profession, (see, for example, Forster et al. (2013) and 0stwald et al. (2013)), which is also the case with the Caregivers Guide and Vade Mecum. In our case, as was shown in the chapters (2-6), the different professional backgrounds, experiences, perspectives and advanced multi-methodological research skills contributed in the programme's development process and impacted on its maturity. So, in general, complex programmes would benefit from a research team with multidisciplinary professional composition. However, our findings in chapter 4 and 6 promote the idea that instead of applying the traditional pathway of a top-down concept development by professional researchers alone, the use of bottom-up approaches might be advantageous. We included end-users and service providers early on and continuously in the new programme's development process. Both groups contributed with insightful knowledge, for example caregivers individual needs vs system needs, as well as with individual and system experience, for example barriers within the current support system. We benefited in particular from the practice-based knowledge of the professionals (service providers), which are routinely involved in caregiver interactions, for example in exploring the approach and timing of caregiver support (Chapter 2, 4 \& 6). Investing in the generation of multi-perspective knowledge might possibly guide the research team during the entire project management life cycle of a new programme's development. We used both approaches of knowledge generation for the development, and sometimes even merged these in one study (chapter 4), which enriched the picture. Researchers might benefit from combining topdown and bottom-up modes of knowledge generation during the development of a new programme. 


\section{Methodological pluralism}

We chose a multi-methodological approach (Morse, 2009) in the different steps of the development process, which helped to answer the research questions in detail and from different perspectives. This approach, especially when combining different qualitative designs, as, for example in chapter 2 and 5, was considered by both the research team and the professionals (service providers) to be reasonable, although it is time- and resource consuming. However, in the Caregivers' Guide and Vade Mecum the advantages of methodological pluralism were evident, as we have reported in earlier chapters, and thus may also be useful for other researchers in the field. Researchers and designers of caregiver support programmes might benefit from methodological pluralism in each phase of the project's management life cycle.

\section{Optimization}

For the research team one of the 'eye-opening' moments was when the preliminary concept was tried out in the everyday working environment (Chapter 4). Optimization helped to identify and address potential weaknesses and mature the concept. Our findings illustrate the value of investing in testing and verifying the concept 's feasibility and completeness in practice, as recently promoted by Bleijenberg et al. (2018). In domains other than public health, an optimization phase is an obligatory part of the project life cycle, e.g. product development. With hindsight, in our case investing in optimization was not considered as waste of time or resources. All involved players: professional researchers, service providers and end-users, benefited from this important step before full-scale implementation, as it resulted in a matured concept. We are certain that especially complex programmes, operating on different levels with multi-stakeholder settings, will gain from investing in an optimization phase.

\section{Participatory approaches}

In order to optimize the preliminary concept we applied Participatory Action Research (PAR) methodology, which turned out to be adequate due to its iterative and systematic character. Other researchers may use other methods for this purpose and further research on different optimization approaches for health or public health programme might be worthwhile. PAR requires continuous stakeholder engagement, and sharing power (Baum, 2016), which may be perceived as disadvantages. In our case, the collective knowledge and stakehol- 
ders' critical feedback acted as a 'compass needle' for fitting the programme in practice. Continuous engagement fostered stakeholders' feeling of ownership, which is important for transferability and sustainability. PAR is frequently used in small-scale public health research in development aid, mostly at community level in Latin America or Africa (Springett, 2017; Wallerstein \& Duran, 2008). In Europa PAR is acknowledged in educational research. However, in public health PAR is applied only in some programmes that aim to empower minorities, e.g. Roma people (Baum, 2016). Our findings show that PAR might be a good alternative during a new public health programme's optimization phase. Increased awareness for the strengths of PAR might be helpful for European public health programmes.

When initiating our second new programme (Vade Mecum) we applied Participatory Health Research (PHR), requiring the engagement of practitioners as co-researchers and aiming to achieve high levels of participation. This proved to be an adequate strategy. PHR enhanced the utilization of practical skills within the setting and provided insightful knowledge. Moreover, using PHR resulted in the empowerment of both co-researchers and professional researchers. PHR strategy is relatively new in Germany. In the recent years a network (PartNet) and a position paper for PHR research has been developed (Wright, 2013). The PhD candidate is part of this network and participated in a capacity building activity (Catholic University of Applied Sciences, Berlin) in order to gain the necessary skills and knowledge for using this strategy. More experience from different public health settings and critical reflections on the strengths and weaknesses of using the PHR strategy would be mandatory. However, in general public health researchers might learn from the gap in using PAR and may use PHR earlier for their purpose.

\section{Reporting}

In general, complex programmes in health care often fail to report systematically on their development process (Möhler et al., 2012). We reported on each phase of the new programme's development (chapter 1-6). Systematic reporting would clearly contribute to scientific knowledge and enhance the transparency and credibility of the work, and therefore such efforts are worthwhile. Moreover, researchers and practitioners would benefit from practical standards or guidelines for reporting. The adapted CReDECI 2 (Möhler et al., 2015) guideline with checklist provides good guidance at an individual level, but does not sufficient- 
ly address the needs at the system level. Elo et al. (2014) propose a checklist, with focus on the preparation, organization and reporting phase, which might also be helpful to researchers in complex programmes.

\section{Policy makers, health system planners and funders in Germany}

In Germany, the quantity of people requiring long-term care and support after rehabilitation is constantly increasing due to over-aging and medical advancement (Wetzstein et al., 2015). Family caregivers are considered as the backbone of long-term support, as they play a prominent and consistent role in the provision of care and support in home environment. It is imperative to prepare caregivers for their new and complex role, to strengthen their emotional, social and financial wellbeing, as well to protect them against the negative consequences of caregiving.

Family caregiving is a critical public health issue and unaddressed needs can develop into a crisis for the patient-caregiver dyad, the support system and our society. For that reason, policy makers, health system planers and funders ought to join forces and concentrate more on addressing family caregivers' complex needs.

In Germany, some caregiver initiatives and projects exist on different organizational levels, however these are fragmented, uneven in different federal states, or inaccessible for the end-users, or unknown to the caregivers, for example 'Familiale Pflege'. No comprehensive caregiver-caregiver support programmes, operating through all phases exist.

Our Caregivers' Guide programme aimed to fill the support gap for stroke caregivers. It was developed in Aachen (Germany) within the system existing at the time (2012-2015) and was perceived by the end-users, service providers and the research team to be helpful at an individual and a system level. However, after the funding phase, all attempts of the research team, the acute hospitals and the communal service providers to sustain this programme at a regional level failed on administrative grounds, for example unclear cost regulations in the Präventionsgesetz (2015). Other funding attempts, for instance Interreg, also failed. Meanwhile the need for support increased, especially in the geriatric departments. In 2017 Vade Mecum, a caregiver programme for elderly people was initiated in one geriatric setting in the Aachen region. However, at this moment in time no comprehensive caregiver-centered support programme is available. 
End-users, service providers and researchers have raised the question of what policy makers need in order to offer comprehensive, accessible and professional support.

The recent decisions and laws in health politicals do frame the legislative conditions for financing comprehensive caregiver support programmes, for example the Präventionsgesetz (2015). Our findings in the 'micro-cosmos' Aachen may help policy makers and health system planners in their attempts to support family caregivers. Political decision makers may actively request proposals for filling this frame with practicable, comprehensive and assessable solutions. From 2013-2015, the Caregivers' Guide research team contributed their knowledge in a North Rhine-specific overview of family caregivers (NRW-sÜPA, Jungbauer et al., 2015) that had been requested by the federal Ministry of Health, Emancipation, Nursing and Ageing (MGEPA). However, how are the suggestions of the different research institutions to be integrated in policies and activities that are accessible and suitable at a grassroots ' level? What is necessary to make change happen for family caregivers in the near future? Do we need more knowledge and research or is political power to initiate comprehensive support required?

\section{Developing, implementing and maintaining comprehensive caregiver support}

Our findings show that in new caregiver programmes it is imperative to perceive the complex needs for caregiver support at an individual and system level. The complex needs might be addressed more holistically when shifting from the linear perception of problem solving and the conventional silo thinking towards systems thinking (WH0, 2009). Our findings illustrate that a comprehensive caregiver support programme, which addressed the needs for caregiver support at both individual and system levels, impacted positively on both levels. Programmes such as the Caregivers' Guide or Vade Mecum may serve as interconnecting elements in the fragmented support system, as they interact on both levels. We believe that policy makers, funders, programme designers and practitioners would benefit from gaining the necessary skills for systems thinking in all phases of the project life cycle.

Our findings show that the development of comprehensive caregiver support requires an in-depth understanding of the complex multi-stakeholder support system. In our case, systematic stakeholder and risk analyses contributed to multi-perspective understanding and identification of implementation barriers. 
What would change in the development of a new public health programme, if policy makers and funders would encourage researchers and designers to use these techniques in the early development phase? Would we gain or lose, when exploring systematically the stakeholders and possible implementation risks?

As has been suggested in the literature (Bakas et al., 2014) and was experienced in our research, caregiver support programmes are most likely to address the actual support needs if their development process is step-wise, iterative and multi-perspective. Exploring the status-quo and assessing the actual need for caregiver support at an individual and a system level seems to be advantageous: through this process policy makers will gain an in-depth and multi-perspective understanding, and may also detect possible implementation barriers early in the project's lifecycle. Applying PHR strategy or working with high degrees of participation by primary stakeholders may serve this purpose. What does this "lesson learnt" indicate for policy makers in terms of resource provision, timing and participation of end-users and service providers?

Complex caregiver support programmes are strongly context-dependent. Therefore, when transferring a good-practice programme that worked in one setting to another, for example TRACKS, it would seem important to invest in an optimization phase. Referring to the changes in the preliminary concept of the Caregivers' Guide in our optimization phase, health system planers may use PAR or other participative approaches for this purpose.

\section{Caregivers as part of the current German support system}

According to the perception of family caregivers, service providers and the research team, up until now the needs and roles of family caregivers are still insufficiently addressed in the current patient-centered national policies or guidelines in Germany. Consequently, professionals may not thoroughly consider family caregivers as part of the patient's support team and fail to include them in transferal or discharge activities. How might health policy makers initiate and promote a mind shift from patient-centered to a more family-centered view? Who might be included in this process and what would be the benefit of a family centered approach? 


\section{Conclusion}

A new, comprehensive stroke caregiver support programme was developed, operating on both individual and system levels. This programme contains eight flexible CBBs: five core CBBs, necessary for individual caregiver support; and three facilitating $\mathrm{CBBs}$, interlinking and safeguarding the programme within the support system. At an individual level the programme impacted in improving caregivers' health literacy and stabilizing their psychosocial health. At the system level, service providers perceived improvements within the actual stroke support system. This programme is based both on international scientific as well as on actual context-specific knowledge and experience. It is the product of a systematic, multi-perspective and-methodological development process, which was characterized as a stepwise and iterative approach.

Developing a new and comprehensive family caregiver programme is not 'simple' or 'complicated' but, rather, a 'complex' task. Consequently, understanding and addressing complexity of the multiple components, stakeholders and levels in all phases of the project's life cycle seems to a requirement. For this purpose, transferable skills from project management, design- and systems-thinking approaches are especially helpful. Systematic stakeholder and risk analyses can assist in exploring the multi-stakeholder setting, and may enable research teams to develop adequate instruments.

Moreover, caregiver support programmes are not implemented in a vacuum but within an existing system. Consequently, developing a new programme based on scientific knowledge alone and not investing in gaining actual context-specific knowledge will possibly result in an incomplete or immature concept. Our findings show that it is valuable both to invest time and effort in generating context-specific knowledge, as well as to test and optimize the preliminary concept in the real-world. As caregiver support programmes impact on both individual and system level, evaluating the change on both levels will be useful.

Bottom-up research strategies and stakeholder participation resulted in the development of a comprehensive, matured and needs-driven concept. Especially the development of a new programme would benefit from increased use of participative working approaches with a high level of participation. End-users and service providers can contribute insightful, practical based knowledge and experience from different perspectives. When initiating a new support programme for a different target group, PHR strategy and early stakeholder engagement appeared to be very promising.

The development process requires a multidisciplinary and experienced research 
team, possessing the confidence and the resources to: (1) apply innovative research designs, (2) utilize new data collection strategies, and (3) share their power by actually engaging with the end-users and service providers.

Family caregivers are the backbone of long-term support in the home care phase. As researchers, it is our societal responsibility to strengthening caregivers' role in the actual support system and to prevent caregiver burden. With this study we reported on the entire project life cycle of a new caregiver support programme's development that was conducted in Aachen, Germany. The new programme was experienced to be helpful on both individual and system levels. However, due to administrative reasons, sustainability within the region was not achieved. Therefore, as of now (2018) a comprehensive caregiver-centered support programme is still absent in the Aachen region. Moreover, transferability to other regions and caregiving groups was not achieved. Consequently, the majority of the 4.7 Million Germany caregivers would possibly not profit from the "good practice" example (NRW award, good practice programme 2014). At this moment the influence of researchers stops. Is this the right moment to hand over the stick to the regional and federal health decision makers? Undoubtedly, it is time to move ahead and to protect and strengthen our backbone, the family caregivers. They deserve it! 
The stepwise development of a comprehensive family caregiver support programme. 
Chapter 8

CHAPTER 8 Summary 
In Germany and internationally, the complex needs of (stroke) family caregivers are often insufficiently addressed due to fragmented, unsuitable, invisible, delayed or even missing support offers within the existing support system. Moreover, during transferal and discharge of the patient, caregivers frequently experience inadequate involvement and lack of preparation for their new role by the system. It is worth mentioning that family caregivers are the key contributor of the long-term support in the home environment, as they provide individual care, emotional support and health navigation assistance to the patient voluntarily (adapted from Family Caregiver Alliance 2018).

Right from the beginning of the patient's hospitalisation phase, caregivers have complex support needs which continue to change during the patient's rehabilitation trajectory. Caregivers may require informational, emotional, psychological and/or peer support. Therefore, insufficiently addressing caregiver's needs may pose negative consequences on their physical, psychological and social health and may reduce the quality of life substantially.

From the public health point of view it is important to invest in the careful development, implementation and evaluation of comprehensive caregiver interventions, in a way to respond to the complex needs of both the individual endusers of the intervention, f.i. family caregivers, and the needs of the system 's service providers, f.i. health professionals. Complex interventions which contain different components and involve multiple stakeholders are most promising.

A personalized and long-term stroke-caregiver support programme, starting early in the acute phase, is missing in Germany. In the Aachen region (Germany), an innovative, multicomponent primary prevention programme for stroke family caregivers - the Caregivers ' Guide - was initiated in 2012 and was continuously developed, implemented and evaluated until 2015. Its purpose was to maintain stroke caregivers' quality of life and to reduce their burden by offering professional support parallel to the existent patient-centred stroke rehabilitation trajectory. In Chapters 2, 3, 4 and 5 of the dissertation a detailed report is given on: (1) how the Caregivers' Guide was developed and implemented; and (2) what the perceived outcomes of the intervention on both the individual and the societal levels were.

After completing the Caregivers' Guide, a new programme for family caregivers in the geriatric setting, so-called Vade Mecum, evolved as a spin-off (2017). Here, we completed the project life cycle of the initial caregiver intervention with this new project initiation phase in a large geriatric hospital setting In Aachen. It was initiated by applying the participatory health research (PHR) 
strategy, which was innovative for the public health domain. The purpose of this new study was to: (1) assess the existing caregiver support offers provided by the multidisciplinary team, and (2) explore professionals' needs for providing comprehensive caregiver support.

The development phase in the lifecycle of the Caregivers' Guide included two steps: (1) developing the preliminary concept which resulted in five `Conceptual Building Blocks` (CBB), and (2) designing of implementation management instruments.

Chapter 2 describes the development of the Caregivers`'Guide where we applied a naturalistic inquiry approach. A qualitative mixed-methods design was used for data collection. First, three separate, explorative, inductive, qualitative sub-studies were conducted: (1) seven explorative interviews with experienced stroke caregivers, (2) six semi-structured interviews with professionals working within stroke rehabilitation, and (3) seventeen participant observations with focus on professional - caregiver interactions. Regional stroke units, rehabilitation centres, outpatient services, and the home care providers were included. By means of a four-step qualitative content analysis, all three datasets were coded, categorized and subsequently condensed into subthemes. Second, outcomes were merged in one overarching qualitative study, clustered into main themes, and finally translated into preliminary CBBs. In all three sub-studies the need for a personalized, holistic and multicomponent caregiver support intervention emerged. The newly developed concept consisted of five flexible CBBs: 'Content', 'Human Resources', 'Personalized Approach', 'Timing', and 'Setting'. The CBB's development was based on the actual contextual needs of stroke caregivers within the existing support system. The application of mixed-methods helped to comprehend the complexity from different perspectives and enabled the context-tailored development the preliminary concept with its $\mathrm{CBB}$ 's.

Chapter 3 concentrates on the second step of the development phase, the design of instruments, aimed to facilitate the implementation of the complex stroke caregiver intervention in the real-life support system. First, different project management techniques were used to systematically analyse the projects stakeholders and possible implementation risks. Stakeholders were identified, classified and assessed using a top-down approach, while implementation risks were identified and assessed applying a bottom-up approach. Second, stakeholders and risks specific knowledge was applied to develop context-tailored 
implementation management instruments. This top-down process resulted in developing two instruments: (1) a comprehensive `stakeholder-risk atlas' providing individual stakeholder information, and (2) an overall 'project implementation strategy'. Systematic analyses enabled the research team to develop context-tailored implementation management instruments. Through stakeholder involvement and engagement insightful system knowledge was generated. Implementation management instruments can facilitate the implementation process and may positively impact the intervention's outcome.

Chapter 4 illuminates the conceptual optimisation process of the Caregivers' Guide preliminary concept with its five $\mathrm{CBB}$ 's when implementing in practice. Optimisation comprised three steps: (1) verifying and fitting the five preliminary CBBs, (2) detecting, developing, verifying and fitting new blocks, and (3) prioritizing all blocks. Participatory Action Research (PAR) which includes iterative cycles of four phases: observe, reflect, plan and act, was applied. A multi-methodological design was chosen to collect data. Optimisation resulted in the Caregivers' Guide matured concept, containing eight CBBs. The five preliminary CBBs: 'Content', 'Human resources', 'Personalised approach', 'Timing', and 'Setting', were improved and prioritised to be the core blocks, providing the base for individual caregiver support. The three new building blocks: 'Network building', 'Communication', and 'Social safety-net' were selected to serve as facilitating blocks, safeguarding the intervention within the complex everyday working routine in the support system. PAR helped to early detect conceptual weaknesses, adapt the concept to the actual needs of both the end-users and the system, and improve the programme's feasibility. Hereby, stakeholders' participation was crucial and their early engagement enhanced the interventions' acceptance in the system. Optimisation may improve the interventions' effectiveness.

Chapter 5 describes the evaluation of Caregivers' Guide intervention. We aimed to gain a comprehensive understanding of the interventions' impact on both individual and system levels. A multi-methodological approach was applied for data collection. Two interconnected studies with two groups of participants were conducted: (1) new caregivers participated in a pre-post design with a quantitative questionnaire and a post-intervention qualitative design with a semistructured interview (quant-QUAL), here they reflected on their individual experience with the intervention as end-user (individual level); and (2) stroke care professionals from different parts of the support system participated 
ex-post with an interview (QUAL-QUAL), reflecting on the impact of the intervention on the supported end-users (individual level) and on their perceived impact on the current stroke support system (system level). Quantitative data showed that providing personalized information improved caregivers' health literacy significantly, and offering psychosocial support stabilized caregivers' psychosocial health. Qualitative data clarified health literacy enhancements regarding knowledge, capability to act and individual empowerment, and psychosocial stabilisation of self-confidence, life balance and emotional well-being. The professionals (system perspective) stated that communication and network-building helped improving the system by positively influencing the daily work, institutional support, quality of care and inter-institutional cooperation. A comprehensive understanding of the interventions' impact was achieved on both levels.

Chapter 6 describes the initial step of the project cycle of assessing the actual situation of the caregiver support provided by the multidisciplinary team in one geriatric department in the Aachen region, and the exploration of professionals' needs for providing comprehensive caregiver support. Participatory Health Research (PHR) strategy was applied in a qualitative study design.

Multiprofessional members from the department were engaged as co-researchers. By the facilitation of an external impulse provider (professional researcher - PhD applicant), a research team was formed and its members were enabled to develop the research question, choose appropriate data collection methods, develop data collection instruments and decide on suitable procedures of engaging family caregivers. Needs and expectations towards the new concept were discussed and research objectives were formulated. A suitable mix of qualitative data collection methods consisting of interviews, focus groups and story-telling, was chosen. Practical solutions for involving family caregivers were discussed. PHR strategy resulted in initiating a qualitative study in the geriatric care setting carried out by their own professionals. High levels of participation were achieved. Knowledge was generated in a co-creative manner, and co-researchers were empowered. Comprehensive understanding and insightful knowledge of the system serves as a starting point for developing a context-tailored new family caregiver concept.

Chapter 7 provides a summary of the main outcomes and a reflection of the entire study as well as some methodological considerations and implications for future research. 
The stepwise development of a comprehensive family caregiver support programme.

\section{8}


Chapter 9

\section{CHAPTER 9 \\ Valorisation, References, List of figures, List of tables}




\section{Valorisation}

This thesis focuses on the stepwise development of a comprehensive caregiver support programme, which was conducted in Aachen, Germany. The current work provides new insights concerning the requirements for a holistic support programme. Parallel to the prevailing patient-centred support system, a system-centred support offer for family caregivers was developed.

The new programme, the Caregivers' Guide, operates on two levels: on the individual family caregiver level as well as on the support system level, which were interconnected with each other from the start of its development. On the individual level, a specially trained social worker offers personalized information and psychosocial support to family caregivers. On the system level, the new programme is interlinked with the existing care and support system by organising activities that enhance network-building and communication between the different support providers, e.g. in workshops, and provide social safety-net opportunities for the involved family caregivers after discharge.

Furthermore, Vade Mecum, a new programme to support family caregivers of elderly in the geriatric department in Würselen, was initiated. A multiperspective understanding of the needs on the individual caregiver and the system level was achieved.

This chapter highlights how the results of this thesis could be beneficial for those who contributed as key stakeholders. In addition, it highlights how the study could contribute on societal level and to the field of public health.

This study aimed to enhance the societal impact by creating value from knowledge by making it suitable and available for societal use as well as translating that knowledge into services (adapted from Drooge \& Jong, 2016). Both the programme's end-users, being the family caregivers, as well as the organisations and their individual practitioners, being the service providers within the system, were involved in the new programme's development process. From the start, the whole study was valorised with the participation of both groups of key stakeholders. Productive interactions, collaboration with knowledge users as well as involvement of knowledge users led to new, context-specific and practice-based knowledge. This was subsequently translated it into the final product: a holistic caregiver support programme. During the programme's life cycle, members of the broader society and the research team also valued the collaboration and productive interactions. 


\section{Family caregivers}

In Germany, the offer of a holistic caregiver support programme like the Caregivers' Guide would be of great value for family caregivers as it will assist them in preparing for and coping with their new role.

Offering needs-driven and personalized information and psychosocial support as focal part of the holistic programme resulted in improving caregivers ' health literacy and helped to (re)-stabilize caregivers' psychosocial health as well as safeguard continuity of support within the system.

For being holistic, a programme needs to consider not only the 'content', e.g. informational and psychosocial support. Other elements turned out to be crucial for the programme's success. During its development and pre-implementation phase, we illustrated that it is possible to develop such a complex programme within an existing care system, with the following elements: early start and for as long as needed (timing), outreach counselling, personalized support mode, professional support, and own choice of place where the counselling is offered (Chapter 2 \& 4). We also specified that all these elements need to be interconnected in a flexible manner.

Our results underline the importance of offering one holistic and flexible support programme developed with the participation of both key stakeholders: end-users and service providers. Their contribution was imperative for gaining a multiperspective understanding and for achieving conceptual maturity, feasibility and acceptance in practice. The service providers contributed in the development of the two management instruments, which aim to guide implementation on programme level and to facilitate the day-to-day interactions with the stakeholders (Chapter 3).

Throughout the entire project life cycle, caregivers were valued by having direct contact with the research team and giving them a voice. Productive interactions between the caregivers and the research team helped to exchange information and experiences, which contributed in gaining a comprehensive understanding of the complex caregiver needs. The appreciation of caregivers' knowledge and the consideration of their expectations shaped the programme from the start of the first contacts with experienced caregivers. During the optimisation phase, family caregivers contributed by critically reflecting on their experiences with 
the new support offer. Their input assisted the team in tailoring the programme to caregivers' actual needs.

The need for early and long-term support along the stroke care trajectory was addressed by the new programme, which was much valued by both the family caregivers and the service providers (Chapter 2 \& 4). Existing support offers in the geographic region Aachen are fragmented and do not proactively engage with family caregivers. However, services, e.g. Kommunaler Pflegestützpunkt, state that most caregivers ask for support too late. Applying an outreach counselling strategy was considered as very valuable by both family caregivers and service providers (chapter 4).

Opposed to common counselling offers in organisational settings, e.g. in the hospital, the opportunity to obtain counselling in a safe environment, e.g. at the caregivers' home, was much appreciated by the programme's end-users. Caregivers specified that this element was especially important in the beginning, when they felt destabilized, e.g. emotionally (chapter 4).

The new programme is interconnected with the actual support system. For that reason, caregivers and professionals within the support system were encouraged by the programme to interact which each other on an individual case level, e.g. during transferals. The knowledge transfer in two directions was valued by both end-users and system providers. It helped to reduce the communication gaps and weaknesses caused by the fragmented support trajectory and helped to understand and address the needs of both caregivers and service providers during transitions.

The programmes' internal and external communication activities, e.g. website and press releases, and network-building activities, e.g. participation in the caregiver symposium, were valued by both caregivers and service providers. On the one hand, the multiple direct and indirect interactions were time-consuming. On the other hand, both activities were perceived as crucial to arouse attention within the society, to facilitate early programme access for caregivers and to interconnect the programme with other support offers within the region, e.g. with practical caregiving courses for the health insurance providers.

The new programme valued caregivers' desire for interacting with peers. We facilitated the establishment of a stroke caregivers-specific peer group within the 
region. Engagement with this group was proactively offered to caregivers in the end of each counselling trajectory. This opportunity was much valued by the caregivers.

The caregiver-focussed programme offers flexible and personalized support by considering different caregiver groups, e.g. spouses, adult children. Moreover, it addresses the various support needs, e.g. emotional support or informational support (Chapter 4). Although this is speculation, our programme might also have had a beneficial effect on the patient. Service providers contemplated that the holistic support might prevent rehospitalisation of the care receiver by equipping the caregiver better for the new role, e.g. with knowledge and skills. However, our way of developing the programme was aiming to address the needs of the caregiver and not of the patient.

\section{Practitioners}

From the start and throughout the entire project life cycle, this holistic caregiver support programme was highly valued by the multiprofessional practitioners, being the service providers within the fragmented support system.

The added support for family caregivers by a professional counsellor was perceived as positively impacting on practitioners' professional performance, the institutional support, the interinstitutional cooperation, the quality of patient care, and the health system development.

The new programme was developed with the participation of practitioners with different professional backgrounds working in the acute, rehabilitation and home care support. These efforts led to a multiperspective understanding of the needs of both the caregiver and the system. Professionals' knowledge and extensive experiences were valued in productive interactions, e.g. weekly reflections within the case managers and social workers in the acute care hospitals. Professionals contributed in the participatory transdisciplinary research during PAR (Chapter 4). Based on their input, three facilitating blocks were added to the core blocks, addressing the system needs: network building, communication and social safety-net.

The new programme sensitized practitioners within the multidisciplinary support team regarding the complexity of caregiver needs and helped to develop a 
'pro-caregiver' climate within their setting. As consequence, caregivers were more and more included in transferal or discharge activities, which was valued by the professionals as securing the quality of care of the patient in the home environment. The 'caregiver-specific information box', which was developed by the programme, may be further utilized by the professionals, e.g. by social workers (Chapter 4). The different documents, written in 'caregiver-friendly' language, may assist caregivers in recalling the information given in the personalized counselling session.

High participation modes (Cornwall, 1996) were achieved in the Caregivers' Guides optimisation and Vade Mecum's initiation phase. In both settings and opposed to the common resistance to modifications, our investments, e.g. in time and resources, resulted in triggering change within the system on individual, professional and system level (Chapter 5 \& Chapter 6). Participation was valued by the professionals as it was perceived by improving their professional performance, e.g. improved collaboration with other service providers.

The programme enabled interprofessional exchange and interinstitutional collaboration. It fostered the process of developing a professional caregiver-focused network within the region. These long-term professional relationships caused synergy effects between the different service providers, e.g. facilitating early contacts between acute clinics and communal services, so called "kurzer Dienstweg" interactions, which was valued as most effective by some professionals. They specified that this interprofessional network augmented their intrinsic working motivation, as especially in difficult cases practical solutions were found in a co-creative manner (Chapter 5).

Professionals in the acute and rehabilitation support system welcomed the option of counselling in the caregiver's home for more practical, patient-centred reasons. Professionals in these settings are currently not allowed to conduct home visits. Therefore, the opportunity to professionally assess the feasibility of home caregiving and the specific needs was considered as safeguarding the quality of care of the patient after transferal (Chapter 5).

Today in Germany, the dynamic and economically driven changes within the health and support system require the further development of the health system, e.g. creation of new job profiles. In the course of the Caregivers' Guide life cycle, the requirements for a special caregiver counsellor were developed in a 
co-creative manner and tested for its feasibility (Chapter 2, Chapter 4). This job description, specifying tasks, competences, experiences, social skills and personality traits, may be useful for professionals in management positions.

\section{Societal level}

During the second part of the Caregivers`' Guide funding phase, more than a few valorisation strategies were applied on societal level. The communal decision makers and the governmental health insurance providers were valued by providing information regarding the programme and its outcomes. In different productive interactions we exchanged caregiver specific information and augmented the consciousness for the complex and long-term needs of family caregivers. The role of the governmental health insurance providers and the communal social services was taken into account by exploring the scope for the programme's transferal into the current support system on regional and communal level in a collaborative manner.

We applied also indirect interactions for valorisation. On federal level, we contributed an "advisory transdisciplinary research" activity, which was aimed at supporting political decision makers in their attempt to improve caregivers' role and to offer appropriate support. This work, together with the other academic contributions, was much appreciated by the commissioner (MGEPA-NRW, Ministry for Health, Emancipation, Nursing and Ageing in North Rhine-Westphalia).

\section{Scientific community}

Apart from generating new and context-specific knowledge regarding family caregiver support in Germany, our study is, to our knowledge, the first published study addressing the complex needs of caregiver support on two interconnected levels, both on individual as well as system level, in one holistic support programme. The approach may set impulses for further research in the field of public health. It may stimulated knowledge users, e.g. researchers or health system developers, to consider the complexity of such programmes in terms of the required components, staff, resources or research resigns.

Our study showed that applying methodological pluralism and investing in including both end-users and service providers resulted in gaining a multiperspective understanding of the actual situation and the needs. This comprehensive approach may assist complex intervention planners and researchers during the initiation, development, implementation and evaluation of a new programme. 
During the programme, the efforts made to achieve high participation levels (Cornwall, 1996) resulted in overcoming the gap between theory and practice. Consulting the programme's key stakeholders, cooperating with the professionals and asking for their active voice (mode 4) lead to achieving a co-learning atmosphere (mode 4), which was very supportive for the new programme. In Germany, participation modes beyond consultation are still seldom in the field of public health. Public health approaches can be potentially valorised, when high participation levels were achieved during their development.

In our study, applying the Participative Health Research (PHR) strategy resulted in an in-depth understanding of the complex needs of both the caregivers and the system (Chapter 6 ). The study's outcomes may motivate other colleagues to invest in early stakeholder engagement and apply different participation strategies during the project's life cycle. This practice-based knowledge may assist researchers and planners in the challenging task of the development of a needs-driven, feasible and acceptable new public health programme.

Transdisciplinary knowledge was applied in both studies. Techniques and strategies from the project management, e.g. stakeholder and risk analyses, as well as from systems- and design thinking, were introduce in a public health programme (Chapter 2, $3 \& 6$ ). It was considered as helpful for the development of this holistic caregiver support programme. Public health researchers may benefit from these techniques and strategies in all phases of a programme.

During the study, dissemination efforts resulted in direct and indirect productive interactions. The new knowledge was disseminated within the scientific community by publishing in international, peer-reviewed journals, contributing on the debates in international conferences as well as by enabling web-based discussions, e.g. via research gate. Likewise, knowledge was directly distributed also to practitioners within the system. Two interprofessional capacity building workshops, focussing on caregiver needs, and two methodological workshops, regarding the Participatory Health Research strategy, were conducted. Both direct and indirect interactions may provoke constructive feedback, which supplements to researchers' knowledge base and contributes in empowering the researcher professionally and individually. 
Chapter 9 


\section{References}

Aaltonen K, Kujala J (2015) Towards an improved understanding of project stakeholder landscapes. International Journal of Project Management; 34:1537-1552.

Abraham C, Denford S, Smith J, Dean S, Greaves C, Lloyd J, Tarrant M, White M, Wyatt K (2015) Designing interventions to change health-related behaviour. In: Richards DA, Hallberg IR (Eds.), Complex interventions in health: An overview of research methods. Routledge, New York, 103pp.

Achterberg T (2015) How to arrive at an implementation plan? In Richards DA, Hallberg IR (Eds) in: Complex interventions in Health: An overview of research methods. Routledge, New York, 282pp.

Ackermann F, Eden C (2011) Strategic management of stakeholders: Theory and practice. Long Range Planning; 44:179-196.

Adelman R, Tmanova L, Delegado D, Dion S, Lachs M (2014) Caregiver burden. A clinical review. Journal of American Medical Association; 311 (19):1052-1059.

Aguirrezabal A, Duarte E, Rueda N, Cervantes C, Marco E, Escalada F (2013) Effects of information and training provision in satisfaction of patients and carers in stroke rehabilitation. NeuroRehabilitation; 33: 639-647.

Ahmeda S, Kima M, Sugandhib N, Phelpsc B, Sabellia R, Diallod M, Youngd P, Duncand D, Kellermane S (2013) Beyond early infant diagnosis: case finding strategies for identification of HIV-infected infants and children. AIDS; 27(2):S235-S245.

Ammar A, Berman K, Amornsawadwatana S (2007) A review of techniques for risk management in projects. Benchmarking: an International Journal; 14 (1):22-36.

Amsden, J; Van Wynsberghe R (2005) Community mapping as a research tool with youth. Action Research; 3:357-381.

Amstrong N, Hearnshaw H, Powell J, Dale J (2007) Stakeholder perspectives on the development of a virtual clinic for diabetes care: qualitative study. Journal of Medical Internet Research; 9:E23.

Anderson C (2010) Presenting and evaluating qualitative research. American Journal of Pharmaceutical Education; 74(8):A41.

Anderson G, Jones F (2000) Knowledge generation in educational administration from the inside-out: The promise and perils of site-based, administrator research. Educational Administration Quarterly; 36:428-64.

Arnold RD, Wade JP (2015) A definition of systems thinking: a systems approach. Procedia Computer Sciences; 44:669678.

Atieno OP (2009) An analysis of the strengths and limitations of qualitative and quantitative research paradigms. Problems of Education in the 21th Century; 13:13-18.

Atkinson R, Crawford L, Ward S (2006) Fundamental uncertainties in projects and the scope of project management. International Journal of Project Management; 24:687-698.

Bäckström B, Sundin K (2010) The experience of being a middle-aged close relative of a person who has suffered a stroke - six months after discharge from a rehabilitation clinic. Scandinavian Journal of Caring Sciences; 24:116-124.

Bakas T, Clark P, Kelly-Hayes M, King R, Lutz B, Miller E (2014) Evidence for stroke family caregiver and dyad interventions: a statement for healthcare professionals from the American Heart Association and American Stroke Association. Stroke; 45(9):2836-2852.

Bakas T, Farran CJ, Austin JK, Given BA, Johnson EA, Williams LS. (2009) Stroke caregiver outcomes from the Telephone Assessment and Skill-Building Kit (TASK). Top Stroke Rehabilitation; 16(2):105-121. 
BAR - Bundesarbeitsgemeinschaft Rehabilitation (2018) Das Phasenmodell der neurologischen Rehabilitation. Online available at: https://www.bar-frankfurt.de/fileadmin/dateiliste/1-News-Seiten/5-BAR_eV/BAR-Symposium_Neuro/ downloads/Hintergrund_neurologisches_Phasenmodell.pdf. Accessed 10.12.2018.

Barbour R (2001) Checklist for improving rigor in qualitative research: a case of tail wagging the dog. British Medical Journal; 322:115-117.

Batterham R, Hawkins M, Collins P, Buchbinder R (2016) Health literacy: applying current concepts to improve health literacy and reduce health inequalities. Public Health; 132:3-12.

Baum F (2016) Power and glory: applying participatory action research in public health. Gaceta Sanitaria (editorial); 30:405-407.

Baum F, MacDougall C, Smith D (2006) Participatory action research. Journal of Epidemiological Community Health; 60:854-57.

Ben Mahmoud-Jouini S, Midler C, Silberzahn P (2016) Contributions of design thinking to project management in an innovation context. Project Management Journal; 47:144-156.

Benjamin EJ, Blaha MJ, Chiuve SE, et al. (2017) on behalf of the American Heart Association Statistics Committee and Stroke Statistics Subcommittee Heart disease and stroke statistics -2017 update: a report from the American Heart Association. Circulation; 135:e229-e445.

Bevan JL, Pecchioni LL (2008) Understanding the impact of family caregiver cancer literacy on patient health outcomes. Patient Education \& Counseling; 71(3):356-364.

Bienstein C (2006) Schlaganfallpatienten und pflegende Angehörige in der postakuten Phase. Eine Literaturanalyse. German. (stroke patients and their family caregivers in the post-acute phase: a literature review). Gütersloh, Stiftung Deutsche Schlaganfallhilfe (Hrsg.) Verlag Bertelsmann Stiftung.

Bircher J, Kuruvilla S (2014) Defining health by addressing individual, social, and environmental determinants: New opportunities for health care and public health. Journal Public Health Policy; 35:363-386.

Bleijenberg N, de Man-van Ginke J, Trappenburg J, Ettema R, Sino C, Heim N, Hafsteindóttir T, Richards D, Schuurmans M. (2018) Increasing value and reducing waste by optimizing the development of complex interventions: Enriching the development phase of the Medical Research Council (MRC) Framework. International Journal of Nursing Studies; 79:86-93.

Blomquist T, Hällgren M, Nilsson A, Söderholm A (2010) Project】as囚practice: In search of project management research that matters. Project Management Journal; 41(1):5-16.

Borglin G (2015) The value of mixed methods for researching complex interventions. In: Richards DA, Hallberg IR, editors. Complex interventions in health. An overview of research methods. New York: Routledge; p.29-45.

Bourne L (2015) Making projects work: Effective stakeholder and communication management. Auerbach Publications, $26 \mathrm{pp}$.

Bradley F, Wiles R, Kinmonth AL, Mant D, Gantley M (1999) Development and evaluation of complex interventions in health services research: case study of the Southampton heart integrated care project (SHIP). British Medical Journal; 318:711-715.

Brainhard J, Hunter P (2016) Do complexity-informed health interventions work? A scoping review. Implementation Sciences; 11:127.

Brereton L, Carroll C, Barnston S (2007) Interventions for adult family carers of people who have had a stroke: a systematic review. Clinical Rehabilitation; 21:867-884.

Brewer L, Horgan F, Hickey A, Williams D (2013) Stroke rehabilitation: recent advances and future therapies. QJM: An International Journal of Medicine; 106:11-25. 
Broese van Groenou M, De Boer A, Iedema J (2013) Positive and negative evaluation of caregiving among three different types of informal care relationships. European Journal of Ageing; 10:301-311.

Brown T, Wyatt J (2010) Design thinking for social innovation. Development Outreach; 12(1):29-34.

Brugha R, Varvasovszky Z (2000) Stakeholder analysis: a review. Health Policy Planning; 15(3):239-246.

Bucher JA, Loscalzo M, Zabora J, Houts PS, Hooker C, Brintzenhofeszoc K (2001) Problem-solving cancer care education for patients and caregivers. Cancer Practice; 9:66-70.

Bulley C, Shiels J, Wilkie K, Salisbury L (2009) Carer experiences of life after stroke - a qualitative analysis. Disability \& Rehabilitation; 32:1406-1413.

Bundesarbeitsgemeinschaft Rehabilitation (BAR) - German Working Group for Rehabilitation (2014) Empfehlungen zur Phase E der neurologischen Rehabilitation. http://www.bar-frankfurt.de/fileadmin/dateiliste/1-News-Seiten/5-BAR_ eV/BAR-Symposium_Neuro/downloads/Hintergrund_neurologisches_Phase. Accessed 14.12.2018.

Bunter Kreis (2017) Fortbildungsbroschüre (capacity building offers). https://www.ispa-bunterkreis.de/fileadmin/ img/pdf-downloads/PDF_Fortbildungsbroschuere_Einzelseiten/2016/2016_06_15_Fortbildungsbroschuere_Web. pdf. Accessed 30.11.2018.

Burton C (2005) Expanding the role of the stroke nurse: a pragmatic clinical trial. Journal of Advanced Nursing; 6:640650.

Burton H, Adams M, Bunton R; Schroder-Back P (2008) Developing stakeholder involvement for introducing public health genomics into public policy. Public Health Genomics; 12:11-19.

Buul L, Sikkers J, Agtmael M, Kramer M, Steen J, Hertogh C (2014) Participatory action research in antimicrobial stewardship: a novel approach to improving antimicrobial prescribing in hospitals and long-term facilities. Journal of Antimicrobial Chemotherapy; 69:1734-1741.

Cameron J, Naglie G, Gignac M, Bayley M, Warner G, Green T, Czerwonka A, Huijbregts M, Silver F, Phillips S, Cheung A (2014) Randomized clinical trial of the timing it right stroke family support program: research protocol. BMC Health Service Research; 14:18.

Cameron J, Naglie G, Silver F, Gignac M (2013) Stroke family caregivers`s support needs change across the care continuum: a qualitative study using the Timing It Right framework. Disability \& Rehabilitation; 35(4):315-324.

Cameron JI, Tsoi C, Marsell A (2008) Optimizing stroke systems of care by enhancing transitions across care environments. Stroke; 39:2637-2643.

Cameron JI, Gignac M (2008) "Timing it Right": a conceptual framework for addressing the support needs of family caregivers to stroke survivors from hospital to home. Patient Education \& Counselling; 70:305-314.

Campbell M, Fritzparticks R, Haines A, Kinmonth A, Sandercrock P, Spiegelhalter D, Tyrer P (2000) Framework for design and evaluation of complex interventions to improve health. British Medical Journal; 321:694-696.

Campbell N, Murray E, Darbyshire J, Emery J, Farmer A, Griffiths F, Guthrie B, Lester H, Wilson P, Kinmonth A (2007). Designing and evaluating complex interventions to improve health care. British Medical Journal (Clinical research ed.). 334:455-459.

Candy B, Jones L, Drake R, Leurent B, King M (2011) Interventions for supporting informal caregivers of patients in the terminal phase of a disease. Cochran Database Systematic Review, 6.

Carden L, Egan T (2008) Does our literature support sectors newer to project management? The search for quality publications relevant to non-traditional industries. Systematic review. Project Management Journal; 36(3):4-27.

Cargo M, Mercer S (2008) The value and challenges of participatory research: strengthening its practice. Annual

Review Public Health; 29: 325-350. 
Carlsson E, Ehnfors M, Eldh AC, Ehrenberg A (2012). Accuracy and continuity in discharge information for patients with eating difficulties after stroke. Journal of Clinical Nursing; 21(1-2):21-31.

Caron F (2014) Project planning and control: early engagement of project stakeholders. Journal of Modern Project Management; 2:84-97.

Center for Disease Control - CDC - (2018). Communication. https://www.cdc.gov/workplacehealthpromotion/planning/communications.html. (accessed 25.11.2018).

Chalmers I, Glasziou P (2009) Avoidable waste in the production and reporting of research evidence. Lancet; 374:8690 .

Chen L, Xiao L, Bellis A (2015) First time stroke survivors and caregivers`’ perception of being engaged in rehabilitation. Journal of American Nursing; 72(1):71-84.

Cheng H, Chair S, Chau J (2014) The effectiveness of psychosocial interventions for stroke family caregivers and stroke survivors: a systematic review and meta-analysis. Patient Education \& Counselling; 95:30-40.

Chippindale S, French L (2001) HIV counselling and the psychosocial management of patients with HIV or AIDS. British Medical Journal; 322:1533-1535.

Clarke D, Forster A (2015) Improving post-stroke recovery: the role of the multidisciplinary health care team. Journal of Multidisciplinary Healthcare; 8:433-442.

Clarke D, Hawkins R, Sadler E, Harding G, McKevitt C, Godfrey M, Dickerson L, Farrin A, Kalra L, Smithard D, Forster A (2014) Introducing structured caregiver training in stroke care: findings from the TRACS process evaluation study. British Medical Journal Open; 4:e004473.

Collins LG, Swartz K (2011) Caregiver care. American Family Physician; 83:1309-1317.

Cordella D (2018) Top-down and bottom-up project management: Leveraging the advantages of the two approaches. https://www.wrike.com/blog/top-down-and-bottom-up-project-management-leveraging-the-advantages-of-thetwo-approaches/. Accessed 10.11.2018.

Cornwall A (2008) Unpacking 'participation': models, meanings and practices. Community Development Journal; 43:269-283.

Cornwall A (1996) Towards participatory practice: participatory rural appraisal (PRA) and the participatory process. In: De Koning K \& Martin M (eds) Participatory Research in Health: Issues and Experiences. Vistaar Publications, New Delhi, India, p.96.

Cornwall A, Jewkes R (1995) What is participatory research? Social Sciences \& Medicine; 41(12):1667-1676.

Corry M, While A, Neenan K, Smith V (2015) A systematic review of systematic reviews on interventions for caregivers of people with chronic conditions. Journal of advanced Nursing; 71:718-34.

Corry M, Clarke M, While AE, Lalor J (2013) Developing complex interventions for nursing: a critical review of key guidelines. Journal of Clinical Nursing; 22(17-18):2366-86.

Craig P, Dieppe P, Macintyre S, Michie S, Nazareth I, Petticrew M (2008) Developing and evaluating complex interventions: the new Medical Research Council guidance. British Medical Journal (Clinical research ed.), 337:979-983.

Creasy KR, Lutz B, Young ME, Ford A, Martz C (2013) The impact of interactions with providers on stroke caregivers' needs. Rehabilitation Nursing; 38:88-98.

Creswell J (2009) Mapping the field of mixed methods research. Journal of Mixed Methods Research; 3:95-108.

Creswell J, Fetters MD, Ivankova NV (2004) Designing a mixed methods study in primary care. Annual Family Medicine; 4(2):7-12. 
Curran G, Bauer M, Pyne J, Stetler C (2012) Effectiveness-implementation hybrid designs: combining elements of clinical effectiveness and implementation research to enhance public health impact. Medical Care; 50:217-226.

Dahmen E (1989) Developmental blocks in industrial economics. Industrial Dynamics; pp109-121.

Damschroder LJ, Aron DC, Keith RE, Kirsh SR, Alexander JA, Lowery JC (2009) Fostering implementation of health services research findings into practice: a consolidated framework for advancing implementation science. Implementation Science; 4(50).

Datta J, Petticrew M (2013) Challenges to evaluating complex interventions: a content analysis of published papers. BMC Public Health; 13:568.

Denscombe M (2005) The good research guide for small-scale social research projects. Second Edition, Open University Press, Berkshire, England.

Department for International Development - DIFID - (2002) Tools for development: A handbook for those engaged in development activity. 2002. http://webarchive.nationalarchives.gov.uk/+/http:/www.dfid.gov.uk/Documents/publications/toolsfordevelopment.pdf. Accessed 10.12.2018.

Dewalt KM, Dewalt BR (2010) Participant observation: a guide for field workers. 2nd edition, Walnut Creek, Alta Mira Press, pp.41-66.

Dogherty EJ, Estabrooks CA (2015) Why do barriers and facilitators matter? In: Richards DA, Hallberg IR (Eds.), Complex interventions in health, Routledge, New York, pp. 273-280.

Dorant E, Boumans NPG (2016) Positive and negative consequences of balancing paid work and informal family care: a survey in two different sectors. International Journal of Health and Psychology Research; 4(1):16-33.

Drooge L, de Jong S (2016) Valorisation: researchers already do much more than they realizes. Rathenau Institute. Available at: https://www.rathenau.nl/en/knowledge-policy/research-valorisation. Accessed 21.02.2019.

Egan M, Anderson S, McTaggart J (2010) Community navigation for stroke survivors and their care partners: description and evaluation. Top Stroke Rehabilitation; 17:183-190.

Ehde D, Wegener S, Williams R, Ephraim P, Stevenson J, Isenberg P; MacKenzie E (2013) Developing, testing and sustaining rehabilitation interventions via participatory action research. Archives of Physical Medicine and Rehabilitation; 94:S30-42.

Elmore DL (2014) The impact of caregiving on physical and mental health: implications for research, practice, education, and policy. In: Talley, R. C. et al. (Eds.), The challenges of mental health caregiving. Springer Sciences+Business, New York, pp.15-30.

Elo S, Kääriäinen M, Kanste 0, Pölkki T, Utriainen K, Kyngäs H (2014) Qualitative content analysis: A focus on trustworthiness. SAGE Open; https://doi.org/10.1177/2158244014522633.

Elo S, Kyngäs H (2008) The qualitative content analyses. Journal of Advanced Nursing; 62(1):1007-115.

Emanuelson I, Wendt LV, Hagberg I, Marchioni-Johansson M, Ekberg G, Olsson U, Larsson J, Egerlund H, Lindgren K, Pestat C (2003) Early community outreach intervention in children with acquired brain injury. International Journal Rehabilitation Research; 26:257-64.

Epstein-Lubow G, Gaudiano BA, Hinckley M, Salloway S, Miller IW (2010) Evidence for the validity of the American Medical Association's Caregiver Self-Assessment Questionnaire as a screening measure for depression. Journal of the American Geriatrics Society; 58(2):387-388.

Eskerod P, Huemann M, Savage G (2016) Project stakeholder management - past and present. Project Management Journal; 46(6):6-14. 
European Commission (2007) Special Eurobarometer 283: Health and long term care in the European Union.; Brussels, Belgium, http://ec.europa.eu/public_opinion/archives/eb_special_300_280_en.htm\#283. Accessed 12.12.2018.

Evans $\mathrm{CJ}$, Harding R, Higginson IJ (2013) 'Best practice` in developing and evaluating palliative and end-o-life care services: A meta-synthesis of research methods for the MORECare project. Palliative Medicine; 27(10):885-898.

Family Caregiver Alliance (2006) Caregiver assessment: principles, guidelines, and strategies for change. Report from a National Consensus Development Conference. Vol. 1. San Francisco, CA; 2006. https://caregiver.org/sites/caregiver. org/files/pdfs/v1_consensus.pdf. Accessed 12.12.2018.

Family Caregivers Alliance (2018) Definitions. Available at: https://www.caregiver.org/definitions. Assessed 12.12.2018.

Forster A, Dickerson J, Young J, Patel A, Kalra L, Nixon J, Smithard D, Knapp M, Holloway I, Anwar S, Farrin A. (2013) A structured training programme for caregivers of inpatients after stroke (TRACS): a cluster randomized controlled trial and cost-effectiveness analysis. TRACS Trial Collaboration. Lancet; 382(9910):2069-2076.

Forster A, Dickerson J, Young J, Patel A, Kalra L, Nixon J (2013) TRACS Trial Collaboration. A structured training programme for caregivers of inpatients after stroke (TRACS): a cluster randomized controlled trial and cost-effectiveness analyses. Lancet; 382:2069-2076.

Forster A, Brown L, Smith J, House A, Knapp P, Wright JJ, Young L (2012) Information provision for stroke patients and their caregivers. Cochrane Database of Systematic Reviews 2012, 3.

Forster A, Armstrong J, Buckley A, Sherry J, Young T, Foliaki S, James-Hohaia TM, Theadom A, McPherson KM (2012) Encouraging family engagement in the rehabilitation process: a rehabilitation provider's development of support strategies for family members of people with traumatic brain injury. Disability \& Rehabilitation; 34:1855-1862.

Forster D, Newton M, McLachlan H (2011). Willis K. Exploring implementation and sustainability of models of care: can theory help? BMC Public Health; 11(S5):S8.

Franzen-Dahlin A, Larson J, Murray V, Wredling R, Billing E (2008) A randomized controlled trial evaluating the effect of a support and education programme for spouses of people affected by stroke. Clinical Rehabilitation; 22:22-730.

Freebody P, Luke A (1990). ` Literacies` programmes: debates and demands in cultural context. Prospect; 5:7-16.

Friesen-Stroms J, Moser A, von der Loo S, Beurskens A; Bours G (2014) Systematic implementation of evidence-based practice in a clinical nursing setting: a participatory action research project. Journal of Clinical Nursing; 24:57-68.

Funk LM, Stajduhar KI (2009) Interviewing family caregivers: implications of the caregiving context for the research interview. Qualitative Health Research; 19:859.

Garlo K, O'Leary JR, Van Ness PH, Fried TR (2010) Burden in caregivers of older adults with advanced illness. Journal of American Geriatric Sociology; 58:2315-2322.

German Federal Statistical Office - Statistisches Bundesamt - (2015) Pflegestatistik 2013. Pflege im Rahmen der Pflegeversicherung. Deutschlandergebnisse. Destatis, Wiesbaden.

German Federal Statistical Office - Statistisches Bundesamt- (2013) Fallpauschalenbezogene Krankenhausstatistik (DRG-Statistik) Operationen und Prozeduren der vollstationären Patientinnen und Patienten in Krankenhäusern - Ausführliche Darstellung. Destatis, Wiesbaden.

Germany Stroke Aid Foundation (2015) Geschichte der Stiftung, Für ein Leben ohne Schlaganfall: History of the Foundation. (For a life against stroke) online available http://www.schlaganfall-hilfe.de/geschichte. Accessed 10.12.2018.

Ghazzawi A, Kuziemsky C, 0 `Sullivan T (2016). Using a complex adaptive system lens to understand family caregiving experiences navigating the stroke rehabilitation system. BMC Health Services Research; 16:538. 
Gibbons M, Limoges C, Nowotny H, Schwartzman S, Scott P, Trow M (1994) The new production of knowledge: the dynamics of science and research in contemporary societies. London: Sage.

Giovannetti ER, Wolff JL, Xue Q, Weiss C0, Leff B, Boult C, Hughes T, Boyd CM (2012) Difficulty assisting with health care tasks among caregivers of multimorbid older adults. Journal of General Internal Medicine; 27:37-44.

Given C, Given B, Stommel M, Collins C, King S, Franklin S (1992) The Caregiver Reaction Assessment (CRA) for caregivers to persons with chronic physical and mental impairments. Research in Nursing \& Health; 15:271-283.

GKV - Gesetzliche Krankenversicherung - (2011) Telefongestützte Intervention für Pflegende Angehörige von Schlaganfall-Betroffenen. Online available: https://www.gkv-spitzenverband.de/media/dokumente/presse/publikationen/ schriftenreihe/GKV-Schriftenreihe_Pflege_Band_8_18968.pdf. Accessed 18.11.2018.

Glass TA, Berkman LF, Hiltunen EF, Furie K, Glymour MM, Fey ME, Ware J (2004) The families in recovery from stroke trial (FIRST): primary study results. Psychosomatic Medicine; 66(6):889-897.

Graneheim U, Lindgren BM, Lindman B (2017) Methodological challenges in qualitative content analyses: A discussion paper. Nurse Education Today; 56:29-34.

Grant J, Hunt C, Steadman L (2014) Common caregiver issues and nursing interventions after a stroke. Stroke; 45:e151-e153.

Gräsel E, Biehler J, Schmidt R, Schupp W (2005) Intensification of the transition between inpatient neurological rehabilitation and home care of stroke patients: controlled clinical trial with follow-up assessment six months after discharge. Clinical Rehabilitation; 19:725-736.

Green LW, George A, Daniel M, Frankish CJ, Herbert CP, Bowie WR, O’Neill M (1995) Study of participatory research in health promotion. Ottawa: Royal Society of Canada, Canada.

Greene J, Caracelli V, Graham W (1989) Towards a conceptual framework for mixed-method evaluation designs. Education \& Policy Analysis; 11:255-74.

Greenhalgh T, Jackson C, Shaw S, Janamian T (2016) Achieving research impact through co-creation in community-based health services: literature review and case study. The Milbank Quarterly; 94:392-429.

Greenwood N, Mackenzie A (2010) Informal caring for stroke survivors: meta-ethnographic review of qualitative literature. Maturias; 66:268-276.

Greenwood N, Mackenzie A, Cloud G, Wilson N (2010) Loss of autonomy, control and independence when caring: a qualitative study of carers of stroke survivors in the first three months after discharge. Disability \& Rehabilitation; 32:125-33.

Greenwood N, Mackenzie A, Cloud GC, Wilson N (2009) Informal primary carers of stroke survivors living at home challenges, satisfaction and coping: a systematic review of qualitative studies. Disability \& Rehabilitation; 31:337-351.

Greenwood-Lee J, Hawe P, Nettel-Aguirre A, Shiell A, Marshall D (2016) Complex intervention modelling should capture the dynamics of adaption. BMC, Medical Research Methodology; 16:51.

Grol R, Wensing M, Bosch M, Hulscher M, Eccles M (2013) Theories on implementation of change in healthcare. In: Improving patient care: The implementation change in health care (Eds: Grol R, Wendsing M, Eccles M, Davis), BMJL books Wiley \& Sons, 0xford, UK.

Gruber M, De Leon N, George G, Thompson P (2015) Managing by design. Academy of Management Journal; 58:1-7.

Guba EG, Lincoln YS (1985) Naturalisic inquiry. Beverly Hills, California; Sage Publications.

Guba, EG (1981) Criteria for assessing the trustworthiness of naturalistic inquiries. Educational Communication \& Technology Journal; 29:75-91. 
Gunderson J, Crepeau-Hobson F, Drennen C (2012) Research to practice: a disaster behavioral health framework. Disaster Prevention \& Management; 21(5):572-83.

Hackett ML, Pickles K (2014) Part I: frequency of depression after stroke: An updated systematic review and meta-analysis of observational studies. Stroke; 9:1017-1025.

Han B, Haley WE (1999) Family caregiving for patients with stroke: review and analysis. Stroke; 30:1478-1485.

Handley M, Gorukanti A, Cattamanchi A (2016) Strategies for implementing sciences: a methodological review. Emergency Medicine Journal; 0:1-5.

Harris JE, Eng JJ, Miller WC, Dawson AS (2010) The role of caregiver involvement in upper-limb treatment in individuals with subacute stroke. Physical Therapy; 90:1302-1310.

Hawe P (2015) Lessons from complex interventions to improve health. Annual Review Public Health; 36:307-323.

Henley R, Marshall R, Vetter S (2011) Integrating mental health services into humanitarian relief responses to social emergencies, disasters, and conflicts: a case study. Journal of Behaviour Health Services \& Research; 38:132-141.

Heuschmann P, Busse 0, Wagner M, Endres M, Villringer A, Röther J, Kolominsky-Rabas PL, Berger K (2010) Schlaganfallhäufigkeit und Versorgung von Schlaganfallpatienten in Deutschland. Aktut Neurology; 37:333-340.

Hillmann S, Wiedmann S, Rücker V, Berger K, Nabavi D, Bruder I, Koennecke HC, Seidel G, Misselwitz B, Janssen A, Burgmeister C, Matthis C, Busse 0, Hermanek P, Heuschmann PU (2017) Stroke unit care in Germany: the German stroke registers study group (ADSR). BMC Neurology; 17:49.

Hjortsø CN (2010) Project management in research capacity building partnerships. Danish Development Research Network, Kopenhagen. http://bsuge.org/fileadmin/user_upload/bsu-ge/Other_Reports/NIC0_Project_Management_ RCB_Guidelines_April_2010.pdu. Accessed 10.12.2018.

Hoddinot J, Britten J, Pill R (2010) Why do interventions work in some places and not others: A breastfeeding support group trial? Social Science \& Medicine; 70:769-778.

Hofstede G (2003) Cultures and organizations. Intercultural cooperation and its importance for survival. London, Profile Books LTD.

Hsieh H, Shannon S (2005) Three approaches to qualitative content analyses. Qualitative Health Research, 15(9):12771288.

Institute of Medicine (2004) Health literacy: a prescription to end confusions. Washington DC: National Academies Press.

Jeffery N (2009) Stakeholder engagement: A road map to meaningful engagement. \#2 in the Doughty Centre 'How to do Corporate Responsibility` Series. 2009. https://www.som.cranfield.ac.uk/som/dinamic-content/media/CR\%20 Stakeholder.pdf. Accessed 10.12.2018.

Jepsen AL, Eskerod P (2009) Stakeholder analysis in projects: challenges in using current guidelines in the practice. International Journal of Project Management; 274:335-343.

Jungbauer J, Floren M, Krieger T (2016) Der Angehörigenlotse: Erprobung und Evaluation eines phasenübergreifenden Beratungskonzepts für Angehörige von Schlaganfallbetroffenen. Praxis Klinische Verhaltensmedizin \& Rehabilitation; 99:161-174.

Jungbauer J, Floren M, Krieger T (2015) Beratung und Begleitung für Angehörige von Schlaganfallpatienten in Nordrhein-Westfalen. In W. Schnepp (Hrsg.), Erstellung einer NRW-spezifischen Übersicht zur Gesamtsituation pflegender Angehöriger (S. 521-558). Universität Witten-Herdecke: Abschlussbericht an das Ministerium für Gesundheit, Emanzipation, Pflege und Alter (MGEPA) des Landes Nordrhein-Westfalen. 
Jungbauer J, Floren M, Krieger T (2014) Der Angehörigenlotse: Ein innovatives Modellprojekt für Angehörige von Schlaganfallpatienten. FORUM sozialarbeit + gesundheit; 3: 22-24.

Kalra L, Evans A, Perez I, Melbourn A, Patel A, Knapp M, Donaldson N (2004) Training carers of stroke patients: randomised controlled trial. British Medical Journal; 328:1099.

Kennon N, Howden P, Hartley M (2009) Who really matter? A stakeholder analysis tool. Extension Farming Systems Journal; 5(2):9-17.

Kerncijfers (2014) The Netherlands Institute for Social Research, SCP, The Hague, Netherlands.

Kessler D, Egan M, Kubina LA (2014) Peer support for stroke survivors: a case study. BMC Health Service Research; 14:256.

Khadka C, Vacik H (2012) Comparing a top-down and bottom-up approach in the identification of criteria and indicators for sustainable community forest management in Nepal. Forestry; 85(1):145-158.

King RB, Hartke T, Houle T, Lee J, Herring G, Alexander-Perterson BS, Raad J (2012) A problem-solving early intervention for stoke caregivers: one year follow-up. Rehabilitation Nursing; 37(5):231-41.

Komatsu H, Yagasaki K (2014) The power of nursing: guiding patients through a journey of uncertainty. European Journal of Oncological Nursing; 18:419-424.

Koshy E, Koshy V, Waterman H (2011) Action research in health care. London: SAGE.

Krieger T, Feron F, Bouman N, Dorant E (2019) Developing implementation management instruments in a complex intervention for stoke caregivers based on combined stakeholder and risk analyses. (in review)

Krieger T, Feron F, Dorant E (2017) Developing a complex intervention programme for informal caregivers of stroke survivors: The Caregivers`' Guide. Scandinavian Journal of Caring Science; 31(1):146-156.

Krieger T, Feron F, Dorant E (2019) Optimising the concept of a complex stroke caregiver support programme via participatory action research. (accepted for publication)

Krieger T, Feron F, Dorant E (2019) Evaluating a complex intervention for stroke caregivers on individual and system level: the Caregivers' Guide. (submitted)

Krippendorff K (2013) Content Analyses. An Introduction on its Methodology. Sage Publication, London.

Kummer K, Budnick A, Blüher S, Dräger D (2010) Gesundheitsförde ᄀrung für ältere pflegende Angehörige. Ressourcen und Risiken - Bedarfslagen und Angebotsstrukturen. Prävention \& Gesund ᄀheitsförderung; 5:89-94.

Kunz A, Wilz G (2011) Die Belastungen pflegender Angehöriger bei Demenz. Entstehungsbedingungen und Interventionsmöglichkeiten. Der Nervenarzt; 82:336-342.

Küttel C, Schäfer-Keller P, Brunner C, Conca A, Schütz P, Frei IA (2015) Daily routine of informal caregivers-needs and concerns with regard to the discharge of their elderly family members from the hospital setting-a qualitative study. Pflege; 28(2):111-21.

Labonte R, Feather J, Hills MA (1999) Story dialogue for health promotion knowledge development and evaluation. Health Education Research; 14:39-50.

Laforest J (2009) Safety Diagnosis Tool Kit for Local Communities. Guide to Organizing Semi-Structured Interviews with Key Informants. Institute National de Santé Publique du Quebec; 2-5.

Larkin M, Boden ZVR, Newton E (2015) On the brink of genuinely collaborative care: experience-based co-design in mental health. Qualitative Health Research; 25:1463-1476. 
Larson J, Franzén-Dahlin A, Billing E, Arbin M, Murray V, Wredling R (2005) The impact of a nurse-led support and education programme for spouses of stroke patients: a randomized controlled trial. Journal of Clinical Nursing; 14(8):9951003.

Legg LA, Quinn TJ, Mahmood F, Weir CJ, Tierney J, Stott DJ, Smith LN, Langhorne P (2011) Non-pharmacological interventions for caregivers of stroke survivors. Cochrane Database Syst Rev; 5(10): CD008179.

Lehto B, Lylmä J, Astedt-Kurki P (2013) The everyday life of adult family members of working aged survivors of stroke during the first year after stroke - an integrative review. Clinical Nursing Studies; 1(3):7-18.

Leiber T, Stensaker B, Harvey L (2015) Impact evaluation of quality assurance in higher education: methodology and causal designs. Quality in Higher Education; 3: 288-311.

Leischow S, Best A, Trochim W, Clark P, Gallagher R, Marcus S, Matthews E (2008) Systems thinking to improve the public's health. American Journal for preventive Medicine; 35:S196-S203.

Lenfle S (2008) Exploration and project management. International Journal of Project Management; 26:469-478.

Levati S, Camplell P, Frost R, Dougall N, Wells M, Donaldson C, Hagen S (2016) 0ptimization of complex health interventions prior to a randomized controlled trial: a scoping review of strategies used. Pilot \& Feasibility Studies; 2:17.

Li X, Xia X, Wang P, Zhang S, Liu M, Wang L (2017) Needs and rights awareness of stroke survivors and caregivers: a cross-sectional, single-centre questionnaire survey. British Medical Journal Open; 7:e013210.

Liedström E, Skovdahl K, Isaksson A, Windah J, Kihlgren A (2014) Understanding the next of kin's experience of their life situation in informal caregiving of older persons. Clinical Nursing Studies; 2:53-62.

Liman TG, Heuschmann PU, Endres M (2011) Changes in cognitive function over 3 years after first-ever stroke and predictors of cognitive impairment and long-term cognitive stability: the Erlangen Stroke Project. Dement Geriatric Cognitive Disorders; 31:291-299.

Lincoln NB, Walker MF, Dixon A, Knights P (2004) Evaluation of a multiprofessional community stroke team: a randomized controlled trial. Clinical Rehabilitation; 18(1):40-47.

Lopez-Hartmann M, Wens J, Verhoeven V, Remmen R (2012) The effect of caregiver support interventions for informal caregivers of community-dwelling frail elderly: a systematic review. International Journal of Integrated Care; 12:1-16.

Loquercio D, Hammersley M, Emmens B (2006) Understanding and addressing staff turnover in humanitarian agencies. Humanitarian Practice Network; 55:1-35.

Loupis YM, Faux SG (2013) Family conferences in stroke rehabilitation: a literature review. Journal of Stroke Cerebrovascular Diseases; 22:883-893.

Lucchi E (2013) Moving from the 'why' to the 'how': reflections on humanitarian response in urban settings. Disasters; 36:87-104.

Lutz B, Camicia M (2016) Supporting the needs of stroke caregivers across the care continuum. Clinical Review; 23(12):557-566.

Lutz B, Young M (2010) Rethinking intervention strategies in stroke family caregiving. Rehabilitation Nursing; 35(4):152-160.

Lutz B, Chumbler NR, Lyles T, Hoffman N, Kobb R (2009) Testing a home-telehealth programme for US veterans recovering from stroke and their family caregivers. Disability \& Rehabilitation; 31(5):402-409.

Lutz B, Young M, Cox K, Martz K, Creasy C (2011) The crisis of stroke: experiences of patients and their family caregivers. Topics in Stroke Rehabilitation; 18:786-797. 
MacDonald C (2012) Understanding participatory action research: a qualitative research methodology option. Canadian Journal of Action research; 13:34-50.

MacIsaac L, Harrison M, Gedfrey C (2010) Supportive care needs of caregivers of individuals following stroke: a synopsis of research. Canadian Journal of Neuroscience Nursing; 32(1):39-46.

Marsden D, Quinn R, Pond N, Golledge R, Neilson C, White J, McElduff P, Pollack M (2010) A multidisciplinary group programme in rural settings for community-dwelling chronic stroke survivors and their carers: a pilot randomized controlled trial. Clinical Rehabilitation; 24(4):328-341.

Mayring P (2000) Qualitative content analyses. Forum Qualitative Social Research, 1(2). http://www.qualitative-research.net/index.php/fqs/article/view/1089, Accessed 12.12.2018.

Meranius MS, Josefsson K (2017) Health and social care management for older adults with multimorbidity: a multiperspective approach. Scandinavian Journal of Caring Science; 31:96-103.

Meyer M (2006) Pflegende Angehörige in Deutschland: Ein Überblick über den derzeitigen Stand und zukünftige Entwicklungen. (Informal Caregivers in Germany. An overview of the status quo and developments) Münster Literatur, 10-11.

Meyer J (2000) Qualitative research in health care. Using qualitative methods in health related action research. British Medical Journal; 320:178-181.

Möhler R, Köpke S, Meyer G (2015) Criteria for reporting the development and evaluation of complex interventions in healthcare: revised guideline (CReDECI 2). Trials; 16(1):204.

Möhler R, Bartoszek G, Köpke S, Meyer G (2012) Proposed criteria for reporting the development and evaluation of complex interventions in healthcare (CReDECI): guideline development. International Journal of Nursing Studies; 49(1):40-46.

Montgomery RV, Stull DE, Borgatta EF (1985) Measurement and analysis of burden. Research \& Aging; 7:137-152.

Moore GF, Evans RE (2017) What theory, for whom and in which context? Reflections on the application of theory in the development and evaluation of complex health interventions. Social Science \& Medicine - Population Health; 3:132135 .

Morse J (2015) Critical analyses of strategies for determining rigor in qualitative analyses. Qualitative Health Research; 25(9):1212-1222.

Morse J, Cheek J (2014) Making room for qualitatively-driven mixed-method research. Qualitative Health Research; 24:3-5.

Morse J (2010) Simultaneous and sequential qualitative mixed methods design. Qualitative Inquiry; 16:483-491.

Morse J (2003) Towards holism: The significance of methodological pluralism. International Journal of Qualitative Methods; 2:13-20.

Murray J, Young J, Forster A, Ashworth R (2003) Developing a primary care-based stroke model: The prevalence of longer-term problems experienced by patients and carers. British Journal of General Practice; 53:803-807.

Mustaro PN, Rossi R (2013) Project management principles applied in academic research projects. Issues in Informing Science and Information Technology; 10:325-340.

Nahm ES, Resnick B, Orwig D, Magaziner J, Bellantoni M, Sterling R, Brennan PF (2012) A theory-based online hip fracture resource center for caregivers. Nursing Research; 61(6):413-422.

National Alliance for Caregiving (2018) From insight to advocacy: addressing family caregiving as a national public health issues. https://www.caregiving.org/wp-content/uploads/2018/01/From-Insight-to-Advocacy_2017_FINAL. pdf. Accessed 10.12.2018. 
National Stroke Association - NSA - (2018) Stroke support groups. http://www.stroke.org/stroke-resources/stroke-support-groups. Accessed 29.11.2018.

Ng GT (2009) Support for family caregivers: what do service providers say about accessibility, availability and affordability of services. Health \& Social Care in the Community; 17(6):590-598.

Nimptsch U, Manski T (2012) Trends in der akutstationären Schlaganfallversorgung in Deutschland. Deutsches Ärzteblatt; 109:51-52.

Nowossadeck S, Engstler H, Klaus D (2016) Pflege und Unterstützung durch Angehörige. Report Altersdaten 01/2016. Deutsches Zentrum für Altersfragen.

Nutbeam D (2008) The evolving concept of health literacy. Social Science \& Medicine; 67:2072-2078.

Nutbeam D (2000) Health literacy as a public health goal: a challenge for contemporary health education and communication strategies in the 21tst century. Health Promotion International; 15(3):259-267.

$0 `$ Leary Z (2004) The essential guide to doing research. SAGE, London, UK.

0’Brien CL, Moore G, Rolley JX, Ski CF, Thompson DR, Lautenschlager NT, Gonzales G, Hsueh YS, Castle D (2014) Exploring health care providers' perceptions of the needs of stroke carers: informing development of an optimal health program. Top Stroke Rehabilitation; 21:421-431.

0'Sullivan T, Corneil W, Kuziemsky C, Toal-Sullivan D (2014) Use of the structured interview matrix to enhance community resilience through collaboration and inclusive engagement. Systems Research \& Behaviour Sciences; 32:616-628.

Oen G; Stormark K (2013) Participatory action esearch in the implementing process of evidence-based intervention to prevent childhood obesity: Project design of the "Healthy Future Study". Journal of Obesity; 1-10.

Onwuegbuzie AJ, Teddlie C (2003) A framework for analyzing data in mixed methods research. In A. Tashakkori \& C. Teddlie (Eds.), Handbook of mixed methods in social and behavioral research (pp. 351-383). Thousand 0aks, CA: Sage.

Osborne RH, Batterham RW, Elsworth GR, Hawkins M, Buchbinder R (2013) The grounded psychometric development and initial validation of the Health Literacy Questionnaire (HLQ). BMC, Public Health; 13(1):658-674.

Ostwald SK, Godwin KM, Cron SG, Kelley CP, Hersch G, Davis S (2014) Home-based psychoeducational and mailed information programs for stroke-caregiving dyads post-discharge: a randomized trial. Disability \& Rehabilitation; $36(1): 55-62$.

Paasche-Orlow MK, Wolf MS (2007) The causal pathways linking health literacy to health outcomes. American Journal of Health Behavior; 31(1):S19e26.

Palmer J, Bozas G, Stephens A, Johnson M, Avery G, Toole L (2013) Developing a complex intervention for the outpatient management of incidentally diagnosed pulmonary embolism in cancer patients. BMC, Health Service Research; 13:235.

Pandi-Perumal S, Akhter S, Zizi F, Jean-Loui G, Ramasubramanian C, Freeman R, Narasimhan M (2015) Project stakeholder management in clinical research environment how to do it right. Review. Frontiers in Psychiatry; 6:71.

Patton MQ (2001) Qualitative Evaluation and Research Methods (2nd Edition). Thousand oaks, CA: Sage Publications, pp.339-371.

Pearce CL, Conger JA, Locke EA (2008) Shared leadership theory. The Leadership Quarterly; 19(5):622-628.

Pelto PJ (2015) What is so new about mixed methods? Qualitative Health Research; 25(6):734-45.

Perry L, Middleton S (2011) An investigation of family carers' needs following stroke survivors' discharge from acute hospital care in Australia. Disability \& Rehabilitation; 33(19-20):1890-1900. 
Pfeiffer K, Beische D, Hautzinger M, Berry JW, Wengert J, Hoffrichter R, Becker C, van Schayck R, Elliott TR (2014) Telephone-based problem-solving intervention for family caregivers of stroke survivors: a randomized controlled trial. Journal of Consultation \& Clinical Psychology; 82:628-643.

Phillips C, Dwan K, Hepworth J, Pearce C, Hall S (2014) Using qualitative mixed methods to small health care organizations while maximizing trustworthiness and authenticity. BMC, Health Service Research; 14:559.

Pieniak S (2017) Die Inanspruchnahme von Beratungs- und Entlastungsleistungen durch pflegende Angehörige von an Demenz erkrankten Familienmitgliedes in der häuslichen Versorgung. Pflegewissenschaften; 1/2: 29-39.

Pindus D, Mullis R, Lim L, Wellwood I, Rundell V, Abd Aziz N, Mant J (2018).Stroke caregivers ' and informal caregivers' experiences of primary care and community health care services: a systematic review and meta-ethnography. PLOSone; 13(2): e0192533.

Pinquart M, Sörensen S (2007) Correlates of physical health of informal caregivers: a meta-analysis. Journal of Gerontology Psychology \& Sciences; 62(2):126-137.

Plank A, Mazzoni V, Cavada L (2012) Becoming a caregiver: new family caregivers`experience during transition from hospital to home. Journal of Clinical Nursing; 21:2072-2082.

Proctor E, Powell B, McMillen J (2013) Implementation strategies: recommendations for specifying and reporting. Implementation Sciences; 8:139.

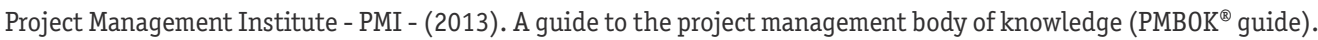
5th edt., Atlanta, pp.391-413.

Putman L, Verbeek-Oudijk D, De Klerk M, Eggink E (2002) Zorg en ondersteuning in Nederland:

Quigley W. The health of health care. Quoting Martin Hickey, former Lovelace CE0. Albuquerque Journal Outlook; 1:39 .

Read S, Maslin-Prothero S (2011) The involvement of users and carers in health and social research: the realities of inclusion and engagement. Qualitative Health Research; 21:704-713.

Reber A, Allen R, Reber E (Eds) (2009) Penguin Dictionary of Psychology. London: Penguin.

Redfern J, McKevitt C, Wolfe S, Charles DA (2006) Development of complex interventions in stroke care: a systematic review. Stroke 2006; 37:2410-2419.

Richards, D.A (2015) The critical importance of patient and public involvement for research into complex interventions. In: Richards, D.A.; Hallberg, I.R., editors. Complex interventions in health. An overview of research methods. Routledge, New York, USA, pp.46-50.

Rigby H, Gubtiz G, Phillips S (2009) Topical review: a systematic review of caregiver burden following stroke. International Journal of Stroke; 4:285-292.

Ringer T, Hazzan AA, Agarwal A, Mutsaers A, Papaioannou A (2017) Relationship between family caregiver burden and physical frailty in older adults without dementia: a systematic review. Systematic Review; 6: 55-66.

Robinson B (1983). Validation of a Caregiver Strain Index. Journal of Gerontology; 38:344-348.

Robinson L, Francis J, James P, Tindle N, Greenwell K, Rodgers H (2005) Caring for carers of people with stroke: developing a complex intervention following the Medical Research Council Framework. Clinical Rehabilitation; 19(5):560571.

Rühli E, Sachs S, Schmitt R, Schneider T (2017) Innovation in multistakeholder settings: The case of a wicked issue in health care. Journal of Business \& Ethics; 143(2):289-305. 
Rychetnik L, Frommer M, Hawe P, Shiell A (2002) Criteria for evaluating evidence on public health interventions. Journal of Epidemiology \& Community Health; 56:119-127.

Sanders K, Schnepel L, Smotherman C, Livingood W, Dodani S, Antonios N, Lukens-Bull K, Balls-Berry J, Johnson Y, Miller T, Hodges W, Falk D, Wood D, Silliman S (2014) Assessing the impact of health literacy on education retention of stroke patients. Prevention Chronic Disease; 10(11):E55.

Scherbring M (2002) Effect of caregiver perception of preparedness on burden in an oncology population. Oncological Nursing Forum; 29:70-76.

Schiller C, Winters M, Hanson H, Ashe M (2013) A framework for stakeholder identification in concept mapping and health research: a novel process and it application to older adult mobility and the built environment. BMC, Public Health; 13:428.

Schlarmann J, Metzing-Blau S, Schnepp W (2011) Implementing and evaluating the first German young-carer project: Interventions, pitfalls and the need for piloting complex interventions. Open Nurse; 5:38-44.

Schreiner M (2012) Qualitative Content Analyses in Practice. SAGE, London.

Schuler M, Oster P (2004) Versorgung von Patienten mit und nach akutem Schlaganfall. Gesundheit Gesellschaft Wissenschaft; 3(4):153-138.

Schumacher KL, Stewart BJ, Archbold PG, Dodd MJ; Dibble SJ (2000) Family caregiving skill: Development of the concept. Research in Nursing Health; 23:191-203.

Schure LM, van den Heuvel ETP, Stewart RE, Sanderman R, de Witte LP, Meyboom-de Jong B (2006) Beyond stroke: Description and evaluation of an effective intervention to support family caregivers of stroke patients. Patient Education \& Counseling; 62(1):46-55.

Seidel VP; Fixson SK (2013) Adopting design thinking in novice multidisciplinary teams: the application and limits of design methods and reflexive practices. Journal of Production Innovation Management; 30:19-33.

Semeus W (2015) Modelling process and outcomes in complex interventions. In In: Richards DA, Hallberg IR, editors. Complex interventions in health. An overview of research methods. New York: Routledge; pp:110-120.

Shenton AK (2004) Strategies for ensuring trustworthiness in qualitative research projects. Education for Information; 63-75.

Shepperd S, Lewin S; Straus S, Clarke M, Eccles MP, Fitzpatrick R, Wong G, Sheikh A (2009) Can we systematically review studies that evaluate complex interventions? PLoS Medicine; 6:e1000086.

Silva AL, Teixeira HJ, Teixeira MJC, Freitas S (2013) The needs of informal caregivers of elderly people living at home: an integrative review. Scandinavian Journal of Caring Science; 27:792-803.

Silver S, Harel Z, McQuillan R, Weizman A, Thomas A, Chertow G, Nesrallah G, Bell C, Chan C (2016) How to begin a quality improvement project. Clinical Journal of American Society of Nephrology; 11(5):893-900.

Silverman D (2005) Doing qualitative research: a practical handbook. London: Sage Publications.

Smith GC, Egbert N, Dellman-Jenkins M, Nanna K, Palmieri PA (2012) Reducing depression in stroke survivors and their informal caregivers: a randomized clinical trial of a Web-based intervention. Rehabilitation Psychology; 57(3):196206.

Smith J, Forster A, House A, Knapp P, Wright J, Young J (2008) Information provision for stroke patients and their caregivers. Cochrane Database Systematic Reviews, Issue 2. 
Smith JE, Smith DL (2000) No map, no guide. Family caregivers ' perception on their journeys through the system. Care Management Journal; 2:27-33.

Smith LN, Lawrence M, Kerr SM, et al. (2004) Informal carers’ experience of caring for stroke survivors. Journal of Advanced Nursing; 46:235-244.

Sorensen K, Van den Broucke S, Pelikan JM, Fullam J, Doyle G, Slonska Z, Brand H (2013) Measuring health literacy in populations: illuminating the design and development process of the European Health Literacy Survey Questionnaire (HLS-EU-Q). BMC Public Health; 13(1):948-957.

Sørensen LV, Waldorff FB, Waldemar G (2008) Early counselling and support for patients with mild Alzheimer's disease and their caregivers: a qualitative study on outcome. Aging \& Mental Health; 12:444-450.

Sparks L, Nussbaum JF (2008) Health literacy and cancer communication with older adults. Patient Education \& Counseling; 71(3):345-350.

Specht R (2014) Intersektorale Kooperation in der neurologischen Frührehabilitation. (Intersectional cooperation in the early neurologic rehabilitation.) KU Gesundheitsmanagement, Genius Rehabilitation; 83:53-54.

Spencer L, Schooley M, Anderson L, Kochtitzky C, DeGroff A, Devlin H, Mercer S (2013) Seeking best practices: A conceptual framework for planning and improving evidence-based practices. Preventing Chronic Disease; 10:E207.

Springett J (2017) Participatory action research. Oxford Bibliographies. DOI: 10.1093/0B0/9780199756797-0156:

Springett J, Wallerstein N (2008) Issues in participatory evaluation. In: Minkler, M., Wallerstein, N. (eds). Community Based Participatory Research for Health. New York, Jossey-Bass, p. 263-286.

Stange KC, Miller WL, McWhinney I (2001) Developing the knowledge base of family practice. Family Medicine; 33:286297.

Statistisches Bundesamt (2015) Pflegestatistik 2013. Pflege im Rahmen der Pflegeversicherung. Deutschlandergebnisse. DESTATIS Wiesbaden.

Steffen AM, McKibbin C, Zeiss AM, Gallagher-Thompson D, Bandura A (2002) The revised scale for caregiving self-efficacy: reliability and validity studies. Journals of Gerontology: Psychological Sciences; 57:74-86.

Stroke Unit Trialists' Collaboration (2013) Organized inpatient (stroke unit) care for stroke. Cochrane Database Syst Rev; 9:CD000197.

Talley RC, Crews JE (2007) Framing the public health of caregiving. American Journal of Public Health; 97(2):224-228.

Thrift AG, Cadilhac DA, Thayabaranathan T, Howard G, Howard VJ, Rothwell PM \& Donnan GA.(2014). Global stroke statistics. International Journal of Stroke; 9:6-18.

Thrift AG, Thayabaranathan T, Howard G, Howard VJ, Rothwell PM, Feigin VL, Norrving B, Donnan GA, Cadilhac DA (2017) Global stroke statistics. International Journal of Stroke; 12(1):13-32.

Thurmond V (2001) The point of triangulation. Journal of Nursing Scholarship; 33:253-58.

Tilling K, Coshall C, McKevitt C, Daneski K, Wolfe C (2005) A family support organiser for stroke patients and their carers: a randomised controlled trial. Cerebrovascular Disability; 20:85-91.

Tong A, Sainsbury P, Craig J (2207) Consolidated criteria for reporting qualitative research (COREQ): a 32-item checklist for interviews and focus groups. International Journal for Qualitative Health Care; 19:349-57.

Tooth L, McKenna K, Barnett A, Prescott C, Murphy S (2005) Caregiver burden, time spent caring and health status in the first 12 months following stroke. Brain Injury; 19:963-974. 
Truman C, Raine P (2001) Involving users in evaluation: The social relations of user participation in health research. Critical Public Health; 11:215-29.

Unrath M, Kalic M., Berger K (2013) Who receives rehabilitation after stroke? Data from the quality assurance project Stroke Register Northwest Germany. Deutsche Ärzteblatt; 110:101-117.

Useros MV, Espin AA, Parra EC, Martinez AB (2012) Family Caregivers: Nurses Perception and Attitudes. Social Medicine; 6:151-161.

Van Daele T, van Audenhove C, Hermans D, van den Bergh 0, van den Brouke S (2012) Empowerment implementation: enhancing fidelity and adaption in a psycho-educational intervention. Health Promotion International; 29(2):212222.

van den Heuvel E, de Witte L, Stewart R, Schre I, Sanderman R, Meyboom-de Jong B (2002). Long-term effects of a group support program and individual support program for informal caregivers of stroke patients: which caregiver benefit most? Patient Education \& Counselling; 47:291-299.

Van Exel NJA, Koopmanschap MA, van den Berg B, Brouwer WBF, van den Bos GAM (2005) Burden of caregiving for stroke patients. Identification of caregivers at risks of adverse health effects. Cerebrovascular Diseases; 19:11-7.

Van Heugten C, Visser-Meily A, Post M, Lindeman E (2006) Care for carers of stroke patients: evidence-based clinical practice guidelines. Journal of Rehabilitation Medicine; 38: 153-158.

Visser-Meily A, Post MW, Riphagen II, Lindeman E (2004) Measures used to assess burden among caregivers of stroke patients: a review. Clinical Rehabilitation; 18:601-623.

Visser-Meily A, van Heutgen C, Post M, Schepers V, Lindeman E (2005) Intervention studies for caregivers of stroke survivors: a critical review. Patient Education \& Counselling; 56:257-267.

Waldman JD (2007) Thinking system needs systems thinking. Systems Research \& Behavioural Sciences; 24:271-284.

Walker D, Bourne L, Shelly A (2008) Influence, stakeholder mapping and visualization. Construction Management \& Economics; 26(6):645-58.

Wallerstein N, Duran B (2008) The conceptual, historical, and practice roots of community based participatory research and related participatory traditions. In Community-based participatory research for health: From process to outcomes. Edited by M. Minkler and N. Wallerstein, 27-52. San Francisco: Jossey-Bass.

Wallerstein N, Duran B (2010) Community-Based Participatory Research Contributions to Intervention Research: The Intersection of Sciences and Practice to Improve Health Equity. American Journal of Public Health; Supl. 1(100):40-46.

Ward S, Chapman C (2008) Stakeholders and uncertainty management in projects. Construction Management \& Economics; 26:563-577.

Ward S, Chapman C (2003) Transforming project risk management into project uncertainty management. International Journal of Project Management; 21: 97-105.

Wensing M, Bosch M, Grol R (2013) Determinants of change. In: Improving patient care: The implementation of change in health care. Grol R, Wensing M, Eccles M, Davis D (Eds.) Wiley Blackwell BMJI Books, 0xford, UK; p.139-150.

Wetzstein M, Rommel A, Lange C (2015) Pflegende Angehörige - Deutschlands größter Pflegedienst. Gesundheitsberichterstattung Kompakt. Robert Koch Institut, Berlin 3/2015.

Willemé P (2010) The long-term care system for the elderly in Belgium. ENEPRI Research Report No. 70, https://ssrn. com/abstract=2033672, Accessed 11.12.2018.

Wilz G, Barskova T (2007) Evaluation of a cognitive behavioral group intervention program for spouses of stroke patients. Behavioral Research \& Therapy; 45:2508-17. 
Wilz G, Böhm B (2007) Interventions for caregivers of stroke patients: need and effectiveness, Psychotherapie, Psychosomatik, medizinische Psychologie; 57: 12-18.

Winstein C (2018) The ATTEND trial: An alternative exploration with implications for future recovery and rehabilitation trials. International Journal of Stroke; 13:112-16.

World Health Organization - WHO - (2011) Psychological First Aid. Guide for field workers. http://apps.who.int/iris/ bitstream/10665/44615/1/9789241548205_eng.pdf. Accessed 12.12.2018.

World Health Organization - WHO - (2009) Systems thinking for health systems strengthening. Savigny, D. \& Adam, T (eds); Available at: www.who.int/iris/bitstream/10665/44204/1/9789241563895_eng.pdf. Accessed 11.12.2018.

World Health Organization - WHO - (1997) Jakarta Declaration on Leading Health Promotion into the 21st Century. World Health organization, Geneva.

World Heart Federation (2015) The global burden of stroke. http://www.world-heart-federation.org/cardiovascular-health/stroke/. Accessed 10.11.2018.

World Stroke Organization (2018) Facts and figures about stroke. http://www.world-stroke.org/component/content/ article/16-forpatients/84-facts-and-figures-about-stroke. Accessed 18.11.2018.

Worthington C, 0'Brien K, Mill J, Caine V, Solomon P, Chaw-Kant J (2016) A mixed-methods outcome evaluation of a mentorship intervention for Canadian nurses in HIV care. Journal Association Nurses AIDS Care; 27(5):677-697.

Wright M (2013) Was ist Partizipative Gesundheitsforschung? (What is participatory health research?) Position paper of the International Collaboration for Participatory Health Research. Prävention \& Gesundheit; 1(3):122-132.

Wright M, Brito I, Cook T, Harris J, Kleba M, Madsen W, Springett J, Wakeford T (2013) What is participatory Health Research? Position Paper No. 1. International Collaboration for participatory Health Research, http://www.icphr.org/ uploads/2/0/3/9/20399575/ichpr_position_paper_1_defintion -_version_may_2013.pdf, Accessed 10.12.2018.

Young L (2006) Participatory action research (PAR): A research strategy for nursing? Western Journal of Nursing Research; 8:499-504.

Yuen E, Knight T, Ricciardelli L, Burney S (2018) Health literacy of caregivers of adult care recipients: A systematic scoping review. Health \& Social Care in the Community; 26(2): e191-e206.

Yuen E, Knight T, Dodson S, Ricciardelli L, Burney S, Livingston PM (2014) Development of the Health Literacy of Caregivers Scale - Cancer (HLCS-C): item generation and content validity testing. BMC Family Practice; 15:202.

Zabaleta-del-Olmo E, Bolibar B, Garcia-Ortiz L, Garcia-Campayo J, Llobera J, Bellon J, Ramos R (2015) Building interventions in primary health care for long-term effectiveness in health promotion and disease prevention. A focus on complex and multi-risk interventions. Editorial. Preventive Medicine; 76 Suppl:S1-4.

Zarit SH, Reever KE, Bach-Peterson (1980) Relatives of the impaired elderly: correlates of feelings of burden. Gerontologist; 20:649-655. 


\section{List of figures}

\section{Chapter 1}

Figure 1: The German stroke rehabilitation support system (adapted from BAR, 2018) 10

Figure 2: Outline of the dissertation showing all steps taken in the development of a new caregiver support programme illustrated on the project life cycles of the Caregivers' Guide and Vade Mecum .16

\section{Chapter 3}

Figure 1: The German stroke rehabilitation support system and the Caregivers' Guide support programme (adapted from BAR, 2014).

Figure 2: The Caregivers`'Guide project management cycle with an elaboration of part 2 of the development phase (adapted from Pandi-Perumal et al., 2015).

Figure 3: The Caregivers`'Guide stakeholder map (adapted from Schiller et al., 2013) .........................50

Figure 4: Results of activity 3: stakeholders' power and interest with corresponding engagement strategies (adapted from Ackermann \& Eden, 2011)

\section{Chapter 4}

Figure 1: Optimising the Caregivers`'Guide preliminary concept via participatory action research. 74

Figure 2: The matured concept of the Caregivers' Guide

\section{Chapter 5}

Figure 1: The German stroke rehabilitation support system (adapted from BAR, 2014) and the timing of intervention with the Caregivers' Guide 95

Figure 2: The Caregivers' Guide project life cycle with the inputs and focus on evaluation on individual and system level .97

Figure 3: Research design of the Caregivers' Guide evaluation on individual and system level ................98

Figure 4: Evaluating the Caregivers' Guide outcome on individual and system level........................... 103

Figure 5: The Caregivers' Guide impacts and outcomes on individual and system level 114

\section{Chapter 6}

Figure 1: Cross-border orientation of Vade Mecum: hospitals in three countries in the Euregion Maas-Rhine joining the project.................................................................... 130

Figure 2: Project management life cycle and type of participation ............................................ 134

Figure 3: System and caregiver problem identification in the geriatric setting: word clouds as presented to

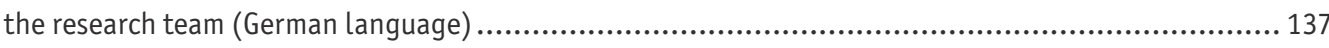

Figure 4: Qualitative data collection methods per participating professional group ........................ 139

\section{Chapter 7}

Figure 1: The key outcomes of the Caregivers' Guide and the Vade Mecum initiation phase 150 


\section{List of tables}

\section{Chapter 2}

Table 1: Examples of the four-step content analysis

Table 2: The development of the conceptual building blocks for the personalized multicomponent caregiver support programme- 'The Caregivers Guide'.

\section{Chapter 3}

Table 1: Results of activity 2: stakeholders' contribution and role in the Caregivers' Guide implementation phase.

Table 2: Results of activities $4 \& 5$ - potential project- or stakeholder-related implementation risks, risk domains and their likelihood.

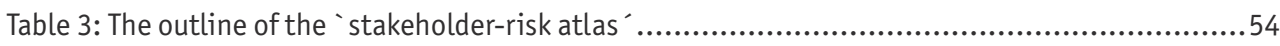

Table 4: The Caregivers' Guide project implementation strategy ............................................ 55

\section{Chapter 4}

Table 1: Participation, stakeholder involvement and research. .69

Table 2: Professionals participating in the participatory action research..................................72

Table 3: Verifying and fitting the preliminary Conceptual Building Block `Human resources` using PAR .76

Table 4: Detecting, developing, verifying and fitting the Caregivers' Guide new conceptual building blocks using PAR

\section{Chapter 5}

Table 1: Professional stakeholder participating in the qualitative study 101

Table 2: Impact on caregivers ' health literacy and psychosocial health, a quantitative pre- $\&$ post intervention study among 62 stroke caregivers supported by the Caregivers' Guide.

Table 3: Impact on caregivers' health literacy and psychosocial health, a qualitative study among 30 stroke caregivers supported by the Caregiver's Guide.

Table 4: Impact of the Caregivers' Guide intervention on caregivers' health literacy and psychosocial health, a qualitative study among 11 professionals working as service providers within the stroke rehabilitation system.

Table 5: Impact of the Caregivers' Guide intervention on system level, a qualitative study among 11 professionals working as service providers in the stroke support system.

\section{Chapter 6}

Table 1. Participation type, stakeholder involvement and research relationship*

Table 2. Overview of personal and group expectations of participation in the PHR project 138

Table 3. Gantt-chart presenting the data collection process in the geriatric department in $2017 \ldots . . . .140$ 
Chapter 9 
The stepwise development of a comprehensive family caregiver support programme. 


\section{CHAPTER 10 Acknowledgements, About the author, List of publications}




\section{Acknowledgements}

This dissertation was a long journey and there was a multitude of individuals which contributed. I am certain that without their assistance, guidance and encouragement this dissertation would not have come to a fruition.

Special acknowledgment goes to my Principal Supervisor, Professor Dr. Frans Feron. Frans, your timely advice, honest interest in family caregiver support, wise and calm guidance in turbulent moments, combined with your humorous way of providing valued feedback was empowering me to start, continue and finalise this dissertation.

My deep gratitude goes to my Co-Supervisor, Doctor Elisabeth Dorant, whose expertise in the field of methodology brought us together. Elisabeth, on a dayto-day basis, you invested countless hours of your time in my professional maturing and equipped me with the confidence in processing the dissertation 'my way'. Thanks for your critical counselling, visioning support and methodological instructions. Your way of mentoring and pushing me beyond my professional boundaries will cause a life-long empowerment, also if I have no instrument to measure it.

Special appreciation goes to Doctor Nicole Boumans. Nicole, I've been motivated and encouraged by our many conversations and honest discussions about the challenge of being a family caregiver and the need for stakeholder and risk analyses when starting a new programme.

I am much grateful to Regina Specht. Over my PhD trajectory and especially during the participative research you progressively stepped into the role of being my 'critical friend'. Regina, thanks a lot for investing your time, sharing your intense experiences with family caregivers and the intricate German support system as well as for posing all the interesting questions along the road. You constant curiosity and encouraging way of posing criticism helped me maturing as professional researcher.

My dissertation is dedicated to all the family caregivers who provide day-byday assistance without being sufficiently prepared, appreciated and supported in their new role by our society. I like to thank all the family caregivers for their participation and provision of insightful knowledge and openness in this difficult phase of their life. Your valuable contributions helped to tailor this programme as near as possible to the complex needs of the end-users. 
I would like to thank all stakeholders, organisations and facilities who accompanied and supported my dissertation. Without your willingness to become involved, this work would not have been possible. A special acknowledgement goes to the co-researchers, which represented the real-life stroke support system in the acute, rehabilitation and home care support in the Aachen region, and to the multidisciplinary geriatric support team of the Rhein-Maas-Clinic in Würselen. You helped me to keep my head out of the clouds and focus on the real requirements of the system for providing comprehensive caregiver support.

Thanks are given to the Catholic University of Applied Sciences and the team of Caregivers Guide, who set the primary conditions for this dissertation. Special thanks goes to Miriam Floren, who was a true companion not only for the family caregivers but also for me. Miriam, I'm certain you will be always professional and emotionally attached to those in need, what makes you special.

I would like to thank Riman Nasher. Riman, our regular meetings, discussing the advancements or challenges regarding our $\mathrm{PhD}$ trajectories meanwhile encouraging ourselves to continue this path, were very essential. Likewise, many thanks for your patience when reading the many, many, many drafts of my articles and supporting me with the academic English.

Thanks goes to my parents, parents-in-law, extended family and friends who supported me on this exciting journey. Thanks for your open ears, your patience, longanimity and wittiness when reflecting on the wicked process of conducting a PhD and the distribution of numerous cups of tea or coffee. Johanna, thanks for your open ear and assisting me with the cover design. Special thanks goes to Barbara Werner, our 'gute Seele'. Barbara, you bolstered me up physically and emotionally in several circumstances. I would especially thank my youngest sister Christiane Hupe. Chris, your constant encouragement, unflinching believe in me and your statement "Sieh den $\mathrm{PhD}$ als Projekt neben vielen anderen wichtigen Dingen in Deinem Leben!" helped me to keep the balance instead of getting lost in the scientific jungle. To make the book layout with you was an inspiring experience.

Special words of applause are for my amazing husband, faithful companion and love of my life Stefan Krieger. Stefan, you were a true pillar. With your positive source of energy, constructive reflection skills, wisdom and talent of detachment, you helped me through some frustrate, tearful and nerve-wracking times. Meanwhile, you did not miss to celebrate the highlights with me. You allowed me 
to focus on this work and empowered me in achieving the top of my professional Uhuru-Peak. Heartfelt thanks are offered to my children. Maximilian and Tabea, you cheerfully endured my working hours during the 'family time slots' over this long distance and my preoccupation with the demanding task of realizing this dissertation. My dears, without your love, positive attitude and tolerance, this dissertation would never have come to completion. 


\section{About the author}

Theresia Krieger (maiden name Hupe) was born on December 04th, 1974 in Görlitz, German Democratic Republic. After graduating from Polytechnic Highschool, she started her vocational training as a nurse at Sankt Hedwigs Hospital (Berlin), which she completed in 1995. Subsequently, she worked for four years at Sankt Hedwigs-Hospital and at Charité in Berlin, predominantly in intensive and critical care units.

From 1999 until 2003 she worked in the field of humanitarian and development aid with different international non-governmental organizations. She was working in India, Brazil, Mozambique, Angola, Sudan and Madagascar in therapeutic or preventive projects as nurse, trainer, medical team leader or project leader. Moreover, she was engaged in diverse quantitative and qualitative research activities, which raised her interest in Public Health studies.

In 2003, she started her academic journey at the University of Applied Sciences Neubrandenburg, Germany, and obtained a BSc degree in Public Health and Administration in 2006. In 2007, she acquired a MSc degree in International Public Health at Queen Margaret University in Edinburgh, Scotland.

Between 2007 and 2010, she was employed as a quality manager for integrated care in an invasive ambulant clinic at MediCenter Düren. In 2010, she worked at Bonn University as a lecturer for Master students in the module Evaluations in the Development Assistance and Humanitarian Aid. From 2010 until 2012, she worked at Bremen University in the Institute for Public Health and Science of Nursing (IPP) as a researcher in the research project Global Disaster Management \& Nursing. Based on this project's outcomes, she developed, coordinated and evaluated the first interdisciplinary summer school: Global Disaster Management at Bremen University. For her efforts in this field she was awarded a fellowship of the World Society of Disaster Nursing. From October 2012 to 2015, she worked at the Catholic University of Applied Sciences North Rhine-Westphalia (KatHo) in the Institute for Health Research and Social Psychiatry (igsp) in Aachen. As a researcher she was involved in the development, implementation and evaluation of the Der Angehörigenlotse (Caregivers'Guide), a complex sup- 
port programme for stroke family caregivers.

In March 2013, she started her PhD trajectory at the department of Social Medicine, CAPHRI (Care and Public Health Research Institute) at Maastricht University. Initially, her PhD focussed on the Caregivers' Guide. Based on the insights from the Caregivers' Guide, she initiated and conducted at Rhein-Maas Klinikum in Würselen a new project, which focused on exploring the status-quo and further needs of the interdisciplinary support team for supporting informal caregivers in the geriatric department. This Participatory Health Research project started in 2017. It was the first step of a new caregiver support programme: Vade Mecum, which is currently running in one of the four hospitals in Aachen with a geriatric care department, and was also included in her PhD dissertation.

Theresia is interested in Public Health research and programmes in dynamic settings. Her expertise highlights the development of complex interventions in public health and health care system development with focus on informal caregivers. She is experienced in mixed methods research, combining qualitative methodologies and applying participatory approaches with high levels of stakeholder participation. She was involved in teaching and tutoring nursing and social science students. Moreover, she possesses a proficiency in cross cultural communication and has trained international health care workers for Medicines Sans Frontiers (MSF) for 11 years.

At present, she works at the Institute for Medical Sociology, Health Science Research and Rehabilitation Science (IMVR) at University Clinic Cologne.

Theresia is married and has two children. 


\section{List of publications}

\section{Scientific articles in international journals}

Krieger T, Specht R, Tischkin J, Steiger I, Dorant E (2019) Assessing the status-quo of family caregiver support and the needs for comprehensive caregiver support in the geriatric department: a multi-methodological study. (in preparation)

Krieger T, Feron F, Dorant E (2019) Evaluating a complex intervention for stroke caregivers on individual and system level: the Caregivers' Guide example. (submitted)

Krieger T, Floren M, Feron F, Dorant E (2019) Optimising the concept of a complex stroke caregiver support programme via Participatory Action Research. Educational Action Research. (accepted for publication)

Krieger T, Boumans N, Feron F, Dorant E (2019) Developing implementation management instruments in a complex intervention for stroke caregivers based on combined stakeholder and risk analyses. Scandinavian Journal of Caring Sciences. (accepted for publication)

Dorant E, Krieger T (2017) Contextual exploration of a new family caregiver support concept for geriatric settings using a participatory health research strategy. International Journal of Environmental Research \& Public Health; 14(12): E1467. doi: 10.3390/ijerph14121467.

Krieger T, Feron F, Dorant E (2017) Developing a complex intervention programme for informal caregivers of stroke survivors: The Caregivers' Guide. Scandinavian Journal of Caring Sciences. 31(1):146-156. doi: 10.1111/ scs.12344.

\section{Publications in German journals}

Krieger T, Floren M, Jungbauer J (2014) Der Angehörigenlotse. Eine Begleitung für die Zeit nach dem Schlaganfall. Angehörige pflegen, 1/2014, 12-15. 
Jungbauer J, Floren M, Krieger T (2015) Beratung und Begleitung für Angehörige von Schlaganfallpatienten in Nordrhein-Westfalen. In W. Schnepp (Hrsg.), Erstellung einer NRW-spezifischen Übersicht zur Gesamtsituation pflegender Angehöriger (S. 521-558). Universität Witten-Herdecke: Abschlussbericht an das Ministerium für Gesundheit, Emanzipation, Pflege und Alter (MGEPA) des Landes Nordrhein-Westfalen.

Görres S, Harenberg N, Krieger T, Magens D, Sandau E (2013) Global Disaster Management \& Nursing. A national Synopsis. Huber Verlag, Bern.

Görres S, Harenberg N, Krieger T (2012) Global Disaster Nursing. Katastropheneinsätze: Pflege spielt eine wichtige Rolle. Die Schwester - Der Pfleger; 51(19):966-969.

\section{Book chapter}

Krieger T (2009) Verhaltenskodex der Helfer - formelle Spielregeln oder mehr? In: Go International. Die Arbeit von medizinischem Fachpersonal im Rahmen der Entwicklungs-zusammenarbeit und Humanitären Hilfe. Elgin Hackenbruch (Hrsg.), Huber Verlag, Bern.

\section{Conference contributions}

Rashid I, Krieger T (2019) Gugurugu, Blut ist im Schuh...? Erfahrungen, Ergebnisse und Herausforderungen mit der Partizipativen Gesundheitsforschungsstrategie in der akademischen Ausbildung für Pflegeberufe und im Akutkrankenhaus. Workshop at Berliner Werkstatt Partizipative Gesundheitsforschung, 1. März 2019, Berlin, Germany.

Dorant E, Krieger T (2018) Complex interventions in public health: critical issues, research strategies and management tools. Workshop at Forschungswelten, 19.20. April 2018, St. Gallen, Switzerland.

Krieger T, Specht R, Rashid I (2018) Mission (im-)possible? Conducting participatory health research in hierarchic settings. Workshop at Forschungswelten, 19.-20. April 2018, St. Gallen, Switzerland. 
Krieger T (2018) Konzeptionelle Optimierung einer komplexen Intervention für pflegende Angehörige von Schlaganfallpatienten - Pflicht oder Kür? Impulse presentation at Forschungswelten 19.-20. April 2018, St. Gallen, Switzerland.

Krieger T (2018) Status-quo and needs assessment for family caregivers in the geriatric setting. Presentation at Versorgungsnetzwerk Geriatrie, 24. April 2018, Aachen, Germany.

Dorant E, Krieger T, Boumans N (2017) Why, when and how to explore stakeholder and implementation risks in complex health interventions: a taster workshop. European Public Health Conference (EUPHA), 1.-4. November 2017, Stockholm, Sweden.

Krieger T, Dorant E (2017) Stakeholder and risk analyses in complex interventions: a taster workshop. Preconference Deutsche Gesellschaft für Sozialmedizin \& Public Health, 04. September 2017, Lübeck, Germany.

Dorant E, Krieger T (2017) Vade Mecum: interprofessional cross-border health system development in the acute geriatric setting. Presentation at the conference: Key Issues in current Health research: Ageing, Health, Equity, 29.-30. June 2017, Bremen, Germany.

Dorant E, Krieger T (2017) Exploring new paths: Conducting a comprehensive stakeholder and risk analysis when preparing a complex intervention in health. Workshop at Forschungswelten 2.-3. March 2017, Trier, Germany.

Krieger T (2016). Effects of a close integration of science and practice in the development and implementation of a counseling and support concept for caregivers of stroke patients: The Aachen pilot project The Caregivers ' Guide. Presentation at Forschungswelten 3.-4. March 2016, Munich, Germany.

Krieger T (2016) Challenges \& lessons learnt from the research project The Caregivers Guide: a complex support offer for stroke family caregivers. Presentation at Armut und Gesundheit, 17.-18. March 2016, Berlin, Germany.

Krieger T, Feron F, Dorant E (2016) Developing conceptual building blocks for a complex support program for stroke caregivers: a mixed methods study. Poster presentation at European Public health Conference (EUPHA), 14.-17. October 2015, Milano, Italy. 
Krieger T (2015) Status-quo and best practice for stroke family caregivers in acute and rehabilitative hospitals in North Rhine-Westphalia, Presentation at Praxisdialog Reha, Pflege und Pflegende Angehörige, 14. September 2015, Kassel, Germany.

\section{Other dissemination}

Krieger T (2016 \& 2017) Nutrition in humanitarian crisis: the perspective of Doctors Without Borders, module facilitator in the Leonardo project (Population \& Health), RWTH Aachen University, Germany.

Krieger T (2002-2014) Cross Cultural Communication \& Proximity, module facilitator, Doctors Without Borders, Bonn, Germany.

Krieger T (2012) First summer school: Global Disaster Management, initiator, team leader and module facilitator, Bremen University, Germany.

Krieger T (2010-2013) Understanding Humanitarian Medical Aid. Module facilitator in the summer school: Global Health, RWTH Aachen University, Germany. 